\title{
DEPLOYMENT OF INNOVATIVE CHARACTERIZATION TECHNOLOGIES AND IMPLEMENTATION OF THE MARSSIM PROCESS AT RADIOLOGICALLY CONTAMINATED SITES
}

\section{FY 2000 PROGRAM DOCUMENT COMPILATION}

\author{
P.D. Kalb, L. Milian \\ Brookhaven National Laboratory \\ L. Luckett \\ Dames and Moore, Inc. \\ D. Watters \\ Cabrera Services, Inc. \\ K. M. Miller, C. Gogolak
}

DOE Environmental Measurements Laboratory

\section{BROOKHBUEN \\ NATIONAL LABORATORY}

\author{
Environmental Sciences Department \\ Brookhaven National Laboratory \\ Brookhaven Science Associates \\ Upton, Long Island, New York 11973
}

Under Contract No. DE-AC02-98CH10886 with the

UNITED STATES DEPARTMENT OF ENERGY 


\section{DISCLAIMER}

This report was prepared as an account of work sponsored by an agency of the United States Government. Neither the United State Government nor any agency thereof, nor any of their employees, not any of their contractors, subcontractors, or their employees, makes any warranty, express or implied, or assumes any legal liability or responsibility for the accuracy, completeness, or usefulness of any information, apparatus, product, or process disclosed, or represents that its use would not infringe privately owned rights. Reference herein to any specific commercial product, process, or service by trade name, trademark, manufacturer, or otherwise, does not necessarily constitute or imply its endorsement, recommendation, or favoring by the United States Government or any agency, contractor, or subcontractor thereof. The views and opinions of authors expressed herein do not necessarily state or reflect those of the United States Government or any agency, contractor or subcontractor thereof. 


\section{INTRODUCTION}

In FY 2000, Brookhaven National Laboratory (BNL) completed an Accelerated Site Technology Deployment (ASTD) project entitled, "Deployment of Innovative In Situ Characterization Technologies and Implementation of the MARSSIM Process at Radiologically Contaminated D\&D Sites." The work, sponsored by the DOE Office of Science and Technology's Decontamination and Decommissioning Focus Area (DDFA) provided assistance for the characterization of the BNL Brookhaven Graphite Research Reactor (BGRR) that was shut down in 1968 and is currently being decommissioned. Several innovative technologies (the Canberra In Situ Object Counting System or ISOCS and the BetaScint Fiber Optic Detector) were deployed to accurately, rapidly, and inexpensively characterize equipment, facilities, and materials to facilitate D\&D operations. The MARSSIM process, usually used for final status surveys, was implemented for on-going characterization to better identify the types and number of samples needed. The project successfully demonstrated the value of in situ characterization combined with MARSSIM, both in terms of reduced costs and lower worker exposure to radiation hazards. The innovative technologies were also shown to compare favorably on a technical basis with conventional baseline characterization techniques.

Additional information can be obtained at the following web sites:

- $\quad$ http://www.bnl.gov/bgrr/

- $\quad$ http://www.dne.bnl.gov/ewtc 


\section{EXECUTIVE SUMMARY}

\section{INTRODUCTION AND BACKGROUND}

One of the most significant issues facing planners of decontamination and decommissioning (D\&D) projects is the cost associated with characterization of the facility. There is uncertainty concerning the amount of data that needs to be collected and the level of analysis required in all phases of a $D \& D$ project, from the initial planning phase through to the closure phase. These uncertainties, which make it difficult to define the full scope of a project at the outset and to prepare with confidence a feasible schedule, can only be reduced by the implementation of an appropriately comprehensive characterization of the facility. Conventional characterization techniques require taking, analyzing, and evaluating a large number of samples; a time-consuming, costly, and potentially hazardous process. Past experiences have shown that characterization tends to be a significant contributor to the total project cost and a pivotal factor in defining and adhering to the project schedule.

This Accelerated Site Technology Deployment (ASTD) project addresses some of the important issues of characterization through deployment of innovative in situ characterization technologies and the implementation of the guidelines contained in the Multi-Agency Radiation Survey and Site Investigation Manual (MARSSIM). It focuses on the characterization of the Brookhaven Graphite Research Reactor (BGRR), which is currently undergoing an accelerated schedule for D\&D. The Environmental Management program of the U.S. Department of Energy (USDOE) includes the D\&D of many different types of nuclear facilities. However, the basic issues of characterization are universal and not dependent of site-specific dissimilarities. Thus successful deployment of the technologies included in this project will provide valuable experience and Alessons learned@that can be shared with facilities throughout the USDOE complex. The project itself involves collaboration between the Brookhaven National Laboratory (BNL) Environmental Sciences Department, BGRR Decommissioning Project (BGRR-DP), the USDOE Environmental Measurements Laboratory (EML), URS Corporation of Ronkonkoma, NY, Canberra Industries of Meriden, CT, Cabrera Services. Inc of East Hartford, CT, and BetaScint, Inc., Kennewick, Washington. Also participating is Bechtel Hanford Inc., which will deploy this approach for characterization as part of the Canyon Disposition Initiative at Hanford. Other DOE sites (e.g., Nevada Test Site) are making plans for additional deployments as part of their D\&D mission.

FY 1999 ACCOMPLISHMENTS

The project was initiated mid-year in FY 1999. Program summary documents included a Technology Deployment Plan submitted to and approved by DOE, and a Technology Fact Sheet. Project technicaldocuments included the project Quality Assurance Project Plan, the Standard Operating Procedure for acquiring gamma radiation spectra with the ISOCS instrument, Project Specific Survey Plans and Project Data Reports. Analytical support of the BGRR-DP included characterization campaigns of the Pile Fan Sump, Above Grade Ducts, and the Exhaust Fan House. Specific details have been provided previously in the FY 1999 Program Document Compilation, October 1999.

\section{FY 2000 ACCOMPLISHMENTS}

The ASTD project was successfully completed in FY 2000. A compilation of project documents is provided in subsequent sections of this document. Program summary documents developed during FY 2000 included a paper appearing in the Proceedings of the Waste Management Conference, an invited presentation to the Canberra Users Group conference, and comparability reports on the ISOCS gamma spectrometer and the BetaScint Sr-90 instrument. The ISOCS Comparability Report also contains comprehensive information on costs and regulatory/institutional issues and thus, doubles as an ASTD cost and performance report. Project technical documents developed during FY 2000 included a Standard Operating Procedure for analyzing gamma radiation spectra using the ISOCS software, an operating procedure for sample processing of contaminated soils when using the BetaScint instrument, Project Specific Survey Plans, and Project Data Reports. Analytical support of the BGRR-DP included continued support on characterization campaigns of the Pile Fan Sump and 
Above Grade Ducts. New campaigns included characterization of the Duct internal components, the Reactor Graphite Pile, the Fuel Transfer Canal, and the Water Treatment House. Additionally, the project supported the BNL Environmental Restoration Division (ERD) with characterization of soils during the Landscape Soil Remediation project.

\section{SUMMARY and CONCLUSIONS}

The success of this ASTD project is measured on several levels. First, the deployment of this innovative approach using in situ characterization, portable field laboratory measurements, and implementation of MARSSIM was successfully established for all three phases of D\&D characterization, i.e., pre-job scoping, on-going disposition of waste, and final status surveys upon completion of the activity. Unlike traditional D\&D projects, since the BGRR-DP is operating on an accelerated schedule, much of the work is being carried out simultaneously. Rather than complete a full characterization of the facility before D\&D work begins, specific removal actions require characterization as the activity progresses. Thus, the need for rapid and cost-effective techniques for characterization is heightened.

Secondly, since the approach used for this ASTD project was not thoroughly proven prior to deployment a large effort was devoted to demonstrating technical comparability to project managers, regulators and stakeholders. During the initial phases, large numbers of replicate samples were taken and analyzed by conventional baseline techniques to ensure that BGRR-DP quality assurance standards were met. ASTD project staff prepared comparisons of data gathered using ISOCS and BetaScint with traditional laboratory methods and presented this information to BGRR-DP staff and regulators from EPA Region II, NYS Department of Environmental Conservation, and the Suffolk County Board of Health. As the results of comparability evaluations became available, approval for these methods was received and the techniques associated with in situ characterization, portable field laboratory measurements, and implementation of MARSSIM were gradually integrated into BGRR-DP procedures.

Clearly, a significant metric for success is cost effectiveness. Integration of this approach and displacement of traditional baseline characterization at BGRR-DP resulted in far fewer samples that needed to be taken, packaged for transport to an offsite laboratory and analyzed. In addition, because samples are analyzed rapidly on-site, cost per sample is drastically reduced. For example, cost per sample for ISOCS measurements was calculated to be $\$ 76$, compared with $\$ 252$ per sample for conventional measurement, a savings of $\$ 175$ per sample. Discounting programmatic costs, the relative cost of deploying ISOCS for BGRR characterization in FY 99 and FY 00 was $\$ 82,000$. The cost for equivalent conventional baseline characterization was estimated to range from a minimum of $\$ 292,000$ to a maximum of $\$ 1,075,000$ depending on the number of analyses displaced. This represents net cost savings ranging from $\$ 210,000$ to $\$ 993,000$. If the total ASTD project cost associated with ISOCS deployment is included, the maximum cost savings range from $-\$ 339,000$ (loss) to $\$ 443,000$ (gain). While both the cost per sample and overall costs are significantly lower using ISOCS in situ and field laboratory characterization, perhaps the greatest cost savings associated with this innovative technology are Ahidden@avings that are more difficult to quantify. These include savings associated with project schedule acceleration, the ability to characterize non-standard systems, and improved health and safety for D\&D workers.

Finally, the most significant criterion for success of this ASTD effort is associated with continued deployment as part of the BGRR-DP and other projects at BNL as well as additional deployments at sites throughout the DOE complex. Investment in the initial ASTD project will continue to see dividends as the inherent cost savings continue to be realized. For example, based on proven success at BGRR (both technical and reduced cost), the BNL Environmental Restoration Division (BNL ERD) deployed ISOCS for cleanup of a large volume of contaminated landscape soils. ASTD team members provided both guidance and technical support for this deployment. In FY 01, BNL is engaged in another ASTD project to characterize subsurface soils beneath structures at the BGRR. Both ISOCS and BetaScint have been incorporated into the project plan for that activity, facilitated through cost savings associated with this project. In addition, ISOCS and MARSSIM are currently being deployed for characterization of the Canyon Disposition Initiative at Hanford, based partly on support from this activity. A new effort to deploy ISOCS and MARSSIM is underway at the Nevada Test Site, as part of a large effort to D\&D their former nuclear rocket test facilities. Based on expertise developed through this ASTD project, BNL is providing technical support and technology transfer assistance to DOE NV. 


\section{ACKNOWLEDGMENTS}

The authors gratefully acknowledge the staff at the BNL Brookhaven Graphite Research Reactor Decommissioning Project for their assistance in planning and coordination of these activities and the BNL Environmental Restoration Division for providing ISOCS equipment used in this project in FY 1999. 


\section{TABLE OF CONTENTS}

Section Document

Introduction

Executive Summary

FY2K Org Chart

\section{Program Summary Documents}

1 Paper presented at Waste Management Conference, March 2000, Tucson, AZ

2 Briefing Slides presented at Canberra User Group Meeting,

3 ISOCS Comparability (ASTD Cost and Performance) Report, BNL-52607

$4 \quad$ BetaScint Comparability Report

\section{Project Technical Documents}

SOP-DAT2 Analysis of Gamma Spectrum Files Using Canberra ISOCS System [Version 3.0 software], Feb 23, 2000

6

ERD-OPM-4.3 Procedure for ASTD sample Processing to Support BGRR Decommissioning Operations, Rev 0, July 12, 2000

7

8

9

$10 \quad$ Data Reports

$11 \quad$ Data Reports

12 Data Reports

13
PSSP No. $2 \mathrm{~K}-01$

Data Reports

PSSP No. 2K-02

PSSP No. $2 \mathrm{~K}-03$
Use of ISOCS in support of BGRR Fan House Drain Pipeline Excavation and Pile Fan Sump Removal, November 23, 1999

ISOCS data obtained in support of BGRR Fan House Drain Pipeline Excavation and Pile Fan Sump Removal

Use of BetaScint in support of BGRR Fan House Drain Pipeline Excavation and Pile Fan Sump Remo val, November 23, 1999

BetaScint data obtained in support of BGRR Fan House Drain Pipeline Excavation and Pile Fan Sump Removal

ISOCS data obtained in support of Characterization of BGRR Above Grade Ducts

ISOCS data obtained in support of Characterization of BGRR Duct Internal Components (e.g., Filter Media, Cooler Coil)

Use of ISOCS in Support of BGRR Reactor Pile Characterization, April 27, 2000 
ISOCS data obtained in support of Characterization of BGRR Reactor Graphite Pile (e.g., Pile and Tunnel Debris, Graphite Dust, West Face Experimental Ports, South Face Debris, West Face Graphite Channel)

ISOCS data obtained in support of Characterization of BGRR Fuel Canal, Water Treatment House and Environs (e.g., Canal Debris and Sub-surface Soils)

ISOCS data obtained in support of BNL-ERD Landscape Soil Remediation Project (independent verification and QA analyses for ERD) 


\section{Accelerated Site Technology Deployment (ASTD) Project Organization Chart}

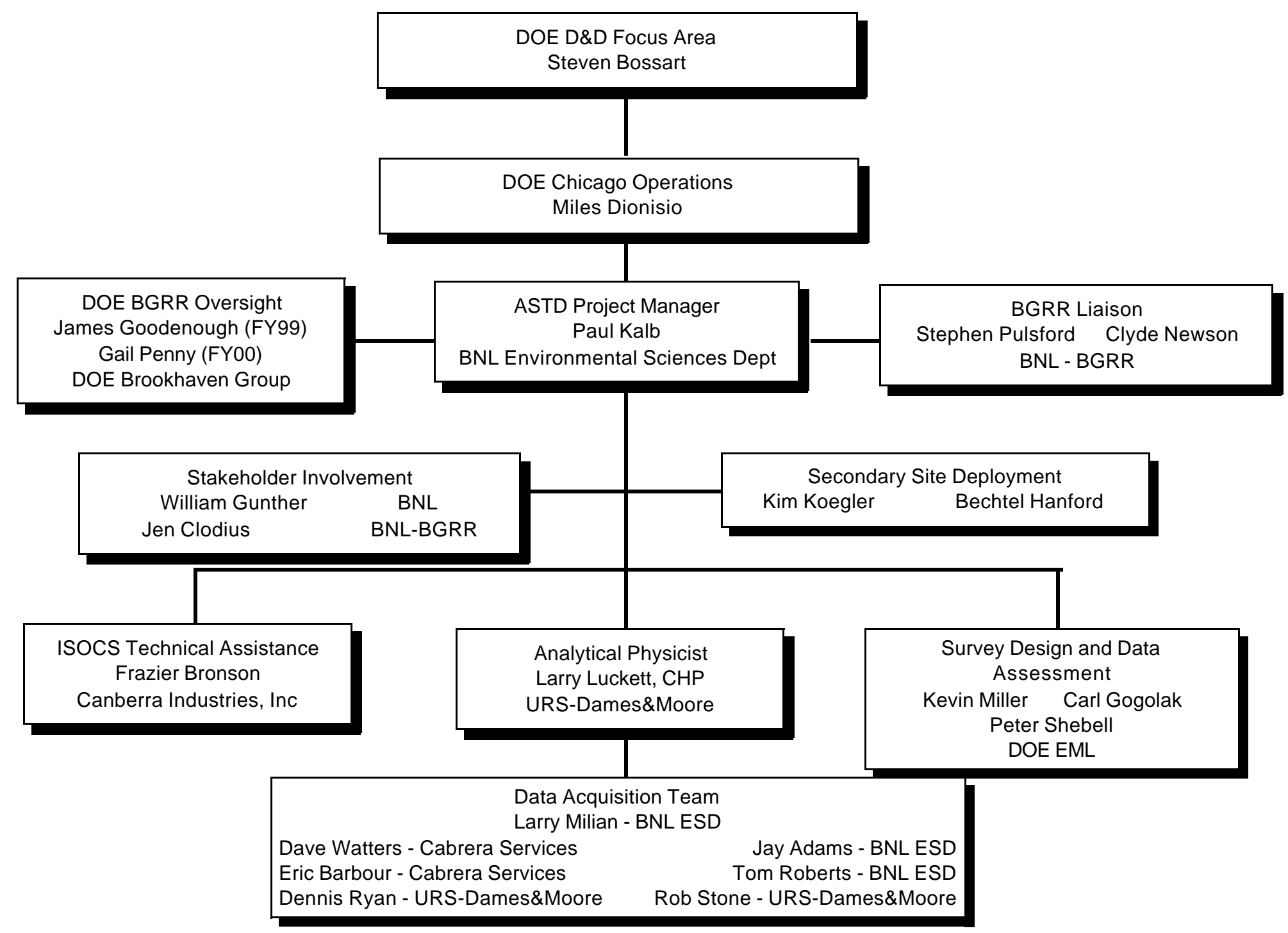


Section 1 


\title{
DEPLOYMENT OF IN SITU MEASUREMENT TECHNIQUES AND THE MARSSIM PROCESS FOR CHARACTERIZATION OF THE BROOKHAVEN GRAPHITE RESEARCH REACTOR
}

\author{
P.D. Kalb, L. Milian \\ Brookhaven National Laboratory \\ L. Luckett \\ Dames and Moore, Inc. \\ D. Watters \\ Cabrera Services, Inc. \\ C. Gogolak \\ DOE Environmental Measurements Laboratory
}

\begin{abstract}
This paper describes a DOE Accelerated Site Technology Deployment project being conducted at Brookhaven National Laboratory to characterize the Brookhaven Graphite Research Reactor facility, which is currently undergoing decontamination and decommissioning. The MARSSIM process is being implemented to provide guidance for survey planning and data evaluation. Innovative in situ analytical techniques are being deployed to quantify the type and extent of radiological contamination including ISOCS (Canberra Industries, Inc.) for gamma emitting radionuclides and BetaScint (BetaScint, Inc.) for Sr-90. These techniques provide a number of advantages compared with conventional characterization methods including near real-time data, ability to evaluate inhomogeneous materials, fewer samples required, and lower radiation dose exposure to personnel. Data has successfully been acquired and evaluated for several BGRR facilities and components including the Pile Fan Sump (PFS), underground piping for the PFS, parking lot areas, Above Ground Ducts, and contaminated cooling fans. Cs-137 is the predominant gamma-emitting radionuclide identified, with smaller quantities of Co-60 and Am-241 detected.
\end{abstract}

\section{INTRODUCTION}

The Brookhaven Graphite Research Reactor (BGRR) is a graphite-moderated, air-cooled, thermal neutron research reactor that operated at Brookhaven National Laboratory (BNL) from 1950 through 1968. Following shutdown, fuel was removed and the facility has been maintained in a safe shutdown mode since then. Many of the major BGRR sub-components are currently scheduled for near-term decontamination and decommissioning (D\&D) including the Pile Fan Sump, above and below ground air ducts, and auxiliary buildings that house fans, filters, instruments, fuel transfer canal and water treatment systems. Figure 1 is a photograph of the Above Ground Ducts and Fan House that drew air through the reactor core for cooling. The Canal House used to facilitate removal of spent fuel and equipment is shown in Figure 2. Characterization of these facilities prior to, during, and after 
dismantlement is required to minimize worker exposure, plan for appropriate disposition of materials and remaining facilities, and demonstrate compliance with applicable environmental regulations.

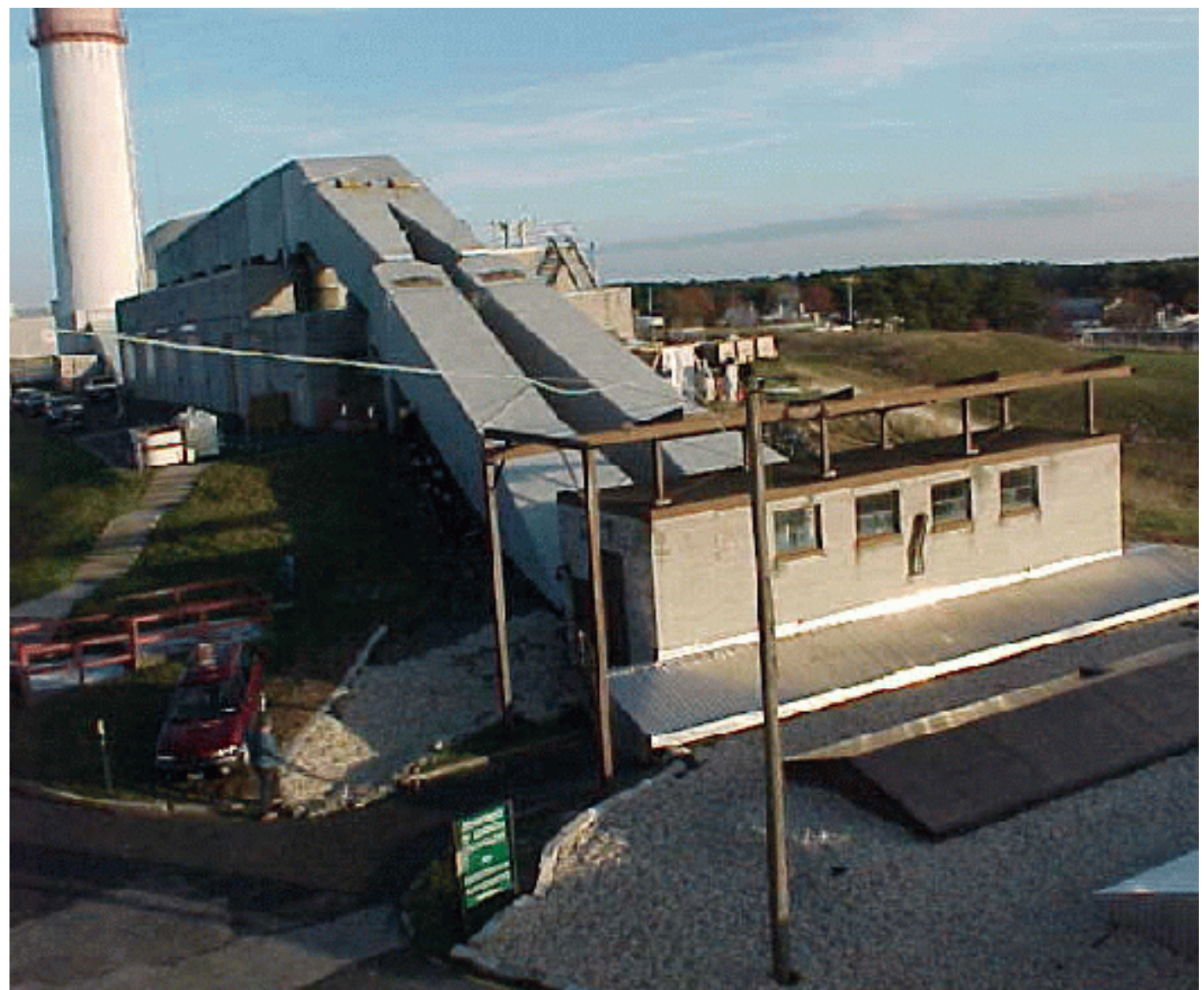

Figure 1 Above ground ducts and Fan House at the BNL BGRR

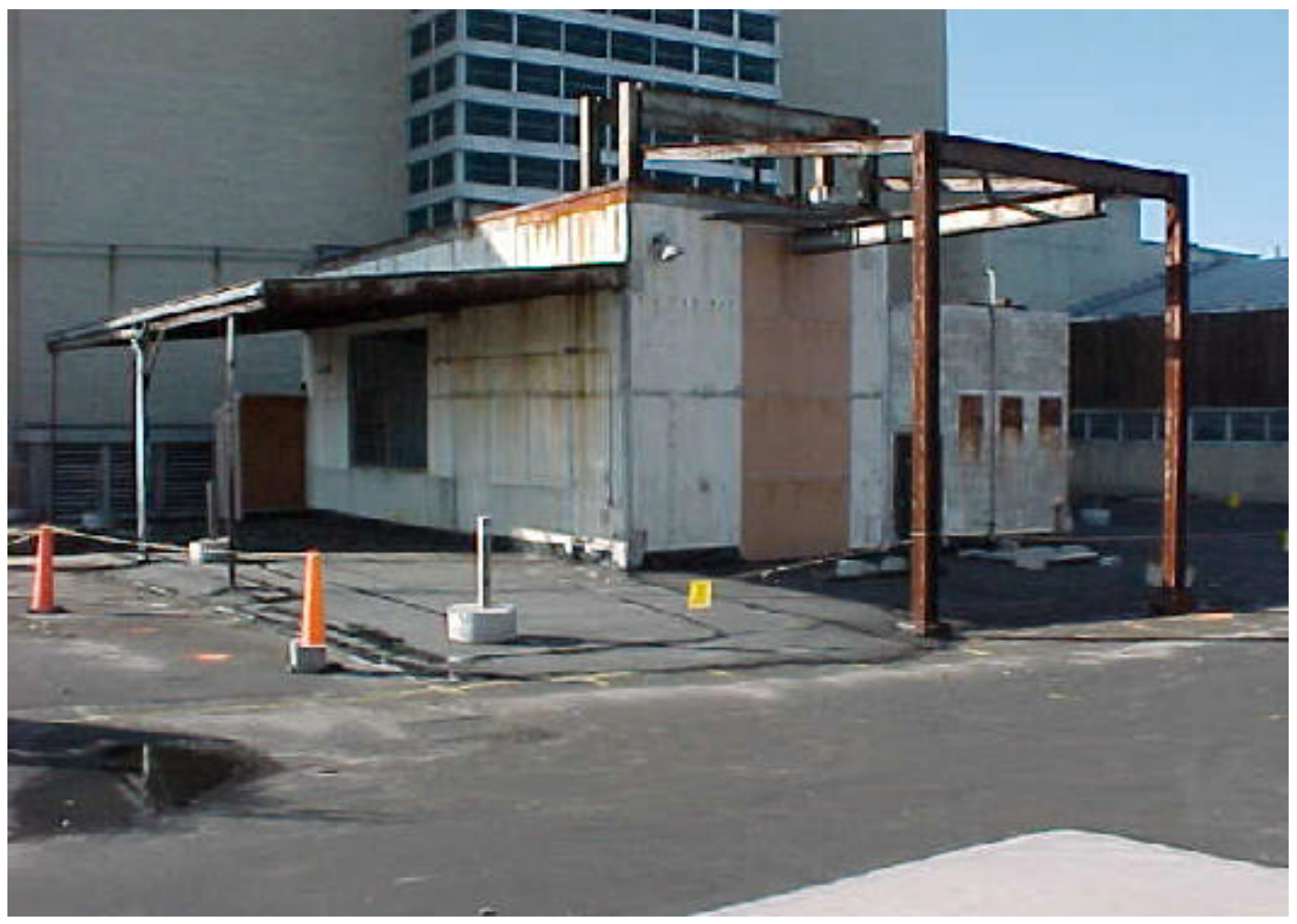

Figure 2 BNL BGRR Canal House structure used for removal of spent fuel and contaminated equipment 


\section{WM'00 Conference, February 27 - March 2, 2000, Tucson, AZ}

Conventional baseline characterization requires the collection of thousands of surface smear, volumetric, and core samples, sending samples for on and off-site analysis, compiling the information in a database, and reviewing the data for quality assurance. Many of the areas requiring characterization are not readily accessible and/or are highly contaminated, further complicating the process. Thus, in addition to being time consuming and costly, the baseline characterization approach can result in excessive radiation exposures to personnel. This paper describes a project sponsored by the DOE Office of Science and Technology (EM-50) under the Accelerated Site Technology Deployment (ASTD) initiative to deploy state-of-the-art techniques and equipment for improved characterization of the BGRR. The approach includes utilization of the innovative Multi-Agency Radiation Survey and Site Investigation Manual (MARSSIM) process and characterization using in situ measurement and analyses.

The MARSSIM approach provides guidance on planning, conducting, evaluating, and documenting environmental radiological surveys of soil and building materials to optimize the sampling process and demonstrate compliance with regulations. The final MARSSIM was published in December 1997 and has already attracted considerable interest from the D\&D community. However, there is little experience in applying the MARSSIM methodology at actual sites. In those cases where it has been used, the emphasis has been on the final status survey design; its application for D\&D characterization is novel. The MARSSIM process involves identifying Data Quality Objectives (DQO) to establish the types of data needed and the confidence levels required. Data validation and verification, as well as data quality assessment, are addressed through implementation of a Quality Assurance Project Plan. Valuable resources and time are saved by focusing on the proper data needed for evaluation.

Conventional gamma spectroscopy requires a major investment for purchase and eventual disposal of a variety of calibration sources that match the geometry and matrix of the expected contaminated medium. For each new geometry, a new calibration standard and hours of instrument calibration are required. This has limited in situ gamma spectrum analysis to simple geometries and contamination distributions. Strontium 90 (Sr-90), a fission product commonly associated with nuclear reactors is a pure beta emitter and thus is not directly detected by gamma spectroscopy. Conventional Sr-90 analysis requires chemical separation of the strontium from the sample matrix, followed by in-growth of the Yttrium 90 (Y-90) progeny for analysis, a time consuming procedure that often takes 1 - 4 weeks.

Measurement of gamma emitting radionuclides is being accomplished using a field deployable gamma spectrometer (In Situ Object Counting System or ISOCS) manufactured by Canberra Industries, Inc. The battery-operated system provides traditional spectra of counts as a function of gamma energy, which are then converted to radionuclide concentration by applying pre-defined geometry templates in the analysis software. Thus, complex contamination distributions (e.g., an inaccessible contaminated pipe within a wall) and resulting quantification of the contamination therein can be identified.

Detection of Sr-90 is being accomplished by means of a field deployable high energy beta scintillation detector manufactured by BetaScint, Inc. This system, can measure Sr-90 and U-238 at approximately $1 \mathrm{pCi} / \mathrm{g}$ above background with a 5-minute count time. Soil samples of $2-3 \mathrm{~kg}$ are collected, analyzed using the BetaScint system and then quantified based on data from a series of known standards prepared using similar media. Measurements are conducted in a field laboratory set up in close proximity to soil removal operations while $\mathrm{D} \& \mathrm{D}$ activities are continuing. 


\section{WM'00 Conference, February 27 - March 2, 2000, Tucson, AZ}

\section{APPLICATION OF THE MARSSIM FOR CHARACTERIZATION}

The MARSSIM approach emphasizes the use of statistical planning and data analysis for demonstrating compliance with a final status survey. There are few examples of how to apply the DQO process for other types of surveys where such formal analyses are not necessary, or even appropriate. One of the objectives of this project is to provide a concrete example of how the MARSSIM methodology can be applied to characterization surveys and to develop a framework for the design of characterization survey plans that can be used to implement the MARSSIM at the BGRR and other DOE sites.

The DQO process is the basis for the performance-based guidance in planning MARSSIM surveys. The steps of the DQO process specified in the MARSSIM include:

1. state the problem

2. identify the decision

3. identify the inputs to the decision

4. define the boundaries (spatial and temporal)

5. develop a decision rule

6. $\quad$ specify limits on decision errors

7. optimize the design for collecting data

Through the implementation in this project, the first four steps of the DQO process are common to both characterization and final status surveys. In the final three steps, there is significant difference in interpretation and application to the characterization survey.

The fifth step in the DQO process is the specification of a decision rule. For the final status survey this usually takes the form of a statistical hypothesis test. For a characterization survey such a highly structured rule will not generally be appropriate. However, it should be possible to identify:

(a) a range of results that clearly indicates that there is no need for remediation in an area,

(b) a range of results that clearly indicates that there is need for remediation in an area, and

(c) an intermediate range of results that may indicate the need for more data before a decision is made.

Such a scheme is loosely patterned after sequential testing procedures, but is primarily intended to differentiate the easy decisions from the more difficult ones so that more resources can be devoted to the areas that need it.

Specifying the acceptable limits on decision errors is the sixth step in the DQO process. For final status surveys, this means specifying Type I and Type II error rates for statistical hypothesis tests. Again, such precision is usually neither desirable nor necessary in a characterization survey.

In a final status survey, the decision errors are used to determine the number of samples it is necessary to collect. The same is true for the characterization survey, except that extensive use of professional judgement must be made to balance the costs of additional measurements against the risk of drawing the wrong conclusion from the data. Optimizing the design of a characterization survey (step seven of the DQO process), involves using all the information available, together with professional judgement, to assess the worth of the information to be gained from additional data in terms of increasing confidence in a remediation decision. This is where the width of the "gray region" expressed by choice (c) of step 5 is used to separate, as efficiently as possible, the easy decisions from the difficult ones. The cost of data 


\section{WM'00 Conference, February 27 - March 2, 2000, Tucson, AZ}

collected early in the characterization can be balanced against the possibility that new data will be needed. The consequence of incorrectly classifying an area as needing remediation when it does not should be balanced against the cost of discovering during a final status survey that an area thought to be clean actually is not. Remediation costs are also balanced against the cost of characterization measurements.

The seven specific elements of the overall DQO process, outlined above, are addressed by the ASTD project team through development of individual project-specific survey plans (PSSPs) in support of individual BGRR D\&D campaigns. The PSSP considers the goals of the intermediate D\&D objective, the baseline characterization elements, and the targeted components of the facility, to identify the scope and content of the in situ characterization efforts using the DQO process. The PSSP provides details on field of view, shielding, and detection levels necessary for the in situ evaluations and identifies sample number designations for items and views of items for tracking and reporting purposes.

Continuity of spectrum analysis and interpretation among the PSSPs is assured by compliance with the ASTD Project In Situ Analysis Quality Assurance Project Plan (QAPP). ${ }^{1}$ This QAPP provides a description of the individuals, organizational responsibilities, and control measures necessary to achieve, verify and demonstrate compliance with both federal and industry quality assurance requirements. This QAPP has been developed using the guidance in EPA QA/G-5 to ensure that appropriate requirements for project data quality have been adequately addressed. ${ }^{2}$

\section{IN SITU GAMMA SPECTROSCOPY}

In situ gamma spectroscopy has been shown to be cost-effective in almost all applications where field sampling and laboratory analyses are the baseline technologies. Results can be obtained immediately following field acquisitions, thereby reducing the time delays incurred by physical sampling and laboratory analysis. In situ measurements can be performed on sealed systems (i.e., without breaching a containment barrier) or remotely (i.e., at a distance from an external radiation source), reducing personnel exposures and/or work hazards. Where independent lab analysis is required prior to free release of materials, in situ measurements serve as a screening technique, eliminating the unnecessary analysis of samples above derived concentration guidelines (DCGLs). Large areas or volumes can be assayed with a large field of view to reduce errors arising from non-homogeneity, providing a more accurate estimate of average radionuclide concentrations. These advantages make in situ spectroscopy an attractive tool for many characterization applications. The Canberra ISOCS system couples previously proven detector hardware with innovative calibration software to produce an integrated instrument capable of quantified analysis in the field comparable to laboratory-grade analysis.

Germanium Detector: The radiation detector utilizes a high purity germanium crystal for high resolution and high efficiency gamma radiation detection. For this application, a Canberra Broad Energy Germanium (BEGe) detector was selected because it enhances the efficiency below $1 \mathrm{MeV}$ while exhibiting increased transparency to high energy gammas, such as those from naturally occurring $\mathrm{K}-40$ and Tl-208 (thorium series progeny). The detector shape (50 $\mathrm{mm}$ diameter by $30 \mathrm{~mm}$ thick) is optimized for analysis of real-world objects in the detector's field of view, but it has less sensitivity to a Marinelli beaker sample geometry than a traditional cylindrical-shaped coaxial detector. The enhanced detector efficiency for low energy gammas (from 30-100 keV) provides a field capability for detection of Am-241 and low energy gammas associated with actinide alpha-emitters that greatly exceeds the capability of traditional detectors. 


\section{WM'00 Conference, February 27 - March 2, 2000, Tucson, AZ}

Modular shields and cart: Useful mechanical components of the ISOCS system include a field deployable mobile cart and a modular system of stainless-steel covered lead shields. Annular side shields of either $19 \mathrm{~mm}$ or $44 \mathrm{~mm}$ lead thickness effectively reduce the detection of interfering radiation from items in the vicinity of the detector and background radiation, resulting in improved system sensitivity. The field of view can be further restricted, from $180 \mathrm{E}$ to $90 \mathrm{E}$ or $30 \mathrm{E}$, by installing lead collimators on the cart's mounting rails, so that items adjacent to the object of interest can be significantly reduced or eliminated from the analysis. In addition, a completely shielded sample chamber can be assembled by combining the components of the two thickness annular shield systems to enable timely, low-background analysis of samples in the field.

Analytical Software: The ISOCS efficiency calibration software provides the user with the ability to quantify nuclide activity easily and reliably. This software employs a mathematical calibration technique that includes detector-specific characteristics, accounts for collimators and/or shields, and models the physical object to be assayed. It uses a combination of Monte Carlo calculations and discrete ordinate attenuation computations to derive efficiency curves (fraction of gammas emitted from the object that interact in the detector for an energy interval) for each specific in situ analysis. Objects are modeled from one of a set of generic sample shapes, such as boxes, cylinders, planes, spheres, pipes, etc. These basic geometry templates have many parameters that can be modified to create an accurate representation of the sample object and detector geometry. Efficiencies can be generated in a few minutes in the field and can be modified easily if needed.

Technology Application: The versatility of the ISOCS system has been demonstrated in numerous situations during initial characterization and decommissioning efforts at the BGRR. Surface soil detection sensitivities of less than $1 \mathrm{pCi} / \mathrm{g}$ have been attained with count times as short as 10 minutes for common gamma emitters such as Cs-137. Final results have been reported the same day, following data review and validation. Lower activities or more difficult to measure objects, such as enclosed systems, buried sources, and low-level surface contamination, can take much longer to measure and evaluate. However, large surface areas or volumes with heterogeneous material distributions can be assayed with a single in situ measurement, thus saving time over other, more manual, methods, such as sampling and remote laboratory analysis.

A typical ISOCS application can be illustrated by reviewing the characterization of core-cooling exhaust fans, prior to their removal, volume reduction, and shipment from the site. Each fan is a massive squirrel-cage type blower, nominally $8 \mathrm{ft} \times 10 \mathrm{ft} \times 12 \mathrm{ft}$, and 14,000 lbs. The fans became internally contaminated, likely as a result of fuel element failure, but the identity, extent, and quantity of radioactive material in the fan internals were unknown. External surveys revealed non-uniform internal deposition with highest readings in the vicinity of the fan volutes, where entrained dust particles would have had a higher probability of settling out due to eddies and dead spaces in air flow currents. Three of the five fans had been upgraded/replaced during the operating life of the reactor. Thus, physical configurations, dimensions, and radionuclide quantities were different from those in the other two fans.

The ISOCS was mobilized to the Fan House containing the five contaminated fans and in situ gamma spectra were acquired from Fan \#5 (representative of Fans \#5 and 4) and Fan \#3 (representative of Fans \#3, 2, and 1). Figure 3 is a photograph of the ISOCS deployed at the BGRR Fan House. Each fan housing was scanned using $44 \mathrm{~mm}$ annular shields and $90^{\mathrm{E}}$ field of view collimators to reduce interference as much as possible from adjacent contaminated structures. Because of the equipment layout, there was no position where gamma spectra could be acquired without structural components 


\section{WM'00 Conference, February 27 - March 2, 2000, Tucson, AZ}

(concrete supports and carbon steel struts) shielding a portion of the field of view. The ISOCS cart was positioned so that the detector was oriented diagonally downwards at the fan housing volute bottom, where surveys indicated an accumulation of radioactivity. Spectra were accumulated for 15 minutes each from two symmetric positions: NE of the housing facing $\mathrm{SW}$ and NW of the housing facing SE. Equipment setup, spectrum acquisition and equipment-breakdown required less than two hours, with only minimal health and safety oversight and no breaching of contamination containment barriers. Radioactivity in the fan housing was modeled as a layer of surface dust, uniformly covering the interior of the carbon steel fan volute (horizontal or diagonal rectangular plane). Due to the complex geometry with intervening structural members, several alternative geometry models were defined. The intervening structural members were adjusted in the models until the results from the symmetric scans were similar. The modeling and analysis of both fans required about six hours.

The results of the analysis are provided in Table 1. The range in the value is representative of the uncertainty in the analysis, and is primarily associated with assumptions on unobserved inner structures of the fan. The table demonstrates that even when using a detector with enhanced low-energy response, the detection level can still be high when the source is shielded by a highly attenuating medium such as this example, inside a carbon steel fan housing. With the use of the ISOCS modeling software, a quantified estimate of the activity in the fan was provided in approximately eight hours, without fabricating a physical radioisotope calibration standard, without breaching contaminated barriers, and without handling and transporting contaminated samples.

Table I Results of In Situ Measurements at BGRR Fan House

\begin{tabular}{|c|c|c|c|c|}
\hline \multirow{2}{*}{ Fan Unit } & \multicolumn{4}{|c|}{ Measured Activity, FCi } \\
\cline { 2 - 5 } & $\begin{array}{c}\text { Cs-137 } \\
\text { low estimate }\end{array}$ & $\begin{array}{c}\text { Cs-137 } \\
\text { high estimate }\end{array}$ & Co-60 & Am-241 \\
\hline Fan No 5 & $75 \pm 3$ & $600 \pm 20$ & $\# 0.1$ & $\# 180$ \\
\hline Fan No 3 & $114 \pm 10$ & $330 \pm 30$ & $4.8 \pm 0.5$ & $\# 800$ \\
\hline
\end{tabular}

Note: $\quad$ The uncertainties in the table represent \pm 2 s counting error; values expressed as “\#” represent the minimum detectable activity and indicate that the radionuclide was not detected. 


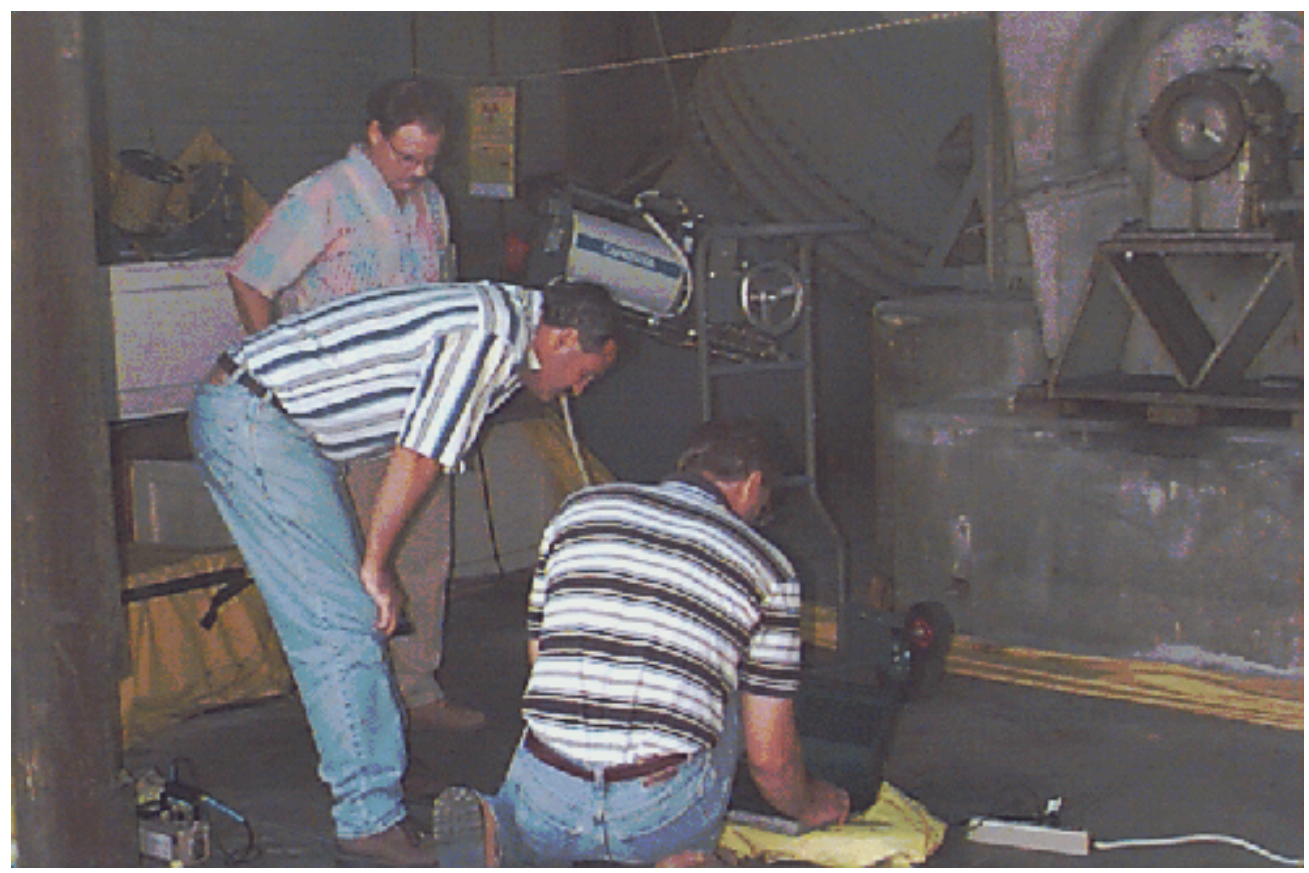

Figure 3 Using in situ ISOCS system to evaluate internal contamination at the BNL BGRR Fan House \#5

Another convenient use of the ISOCS technology is the rapid quantification of soil activity in the field. The use of the modular shields to construct a low-background counting chamber on the mobile cart/stand provides a laboratory quality, quantified analysis that is available in almost real time at the point of sampling. The typical detection levels attained by a five-minute count of a soil sample in a one liter high density polyethylene bottle are illustrated in Table 2.

Table II Typical Minimum Detectable Activity for 5-min Assay of 1L Soil Samples

\begin{tabular}{|l|c|c|c|c|c|c|c|}
\hline Radionuclide & Co-60 & Cs-137 & Eu-152 & Th-232 $^{(a)}$ & Ra-226 $^{(b)}$ & U-235 & Am-241 \\
\hline MDA (pCi/g) & 0.26 & 0.24 & 0.32 & 0.35 & 0.43 & 0.20 & 0.24 \\
\hline
\end{tabular}

(b) Ra-226 activity inferred from Bi-214 assuming secular equilibrium.

Observations: Data has successfully been acquired and evaluated for several BGRR facilities and components including the Pile Fan Sump (PFS), underground piping for the PFS, parking lot areas, Above Ground Ducts, and contaminated cooling fans. Through deployment of ISOCS to date, the ability to provide individual isotopic identification and quantitative assays in the field quickly and reliably has highlighted several advantages of the technology:
C reduction of the cost and time delay associated with sampling and laboratory analysis
C reduction of the potential hazards of contaminated system entry and sampling/measurement
C the ability to derive efficiencies for objects without purchasing or fabricating radioactive standards
C enhanced detection sensitivity by using the annular shields and collimators 


\section{WM'00 Conference, February 27 - March 2, 2000, Tucson, AZ}

One design limitation has been identified that affects the efficient use of the BEGe system in the characterization phase of a D\&D project. The $30 \mathrm{E}$ collimator shields over $90 \%$ of the sensitive area of the detector, thus negating any increased sensitivity of the detector. Having to rely on only the $90 \mathrm{E}$ collimator results in some assays being more complex and less specific, since adjacent sources cannot be readily screened from the primary object spectrum.

\section{FIELD DEPLOYABLE SR-90 ANALYSIS}

Technology Description: The BetaScint system consists of a multi-layer beta scintillation detector array with a beta radiation entrance window measuring $30-\mathrm{cm}$ by $60-\mathrm{cm}$. Scintillating fibers are fashioned into ribbons, which are stacked vertically. Soil samples are prepared, transferred to large area counting trays, and positioned beneath the detector window for analysis. Beta particles that pass through the detector window excite electrons in the scintillating ribbons resulting in the emission of light pulses, which are counted by photomultiplier tubes. Coincident circuitry to detect simultaneous events in several ribbon layers distinguishes high energy betas (Sr-90) from lower energy contaminants and background.

Initially, the strontium-90 detection efficiency of the BetaScint system is established by measuring its response to site-specific calibration standards. These calibration standards are prepared by spiking clean (non-contaminated) site soils with known quantities of strontium-90. The net system response is directly proportional to strontium-90 activity concentration because it is almost entirely due to strontium-90 beta interactions.

Routine daily operations of the BetaScint system include the performance of daily quality control checks and background measurements. Quality control checks consist of analysis of a calibration standard of known activity. The results of the quality control checks are compared against established acceptance criteria to determine whether the instrument is functioning properly. Background checks are performed by counting with no samples in place (i.e., bare detector.) These measurements, which are performed daily at a minimum, are subtracted from gross sample counts to establish net detector response. For calibration and operation, a 2 - $3 \mathrm{~kg}$ sample is typically dried, sieved to remove organic matter and rocks over $6 \mathrm{~mm}$ in size, and spread evenly over a large area counting tray. The sample tray is then positioned beneath the window of the detector and counted for five minutes. Following the analysis, the system reports the number of coincident events and the counts are converted to Sr-90 activity concentration in the soil, using the detection efficiency correlation established with the spiked site soils.

Implementation at BNL: The BetaScint system was deployed at Brookhaven for a two week demonstration during the period of December 6 - 17, 1999. Soil samples from the BGRR site and other environmental restoration areas at BNL were collected and analyzed using the system. Figure 4 is a photo of the BetaScint equipment system set up at BNL.

Four calibration standards were prepared from a NIST traceable Sr-90 solution and uncontaminated site soils. . Following preparation, the calibration standards were analyzed by the BetaScint system and a Sr-90 detection efficiency correlation was established. It should be noted that the observed efficiency, 0.67 counts/second per pCi/gram, was virtually identical to the efficiency established by BetaScint at other sites. ${ }^{3}$

During the two-week demonstration, a total of 145 evaluations were performed on 35 samples. The analytical count time for these analyses was 5-minutes. Based on the BetaScint results, Sr-90 activity 


\section{WM'00 Conference, February 27 - March 2, 2000, Tucson, AZ}

concentrations in these samples ranged from non-detectable to approximately $70 \mathrm{pCi} / \mathrm{gram}$. The 5minute count time yielded a minimum detectable activity concentration of approximately $1.2 \mathrm{pCi} / \mathrm{gram}$ at the $95 \%$ confidence level, which is considerably less than the BGRR DGCL for Sr-90 of 15 pCi/gram.

The calibration standards were re-analyzed by the BetaScint following system calibration in order to evaluate the precision of the BetaScint analyses,. The results of these analyses (Table 3) are within \pm $8 \%$ of the calibration standard activity concentrations, indicating that the system exhibits acceptable levels of reproducible detection. To assess instrument accuracy, 7 soil samples and aliquots from the 4 calibration standards were sent off-site for conventional baseline Sr-90 analysis to facilitate comparison; the results of these analyses are still pending.

Table III Results of Calibration Standard Measurements

\begin{tabular}{|c|c|c|}
\hline $\begin{array}{c}\text { Spiked Sr-90 } \\
\text { Concentration } \\
(\mathrm{pCi} / \mathrm{g})\end{array}$ & $\begin{array}{c}\text { Measured Sr-90 } \\
\text { Concentration } \\
(\mathrm{pCi} / \mathrm{g})\end{array}$ & \% Difference \\
\hline 7.5 & $7.9 \pm 1$ & 5 \\
\hline 15 & $16 \pm 2$ & 7 \\
\hline 22.5 & $22.4 \pm 2$ & 1 \\
\hline \hline 610 & $562 \pm 40$ & 8 \\
\hline (a) Errors reported at the $95 \%$ confidence level
\end{tabular}

Daily, or more frequent, quality control checks were performed (a total of 25) by analyzing the 22.5 pCi/gram calibration standard that had been prepared. The average result of these analyses was 22.2 $\mathrm{pCi}$ /gram (see Figure 5.). All results were within $\pm 2 \mathrm{~s}$ of the average value, with the exception of one result that was slightly less than $2 \mathrm{~s}$, indicating that the system response is stable over time and exhibits acceptable levels of precision. Duplicate analyses were also performed on most samples to evaluate the precision of the system. In general, the results of duplicate analyses were within acceptable statistical bounds. 
WM'00 Conference, February 27 - March 2, 2000, Tucson, AZ

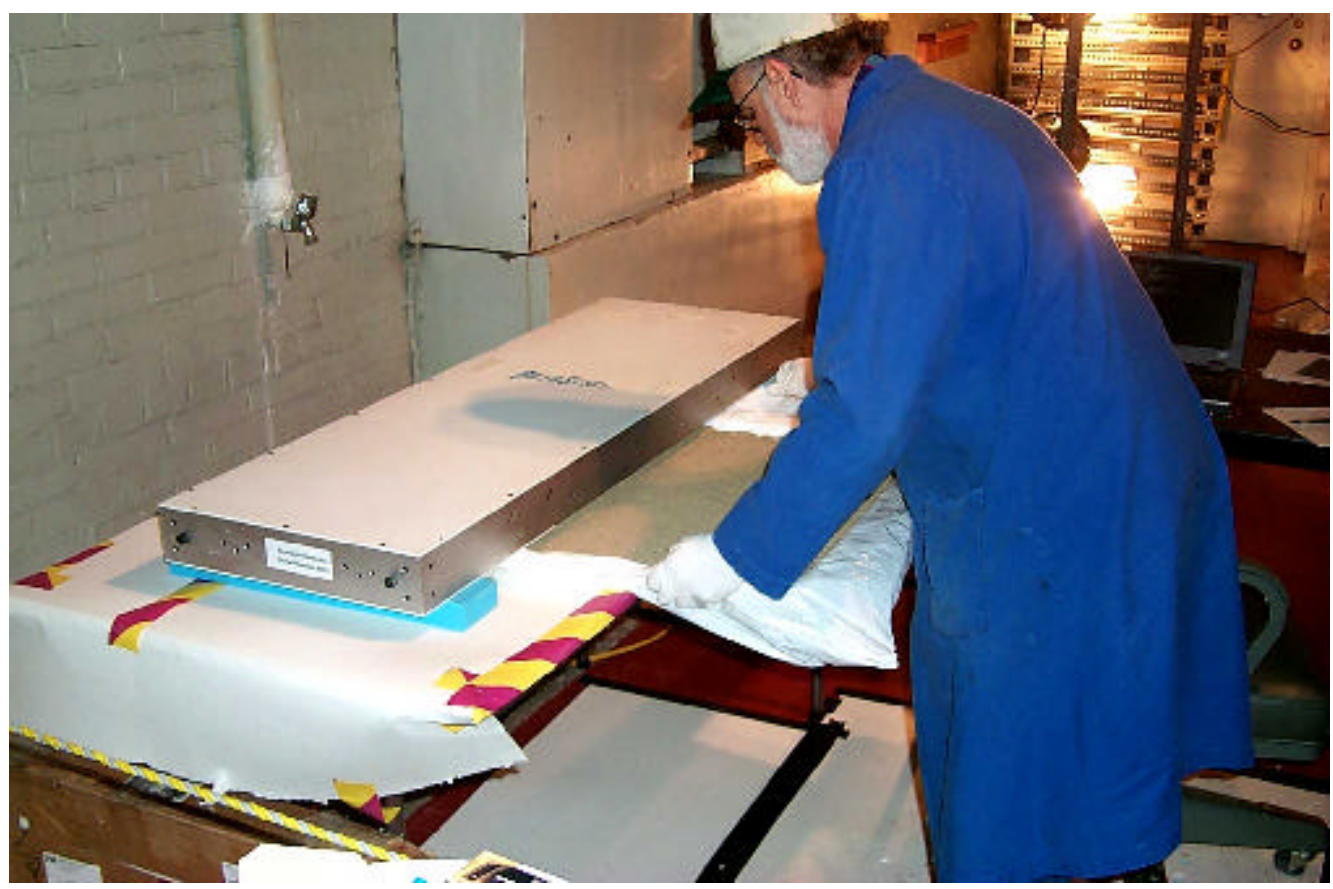

Figure 4 Loading soil sample for Sr-90 BetaScint analysis at BNL

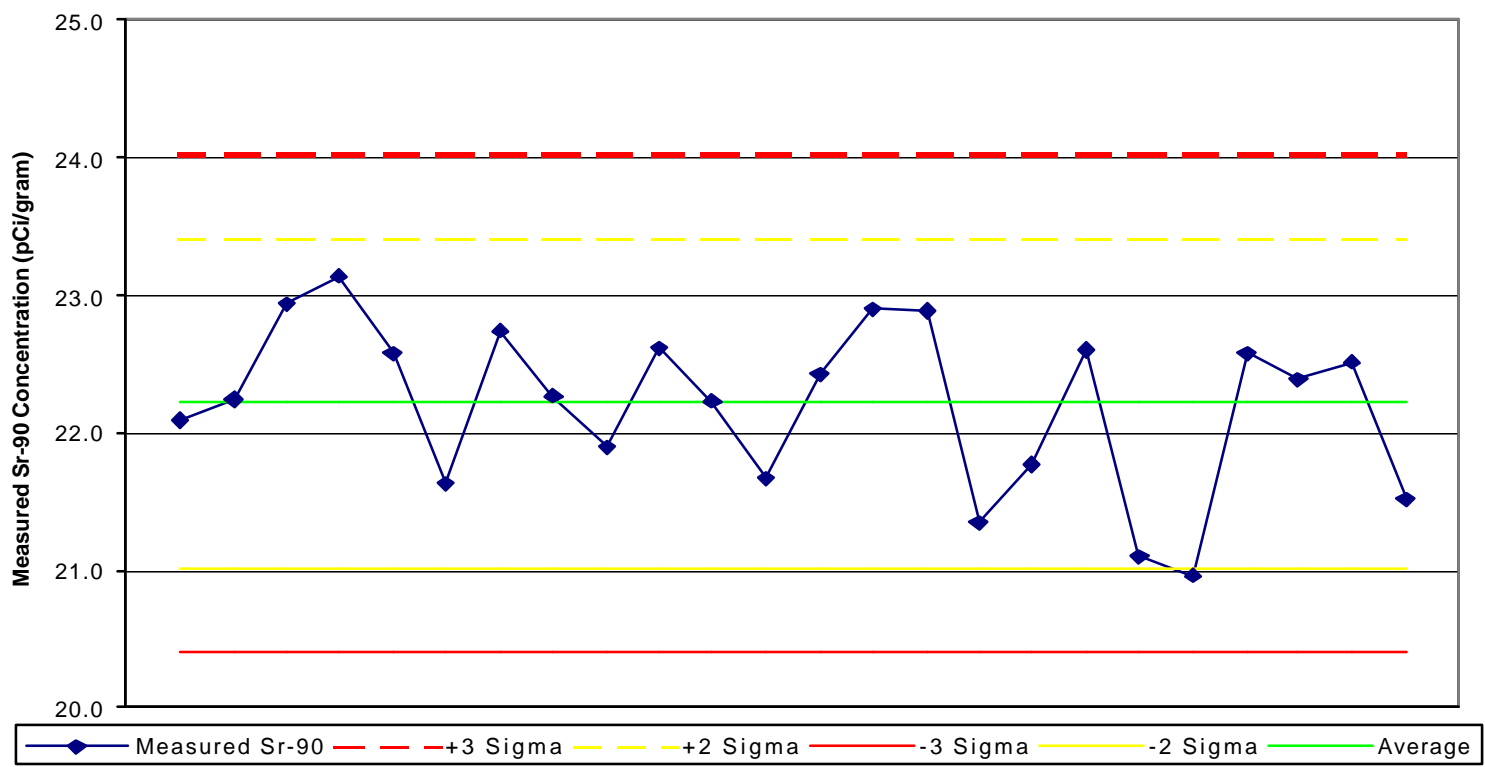

Figure 5 Results of quality control measurements for BetaScint in response to $22.5 \mathrm{pCi} / \mathrm{g}$ calibration source 


\section{WM'00 Conference, February 27 - March 2, 2000, Tucson, AZ}

\section{SUMMARY AND CONCLUSIONS}

The MARSSIM guidance, with its emphasis on final status survey design, has been applied in the characterization phase through a modification of the final steps of the DQO process. In situ data have successfully been acquired and evaluated for several BGRR D\&D objectives, and the ability to provide individual isotopic identification and quantitative assays in the field quickly and reliably has highlighted several advantages of the technology. In particular, the Canberra ISOCS system can be used to effectively measure gamma emitting contamination in areas difficult to assay (e.g., pipes and equipment or areas with high radiation levels) or as a field deployable gamma spectroscopy laboratory for volumetric samples. BetaScint provides a field deployable system for near real-time (approx $20 \mathrm{~min}$ ) evaluation of Sr-90 with good detection limits ( $1 \mathrm{pCi} / \mathrm{g}$ concentrations). Together, the use of MARSSIM with in situ characterization techniques is enabling accelerated, accurate, and costeffective evaluation of equipment, structures, and materials at the BNL BGRR.

\section{ACKNOWLEDGMENTS}

The authors gratefully acknowledge the U.S. Department of Energy Office of Science and Technology Decontamination and Decommissioning Focus Area and the Brookhaven BGRR Decommissioning Project for their support of this effort.

\section{REFERENCES}

1. In Situ Analysis Quality Assurance Project Plan, Brookhaven National Laboratory Accelerated Site Technology Deployment Project, Upton, NY. July 1999.

2. U.S. EPA, EPA Guidance for Quality Assurance Project Plans, EPA QA/G-5, US Environmental Protection Agency, Washington, DC. February 1998.

3. U.S. DOE, BetaScint Fiber-Optic Sensor for Detecting Strontium-90 and Uranium-238 in Soil, Innovative Technology Summary Report, OST \#70, U.S. Department of Energy Office of Environmental Management, Office of Science and Technology, December 1998. 


\section{Section 2}




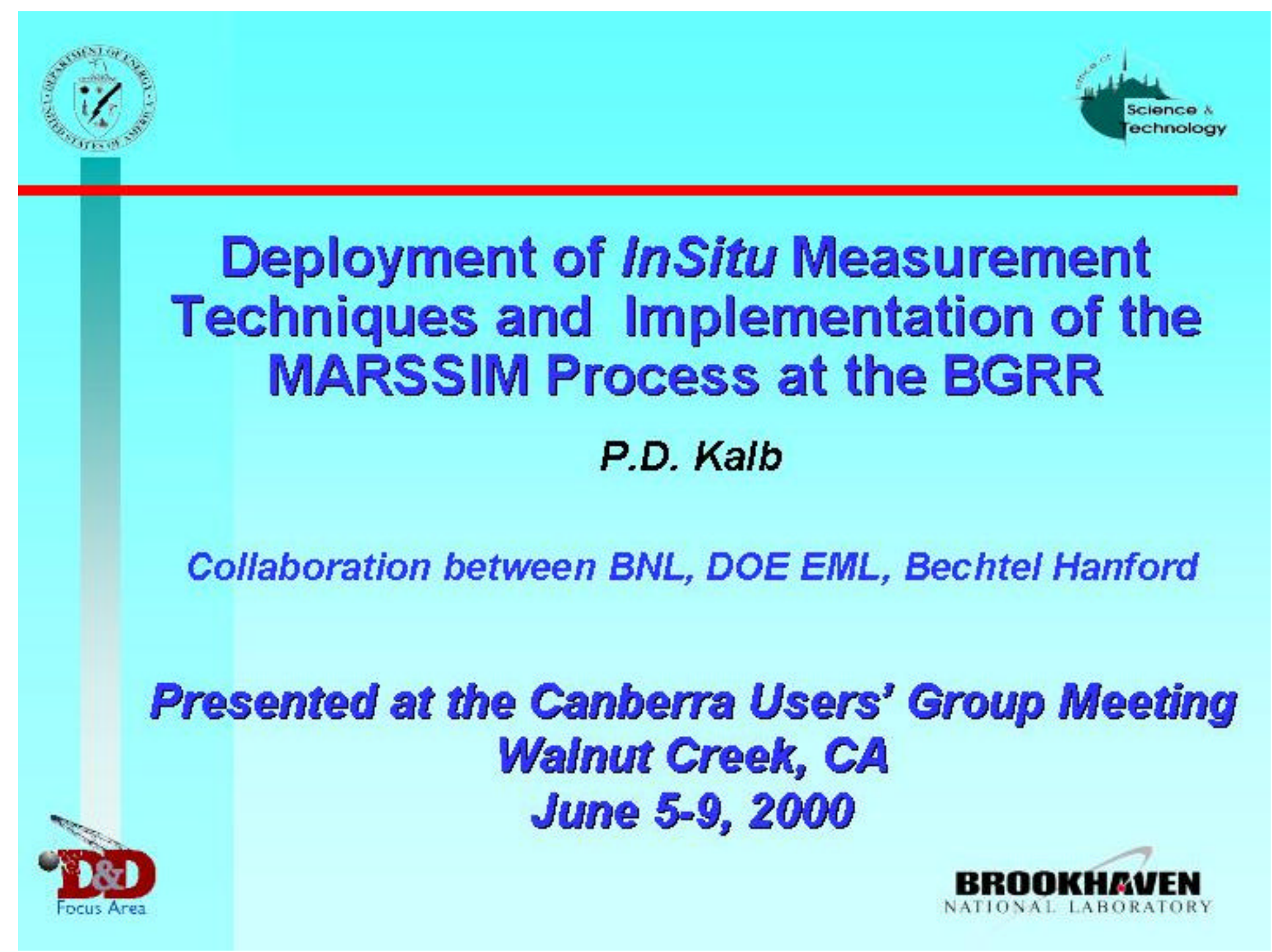




\section{Overview}

- Background

- Technology Need

- Project Description

Goals

$\checkmark$ Technical Approach

$\checkmark$ Technology Description

- Technical Progress

- Summary and Conclusions 


\section{Background}

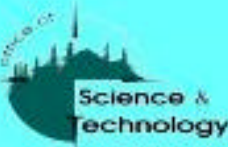

THE NEW YORK TUMFS, SUNDAY, FEBRUARY 12 , am

Old B.N.L. Reactor Is Being Dismantled

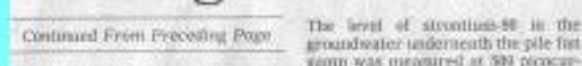

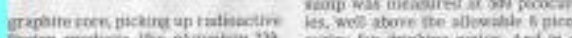

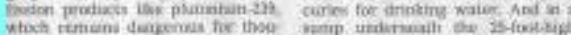

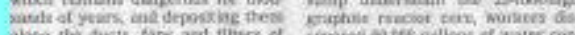

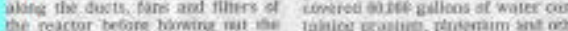

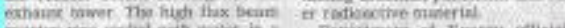

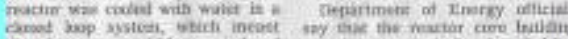

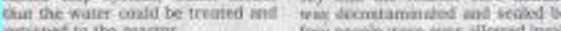

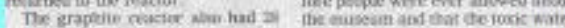

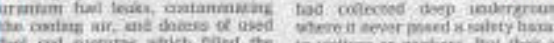

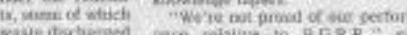

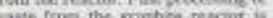

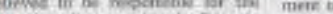

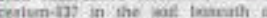

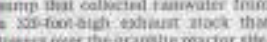

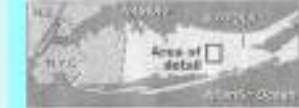

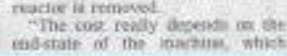

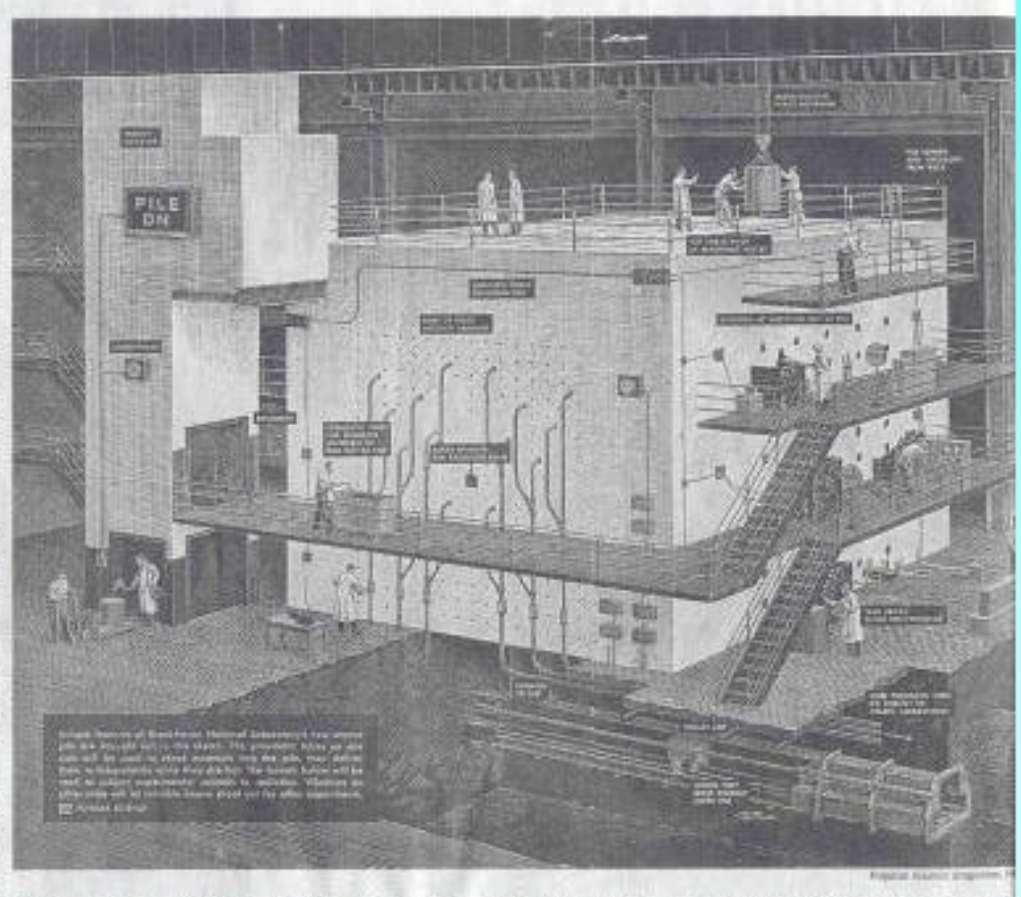




\section{Background}

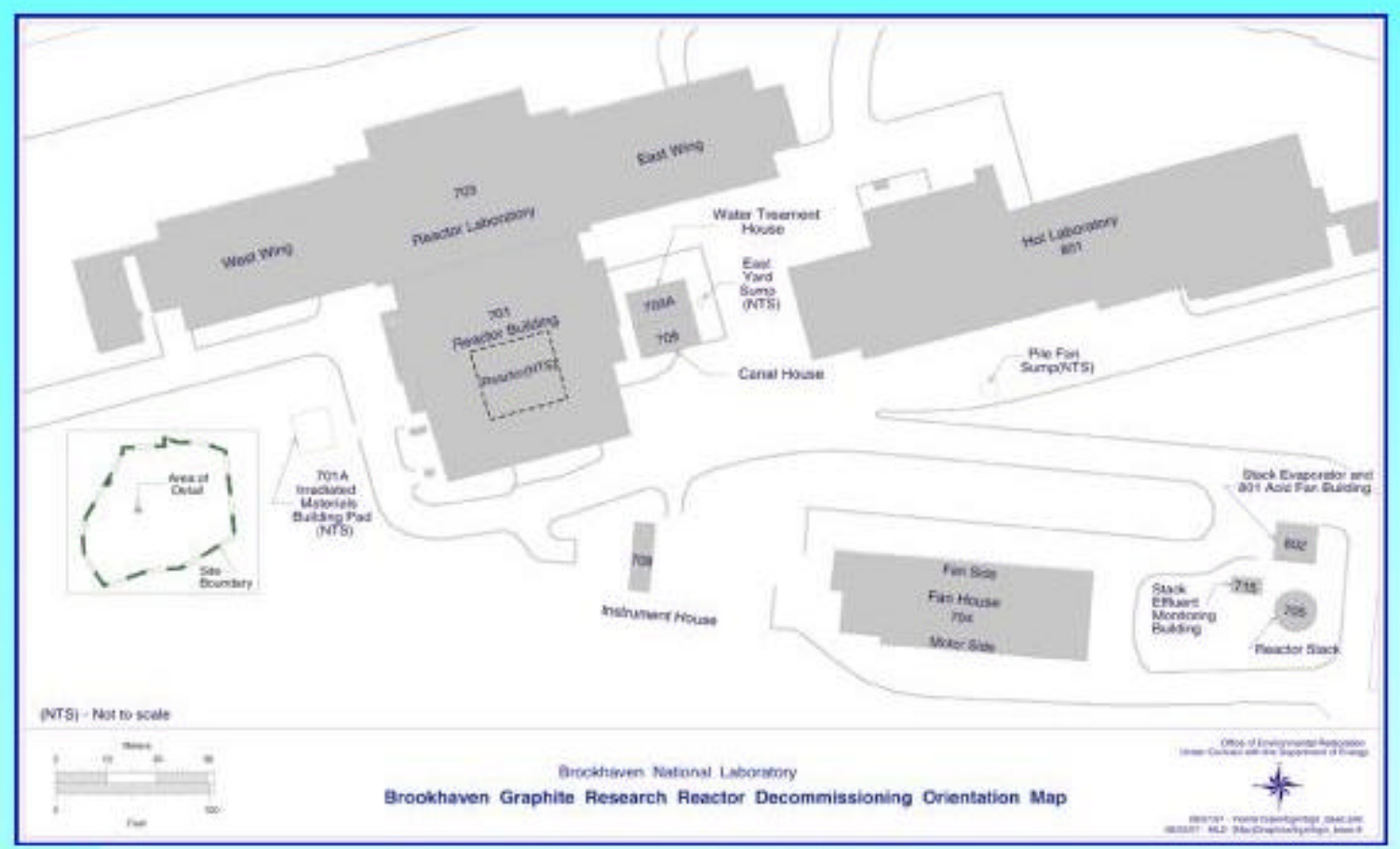

\section{Plan View of BGRR}




\section{Background}

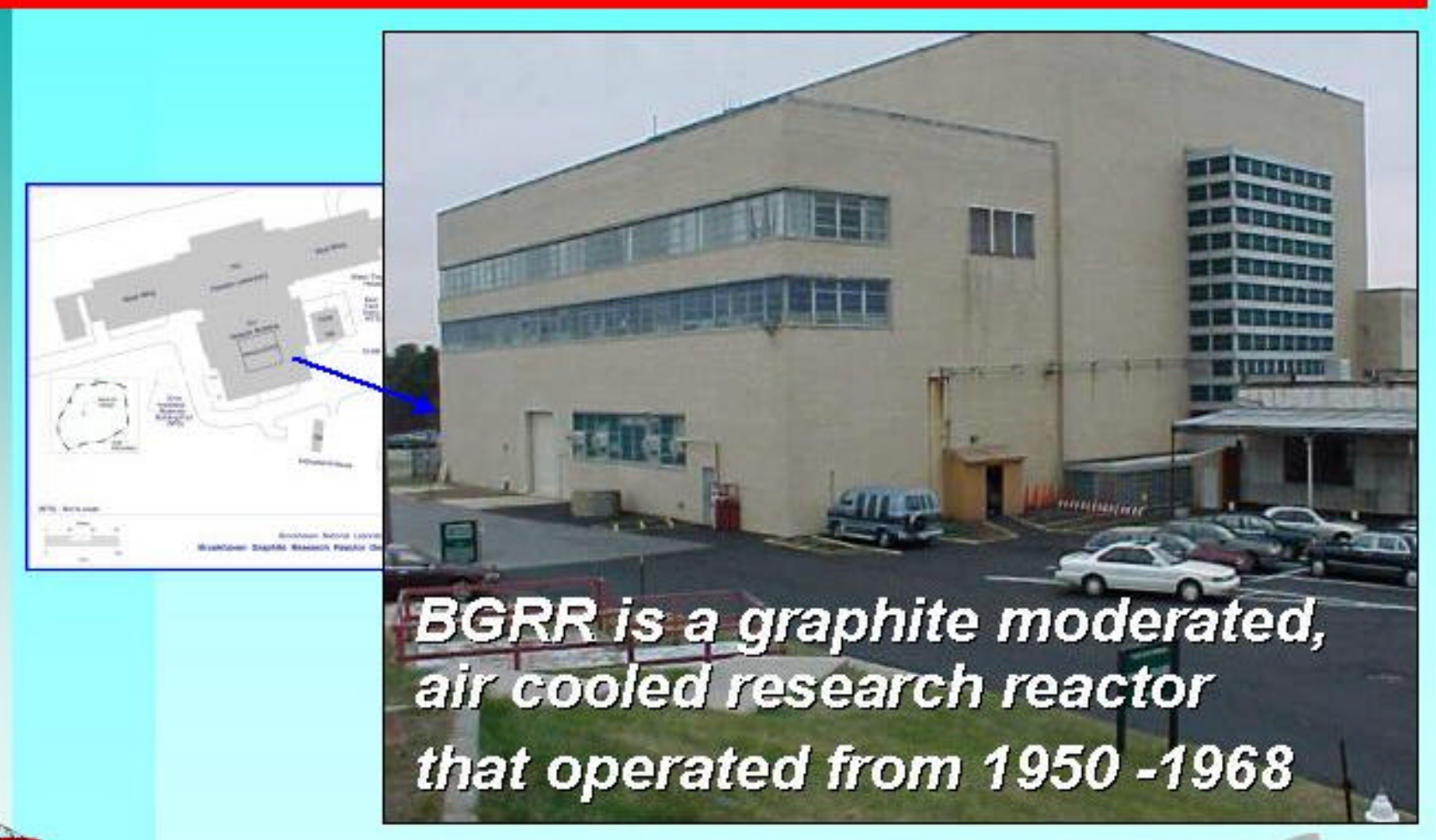




\section{1/. Background}

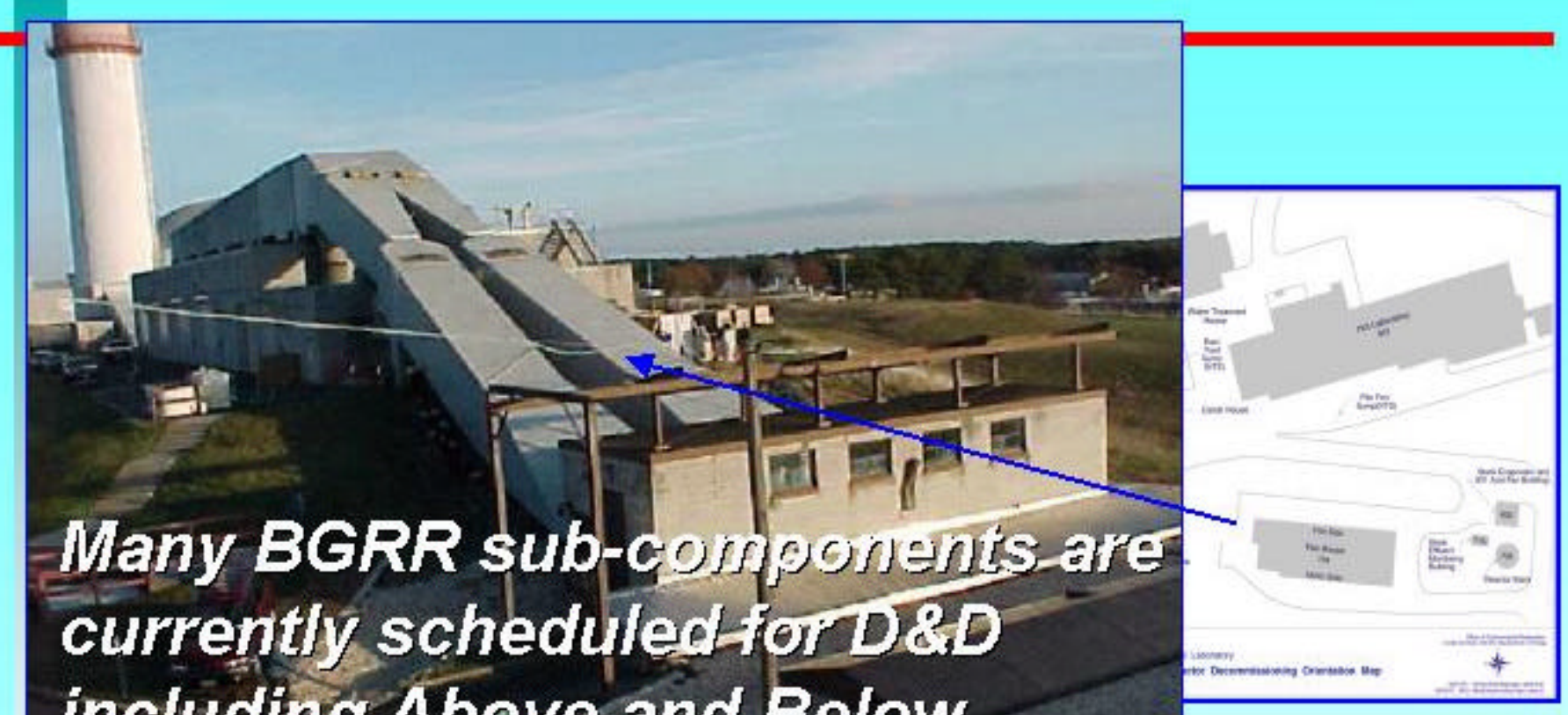

including Above and Below Ground Air Ducts, Fan House, 


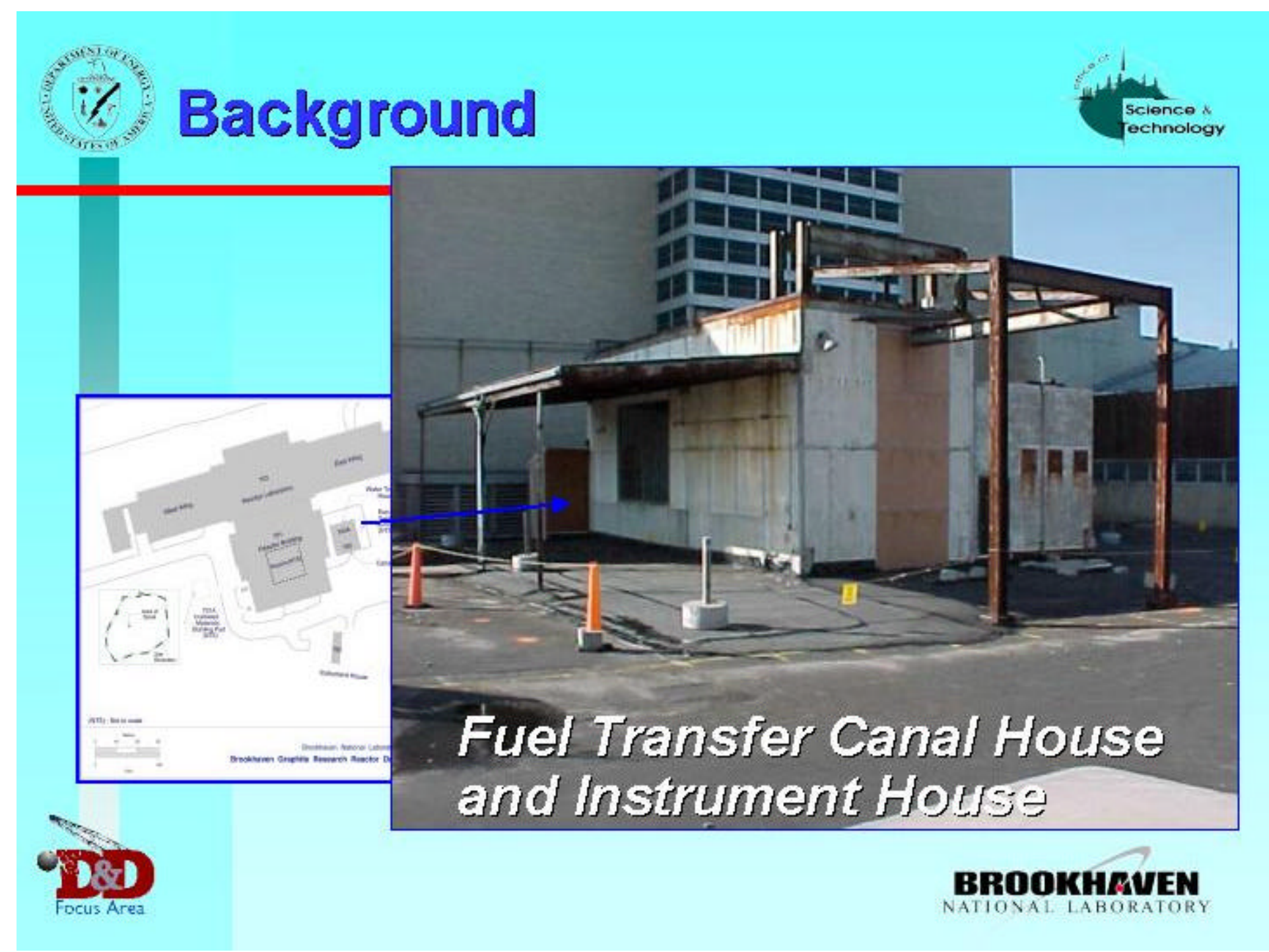




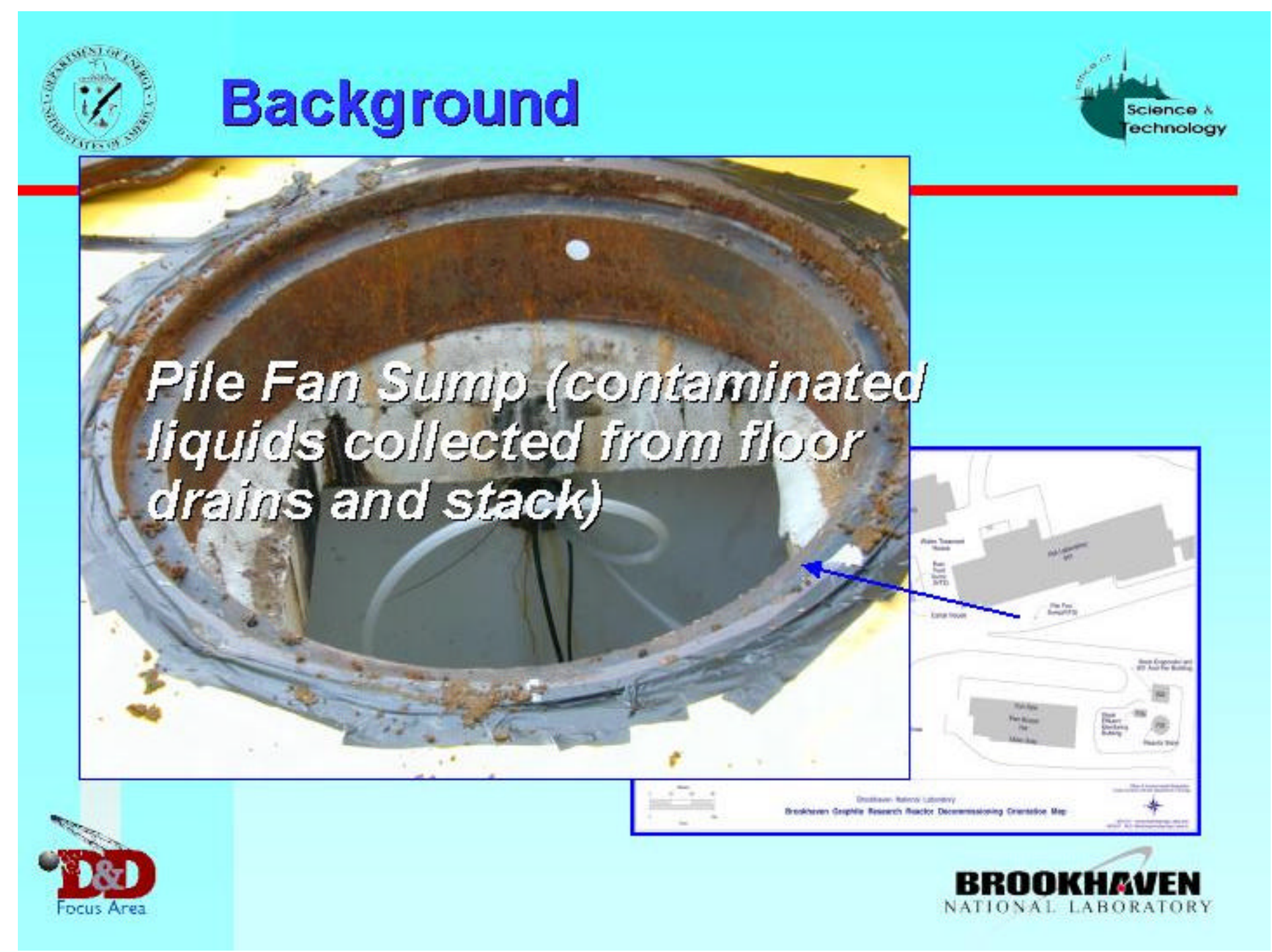




\section{Technology Need}

- D\&D characterization is required to:

$\checkmark$ minimize worker exposure

$\checkmark$ plan for appropriate disposition of materials and remaining facilities

$\checkmark$ demonstrate compliance with applicable environmental regulations

- Characterization applied in three stages:

$\checkmark$ Pre D\&D scoping

$\checkmark$ During D\&D operations

$\checkmark$ Post D\&D final status survey 


\section{Baseline Characterization}

- Baseline approach is time consuming and costly:

$\checkmark$ collect thousands of surface smear, volumetric, and core samples

$\checkmark$ ship samples for analysis

$\checkmark$ wait for results (14 -28 day turn around typical)

- Many areas difficult to access or highly contaminated

- Difficult to measure heterogeneous contamination 


\section{Innovative Characterization}

- Multi Agency Radiation Survey \& Site Investigation Manual (MARSSIM) process:

$\checkmark$ optimize survey design

$\checkmark$ reduce unnecessary sampling

$\checkmark$ save time and money

- In situ techniques:

$\checkmark$ monitor remotely, reducing personnel exposures

$\checkmark$ improved characterization of heterogeneous distribution of contamination

$\checkmark$ faster turn-around time

$\checkmark$ lower analytical costs 


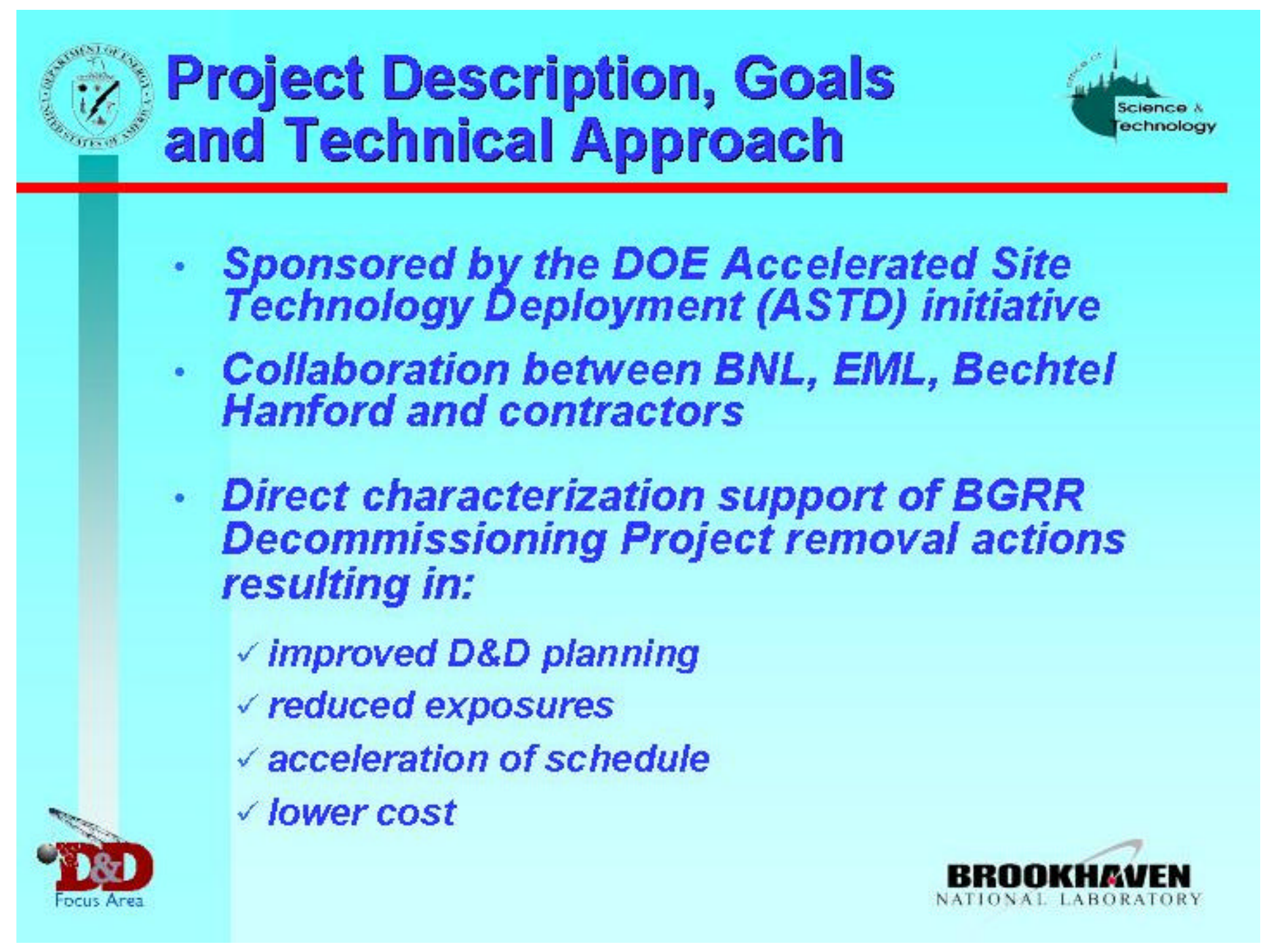




\section{i) Project Description, Goals}

and Technical Approach

- Implement MARSSIM process for D\&D characterization as well as final status survey

- Deploy innovative in situ characterization techniques:

$\checkmark$ Canberra In situ Object Counting System (ISOCS) for gamma emitting nuclides

$\checkmark$ BetaScint fiber optic sensor for Sr-90 


\section{Multi Agency Radiation Survey and}

Site Investigation Manual (MARSSIM)

- MARSSIM process developed for final status surveys - Application for D\&D characterization is unique

- MARSSIM emphasizes statistical planning and analysis to demonstrate compliance with cleanup guidelines

- Incorporates:

$\checkmark$ Data Quality Objective (DQO) process

$\checkmark$ Quality Assurance Project Plan (QAPP)

$\checkmark$ Data Assessment 


\section{MARSSIM \\ Technical Progress}

- QAPP prepared using EPA QA/G-5 guidance and approved by project team

- Standard Operating Procedures (SOP) prepared for general measurement activities

- Project Specific Survey Plans (PSSP) prepared for specific measurement activities

DQO process to identify scope and content of characterization

- identifies field of view, shielding, and detection levels necessary

specific sampling protocol 


\section{Canberra In Situ Object Counting System (ISOCS)}
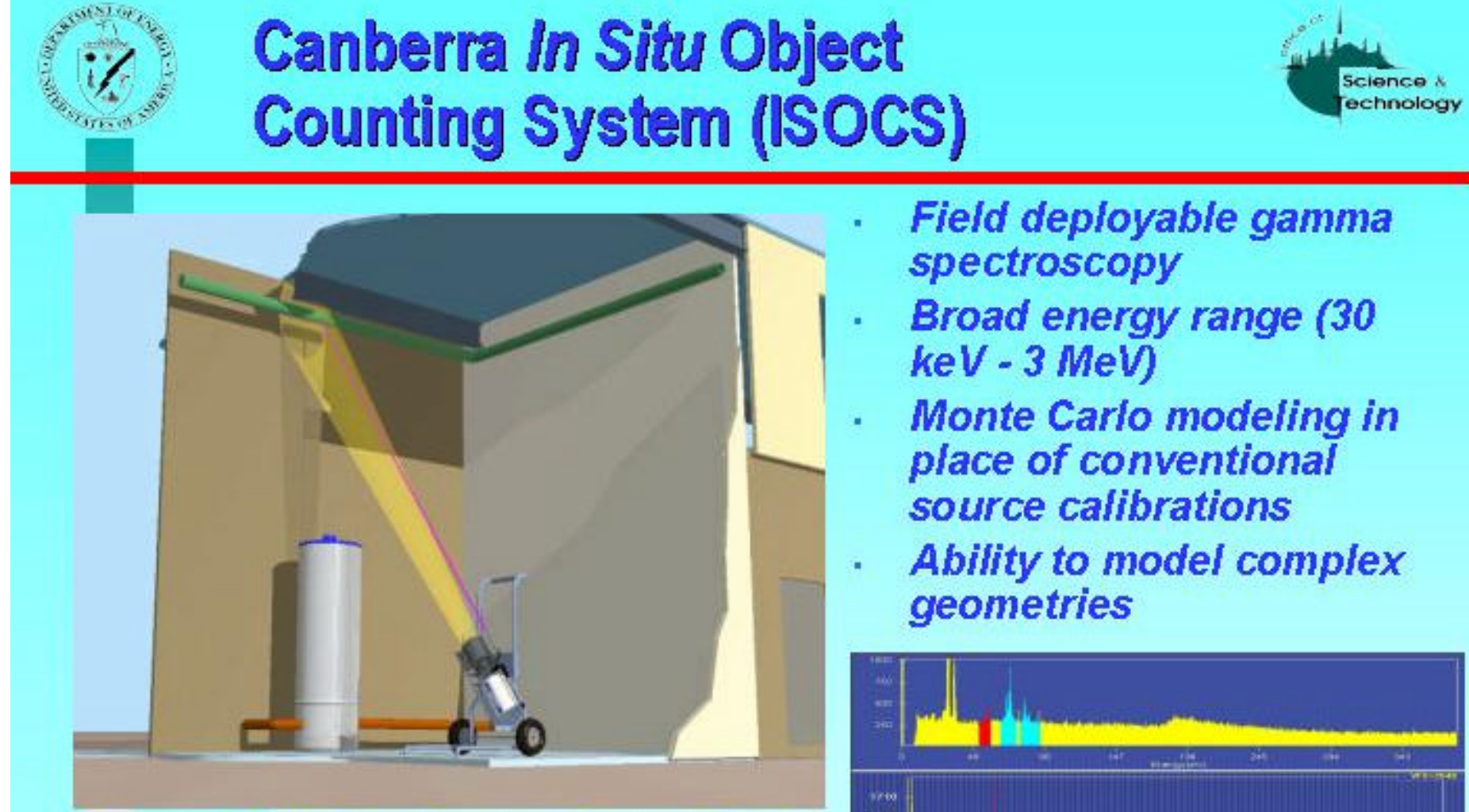

Canberra in Situ Object Counting System (ISOCS) measuring contamination within a pipe

- Field deployable gamma spectroscopy

- Broad energy range (30 keV - $3 \mathrm{MeV})$

- Monte Carlo modeling in place of conventional source calibrations

- Ability to model complex geometries

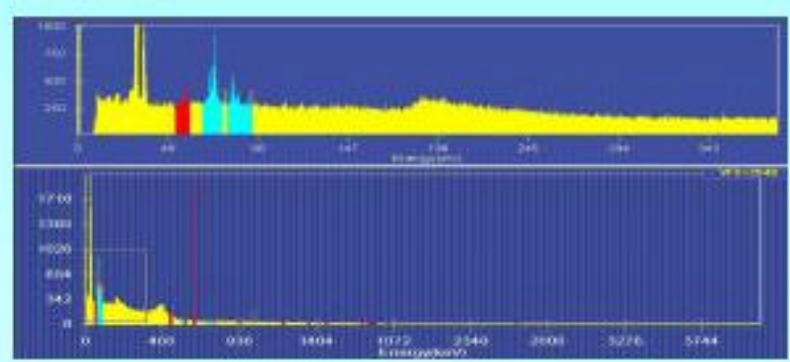




\section{ISOCS Technical Progress}

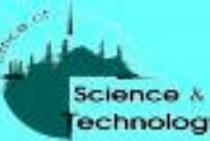

ISOCS Characterization of BGRR Above Ground Ducts

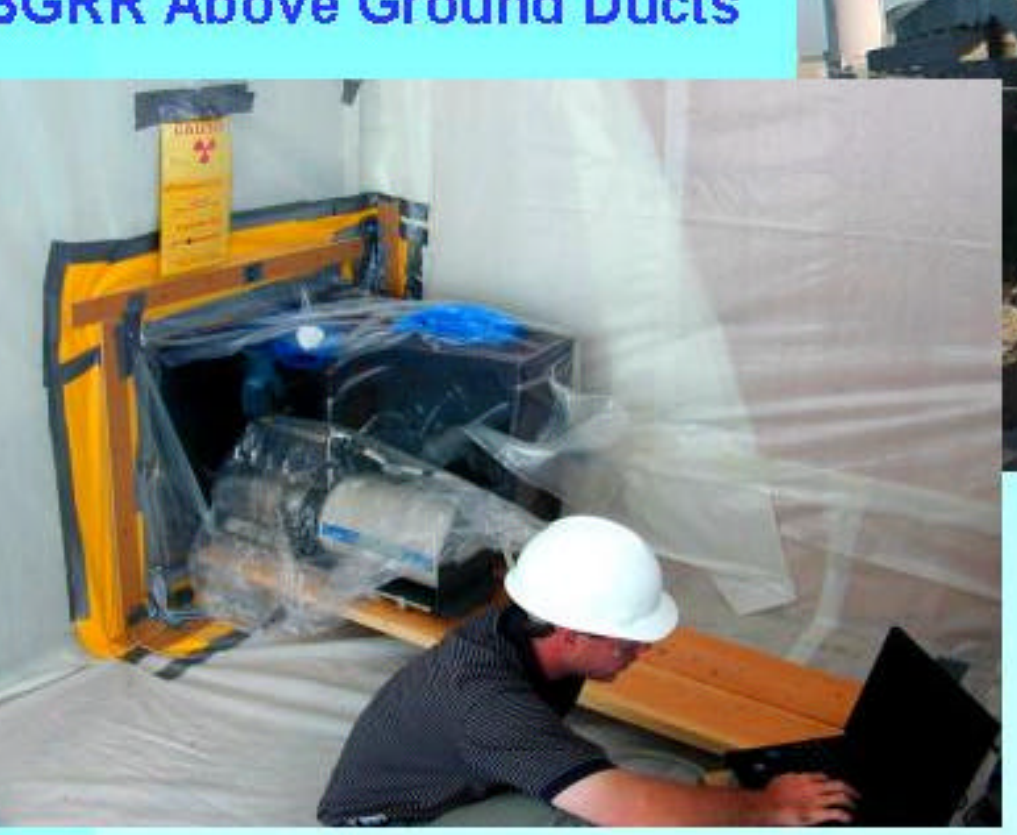




\section{ISOCS Technical Progress}

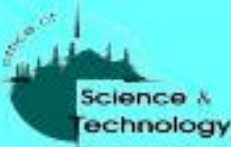

Characterizing the BGRR Pile Fan Sump

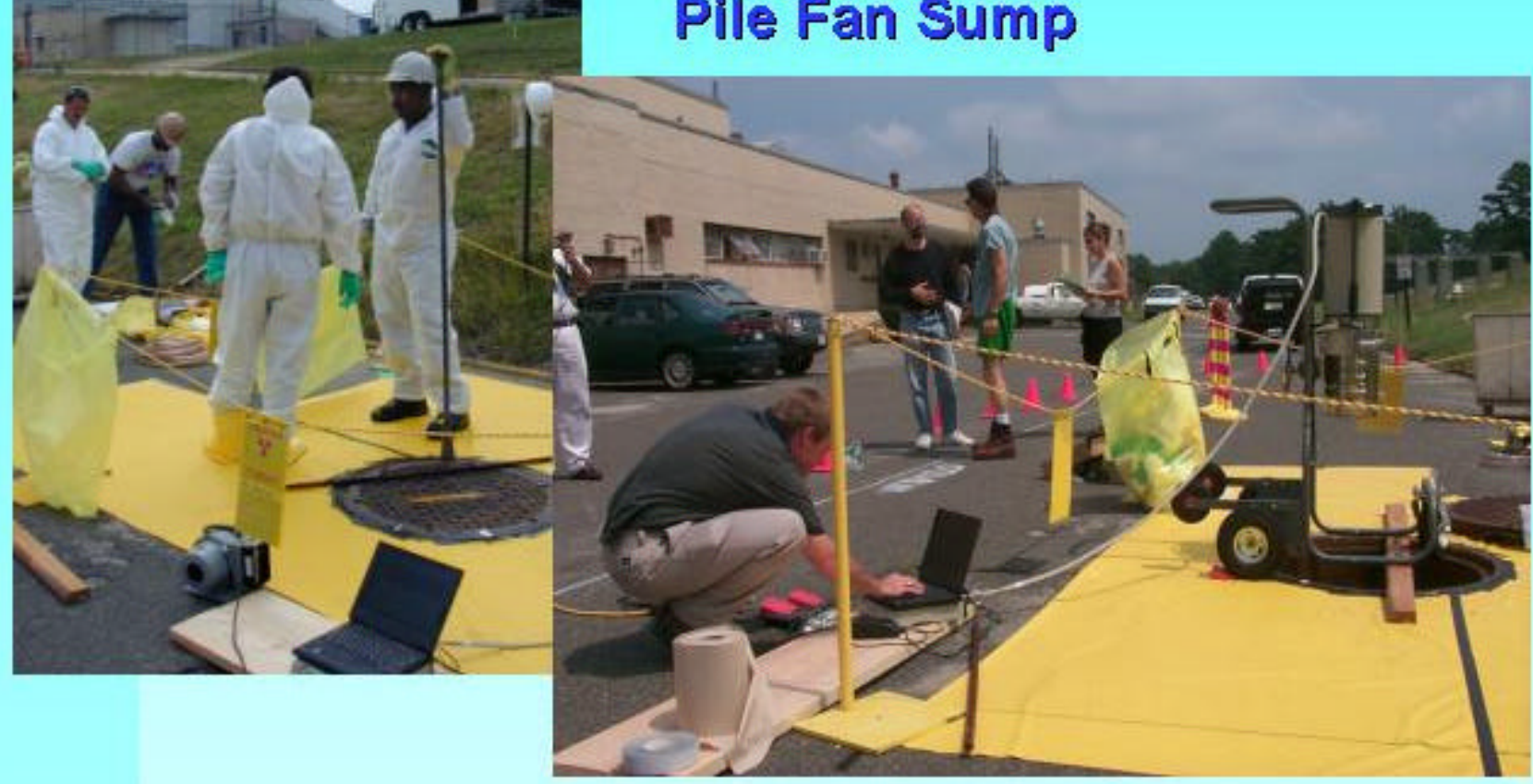




\section{ISOCS Technical Progress}

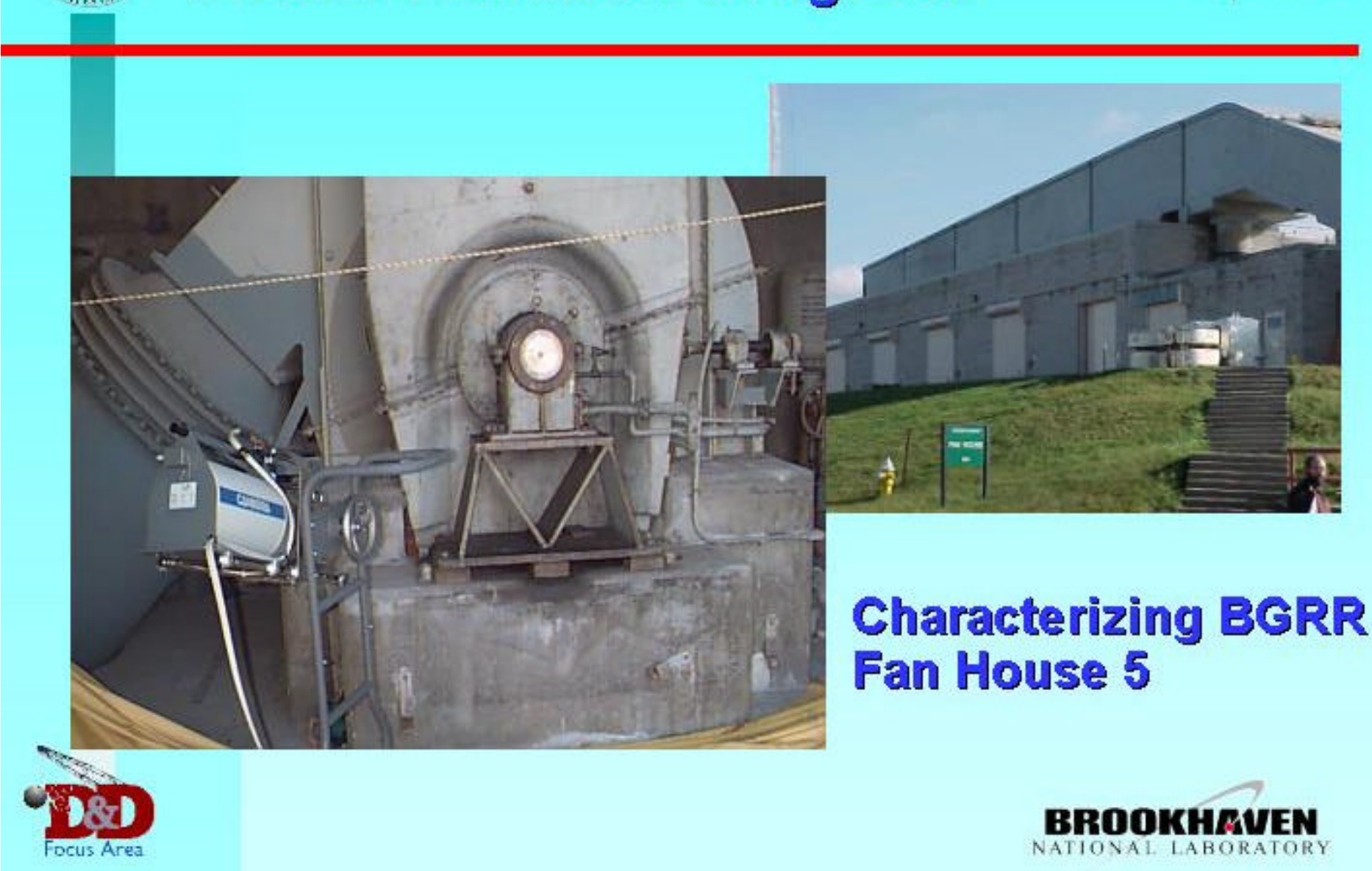




\section{ISOCS Technical Progress}

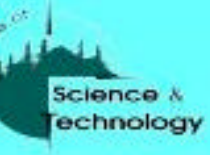

Characterization of Pile Fan Sump Soils $1 \ldots+2$

- 600 samples eval hatedin 4 weeks

- Samplesianalyzed immediately upon tollection

- Estimated savings of $>\$ 150 K$

- Estimated schedule acceleration of 2 months
- ISOCS deployed as a field lab to analyze PFS soils during excavation

- Provides field engineers real time, critical info on:

soil disposition

- how deep to dig

- Accelerates schedule

- Improves QA

- Saves money 


\section{Characterization of the Pile}
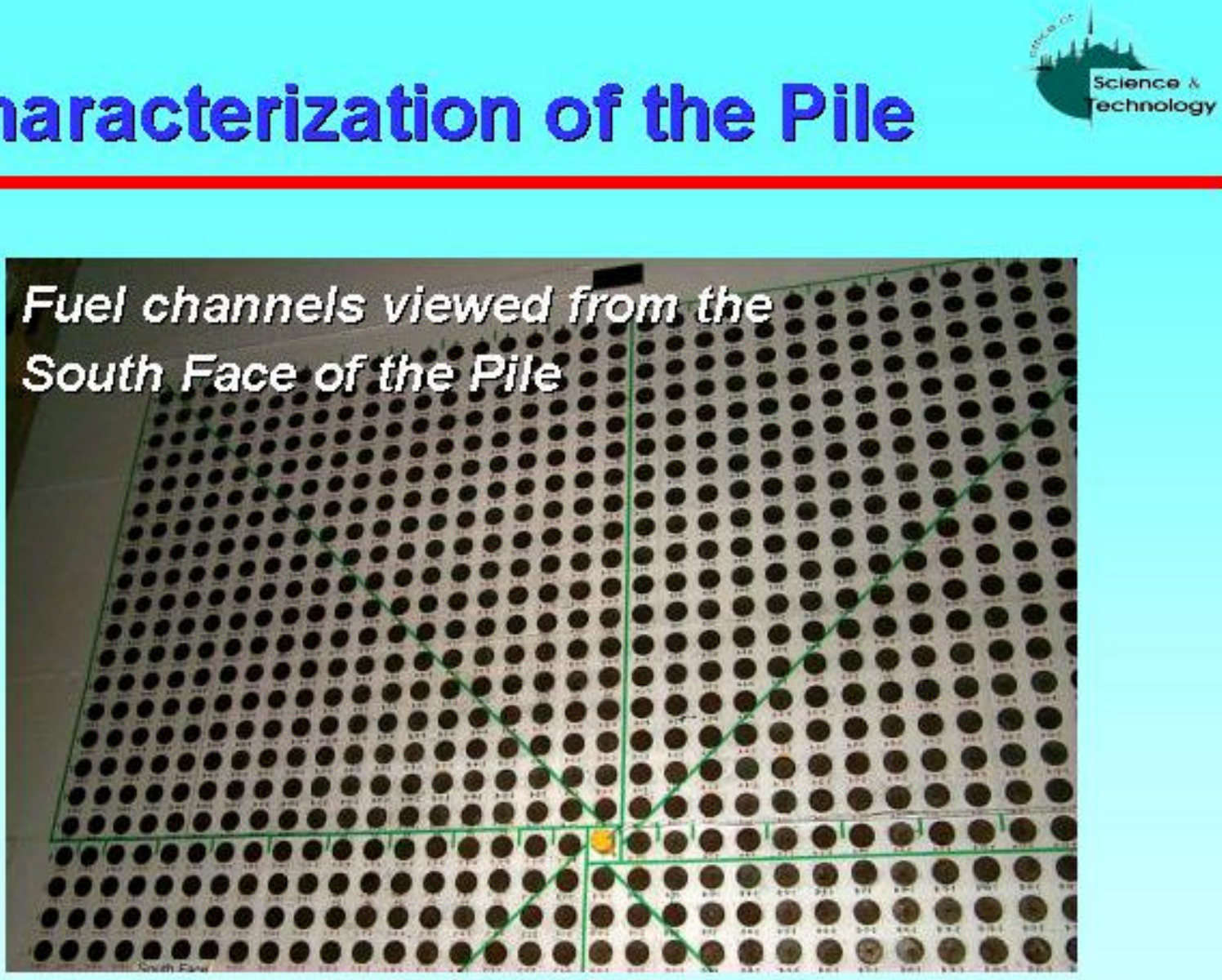


\section{Characterization of the Pile}
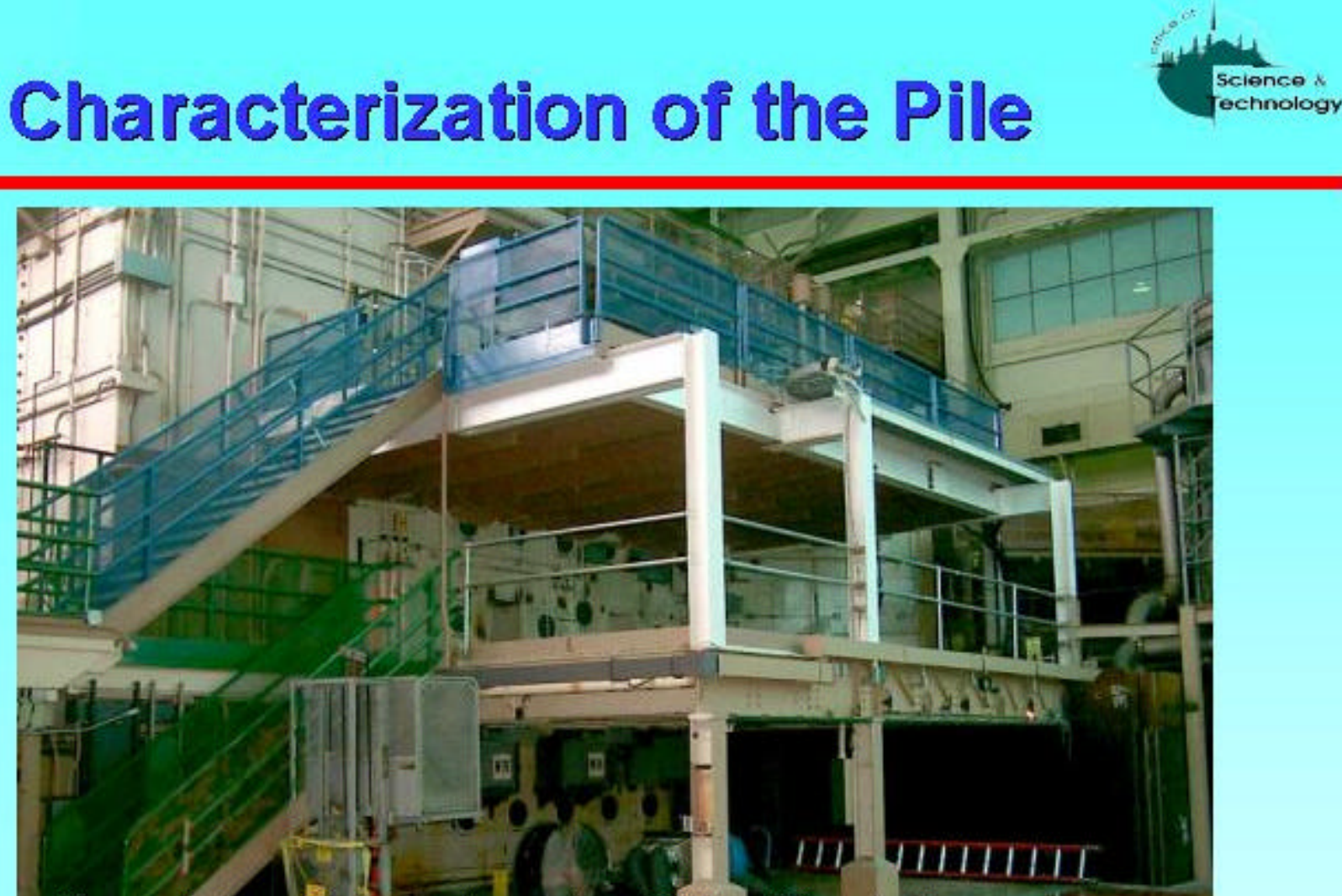

Far view of the Reactor Plle West Face 


\section{Characterization of the Pile}

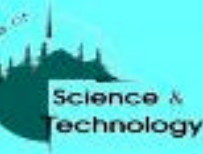

Close-up view of West Face Experimental Ports

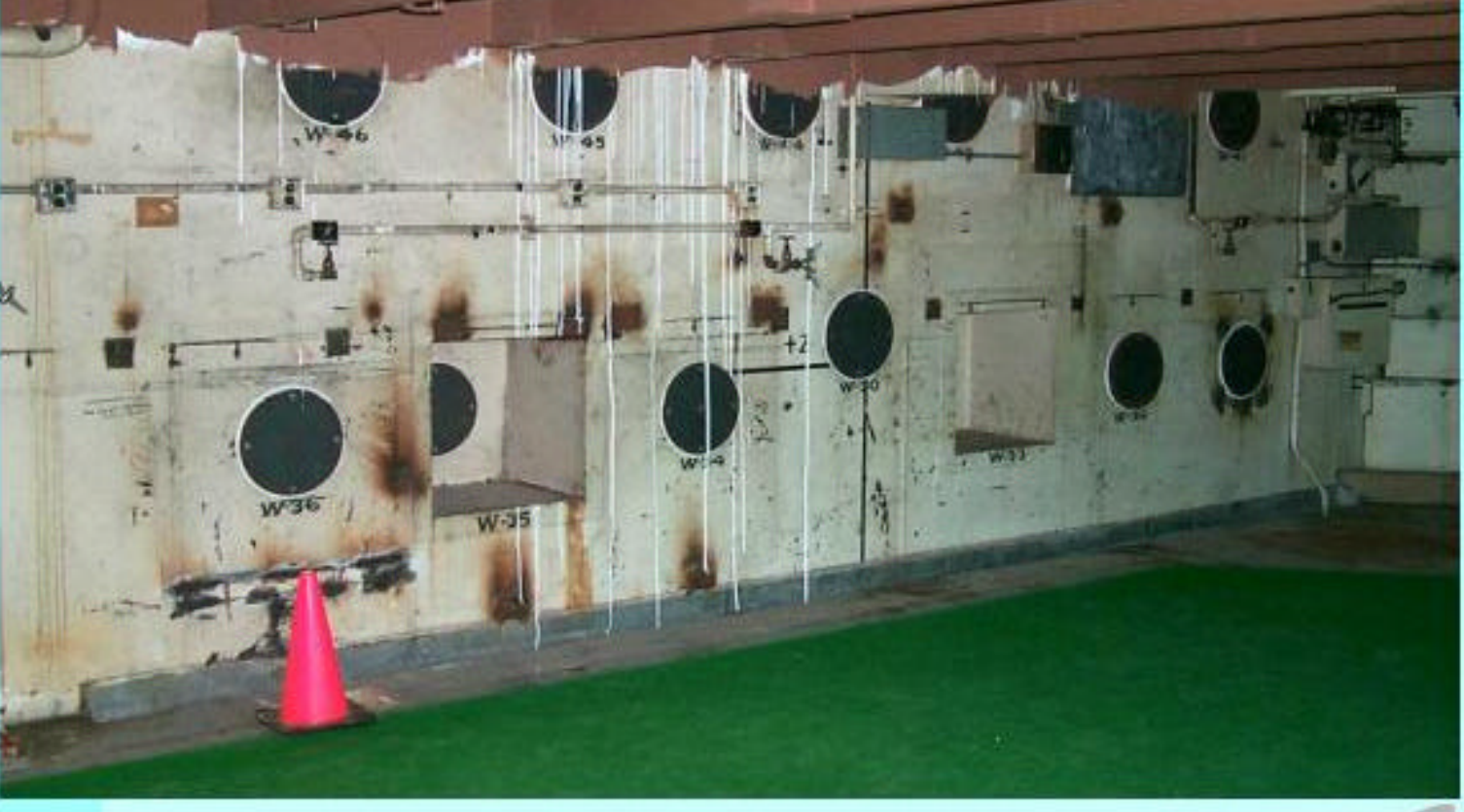




\section{In Situ ISOCS vs. EML Intercomparison Data}

\section{Cs-137 in Uncontaminated BNL Soil}

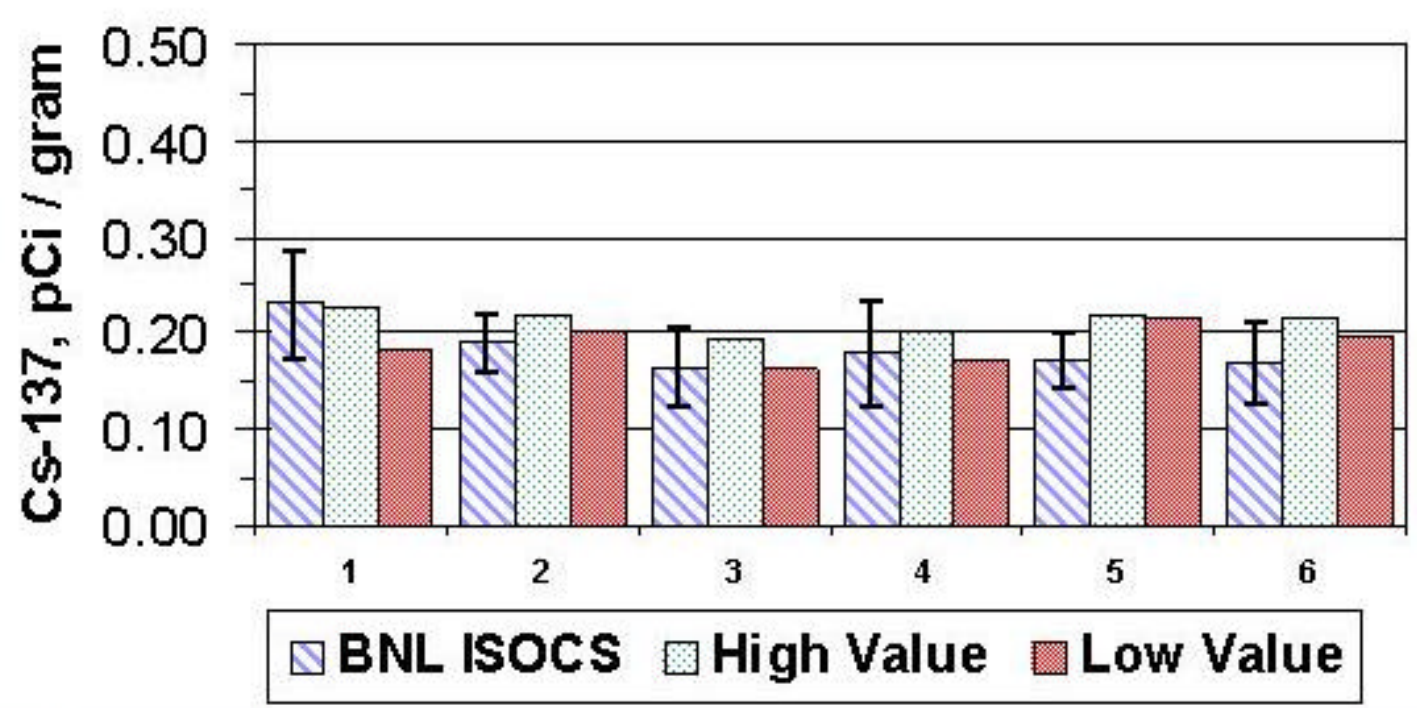




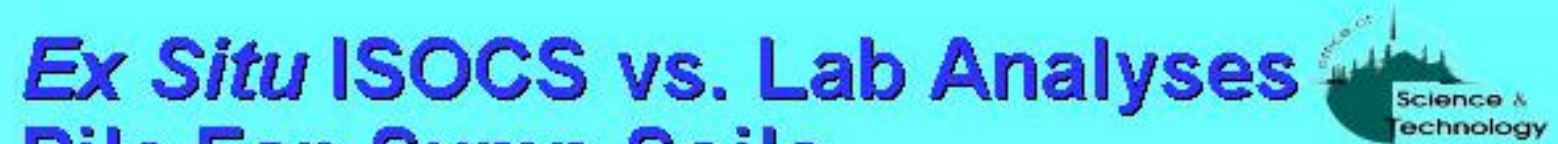 Pile Fan Sump Soils}

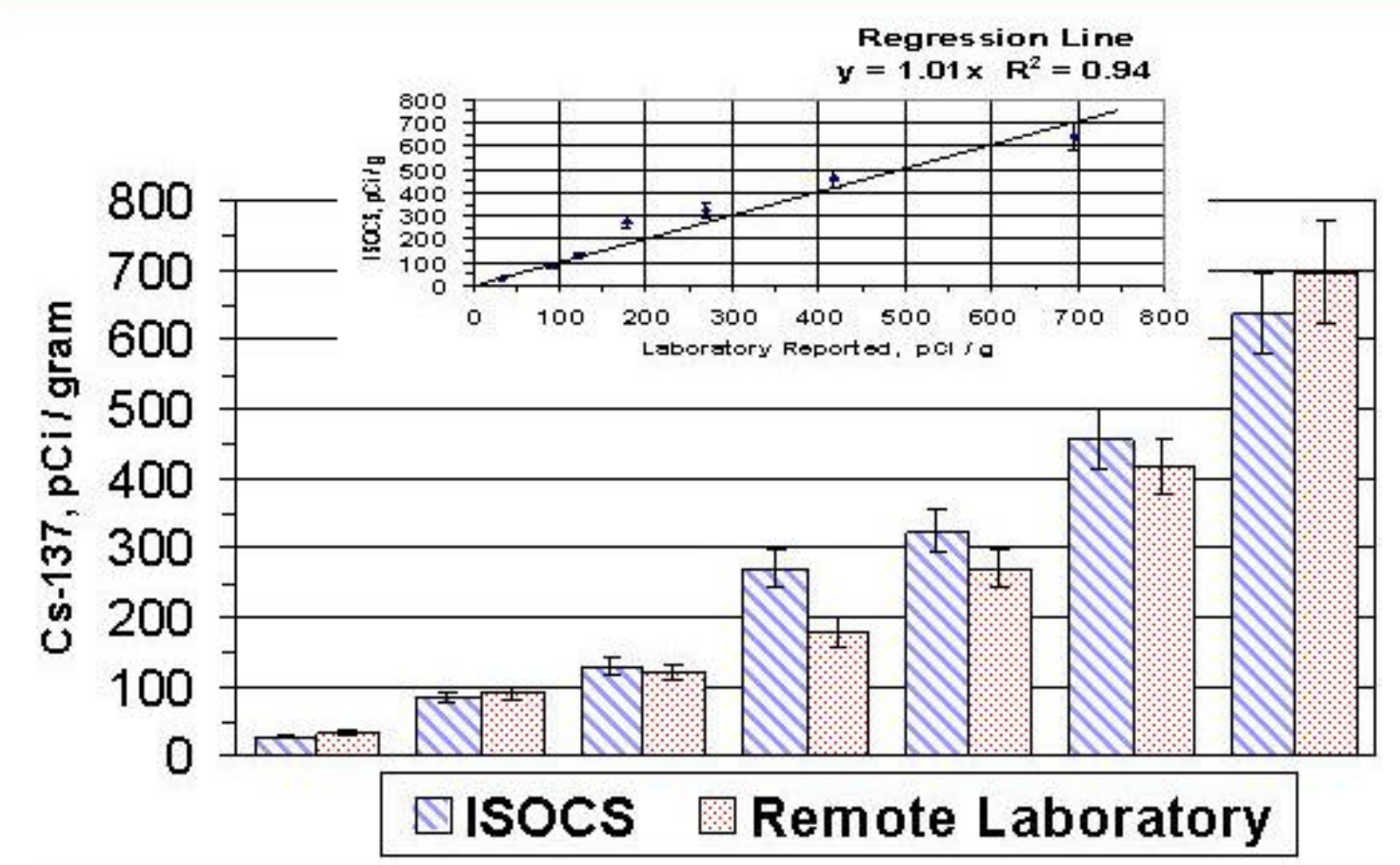




\section{i) In Situ ISOCS vs. Lab Analyses: Contaminated Landscape Soil}

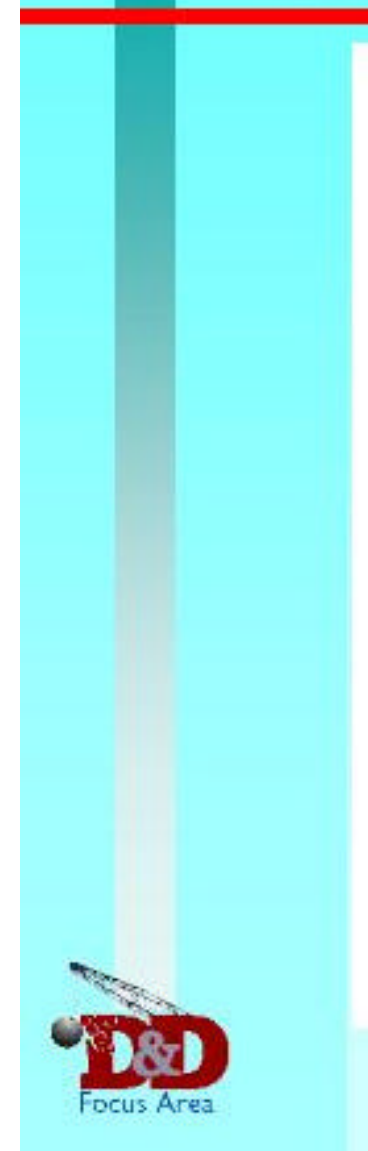

Lab Samples Taken at 0 - 6" depth

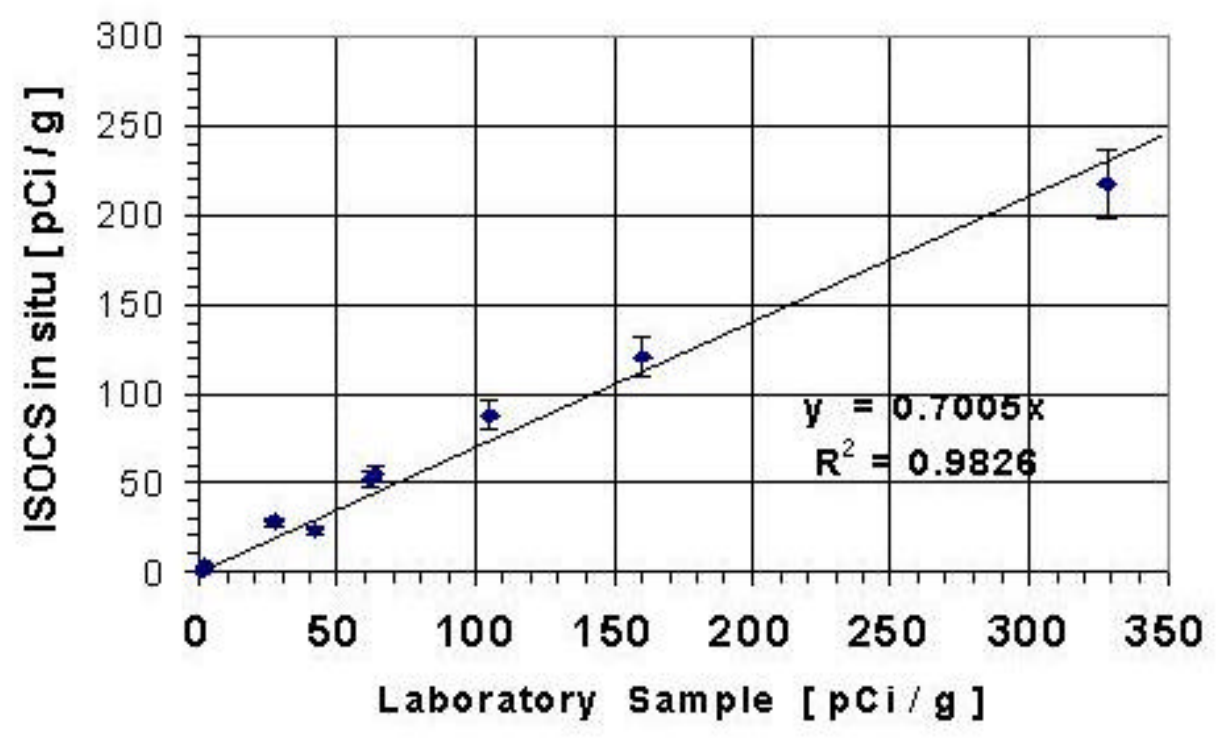




\section{BetaScint Fiber Optic Sensor}

- Field deployable, near real-time analysis for Sr-90 and U-238@ $\$ 35-\$ 60 /$ sample

- Conventional techniques require 1 - 4 wks@ $\$ 200$ $\$ 300 /$ sample

- $1 \mathrm{pCi} / \mathrm{g}$ detection limit

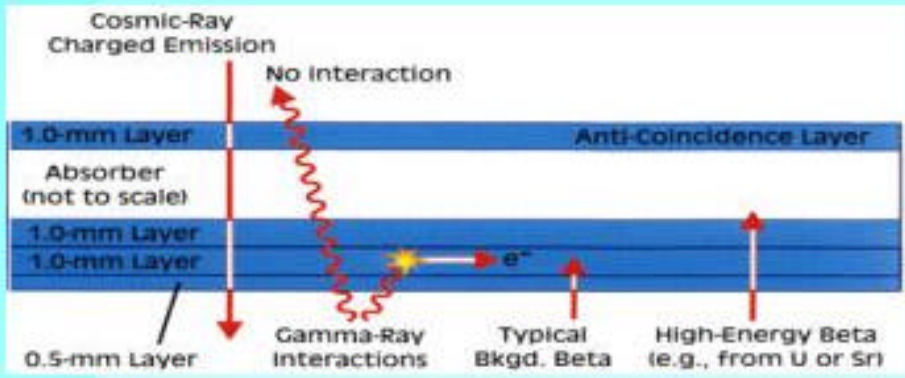

Schematic cross-section of Sr-90 sensor

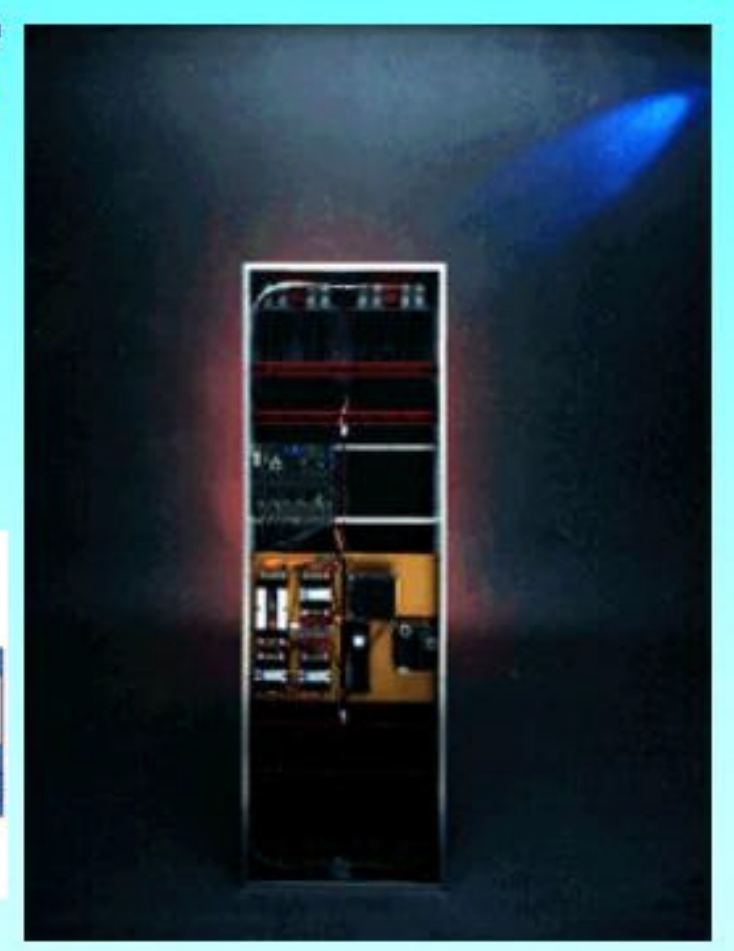

BROOKHAUEN 


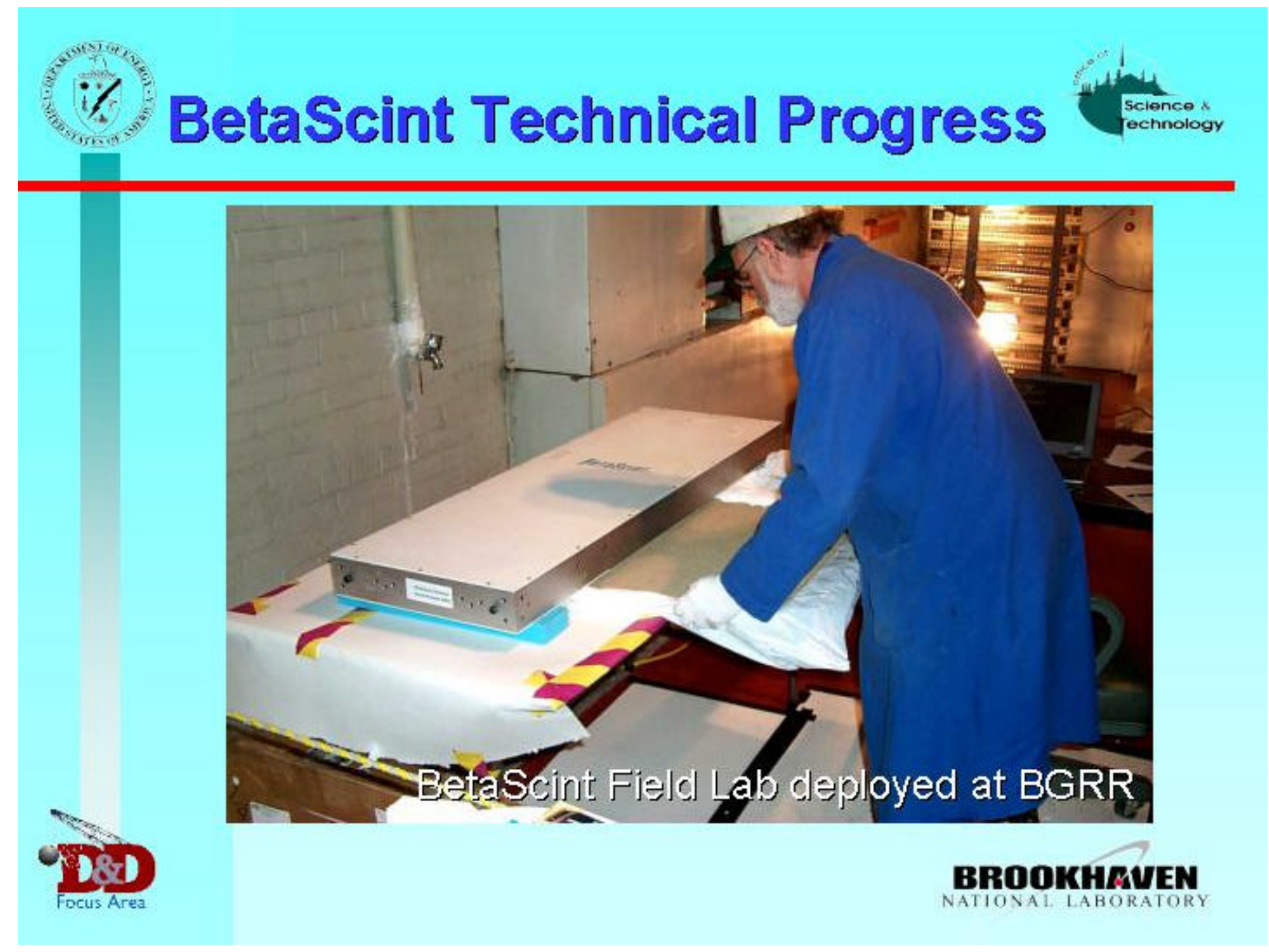




\section{Betascint vs. Baseline Analyses Fomear}

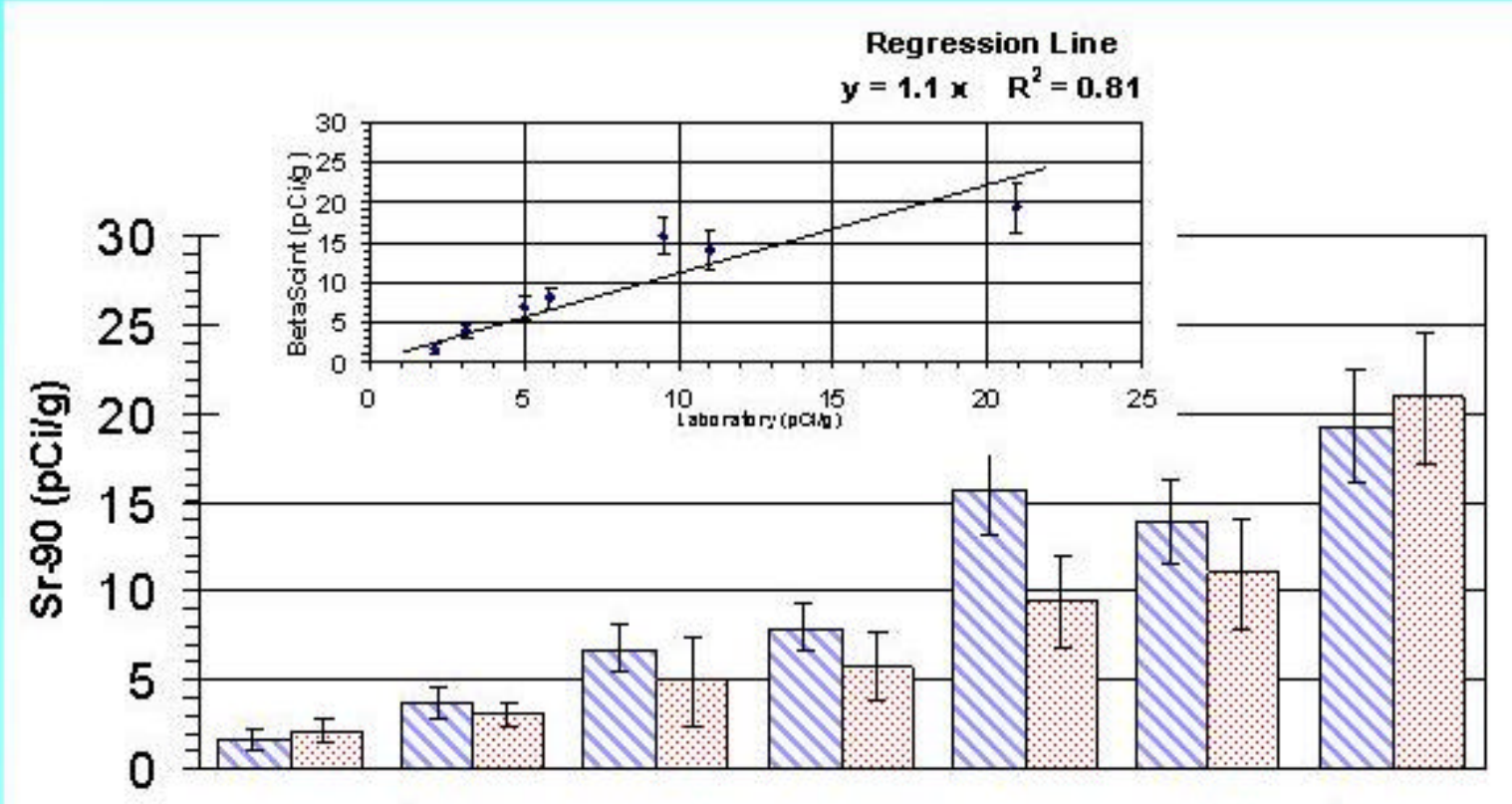

$\triangle$ BetaScint $\quad$ Laboratory 


\section{Future Plans}

- Complete in situ characterization of facilities (e.g., Instrument House, Filter, Canal House, Pile)

- Complete in situ characterization of soils and waste as generated

- Issue Final Report including technical and cost comparisons of in situ and conventional techniques

- BGRR Decommissioning Project to fund continued deployment in FY 01 and beyond

- Assist Hanford for secondary deployment at Canyon Disposition Initiative and other interested sites (e.g., Nevada Test Site D\&D) 


\section{Summary and Conclusions}

- MARSSIM approach can be effectively applied for D\&D characterization

- ISOCS is a versatile and accurate characterization tool for both in situ and field lab applications

- BetaScint provides faster, better, cheaper results for measurement of Sr-90 in soils

- Through implementation of MARSSIM and deployment of in situ techniques, this ASTD project is resulting in:

- lower characterization costs

- accelerated project schedule

- improved data quality

r reduced personnel exposure 
Section 3 


\title{
Accelerated Site Technology Deployment
}

\section{Cost and Performance Report}

\section{COMPARABILITY OF ISOCS \\ INSTRUMENT IN RADIONUCLIDE \\ CHARACTERIZATION AT \\ BROOKHAVEN NATIONAL \\ LABORATORY}

Paul Kalb

Brookhaven National Laboratory

\author{
Larry Luckett \\ URS Corporation
}

Kevin Miller, Carl Gogolak

DOE Environmental Measurements Laboratory

Larry Milian

Brookhaven National Laboratory

BRDOMHEYEN

Environmental Research \& Technology Division

Environmental Sciences Department

Brookhaven National Laboratory

Upton, New York 11973

Under Contract No. DE-AC02-98CH10886 with the UNITED STATES DEPARTMENT OF ENERGY 


\section{DISCLAIMER}

This report was prepared as an account of work sponsored by an agency of the United States Government. Neither the United States Government nor any agency thereof, nor any of their employees, nor any of their contractors, subcontractors, or their employees, makes any warranty, express or implied, or assumes any legal liability or responsibility for the accuracy, completeness, or usefulness of any information, apparatus, product, or process disclosed, or represents that its use would not infringe privately held rights. Reference herein to any specific commercial product, process or service by trade name, trademark, manufacturer, or otherwise does not necessarily constitute or imply its endorsement, recommendation, or favoring by the United States Government or any agency, contractor or subcontractor thereof. The views and opinions of authors expressed herein do not necessarily reflect those of the United States Government or any agency, contractor or subcontractor thereof. 


\section{COMPARABILITY OF ISOCS INSTRUMENT IN RADIONUCLIDE CHARACTERIZATION AT BROOKHAVEN NATIONAL LABORATORY ${ }^{*}$}

PAUL D. KALB

Brookhaven National Laboratory

LARRY W. LUCKETT

URS Corporation

KEVIN M. MILLER

Environmental Measurements

Laboratory

CARL V. GOGOLAK

Environmental Measurements

Laboratory

LAURENCE W. MILIAN

Brookhaven National Laboratory

\begin{abstract}
This report describes a DOE Accelerated Site Technology Deployment project being conducted at Brookhaven National Laboratory to deploy innovative, radiological, in situ analytical techniques. The technologies are being deployed in support of efforts to characterize the Brookhaven Graphite Research Reactor (BGRR) facility, which is currently undergoing decontamination and decommissioning.

This report focuses on the deployment of the Canberra Industries In Situ Object Counting System (ISOCS) and assesses its data comparability to baseline methods of sampling and laboratory analysis. The batteryoperated, field deployable gamma spectrometer provides traditional spectra of counts as a function of gamma energy. The spectra are then converted to radionuclide concentration by applying innovative efficiency calculations using monte carlo statistical methods and pre-defined geometry templates in the analysis software. Measurement of gamma emitting radionuclides has been accomplished during characterization of several BGRR components including the Pile Fan Sump, Above Ground Ducts, contaminated cooling fans, and graphite pile internals. Cs-137 is the predominant gamma-emitting radionuclide identified, with smaller quantities of Co-60 and Am-241 detected.
\end{abstract}

The Project used the Multi-Agency Radiation Survey and Site Investigation Manual guidance and the Data Quality Objectives process to provide direction for survey planning and data quality assessment. Analytical results have been used to calculate data quality indicators (DQI) for the ISOCS measurements. Among the DQIs assessed in the report are sensitivity, accuracy, precision, bias, and minimum detectable concentration. The assessment of the in situ data quality using the DQIs demonstrates that the ISOCS data quality can be comparable to definitive level laboratory analysis when the field instrument is supported by an appropriate Quality Assurance Project Plan. A discussion of the results obtained by ISOCS analysis of objects that could not be analyzed readily by conventional methods demonstrates a powerful application of the instrument. In conclusion, a comparison of costs associated with the analysis on the ISOCS instrument to the costs of conventional sampling and laboratory analysis is presented.

\footnotetext{
*This work was performed under the auspices of the U.S. Department of Energy.
} 


\section{TABLE OF CONTENTS}

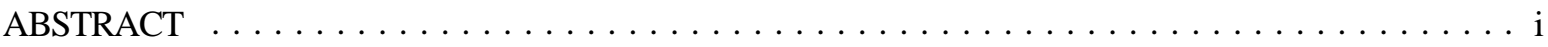

TABLE OF CONTENTS $\ldots \ldots \ldots \ldots \ldots \ldots \ldots \ldots \ldots \ldots \ldots \ldots \ldots \ldots \ldots \ldots \ldots \ldots$

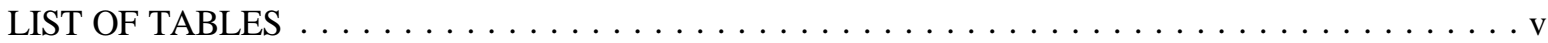

LIST OF FIGURES $\ldots \ldots \ldots \ldots \ldots \ldots \ldots \ldots \ldots \ldots \ldots \ldots \ldots \ldots \ldots \ldots \ldots \ldots \ldots$

ACRONYMS AND ABBREVIATIONS $\ldots \ldots \ldots \ldots \ldots \ldots \ldots \ldots \ldots \ldots \ldots \ldots$ ix

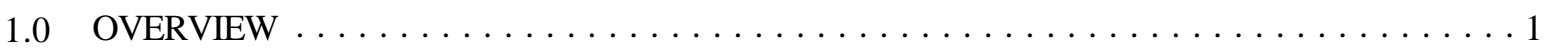

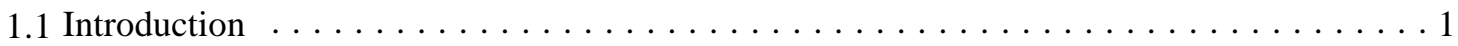

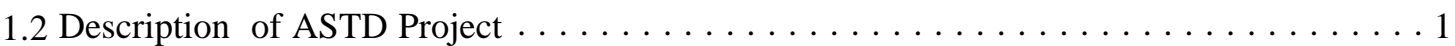

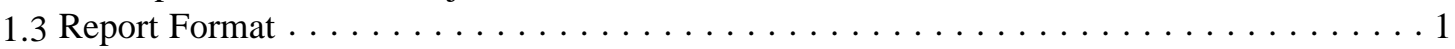

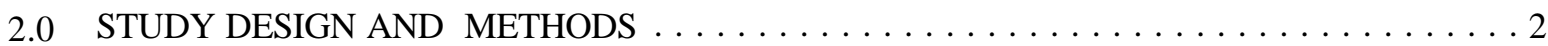

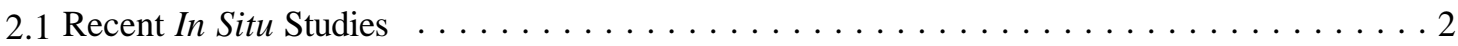

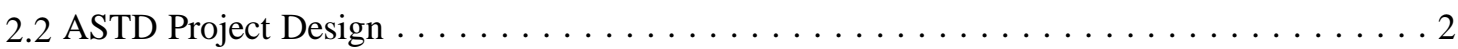

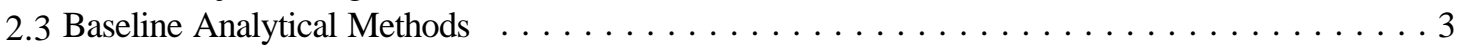

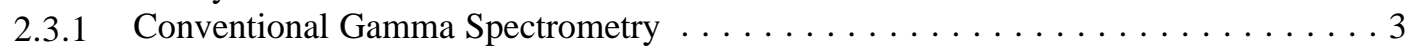

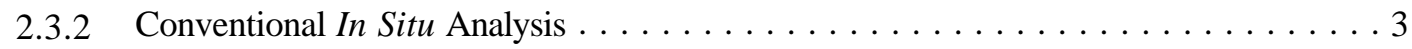

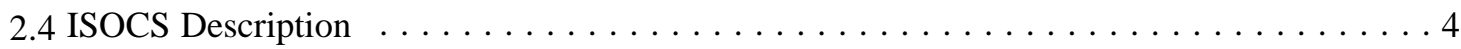

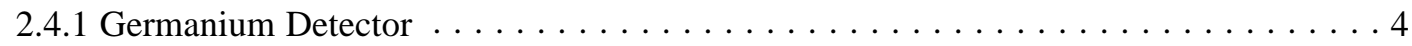

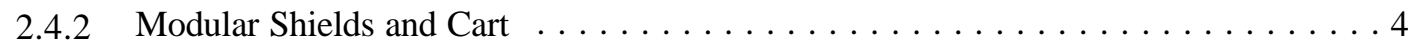

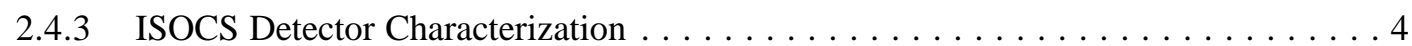

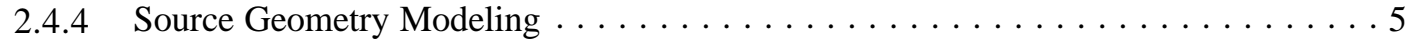

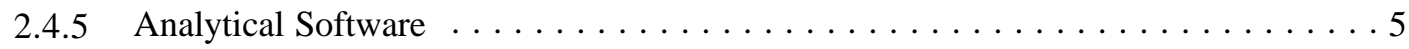

2.4 .6 Validation of the ISOCS Computation $\ldots \ldots \ldots \ldots \ldots \ldots \ldots \ldots \ldots \ldots \ldots \ldots \ldots \ldots \ldots \ldots$

3.0 BASIS FOR ASSESSING DATA QUALITY LEVEL $\ldots \ldots \ldots \ldots \ldots \ldots \ldots \ldots \ldots \ldots$

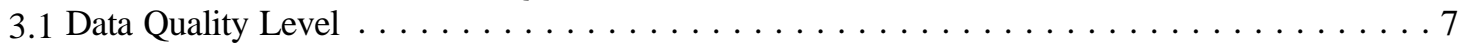

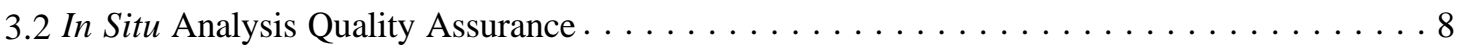

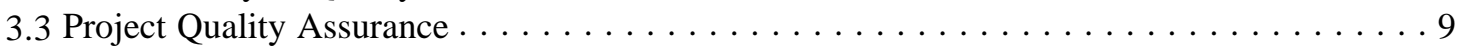

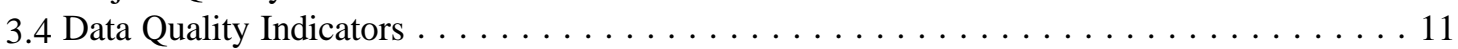

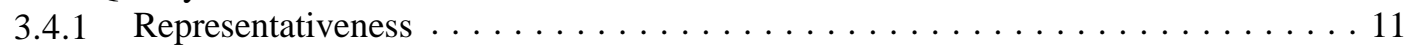

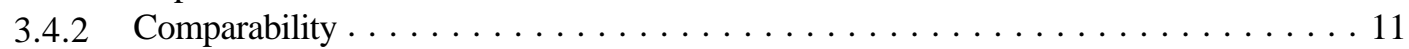

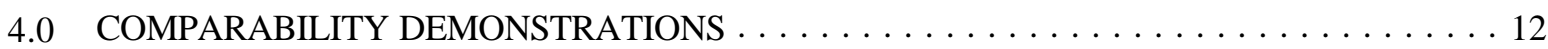

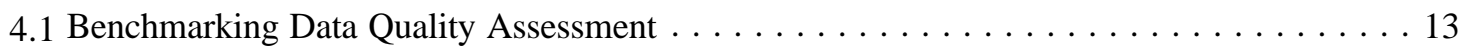

4.1.1 Assessment 1: Instrument Sensitivity to Source Width . . . . . . . . . . . 13

4.1.2 Assessment 2: Instrument Sensitivity to Source Thickness . . . . . . . . . . . 15

4.1.3 Assessment 3: Analytical Accuracy to a Point Source . . . . . . . . . . . . . . . . 17

4.1.4 Assessment 4: Analytical Accuracy to an Extended Source . . . . . . . . . . . 17

4.1.5 Assessment 5: Analytical Accuracy through Intercomparison . . . . . . . . . . 18

4.1.6 Assessment 6: Analytical Precision Over an Extended Period . . . . . . . . . . . . . . 19

4.1.7 Assessment 7: Analytical Precision in Duplicate Analyses . . . . . . . . . . 20 
4.1.8 Assessment 8: Analytical Minimum Detectable Concentration . . . . . . . . 21

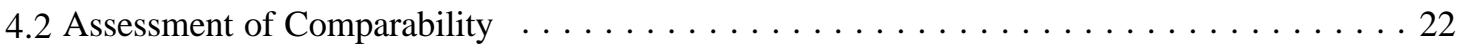

4.2.1 ISOCS Sample Analysis vs Laboratory Sample Analysis . . . . . . . . . . . . 22

4.2.2 ISOCS In Situ Analysis vs Laboratory Sample Analysis . . . . . . . . . . . . . . . 24

5.0 ANALYSIS OF DISTINCTIVE OBJECTS NOT EASILY EVALUATED . . . . . . . . . . 27

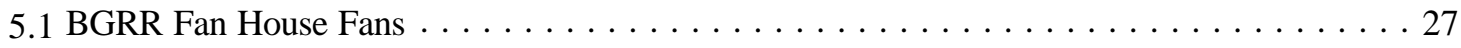

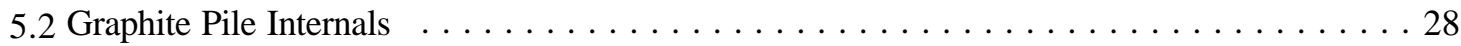

6.0 COST COMPARISON OF ISOCS AND BASELINE CHARACTERIZATION TECHNOLOGIES

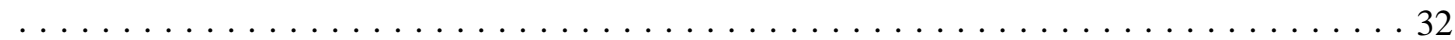

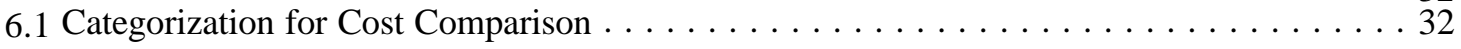

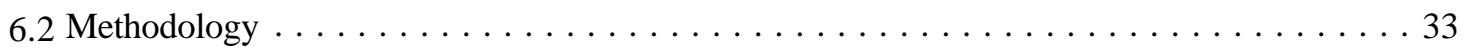

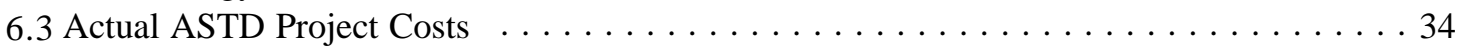

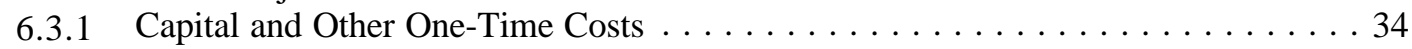

6.3.2 Project Costs Unrelated to ISOCS Deployment $\ldots \ldots \ldots \ldots \ldots \ldots \ldots \ldots \ldots$

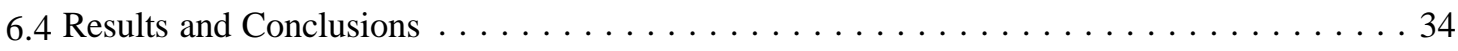

7.0 REGULATORY/INSTITUTIONAL ISSUES $\ldots \ldots \ldots \ldots \ldots \ldots \ldots \ldots \ldots \ldots \ldots \ldots$

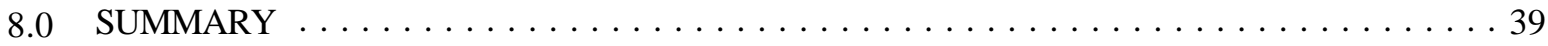

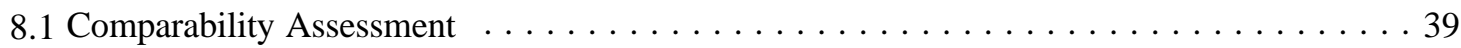

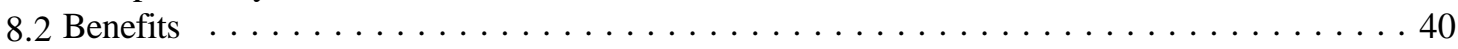

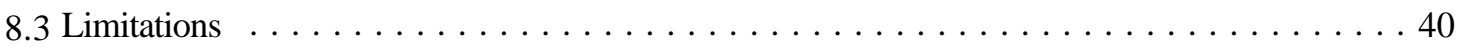

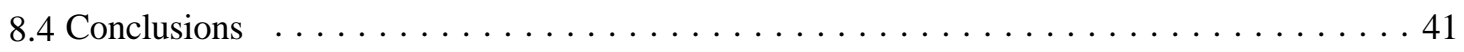

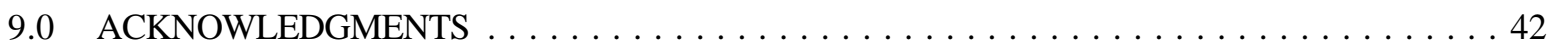

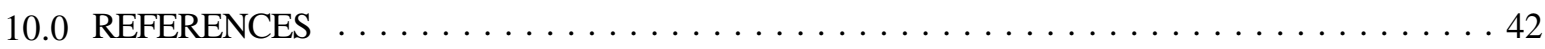

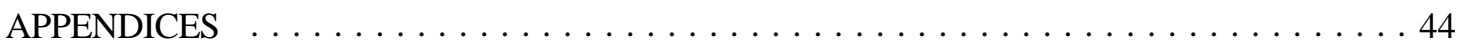

A. Summary List of Project Measurements and Scans

B. Project Participants

C. Cost Analysis Data Tables

D. Glossary 


\section{LIST OF TABLES}

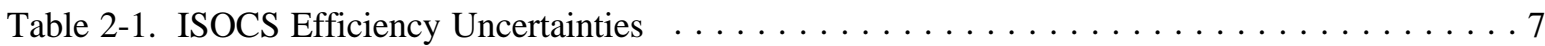

Table 3-2. EPA Requirements to Project QAPP Crosswalk $\ldots \ldots \ldots \ldots \ldots \ldots \ldots \ldots \ldots$

Table 3-3. Criteria for Categorizing Data Quality Level $\ldots \ldots \ldots \ldots \ldots \ldots \ldots \ldots \ldots \ldots$

Table 4-1. Assessment of Point Source Accuracy $\ldots \ldots \ldots \ldots \ldots \ldots \ldots \ldots \ldots \ldots \ldots$

Table 4-3. In Situ Quality Control Indicators and Limits . . . . . . . . . . . . . . . . . . . 19

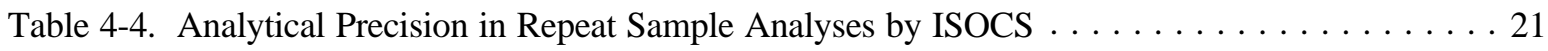

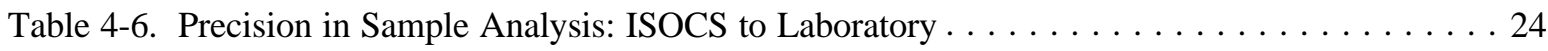

Table 5-1. Results of In Situ Measurements at BGRR Fan House $\ldots \ldots \ldots \ldots \ldots \ldots \ldots$

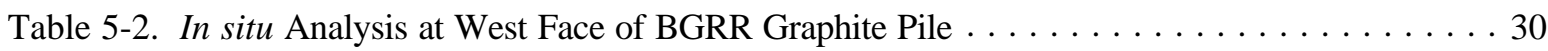

Table 6-1. General Categories for BGRR ISOCS Characterization $\ldots \ldots \ldots \ldots \ldots \ldots \ldots \ldots \ldots$

Table 6-2. Identification of Cost Comparison Scenario Data Tables $\ldots \ldots \ldots \ldots \ldots \ldots \ldots$

Table 6-3. Actual Costs to Implement ISOCS for Characterization of BGRR $\ldots \ldots \ldots \ldots \ldots$

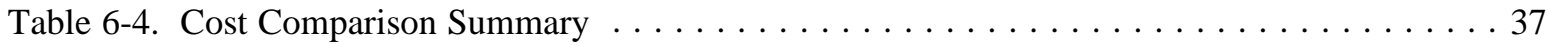




\section{LIST OF FIGURES}

Figure 2-1. Comparison of BEGe detector response

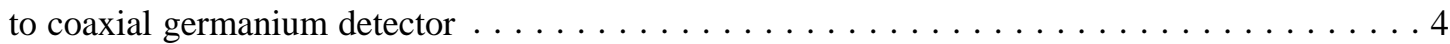

Figure 2-2. ISOCS cart with detector, cryostat and modular shield system $\ldots \ldots \ldots \ldots \ldots$

Figure $2-3$. ISOCS efficiency response curve interface $\ldots \ldots \ldots \ldots \ldots \ldots \ldots \ldots \ldots \ldots \ldots \ldots \ldots$

Figure 4-1. ISOCS detector response to surface soil contamination layer diameter

at 1 meter with $180 \mathrm{E}$ FOV collimator and $44 \mathrm{~mm}$ annular shields $\ldots \ldots \ldots \ldots \ldots \ldots$

Figure 4-2. ISOCS detector response to surface soil contamination layer diameter

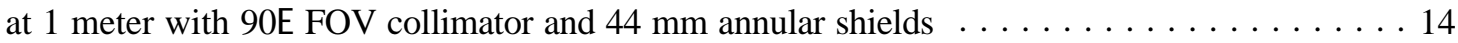

Figure 4-3. ISOCS detector response to surface soil contamination layer thickness

at 1 meter with $180 \mathrm{E}$ FOV collimator and $44 \mathrm{~mm}$ annular shields $\ldots \ldots \ldots \ldots \ldots \ldots$

Figure 4-4. ISOCS detector response to surface soil contamination layer thickness

at 1 meter with 90E FOV collimator and $44 \mathrm{~mm}$ annular shields $\ldots \ldots \ldots \ldots \ldots \ldots \ldots$

Figure 4-5. Comparison of ISOCS in situ analysis to inter-comparison study . . . . . . . . . . 19

Figure 4-6. ISOCS analytical precision over extended time period $\ldots \ldots \ldots \ldots \ldots \ldots \ldots$

Figure 4-7. ISOCS instrument configured for sample

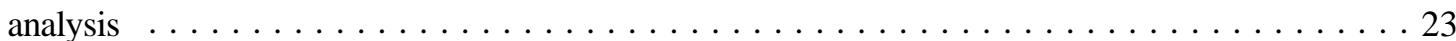

Figure 4-8. Correlation between ISOCS sample and

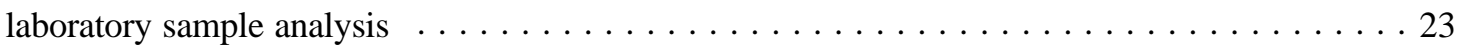

Figure 4-9. Analysis positions for in situ vs laboratory comparability $\ldots \ldots \ldots \ldots \ldots \ldots \ldots 25$

Figure 4-10. Locations of samples for composite at each analysis position $\ldots \ldots \ldots \ldots \ldots$

Figure 4-11. Correlation between ISOCS in situ and laboratory sample analysis $\ldots \ldots \ldots \ldots$

Figure 5-2. West face of the BGRR showing access to experimental port locations $\ldots \ldots \ldots 29$

Figure 5-3. In situ measurement of pile internals at Experimental Port No W-54 . . . . . . . . . . 29

Figure 6-1. Comparison of ISOCS and baseline characterization costs by category . . . . . . 38

Figure 6-2. Comparison of total ISOCS and baseline characterization costs $\ldots \ldots \ldots \ldots$ 


\section{ACRONYMS AND ABBREVIATIONS}

\begin{tabular}{|c|c|c|c|}
\hline AIF & Atomic Industrial Forum & $\mathrm{keV}$ & kilo electronVolts (energy) \\
\hline ALARA & As Low As Reasonably Achievable & MARSSIM & $\begin{array}{l}\text { Multi-Agency Radiation Survey and } \\
\text { Site Investigation Manual }\end{array}$ \\
\hline ANSI & American National Standards Institute & & \\
\hline ASTD & Accelerated Site Technology Deployment & MCA & Multi-channel Analyzer \\
\hline BEGe & Broad energy germanium [detector] & MDA & minimum detectable activity \\
\hline BGRR & Brookhaven Graphite Research Reactor & MDC & minimum detectable concentration \\
\hline BNL & Brookhaven National Laboratory & MCNP & Monte Carlo Nuclear particle \\
\hline CERCLA & $\begin{array}{l}\text { Comprehensive Environmental Response, } \\
\text { Compensation and Liability Act }\end{array}$ & NIST & $\begin{array}{l}\text { US National Institute of Standards } \\
\text { and Technology }\end{array}$ \\
\hline D\&D & Decontamination and Decommissioning & NRC & US Nuclear Regulatory Commission \\
\hline DOE & US Department of Energy & PARCC & $\begin{array}{l}\text { QA parameters of precision, accuracy } \\
\text { representativeness, completeness and } \\
\text { comparability }\end{array}$ \\
\hline DQA & Data Quality Assessment & & \\
\hline DQI & Data Quality Indicator & PBMS & $\begin{array}{l}\text { performance-based measurement } \\
\text { system }\end{array}$ \\
\hline DQO & Data Quality Objective & PLF & Productivity Loss Factor \\
\hline EML & $\begin{array}{l}\text { US DOE Environmental Measurements } \\
\text { Laboratory }\end{array}$ & PSSP & Project Specific Survey Plan \\
\hline EPA & US Environmental Protection Agency & QA & Quality Assurance \\
\hline & & QC & Quality Control \\
\hline ex situ & $\begin{array}{l}\text { out of position, a sample removed and } \\
\text { relocated for analysis }\end{array}$ & QAPP & Quality Assurance Project Plan \\
\hline FOV & Field of View & RPD & Relative percent difference \\
\hline HPGe & hyper-pure gemanium [detector] & RCRA & $\begin{array}{l}\text { Resource Conservation and Recovery } \\
\text { Act }\end{array}$ \\
\hline in situ & $\begin{array}{l}\text { in position, usually without disturbing } \\
\text { or sampling the media }\end{array}$ & SOP & Standard operating procedure \\
\hline ISOCS & In Situ Object Counting System & WAC & Waste Acceptance Criteria \\
\hline
\end{tabular}


March 2001 


\section{COMPARABILITY OF ISOCS INSTRUMENT IN RADIONUCLIDE CHARACTERIZATION AT BROOKHAVEN NATIONAL LABORATORY}

\subsection{OVERVIEW}

\subsection{Introduction}

This report describes a project sponsored by the DOE Office of Science and Technology (EM-50) under the Accelerated Site Technology Deployment (ASTD) initiative to deploy state-of-the-art techniques and equipment for improved characterization of nuclear facilities during characterization, decommissioning, and surveys for final status certification. Measurement of gamma emitting radionuclides is being accomplished using a field deployable gamma spectrometer (In Situ Object Counting System or ISOCS) manufactured by Canberra Industries, Inc. This report assesses the operational capabilities of the ISOCS instrument and the comparability of the field instrument results to results generated through the laboratory analysis of physical samples.

\subsection{Description of ASTD Project}

This Accelerated Site Technology Deployment (ASTD) project addresses some of the important issues of radioactive material characterization through deployment of an innovative in situ characterization technology. This project focuses on the characterization of the Brookhaven Graphite Research Reactor (BGRR), which is currently undergoing stabilization and near-term D\&D. While the Environmental Management program of the U.S. Department of Energy (DOE) includes the D\&D of many different types of nuclear facilities, the basic issues of characterization are universal and not dependent on site-specific dissimilarities.

The Brookhaven Graphite Research Reactor (BGRR) is a graphite-moderated, air-cooled, thermal neutron research reactor that operated at Brookhaven National Laboratory (BNL) from 1950 through 1968. Followingshutdown, fuel was removed and the facility has been maintained in a safe shutdown mode since then. Many of the major BGRR sub-components are currently scheduled for nearterm decontamination and decommissioning (D\&D) including the Pile Fan Sump, above and below ground air ducts, and auxiliary buildings that house fans, filters, instruments, fuel transfer canal and water treatment systems. Characterization of these facilities prior to, during, and after dismantlement is required to minimize worker exposure, plan for appropriate disposition of materials and remaining facilities, and demonstrate compliance with applicable environmental regulations. Due to the 30 years interval since shutdown, short-lived radionuclides have undergone considerable decay. Cs137 is the predominant gamma-emitting radionuclide identified, with smaller quantities of Co-60, Eu-152, Eu154, and Am-241 detected.

The project execution involved collaboration between BNL, the U.S. DOE Environmental Measurements Laboratory (EML), URS Corporation of Ronkonkoma, NY, Canberra Industries of Meriden, CT, and Cabrera Services. Inc of East Hartford, CT. Also participating in the plan was Bechtel Hanford Inc., which plans to deploy this approach for characterization of nuclear facilities at Hanford. Successful demonstration of comparability of the in situ technology provides an additional capability in nuclear characterization for DOE D\&D undertakings. This deployment project also provides valuable experience and "lessons learned" that can be shared with facilities throughout the USDOE complex.

\subsection{Report Format}

This report describes the Canberra ISOCS instrument and the mathematical characterization (calibration) of the detector. Then a description of instrument response to field of view, depth of source, point source response and extended source response are described. This paper then discusses data quality indicators the basis for analytical comparability and demonstrates the comparability of the ISOCS instrument analysis to laboratory sample analysis. A discussion of the results obtained by ISOCS analysis of objects that could not be analyzed readily by conventional methods demonstrates a powerful application of the instrument. A comparison of costs associated with the analysis on the ISOCS instrument to the costs of conventional sampling and laboratory analysis is presented. Appendices to this report provide details of studies performed, project organization, cost assumptions, and a glossary of terms. 


\subsection{STUDY DESIGN AND METHODS}

In situ gamma spectroscopy has been shown to be costeffective in almost all applications where field sampling and laboratory analyses are the baseline technologies. Results can be obtained immediately following field acquisitions, thereby reducing the time delays incurred by physical sampling and laboratory analysis. In situ measurements can be performed on sealed systems (i.e., without breaching a containment barrier) or remotely (i.e., at a distance from an external radiation source), reducing personnel exposures and/or work hazards. When analysis by an independent laboratory is required by the project regulator prior to free release of materials, in situ measurements serve as a screening technique, eliminating the unnecessary analysis of samples above the derived concentration guideline level (DCGL). Large areas or volumes can be assayed with a large field of view to reduce errors arising from non-homogeneity, providing a more accurate estimate of average radionuclide concentrations. These advantages make in situ spectroscopy an attractive tool for many characterization applications.

\subsection{Recent In Situ Studies}

a. The DOE Fernald Area Office performed a study of comparability of traditional in situ gamma spectroscopy to the results of laboratory analysis of samples [ref 14]. The study was performed to demonstrate the comparable decision on disposition of remediated land parcels derived from either field or laboratory analysis. Due to heterogeneously contaminated surface soils and difficult to detect contaminants that also appeared in the background, the study was required to obtain as many as 15 samples from the field of view of the in situ spectrometer for correlation to the single in situ measurement. The study concluded that HPGe measurements of total uranium and thorium could meet certain of the QC acceptance criteria established by the project QAPP. Measurements of Ra226 could only meet the QC criteria if corrected for disequilibrium caused by radon emanation.

b. The DOE Office of Science and Technology sponsored a demonstration of the ISOCS technology at the Argonne CP-5 Research Reactor [ref 15]. This demonstration, limited to performance over three days, determined that:

- The ISOCS can provide rapid, real time information on the type of radionuclides and the magnitude of the radiological hazard.

- As the ISOCS assay system is relatively new, it will be necessary to demonstrate the accuracy of the ISOCS system in relation to the standard baseline analysis.

It is this comparison of the ISOCS to baseline analysis technology that is addressed in this report.

\subsection{ASTD Project Design}

The ASTD project plan is built around the guidance contained in the Multi-Agency Radiation Survey and Site Investigation Manual (MARSSIM), published in December 1997 under the auspices of the U.S. Environmental Protection Agency (EPA) but compiled in collaboration with the USDOE, the U.S. Department of Defense, and the U.S. Nuclear Regulatory Agency [ref 13]. The MARSSIM was developed to provide a nationally-consistent consensus approach to conducting radiation surveys and investigations at potentially contaminated sites. The approach adopted in the MARSSIM is scientifically rigorous and yet flexible enough to be applied to a variety of site cleanup conditions. The MARSSIM provides information on planning, conducting, evaluating, and documenting environmental radiological surveys of surface soil and building surfaces for demonstrating compliance with regulations. Its focus is on the final status survey that is used in judging if a remediated site meets the applicable release criteria.

To date, the MARSSIM has been used primarily in determining the post-remediation status of a site or facility, not the condition prior to the initiation of remediation or decommissioning activities. However, the technical guidance contained within MARSSIM regarding the conduct of radiation surveys and site investigations has generic application, and has the potential for use in any situation involving radioactive contamination, whether or not a release criterion is to be applied. Using the MARSSIM to guide the characterization process in this project helped to optimize the survey design and to reduce or eliminate unnecessary samples, saving both time and money.

The Data Quality Objective (DQO) process is the basis for the performance-based guidance in planning MARSSIM surveys. Because the MARSSIM emphasizes the use of statistical planning and data analysis for demonstrating compliance with a final status survey, there are few examples of how to apply the DQO process for other types of surveys where such formal analyses are not necessary, or even appropriate. For example, data are collected during characterization surveys in order to determine the extent, but not necessarily the amount, of contamination. This does 
not mean that the data do not meet the objectives of compliance demonstration, but it may mean that formal statistical tests would be of little or no value because the data have not been collected for that purpose. However, all analytical data should be of a quality, demonstrable through the DQO process, to support the determination or decision needed.

\subsection{Baseline Analytical Methods}

Conventional or baseline characterization in nuclear facility D\&D requires the collection of thousands of surface smear, volumetric, and core samples, sending samples for on and off-site analysis, compiling the information in a database, and reviewing the data for quality assurance. Many of the areas requiring characterization are not readily accessible and/or are highly contaminated, further complicating the process. Thus, in addition to being time consuming and costly, the baseline characterization approach can result in excessive radiation exposures to personnel.

2.3.1 Conventional Gamma Spectrometry. The conventional laboratory gamma spectrometry system consists of a germanium detector connected to a dewar or cryostat of liquid nitrogen, a high voltage power supply, a spectroscopy grade amplifier, an analog to digital converter, and a multi-channel analyzer (MCA). When a gamma ray interacts with a germanium crystal, it produces electron-hole charge pairs which are collected rapidly. The total charge collected is proportional to the deposited energy.

The spectrometer system is energy calibrated using isotopes that emit at least two known gamma ray energies, so the MCA data channels are correlated to an energy equivalence. A curve of gamma ray energy versus counting efficiency is generated using known concentrations of mixed isotopes. The center of each gaussian-shaped peak corresponds to the gamma ray energy that produced it, the combination of peaks identifies each radionuclide, and the area under selected peaks is a measure of the amount of that radionuclide in the sample. Since the counting efficiency depends on the distance from the sample to the detector, each geometry must be given a separate efficiency calibration curve.

Samples are placed in containers and tare weighed. Standard practice is to dry solids and homogenize using a ball mill process prior to analysis. Plastic petri dishes sit atop the detector and are useful for small volumes or low energies, while Marinelli beakers fit around the detector and provide exceptional counting efficiency for volume samples. For environmental levels of contaminants, the sample and germanium detector are usually placed within a lead-shielded counting cavity, to lower interference from radionuclides in the surroundings. Counting times of 1000 seconds to 1000 minutes are typical. Each peak is identified manually or by gamma spectrometry analysis software. The counts in each peak or energy band, the sample weight, the efficiency calibration curve, and the isotope's decay scheme are factored together to calculate the concentration of radionuclide in the sample. The system accurately identifies and quantifies the concentrations of multiple gamma-emitting radionuclides in samples like soil, water, and air filters when a reference standard of known activity is available in a similar matrix and geometry [ref 13]. The availability of the reference standard requires preparation of a radioactive source that eventually must be disposed, thus increasing cost and generating secondary waste.

2.3.2 Conventional In Situ Analysis. The advantages of in situ measurements over traditional sampling methods have been known and appreciated for some time. These advantages include:

- $\quad$ reducing the potentially large errors associated with random sampling of non-homogeneous source distributions;

- reducing costs and improving safety by minimizing the sampling process; and

- $\quad$ essentially eliminating the delay time between sample collection and availability of nuclide-specific analysis results.

There have been many advances in gamma detection hardware and analysis software during the past 10 years, which now make it much more practical to perform in situ gamma spectroscopy. These advances include: large high-purity germanium detectors which provide the required resolution and sensitivity, rugged multi-attitude cryostats allowing the detector to be aimed in any direction and ensuring adequate liquid nitrogen holding times, laboratory-quality battery-powered portable MCAs, portable laptop-size computers with tremendous processing power and data storage capacity, and sophisticated and easy-to-use spectral analysis software.

In order to use the acquired pulse height spectrum for quantitative assessment of radioactivity, an efficiency calibration must be performed. This is normally done with the use of known quantities of radioactive materials in fixed distributions. Previous techniques used, involving uniform mixtures of radionuclides or large numbers of small sources in inert matrices, are very expensive. The user must purchase radioactive sources of the proper range of activity and energy, distribute the 
source appropriately, and finally dispose of the source as radioactive waste.

For each new geometry, a new calibration standard and one to several hours of instrument calibration are required. This has limited in situ gamma spectrum analysis to simple geometries and contamination distributions. The mathematical detector characterization of the Canberra ISOCS is the innovative response to this problematic aspect of conventional in situ analysis.

\subsection{ISOCS Description}

ISOCS is a complete In Situ Object Counting System developed by Canberra for use in a wide variety of measurement applications [ref 2, ref 4]. The batteryoperated system provides traditional spectra of counts as a function of gamma energy, which are then converted to radionuclide concentration by applying pre-defined geometry templates in the analysis software. The ISOCS software overcomes the limitations of traditional (tedious and expensive) efficiency calibration techniques, and allows practical modeling and accurate assay of almost any object in the workplace. Thus, complex contamination distributions (e.g., an inaccessible contaminated pipe within a wall) can be identified, and resulting quantification of the contamination therein can be performed.

2.4.1 Germanium Detector. The gamma radiation detector utilizes a high purity germanium crystal for high resolution and high efficiency gamma radiation detection. For the ASTD project, a Canberra Broad Energy Germanium (BEGe) detector was selected because it enhances the efficiency of gamma radiation detection below $100 \mathrm{keV}$ while exhibiting increased transparency to high energy gammas, such as those from naturally occurring K-40. Typical energy response curves for the BEGe and the conventional Coaxial detectors are illustrated in Figure 2-1.

The wide, squat shape of the BEGe detector (active volume of $80 \mathrm{~mm}$ diameter by $30 \mathrm{~mm}$ thick) is optimized for analysis of objects in front of the detector. However, it has less sensitivity to a Marinelli beaker sample geometry than a traditional co-axial detector whose diameter is smaller than its thickness. The enhanced BEGe detector efficiency for low energy gammas (from 30-100 keV) provides a field capability for detection of Am-241 and low energy gammas associated with actinide alphaemitters that greatly exceeds the capability of traditional detectors.

There is a drawback to using the BEGe detector. The ISOCS $30 \mathrm{E}$ field of view (FOV) collimator is designed for

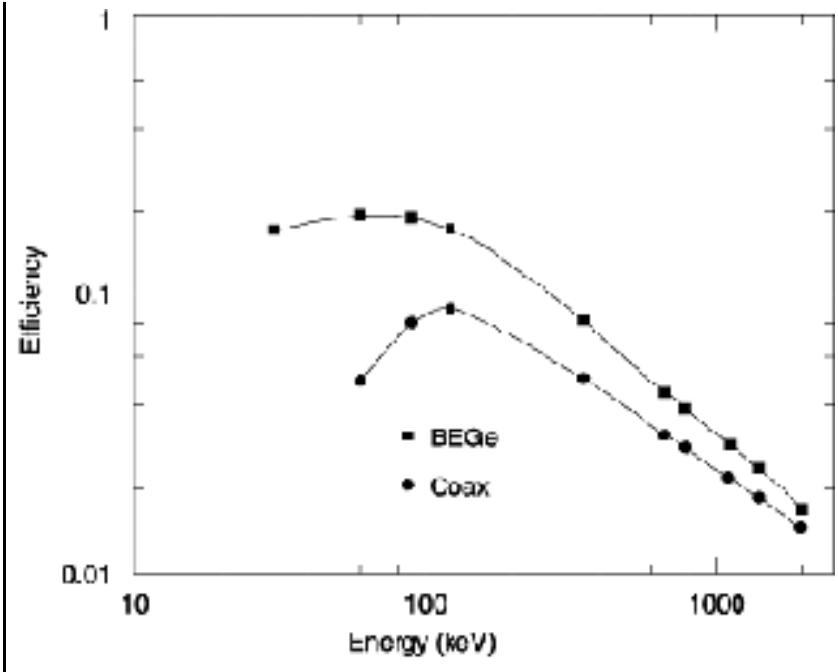

Figure 2-1. Comparison of BEGe detector response to coaxial germanium detector (Canberra, 1999)

use with a standard narrow co-axial detector, and its use is impractical with the BEGe detector. The wide, flat shape of the BEGe results in the $30 \mathrm{E}$ FOV collimator shielding over $80 \%$ of the active BEGe detector region. This shielding decreases the sensitivity of the detector, which increases the time to acquire a spectrum with enough counts to provide minimal statistical uncertainty. This limitation could be rectified by the manufacturer producing a re-designed collimator for use with the BEGe detector.

2.4.2 Modular Shields and Cart. Mechanical components of the ISOCS system, including a field deployable mobile cart and a modular system of stainless-steel covered lead shields are shown in Figure 2-2. Annular side shields of either $19 \mathrm{~mm}$ (0.75 in) or 44 $\mathrm{mm}$ (1.75 in) lead thickness effectively reduce the detection of interfering radiation from items in the vicinity of the detector and from background radiation, resulting in improved system sensitivity. The detector's field of view can be further restricted, from $180 \mathrm{E}$ to $90 \mathrm{E}$ or $30 \mathrm{E}$, by installing lead collimators on the cart's mounting rails, so that interference from items adjacent to the object of interest can be significantly reduced or eliminated from the analysis. In addition, a completely shielded sample chamber can be assembled by stacking the components of the two thickness annular shield systems to enable timely, low-background analysis of samples in the field.

2.4.3 ISOCS Detector Characterization. Previous attempts at simplified mathematical calibrations have had accuracy shortcomings due to assumptions that the 
detector was a point detector, and due to limitations in sample shapes accommodated. With ISOCS, however, each individual detector has a unique set of characteristics that are used to generate the calibration data [Ref 2]. This process employs a two-phase, mathematical computation technique that includes detector-specific characteristics, accounts for collimators and/or shields, and models the physical object to be assayed. It uses a combination of Monte Carlo calculations and discrete ordinate attenuation computations to derive efficiency curves for quantitative spectral analysis.

Canberra uses the Monte Carlo Neutron-Particle (MCNP) code for the detector characterization phase of the process [Ref 1]. To accurately represent the Ge detector response, the MCNP model must be rather complex, and typically requires approximately 25 different physical elements. Even with fast 64 bit $300 \mathrm{MHz}$ computers, and special biasing procedures, these efficiencies can take days to compute. To ensure the maximum accuracy and to minimize subsequent analysis times, this phase of the detector characterization is performed on each detector by Canberra at the factory before it is delivered.

The output of the detector characterization process is a series of equations that defines the detector response (in terms of fraction of gammas emitted from the object that interact in the detector):

- at any distance from the end-cap, from 0 to 50 meter;

- $\quad$ at any energy from $3-7000 \mathrm{keV}$; and

- $\quad$ at any angle in all 4-pi directions.

The results of this individual detector characterization are incorporated as a part of the calibration software. Individual detector characterization is recalled by the user when quantifying an individual gamma spectrum.

2.4.4 Source Geometry Modeling. The user phase of the efficiency computation allows accurate efficiency calibrations to be performed rapidly for a wide variety of sample shapes, sizes, densities and distances between the sample and the detector. Objects are modeled from one of a set of generic sample shapes, such as boxes, cylinders, planes, spheres, pipes, etc. These basic geometry templates have many parameters that can be modified to create an accurate representation of the sample object and detector geometry.

Photon attenuation effects due to collimators and shielding components (if present) can be included in the efficiency calibration process. Attenuation effects due to the sample material itself, the container walls (if any), and the air between the sample and the detector are also

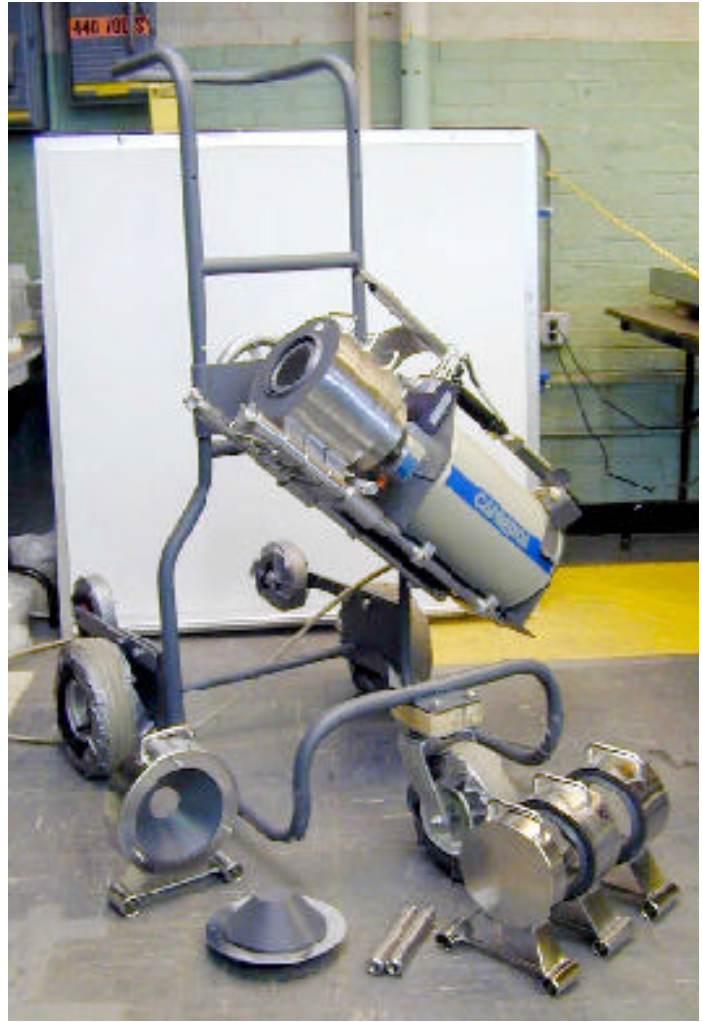

Figure 2-2. ISOCS cart with detector, cryostat and modular shield system

included in the calculations. For typical objects and energy ranges of interest, an experienced user can complete the entire efficiency calibration process in several minutes or less. Exposure parameters and efficiencies can be generated in a few minutes in the field and can be modified easily if needed.

At this point, the data is presented and stored just as it would be using the conventional process, that is as if the user had prepared a multiple energy calibration source in the appropriate geometry, counted it, analyzed the spectrum, and computed the efficiency based upon the data in the calibration source certificate file. The resulting ISOCS efficiency calibration functions can then be used to analyze acquired spectral data files with the standard spectrometry analysis software.

2.4.5 Analytical Software. The output of the ISOCS process is a set of energy/efficiency/error triplets. Upon exiting the ISOCS user interface, this data is converted into the energy-efficiency curve format and is displayed for the user as shown in Figure 2-3. The user can manipulate Canberra's standard efficiency response curve interface to determine the best equation that 
represents the energy vs. efficiency function. After the calibration curve is accepted, it is stored as an efficiency file, and is available for re-analysis of previous spectra or for newly acquired spectra from sources that are described by the same geometry parameters.

2.4.6 Validation of the ISOCS Computation. Given the uniqueness of the ISOCS mathematical calibration, Canberra Industries has performed a series of internal consistency tests and efficiency validations of the ISOCS methodology [ref 3 ]. These evaluations were conducted by Canberra to ensure that the ISOCS version 3.0 software handles the physics correctly for different source shapes and sizes, and for different source-detector geometries. The following discussion summarizes the validation performed by Canberra as reported in the validation document.

2.4.6.1 Internal Consistency Tests. Internal consistency tests were designed to demonstrate that the ISOCS software treated source geometries in a consistent manner when defined using several of the available geometry templates. Eight shaped objects (point, sphere, box, etc) were modeled using from 4 to 11 geometry templates of equivalent geometrical shape. If a given source geometry can be configured using different templates, then ISOCS should give the same efficiency values for different templates. The tests indicated that for the eight shapes, the percent difference in efficiency at a given energy value ranged:

- $\quad$ between $0.10 \%$ to $1.12 \%$ for energies below 150 $\mathrm{keV}$; and

- between $0.05 \%$ to $0.56 \%$ for energies greater than $150 \mathrm{keV}$.

Thus the detector characterization and template definition scheme is internally consistent across the 11 geometry templates.

2.4.6.2 Validation Tests. Validation tests were performed by Canberra to demonstrate the accuracy of the ISOCS efficiency calibrations when compared to actual, physical sources. The tests involved 119 different, multi-energy sources in three categories of spectrum acquisition,

a. field counting geometries, involving large sources (>1 $\mathrm{m}^{3}$ in volume) and/or large sourceto-detector distances (>1 m);

b. laboratory counting geometries, involving small volume sources located within 1 meter of the detector;

c. collimated geometries, similar to the field counting geometries, using annular shields and $180 \mathrm{E}, 90 \mathrm{E}$ or $30 \mathrm{E}$ FOV collimators.

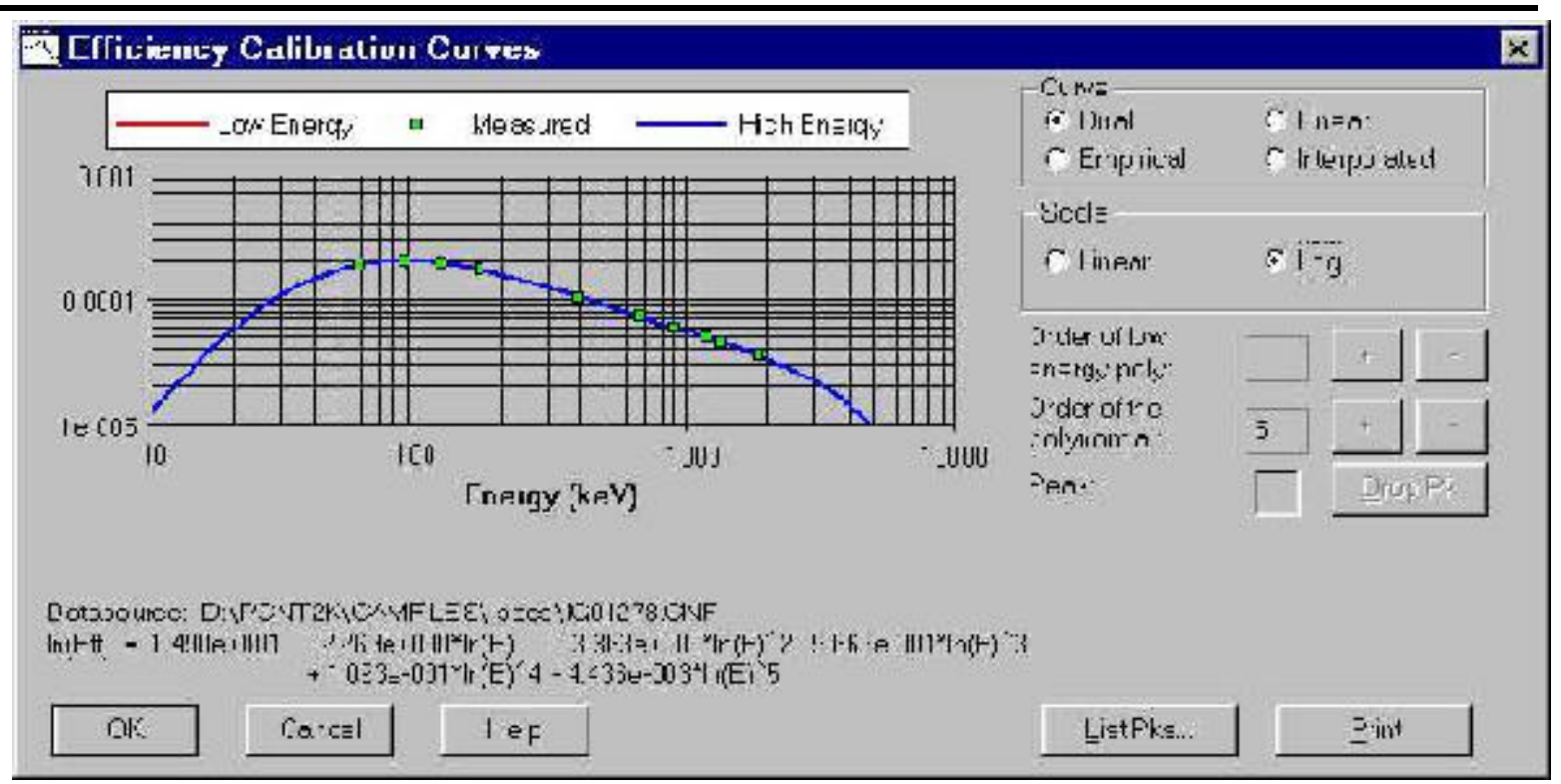

Figure 2-3. ISOCS efficiency response curve interface 
The tests indicated that for the three conditions, the percent difference in efficiency at a given energy value ranged:

- $\quad$ between $-1 \%$ to $-2 \%$ for energies below $150 \mathrm{keV}$;

- $\quad$ between $+0 \%$ to $+6 \%$ for energies greater than 150 $\mathrm{keV}$; and

- $\quad$ between $+0 \%$ to $+2 \%$ for all energies, pooled data. The validation tests demonstrated that for all three categories, the average ISOCS calculated efficiency to true efficiency ratios were very close to unity. The greatest deviation $(+6 \%)$ occurred for the higher energy gammas in the laboratory geometry.

2.4.6.3 Propagated Uncertainty. In concluding the software validation, Canberra presented the values in Table 2-1 for uncertainty in the efficiency calculation. These values are present as defaults in the analysis software code and are used with the counting uncertainty to develop a propagated total uncertainty for the measurement result.

The software allows these default values to be changed
Table 2-1. ISOCS Efficiency Uncertainties

\begin{tabular}{|l|c|c|}
\hline $\begin{array}{l}\text { Geometry } \\
\text { Condition }\end{array}$ & Energy Range & $\begin{array}{c}\text { Rel Std } \\
\text { Dev (\%) }\end{array}$ \\
\hline \multirow{2}{*}{$\begin{array}{l}\text { Laboratory } \\
\text { Sources }\end{array}$} & $50-100 \mathrm{keV}$ & 7.1 \\
\cline { 2 - 3 } & $100-400 \mathrm{keV}$ & 6.0 \\
\cline { 2 - 3 } & $400-7000 \mathrm{keV}$ & 4.3 \\
\hline $\begin{array}{l}\text { Field } \\
\text { Sources and } \\
\text { Collimated } \\
\text { Geometry }\end{array}$ & $100-400 \mathrm{keV}$ & 10.6 \\
\cline { 2 - 3 } & $400-7000 \mathrm{keV}$ & 7.5 \\
\hline
\end{tabular}

by the analyst, when other sources of error are known or eliminated. For instance, Canberra recommends that under conditions of heavy attenuation (transmission less than $1 \%$ due to an absorber between the source and the detector), an additional multiplication of the error by a factor of $1.5-2.0$ be applied.

\subsection{BASIS FOR ASSESSING DATA QUALITY LEVEL}

This ASTD Project is designed to demonstrate that in situ gamma spectrum analysis can be used in lieu of laboratory analysis in one or more of the following situations during the D\&D process:

- Defining worker protection requirements in the design of work packages;

- Controlling work progress, excavation advancement and waste segregation;

- Waste characterization to demonstrate compliance with waste acceptance criteria; and

- $\quad$ Performing final status surveys for remediated facilities and land areas.

Since each of these phases uses the data for a different purpose, with different consequences for level of precision, accuracy and timely acquisition of results, the data quality requirements are not identical.

The Data Quality Objective (DQO) process has been developed to address the differing issues and requirements on the data use, in order to optimize the return of useful, relevant data for the collection and analytical efforts. The following discussion of data quality is distilled from federal agency guidance provided in EPA data quality documents [ref 10, ref 11, and ref 12] and in the Multi-Agency Radiation Survey and Site Investigation Manual (MARSSIM) [ref 13].

\subsection{Data Quality Level}

Despite a number of successful applications of in situ spectrometry over the years, issues have arisen regarding the level of data quality that is obtained with field measurement techniques for the purposes of demonstrating compliance with the Resource Conservation and Recovery Act (RCRA), the Comprehensive Environmental Response, Compensation and Liability Act (CERCLA), the Waste Acceptance Criteria (WAC) at disposal facilities, and other regulatory compliance mandates. In the past, EPA defined different levels of data quality, termed "analytical support levels," by the types of technology and documentation used, and the degree of analytical sophistication [ref 17]. Notwithstanding this intent, the actual titles provided to the analytical levels by the EPA guidance tended to associate the level of quality with the location of the analysis. The relevant levels are:

- $\quad$ Level IV - "Contract Laboratory Program Routine Analytical Services" - characterized by rigorous QA/QC protocols and documentation, providing qualitative and quantitative analytical data.

- $\quad$ Level II - "Field Analysis" - characterized by the use of portable analytical instruments which can be used on-site, or in mobile laboratories stationed near a site (close support labs). Depending on the types of contaminants, sample matrix, and 
personnel skills, qualitative and quantitative data can be obtained.

- $\quad$ Level I - "Field Screening" - characterized by the use of portable instruments which can help provide real-time data to assist in the optimization of sampling point locations and in health and safety support.

Thus, field measurements, by definition and common usage, have been considered not to possess the quality control that needs to be established to match data quality from the laboratory.

The distinction between screening level and higher quality measurements is based on factors relating to data quality which should be demonstrable. In principle, the rigorous $\mathrm{QA} / \mathrm{QC}$ protocols and documentation required for definitive analysis using EPA Contract Laboratory Program (CLP) procedures could be applied to radionuclide specific field measurements. Using field techniques at a higher analytical level is also in keeping with the latest EPA proposals for performance-based measurement systems (PBMS). PBMS is a process in which data quality needs, mandates, or limitations of a program or project are specified and serve as a criterion for selecting appropriate analytical methods. Under the PBMS framework, the performance of the method employed is emphasized rather than the specific technique or procedure [or location] used in the analysis. Equally stressed in this system is the requirement that the performance of the method be documented by the laboratory that appropriate QA/QC procedures have been conducted to verify the performance. PBMS applies to physical and chemical techniques of analysis performed in the field as well as in the laboratory [ref 11].

Thus, data quality is assured by adherence to a quality assurance program, regardless of whether analysis occurs in the field or in the laboratory. The quality assurance program establishes the required data quality indicators, procedures and operations. Data quality assessment determines the validity and performance of the data collection design, determines the adequacy of the data set for its intended use, and ultimately determines whether the in situ analysis can be used (is "comparable" or not).

From this discussion, it is evident that quality data may be generated in the field, as long as the project DQOs and QA/QC requirements are satisfied. It is the assessment of the total data quality, not the identification of which specific method or instrument was used, that establishes the confidence in the analysis and determines the data quality level.
Table 3-1. The Data Quality Objective Process

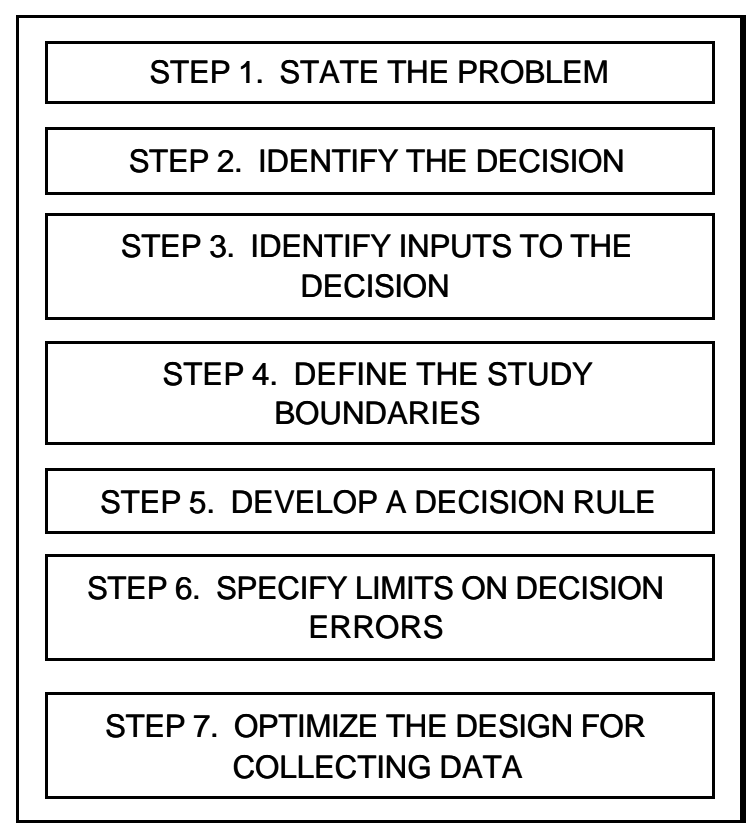

3.2 In Situ Analysis Quality Assurance

The BNL-ASTD project used the DQO process as the basis for the performance-based guidance in planning characterization and final status surveys. The steps of the DQO process identified in the EPA guidance are shown in Table 3-1.

In the implementation of this project, the first four steps of the DQO process are common to both characterization and final status surveys. In the final three steps, there is significant difference in interpretation and application to the characterization survey.

The fifth step in the DQO process is the specification of a decision rule. For the final status survey Step 5 usually takes the form of a statistical hypothesis test. For a characterization survey such a highly structured rule will not generally be appropriate. However, in characterization surveys it should be possible to identify:

- a range of results that clearly indicates that there is no need for remediation in an area; a range of results that clearly indicates that there is need for remediation in an area; and

- $\quad$ an intermediate range of results that may indicate the need for more data before a decision is made.

Such a scheme is loosely patterned after sequential testing procedures, but is primarily intended to differentiate the easy decisions from the more difficult ones so that more resources can be devoted to the areas that need it. 
Specifying acceptable limits on decision errors is the sixth step in the DQO process. For final status surveys, Step 6 means specifying decision error rates for Type I (false positive or false rejection) errors and Type II (false negative or false acceptance) errors for statistical hypothesis tests. Again, such precision is usually neither desirable nor necessary in a characterization survey. In a final status survey, the decision errors are used to determine the number of samples it is necessary to collect. The same is true for the characterization survey, except that extensive use of professional judgement is made to balance the costs of additional measurements against the risk of drawing the wrong conclusion from the data.

Optimizing the design of a characterization survey (step seven of the DQO process), involves using all the information available, together with professional judgement, to assess the worth of the information to be gained from additional data in terms of increasing confidence in a remediation decision. This is where the width of the "gray region" expressed by choice (c) of Step 5 is used to separate, as efficiently as possible, the easy decisions from the difficult ones. The cost of data collected early in the characterization can be balanced against the possibility that new data will be needed. The consequence of incorrectly classifying an area as needing remediation when it does not should be balanced against the cost of discovering during a final status survey that an area thought to be clean actually is not. Remediation costs are also balanced against the cost of characterization measurements.

The seven specific elements of the overall DQO process, outlined above, are addressed by the ASTD project team through development of individual project-specific survey plans (PSSPs) in support of individual BGRR D\&D campaigns. The PSSP considers the goals of the intermediate D\&D objective, the baseline characterization elements, and the targeted components of the facility, to identify the scope and content of the in situ characterization efforts using the DQO process. The PSSP provides details on field of view, shielding, and detection levels necessary for the in situ evaluations and identifies sample number designations for items and views of items for tracking and reporting purposes.

\subsection{Project Quality Assurance}

Continuity of spectrum analysis and interpretation among the PSSPs is assured by compliance with the ASTD Project In Situ Analysis Quality Assurance Project Plan (QAPP). This QAPP provides a description of the individuals, organizational responsibilities, and control measures necessary to achieve, verify and demonstrate compliance with both federal and industry quality assurance requirements. This QAPP has been developed using the guidance in EPA QA/G-5 [ ref 11 ] to ensure that appropriate requirements for project data quality have been adequately addressed. The incorporation of EPA QAPP guidance into the ASTD Project QAPP is demonstrated in Table 3-2.

In addition to the Project QAPP, instrument operations and spectrum analysis were standardized by the use of written procedures. These procedures included:

- SOP - DAT1, Standard Operating Procedure for Gamma Spectrum Acquisition Using Canberra ISOCS System, version 1, August 19, 1999. This procedure is used to acquire a gamma radiation spectrum for determining qualitatively, the gamma emitting radionuclides in situ and in samples. This procedure describes the steps necessary for routine operation of the Canberra gamma spectroscopy system, GENIE-2000 and ProCOUNT. Instructions are provided for identifying hardware components, proper equipment setup, routine instrument operation, infield spectrum acquisition (sample counting), and spectrum file management.

SOP - DAT2, Analysis of Gamma Spectrum Files Using Canberra ISOCS System [Software ver 3.0], version 3, February 23, 2000. This procedure describes the steps necessary for quantitative gamma spectrum analysis and reporting using version 3.0 of the Canberra In Situ Object Counting System (ISOCS) Software. Instructions are provided for software environment setup, routine spectrum analysis, software modifications for specific acquisition and analysis requirements, and spectrum file management. The procedure covers the computation steps following spectrum acquisition (accomplished using SOP-DAT1), the development of a quantitative result from the gamma radiation spectrum and acquisition geometry parameters.

ERD-OPM-4.3, Procedure for ASTD Sample Processing to Support BGRR Decommissioning Operations, revision 0, July 12, 2000. This is a work flow procedure to ensure proper, safe, and consistent handling and processing of potentially contaminated samples by instrument operators. 
Table 3-2. EPA Requirements to Project QAPP Crosswalk

\begin{tabular}{|c|c|}
\hline QAPP ELEMENT (defined in EPA QA/R-5) & $\begin{array}{c}\text { Location in } \\
\text { ASTD Project QAPP }\end{array}$ \\
\hline \multicolumn{2}{|l|}{ A. Project Management } \\
\hline A-1 Title and Approval Sheet & Cover Page \\
\hline A-2 Table of Contents & Page ii \\
\hline A-3 Distribution List & Page i \\
\hline A-4 Project/Task Organization & $\S 2.1$ \\
\hline A-5 Problem Definition/Background & $\S 1.1$ \\
\hline A-6 Project/Task Description & $\S 1.2$ \\
\hline A-7 Quality Objectives and Criteria for Measurement & $\S 3.1$ \\
\hline A-8 Special Training Requirements / Certifications & $\S 2.3$ \\
\hline A-9 Documentation and Records & $\S 6$ \\
\hline \multicolumn{2}{|l|}{ B. Measurement / Data Acquisition } \\
\hline B-1 Sampling Process Design & $\S 3.2$ \\
\hline B-2 Sampling Methods Requirements & $\S 3.3$, SOP-DAT1 \\
\hline B-3 Sample Handling and Custody Requirements & $\S 3.4$ \\
\hline B-4 Analytical Methods Requirements & $\S 3.5$, SOP-DAT2 \\
\hline B-5 Quality Control Requirements & $\S 4.1$ \\
\hline B-6 Instrument/Equipment Testing, Inspection and Maintenance Requirements & $\S 4.2$ \\
\hline B-7 Instrument Calibration and Frequency & $\S 4.3$ \\
\hline B-8 Inspection/Acceptance Requirements for Supplies and Consumables & $\S 5$ \\
\hline B-9 Data Acquisition Requirements (Non-direct measurements) & $\S 5$ \\
\hline B-10 Data Management & $\S 6$ \\
\hline \multicolumn{2}{|l|}{ C. Assessment / Oversight } \\
\hline C-1 Assessment and response Actions & $\S 7.1$ \\
\hline C-2 Reports to Management & $\S 7.2$ \\
\hline \multicolumn{2}{|l|}{ D. Data Validation and Usability } \\
\hline D-1 Data Review, Validation and Verification Requirements & $\S 8.1$ \\
\hline D-2 Validation and Verification Methods & $\S 8.2$ \\
\hline D-3 Reconciliation with Data Quality Objectives & $\S 8.3$ \\
\hline
\end{tabular}

Ref: U. S. EPA, EPA Guidance for Quality Assurance Project Plans (EPA QA/G-5), EPA/600/R-98/018, U. S. Environmental Protection Agency, Washington, DC. February 1998. 


\subsection{Data Quality Indicators}

Data Quality Indicators (DQIs) are qualitative and quantitative descriptors used in interpreting the degree of acceptability or utility of data. The principal DQIs are precision, bias, representativeness, comparability, and completeness. Secondary DQIs include sensitivity, recovery, memory effects, limit of detection, repeatability, and reproducibility. Establishing acceptance criteria for the DQIs sets quantitative goals for the quality of data generated in the analytical measurement process. Quantitative DQIs will be discussed in Section 4, below. The non-quantitative aspects of DQIs are addressed here.

3.4.1 Representativeness. Representativeness refers to the degree to which a measurement reflects the condition at a location or whether a group of measurements reflects the conditions in a particular area. Generally, one desires that measurements (or samples) provide an estimated value of a mean radionuclide concentration that in turn yields a dose estimate (and thus risk) to the average member of a critical group for a particular scenario. In order to achieve representativeness, a number of samples or measurements in a given area would be required in order to achieve a given confidence level or power using a statistical test.

Representativeness is affected by the heterogeneity of the contaminants in the media under investigation. Perhaps more than any other factor, field and laboratory measurements may differ at any particular measurement location due to the effects of heterogeneity. Heterogeneity can exist in both the lateral and depth distribution of a contaminant and can take the form of changes in concentration across various distances:

- a centimeter or less, as would result from hot particles;

- $\quad$ meters, as might occur from dumping and localized spills; and

- tens or hundreds of meters, as from up-wind airborne sources.

Survey designs incorporate techniques and sample/measurement densities to accommodate these variations. The number of measurements and the standard deviation about the mean are fundamental parameters to judge whether the mean concentration that is measured is within a certain confidence limit. These parameters can be used to compute the " $t$ " statistic or applied to other statistical tests.

Where variations in concentration occur on a scale of tens of meters or more, it can be expected that either field measurements or soil sampling will give similar results. It is where variations on the scale of a few meters or less occur that agreement in the results between any pair of measurements (i.e., two soil sample results or a field measurement and a soil sample result) might suffer. However, if the mean concentration in an area must be determined, a sufficient number of measurements or samples can ultimately yield the same average result, regardless of where the measurements or samples are taken within the area under investigation.

Depending upon the objectives of a measurement program, a field method could inherently have an advantage over discrete sampling. If the viewing area of a field instrument is significantly larger than the area of a soil sample, a set of field measurement results would tend to show a smaller standard deviation as compared to a set of soil sample data in a heterogeneous area. The mean obtained for a given number of field instrument measurements would then be more representative of the true mean than the mean obtained from a similar number of discrete samples. A wide measurement area represented by a field method could also be consistent with the assumptions of a dose model such as RESRAD, which uses the average concentration over a large contaminated area.

The in situ measurement might also be more representative of actual radioactivity concentrations. Since samples in the laboratory are often screened to remove rocks, sticks and non-soil matter and are almost always dried before analysis, the laboratory concentration result is consequently biased high. The in situ analysis measures the soil "as found", which is more representative of the actual conditions, but is usually lower in magnitude than the laboratory result.

Because the in situ field of view of the ISOCS is greater than the area of an individual sample, the ISOCS measurements will generally be more representative of the average contamination in an area than a single sample with much smaller support. In general, up to ten or more samples may be required to determine the average concentration comparable to a single ISOCS wide-area measurement.

3.4.2 Comparability. Comparability is the qualitative term that expresses the confidence that two data sets can contribute to a common analysis and interpretation [ ref 11]. Comparability is one of the principal Data Quality Indicators (DQIs) identified by the US EPA. The DQIs are quantitative and qualitative descriptors used in interpreting the degree of acceptability or utility of data.

Comparability is a critical factor that readily establishes the validity of a field technique. It can be established by performing a study where field measurement results are compared to those given by an independent technique 
such as sampling and lab analysis. In some situations, it may be possible to compare two different field techniques. Numerical criteria proposed to determine an analytical method data quality level [ref 9] are provided in Table 3-3.

In performing a direct comparison study, it is important to establish that the two techniques are measuring the same thing. For instance, a technique that measures a contaminant concentration in the surface soil may compare poorly to one that is integrating down to greater depths. This situation would result where there is a nonuniform concentration depth profile of the contaminant. Where comparisons are made to soil samples, core depths can be adjusted to better match the effective viewing depth of the field measurement. The lateral distribution of the contaminant concentration across the ground could also be a factor. In this situation, compositing samples may be required to yield a better average with which to compare a field technique.
Table 3-3. Criteria for Categorizing Data Quality Level

\begin{tabular}{|l|c|c|}
\hline $\begin{array}{l}\text { Data Quality } \\
\text { Level }\end{array}$ & $\begin{array}{c}\text { Coefficient of } \\
\text { Variation }\end{array}$ & $\begin{array}{c}\text { Relative Percent } \\
\text { Difference }\end{array}$ \\
\hline $\begin{array}{l}\text { Definitive } \\
\text { Level }\end{array}$ & $0.85<\mathrm{R}^{2}<1.0$ & $\mathrm{RPD}<10 \%$ \\
\hline $\begin{array}{l}\text { Quantitative } \\
\text { Screening } \\
\text { Level }\end{array}$ & $0.70<\mathrm{R}^{2}<1.0$ & $\mathrm{RPD}<20 \%$ \\
\hline $\begin{array}{l}\text { Qualitative } \\
\text { Screening } \\
\text { Level }\end{array}$ & $\mathrm{R}^{2}<0.70$ & $\begin{array}{c}20 \%<\mathrm{RPD} ; \\
\text { False Negative } \\
\text { rate }<10 \%\end{array}$ \\
\hline
\end{tabular}

ref: U. S. EPA, EPA Environmental Technology Verification Report: Field Portable X-ray Fluorescence Analyzer, EPA/600/R-97/150, Washington, DC. March 1998.

\subsection{COMPARABILITY DEMONSTRATIONS}

An objective of this ASTD project is to document the comparability and quality of the ISOCS system field measurements. However, data "quality" or "comparability" as a concept is meaningful only when it relates to the intended use of the data. Data quality indicators, yardsticks for judging whether or not the data set is adequate, are essential criteria for ensuring that data fulfill the overall DQOs for the project. The context of the use of the data set is the basis for establishing data quality indicators during the planning phase of the DQO process.

The data quality assessment process is the statistical and scientific evaluation of data to determine if the data are of the right type, quality, and quantity to support their intended use. The DQA process addresses two fundamental questions [ ref 12 ]:

- Can the decision (or estimate) be made with the desired confidence, given the quality of the data set?

- How well can the sampling (in this case the in situ analysis) design be expected to perform over a wide range of possible outcomes?

Note that the first question does not require that data from two measurement methods produce the same numerical result. It is the decision drawn from the data that must be the same. During a characterization phase project, less correspondence in reported results may be acceptable, while for the determination of unrestricted release less variation in the data sets might be required. The degree of acceptable correspondence or variation required is established in the DQO process. The second question recognizes that the measurement method performance must be understood over a wide range, so that its application for various decisions may be evaluated in the DQO planning process.

In this section, the data quality indicators are assessed in the context of the second question: If the ISOCS in situ analysis is used in an environmental/D\&D study, would the data be expected to support the intended use for various decisions and with what desired level of confidence?

Initially, the quantitative data quality indicators of sensitivity, precision, accuracy, and detection limit are assessed. Then the issue of comparability is addressed by reviewing the implementation of ISOCS analysis for two data sets:

- ISOCS analysis of ex situ samples, in a field laboratory set-up; and

- ISOCS analysis of in situ surface soil, the most common use for in situ gamma spectrometry. 
Finally a powerful use of the ISOCS system, for objects that cannot be evaluated by conventional methods, is discussed.

\subsection{Benchmarking Data Quality Assessment}

As part of the deployment of the ISOCS, the BNL ASTD Project needed to demonstrate that this system provides data of sufficient quality for their intended use, compared to the baseline technology of collecting samples for laboratory analysis. The demonstration of data quality involves the assessment of data quality indicators, indicators that provide quantitative and qualitative measures of the degree of acceptability or utility of the data.

One aspect of comparability of the ISOCS measurements relies on the validity and reproducibility of the ISOCS mathematical efficiency computation. Another aspect is the stability and precision of repeated measurements. The sensitivity of the measurement to the interaction between size of the in situ field of view (FOV) and the size of the object are important to understand. The assessment of these indicators of data quality form the basis for confidence in the comparability of the analysis method or system.

4.1.1 Assessment 1: Instrument Sensitivity to Source Width. For analysis performed in the laboratory, the sample is finite and well defined by the physical container dimension. For analysis performed in situ, it is necessary to identify the lateral boundaries of the detector FOV in order to define what "sample" is actually being analyzed. This can be easily accomplished with the ISOCS efficiency computation code by calculating the efficiency response to a series of virtual contamination sources.

To assess the influence of source diameter, the detector efficiency response was calculated under the following simulated geometry conditions:

- a circular contaminated soil layer, $1.6 \mathrm{~g} / \mathrm{cm}^{3}$ density, $15 \mathrm{~cm}$ (6 inches) thick, lying on the surface, centered on the detector axis,

- a uniformly mixed contaminated layer with normalized activity concentration of $1 \mathrm{pCi} / \mathrm{g}$ for gamma energies of $59.5 \mathrm{keV}$ (Am-241), $661.6 \mathrm{keV}$ (Cs-137), $1173.2 \mathrm{keV}$ (Co-60), and $1460.8 \mathrm{keV}$ (K$40)$,
- a BEGe detector oriented to look vertically downward from a distance of 1 meter (39.4 inches) above the soil surface, and

- $\quad$ detector shielded by $44 \mathrm{~mm}$ (1.7 in) lead annular side shields.

The source diameter was increased step-wise from $0.5 \mathrm{~m}$ (18.7 in), and the efficiency was re-calculated at each diameter until the difference in detector efficiency with a change in diameter varied less than $\pm 0.5 \%$. The calculated efficiency was then normalized by dividing by the maximum calculated efficiency for that energy.

Calculations were performed for two cases:

- Without a collimator, providing a $180 \mathrm{E}$ or 2 pi FOV; and

- $\quad$ With the 90E FOV collimator.

The results of the simulation are shown in Figure 4-1 for the 180E FOV and in Figure 4-2 for the 90E FOV.

Many studies of in situ analysis of large areas assume an area of approximately 10 meters diameter is "seen" by an unshielded detector [ref 6, ref 14]. The use of the annular shields illustrates that $95 \%$ of the BEGe response is achieved from radionuclides in a diameter of

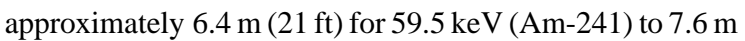
(25 ft) for $1460 \mathrm{keV}(\mathrm{K}-40)$. The use of the annular shields reduces the influence of adjacent, interfering sources.

With the 90E FOV collimator, the area "seen" by the BEGe detector varies little with gamma ray energy, as shown in Figure 4-2. What should be noted for the $90 \mathrm{E}$ FOV is the penumbra effect of the collimator for all energies. For a "90E FOV", at 1 meter distance the field should have a 2 meter diameter. The curves in Figure 4-2 show that fully $22 \%$ to $27 \%$ of the instrument response comes from radioactive material beyond the assumed edge at 2.0 meters. The $95 \%$ response level occurs for a field diameter of approximately 2.75 meters, which corresponds to a "108E FOV."

The Canberra "30E FOV" collimator is designed for use with a standard "co-axial" HPGe detector, and it is incompatible with the BEGe detector. The flat shape of the BEGe results in the $30 \mathrm{EFOV}$ collimator shielding over $80 \%$ of the active BEGe detector region. This shielding decreases the sensitivity of the detector which increases the time to acquire a spectrum with enough counts to provide minimal statistical uncertainty. The collimator also increases the ISOCS efficiency calculation time dramatically. 


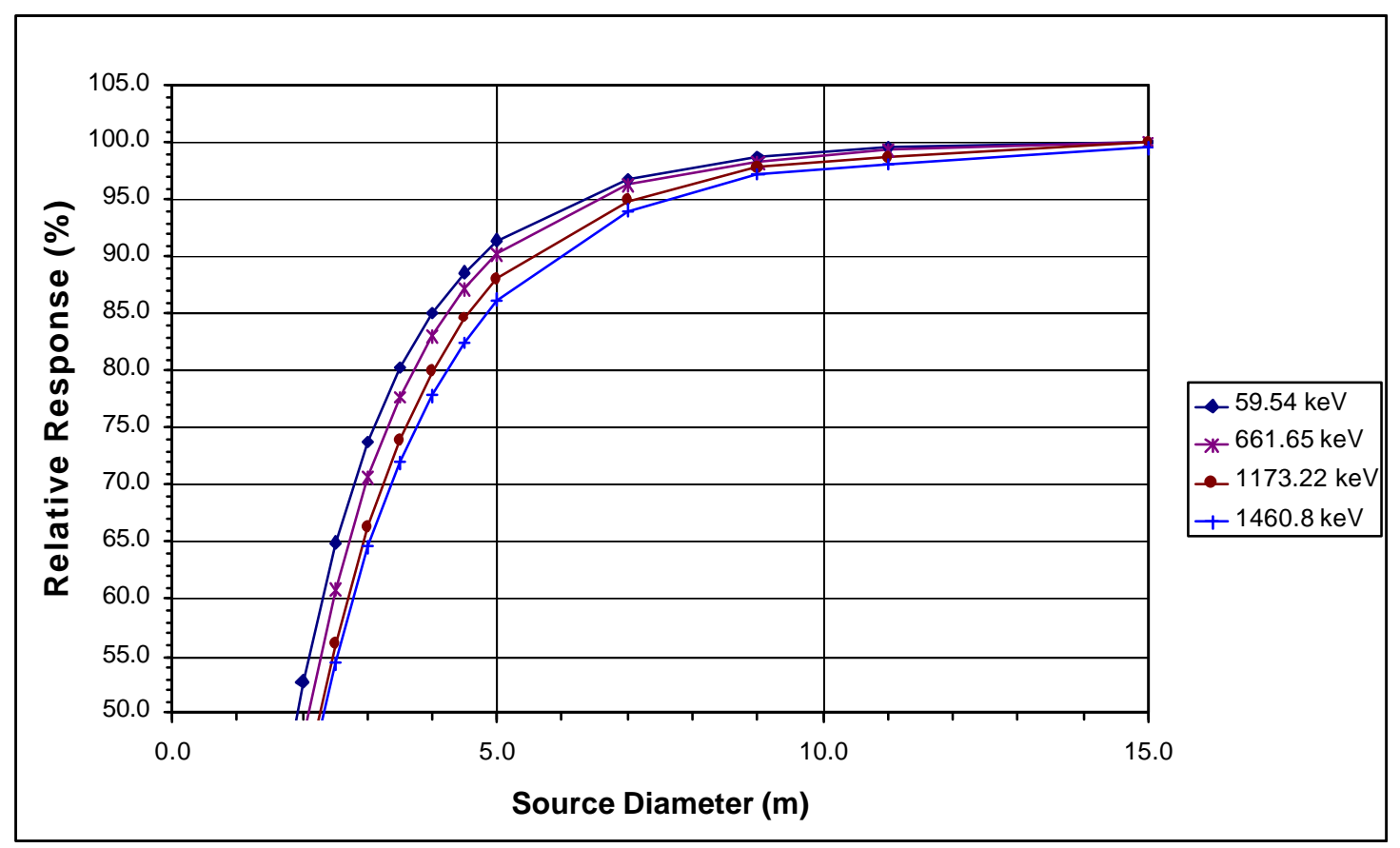

Figure 4-1. ISOCS detector response to surface soil contamination layer diameter at 1 meter with $180 \mathrm{E}$ FOV collimator and $44 \mathrm{~mm}$ annular shields

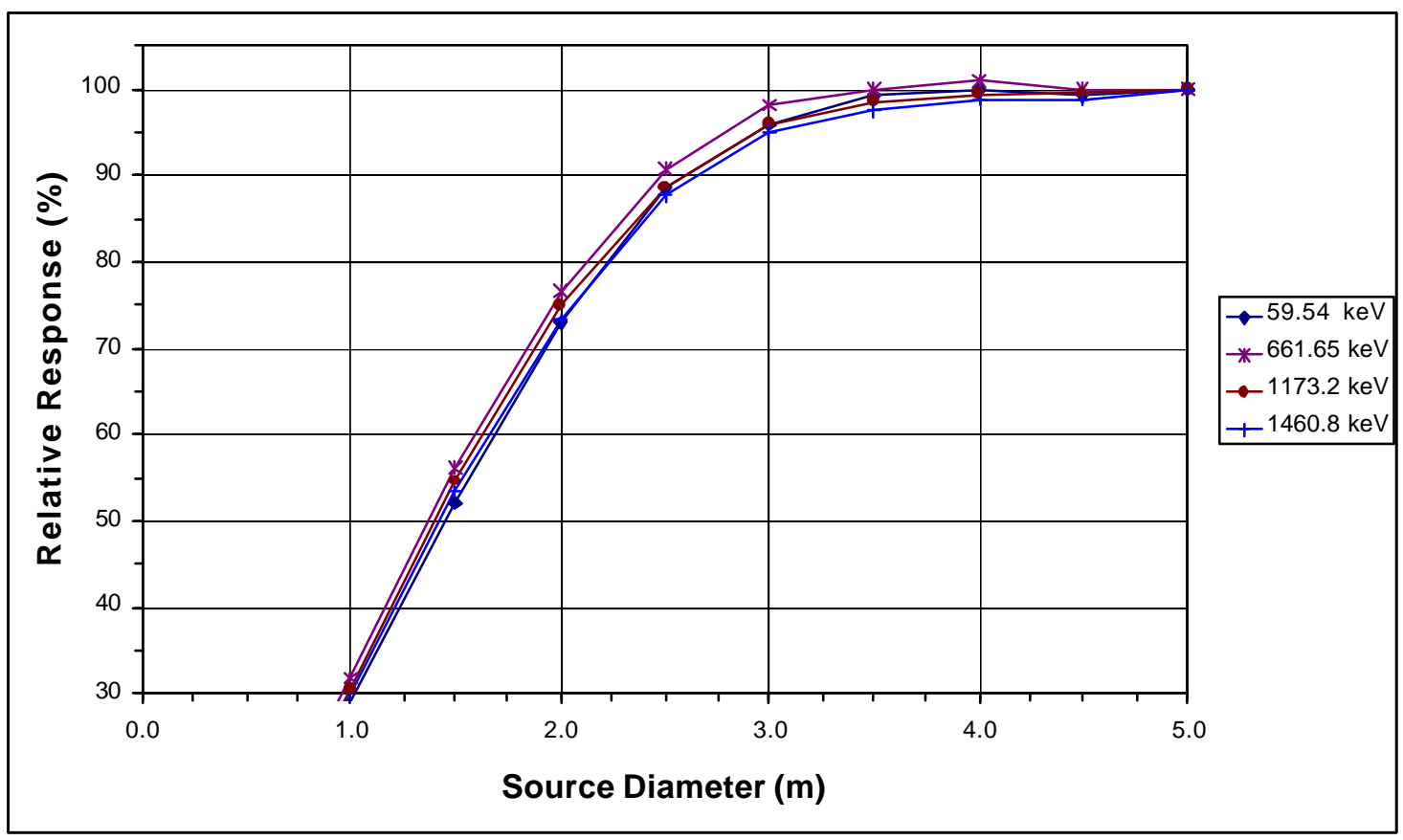

Figure 4-2. ISOCS detector response to surface soil contamination layer diameter at 1 meter with 90E FOV collimator and $44 \mathrm{~mm}$ annular shields 
When using any collimator to reduce interference from an adjacent radionuclide source, the effect of penumbra penetration should be considered. The "effective" diameter for the $90 \mathrm{E}$ FOV collimator with the BEGe detector is approximately $40 \%$ larger than would be expected by "sharp" geometry alone. While the software correctly handles the penumbra penetration effect, when positioning or aiming the detector, the operator should be aware that adjacent objects may influence the measurement when near the "edge" of the FOV.

There are "effective" source dimensions, based on parameters of source distribution and FOV collimators. The use of greater dimensions in the geometry model enables the exact mathematical solution, but contributes little to the effective activity measurement reported by the ISOCS calculation. The code run time necessary to determine the detector-geometry efficiency can be reduced by choosing "effective" source dimensions, with impact on the analytical results that is insignificant when compared to other uncertainties in the analysis.

4.1.2 Assessment 2: Instrument Sensitivity to Source Thickness. As with the diameter, for analyses performed in situ there is an uncertainty in the thickness of the radiation source that is being measured. For physical samples, the depth of the sample layer is usually well defined and recorded when the sample is collected. Gamma photons of different energies are attenuated differently for the same thickness of a medium, so the detector response would be expected to differ also. Thus to have confidence in the in situ analysis, it is necessary to assess the influence of the source thickness in order to define what "sample" is actually being analyzed. This can be easily accomplished with the ISOCS efficiency computation code by calculating the efficiency response to a series of virtual contamination sources.

The detector efficiency response was calculated under the following simulated geometry conditions:

- a circular contaminated soil layer, $1.6 \mathrm{~g} / \mathrm{cm}^{3}$ density, $10 \mathrm{~m}$ (394 inches) diameter, lying on the surface, centered on the detector axis;

- a uniformly mixed contaminated layer with normalized activity concentration of $1 \mathrm{pCi} / \mathrm{g}$ for gamma energies of $59.5 \mathrm{keV}$ (Am-241), $661.6 \mathrm{keV}$ (Cs-137), $1173.2 \mathrm{keV}$ (Co-60), and $1460.8 \mathrm{keV}$ (K40);
- a BEGe detector oriented to look vertically downward from a distance of 1 meter (39.4 inches) above the soil surface; and

- $\quad$ detector shielded by $44 \mathrm{~mm}$ (1.7 in) lead annular side shields.

The source thickness was increased step-wise from 1.0 $\mathrm{cm}(0.4 \mathrm{inch})$, and the efficiency was re-calculated with each thickness until the difference in detector efficiency with a change in thickness varied less than $\pm 0.5 \%$. The calculated efficiency was then normalized by dividing by the maximum calculated efficiency for that energy.

Calculations were performed for two cases:

- Without a collimator, providing a $180 \mathrm{E}$ or 2 pi FOV; and

- With the $90 \mathrm{E}$ FOV collimator.

The results of the simulation are shown in Figure 4-3 for the 180E FOV and in Figure 4-4 for the 90E FOV.

The results in Figure 4-3 and Figure 4-4 disclose that there is little difference in detector response with source thickness between the two FOVs evaluated. The figures do demonstrate the magnitude of the difference on response depending on the energy of the gamma ray. For many in situ applications, the depth of the field of view is assumed to be $10-15 \mathrm{~cm}$ (4-6 inches), usually with the wording like "...average thickness for medium to high energy gamma rays" [ref 6, ref 7, ref 14].

For low energy gammas like $59.5 \mathrm{keV}(\mathrm{Am}-241), 50 \%$ of the detector response is to radioactivity in the top $1.2 \mathrm{~cm}(0.5$ inch) of soil and $95 \%$ of the response is from approximately $6.5 \mathrm{~cm}$ (2.5 inches). Conversely, for a high energy gamma emitter, such as $1173.2 \mathrm{keV}$ (Co-60), $15 \%$ of the response is from activity deeper than $15 \mathrm{~cm}$ ( 6 inches).

As with the source diameter discussed in Section 4.1.1 above, there are "effective" source thicknesses, based on source parameters and FOV collimators. The use of greater dimensions in the model contributes to the exact mathematical calculation, but contributes little to the effective activity measurement of the ISOCS calculation. The code run time necessary to determine the detectorgeometry efficiency can be reduced by choosing "effective" source dimensions, with insignificant impact on the analytical results. 


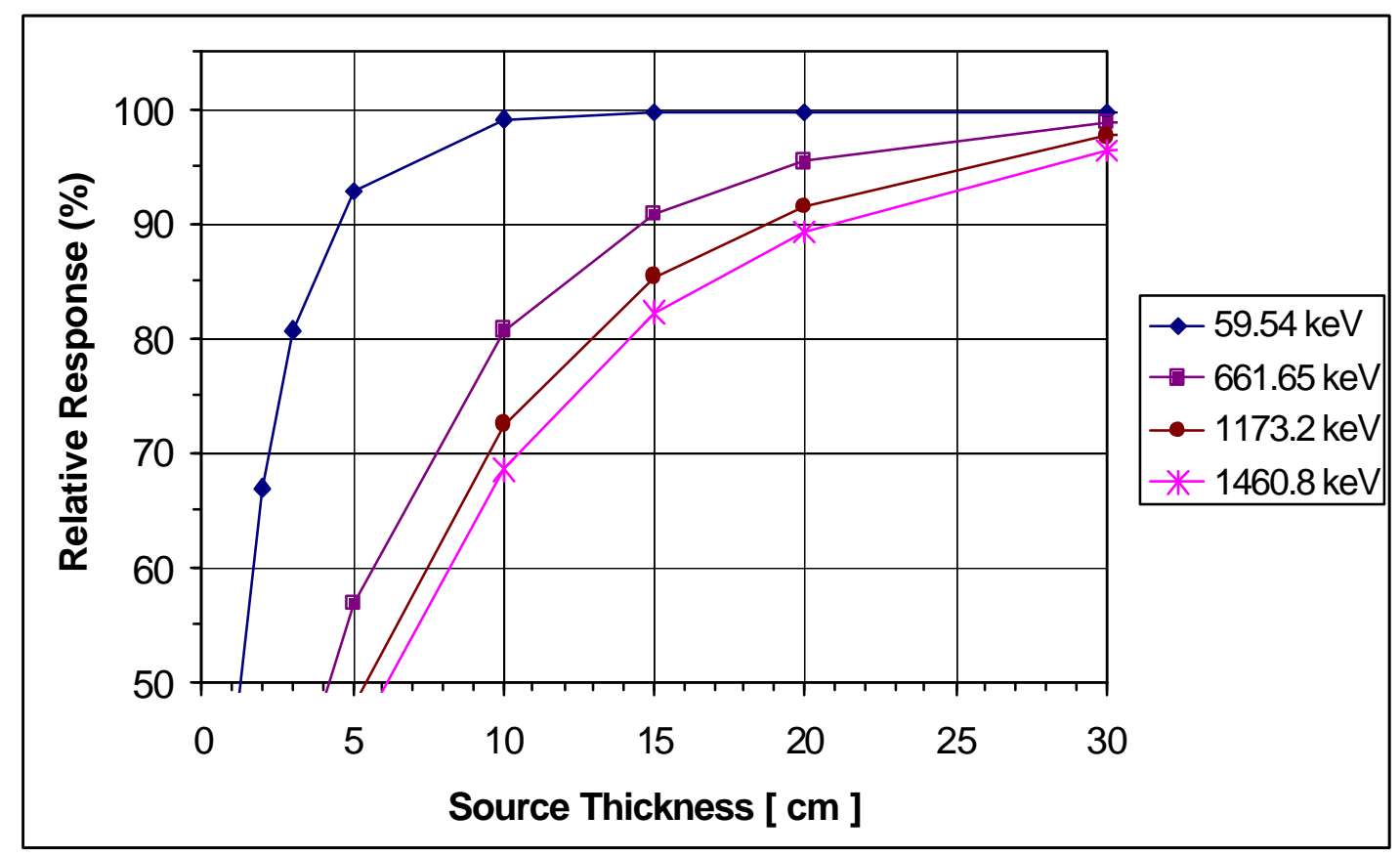

Figure 4-3. ISOCS detector response to surface soil contamination layer thickness at 1 meter with $180 \mathrm{E}$ FOV collimator and $44 \mathrm{~mm}$ annular shields

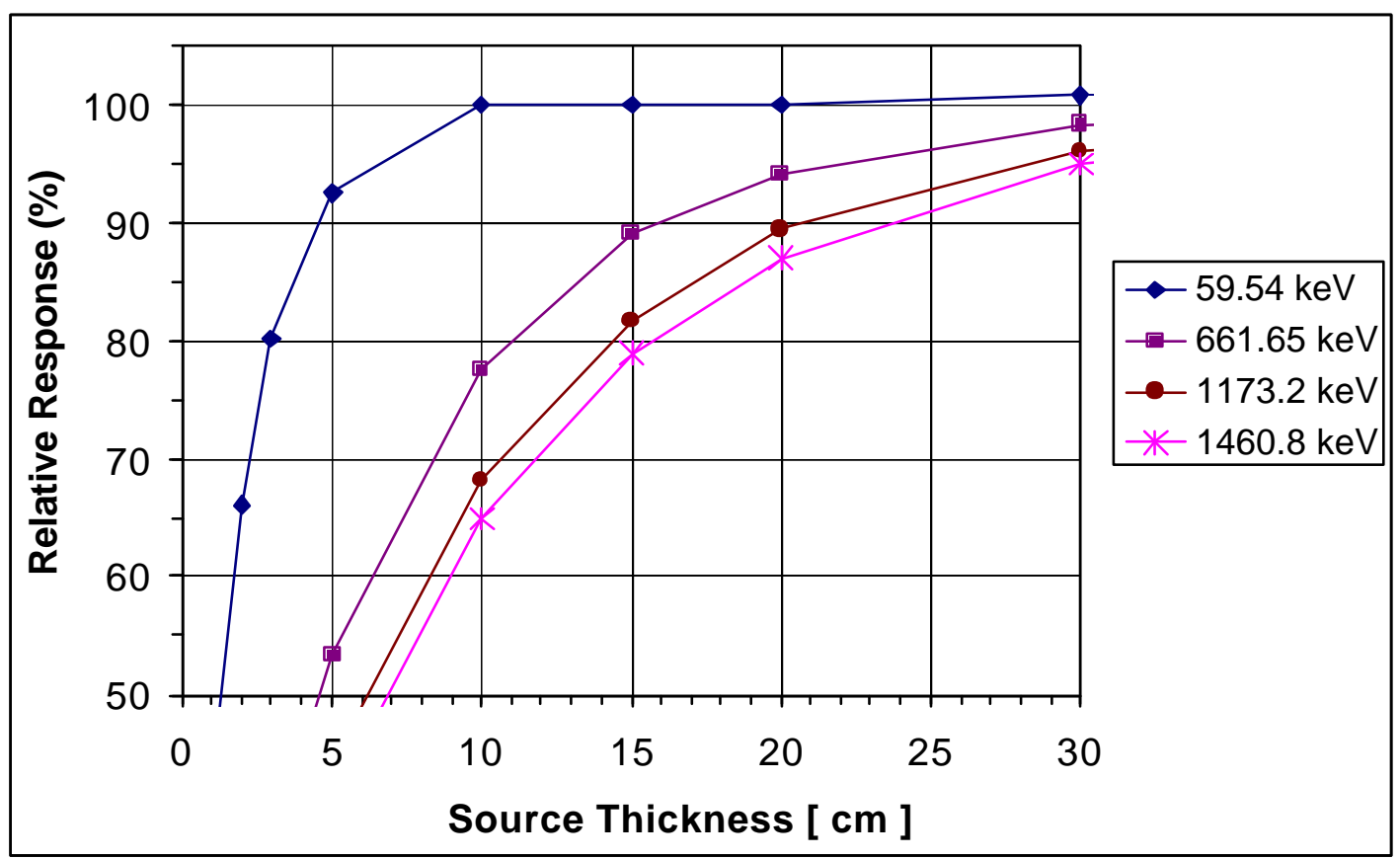

Figure 4-4. ISOCS detector response to surface soil contamination layer thickness at 1 meter with 90E FOV collimator and $44 \mathrm{~mm}$ annular shields 
4.1.3 Assessment 3: Analytical Accuracy to a Point Source. Analytical accuracy is an important, critical data quality indicator. The ISOCS code verification by Canberra Industries, discussed in Section 2.4.6 above, demonstrated internal consistency and accuracy of the analysis software itself. A benchmark for use of the system is that local operators should demonstrate the capability of interpreting and using the ISOCS computation methods to achieve accurate results.

For this assessment a spectrum of an NIST traceable Eu152 source in a $0.5 \mathrm{~mm}$ capsule was acquired for 10 minutes. The source was positioned perpendicular and $30.5 \mathrm{~cm}$ away from the center of the detector end-cap, with the $47 \mathrm{~mm}$ annular shields around the detector. This geometry corresponds to the "laboratory counting" in situ geometry category identified in the Canberra Industries validation tests, a relatively high activity close to the detector (section 2.4.6.2 above). The quantification accuracy was calculated by using the simple cylinder ISOCS efficiency geometry model. An ambient background spectrum was accumulated with the source absent and demonstrated that Eu-152 was not present in the detector field of view. The results of the analysis are provided in the Table 4-1.

As shown in Table 4-1, the ISOCS system measurement is in excellent agreement with the manufacturer-specified source activity. Performance of this benchmark demonstrated the capability to use the ISOCS geometry templates to accurately model a physical exposure geometry and come up with accurate activity determinations.

4.1.4 Assessment 4: Analytical Accuracy to an Extended Source. For an assessment of analytical accuracy for the "field counting" in situ geometry category, in situ spectra were accumulated at an agricultural test pad at BNL. The accuracy of the in situ measurements is assessed by comparison to laboratory

Table 4-1. Assessment of Point Source Accuracy

\begin{tabular}{|c|c|c|c|}
\hline \multirow{2}{*}{$\begin{array}{l}\text { Radio- } \\
\text { nuclide }\end{array}$} & \multicolumn{2}{|c|}{ Point Source Activity (FCi) } & \multirow{2}{*}{$\begin{array}{c}\text { Per cent } \\
\text { Difference }\end{array}$} \\
\hline & $\begin{array}{l}\text { Manufacturer } \\
\text { Specified }\end{array}$ & $\begin{array}{c}\text { ISOCS } \\
\text { Measured }\end{array}$ & \\
\hline Eu-152 & $0.714 \pm 0.036^{(1)}$ & $0.699 \pm 0.022^{(2)}$ & $-2.1 \%$ \\
\hline
\end{tabular}

(1) Activity uncertainty of $5 \%$ at $99.7 \%$ confidence level, as specified by source manufacturer.

(2) Measurement errors reported at the $95 \%$ confidence level and represent only counting error and ISOCSgenerated efficiency errors. analysis of soil samples collected from the same area. The area is the location designated 'Site X', where EML conducted an in situ intercomparison study in the fall of 1997 [ ref 7 ].

Site $X$, an approximately $100 \mathrm{~m}$ by $100 \mathrm{~m}$ area, has been used by EML as a field baseline study area. Gamma-rayemitting radionuclides are present in the soil at ambient levels of naturally occurring radionuclides (background) and the nuclear weapons test fallout product Cs-137. The prior use of this site and the tilling operations that have taken place over the years make it a fairly homogenous area in terms of the lateral and depth distributions of the radionuclides. In the 1997 study at this site, six organizations participated in an in situ gamma ray spectrometer intercomparison, acquiring measurements at each apex of a regular hexagon of $5 \mathrm{~m}$ sides. After the in situ measurements, the EML collected 19 soil samples on a 5-m triangular grid overlying the hexagon for laboratory analysis to use in evaluating the in situ determinations.

The ASTD Project deployed to Site $X$ in the fall of 1999 to acquire in situ spectra for comparison with the previous study results. Gamma ray spectra were accumulated in situ for 20 minutes at the six locations used in the prior study. The BEGe detector was mounted on the mobile cart and oriented to look vertically downward from a distance of 1 meter (39.4 inches) above the soil surface. The detector was shielded by $44 \mathrm{~mm}$ ( $1.7 \mathrm{in}$ ) lead annular side shields for a 180 E FOV. Surface soil activity at each spectrum accumulation location was quantified using the uniform, circular plane geometry template, (contaminated layer $15 \mathrm{~cm}$ thick, $10 \mathrm{~m}$ diameter, with soil density of 1.6 $\mathrm{g} / \mathrm{cm}^{3}$ ). For data comparison, the ASTD ISOCS measurement results were corrected for radioactive decay occurring during the period between the original intercomparison in Fall 1997 and the ASTD measurements in Fall 1999. Results of the in situ measurements and the soil sample analysis are provided in Table 4-2.

In situ measurements with the ISOCS instrument were marginally lower than the results reported by the laboratory (percent difference of the means is $10 \%$ ). The low response of the ISOCS instrument can be partially explained by considering the following points that apply to any in situ measurement:

The in situ result is for "as found" soil, which contains a non-uniform distribution of uncontaminated rocks and organic material. This material is removed from the sample before laboratory analysis. The extraneous material adds uncontaminated mass to the in situ soil that 
decreases the reported radionuclide concentration (activity per gram).

- The in situ result is for "as found" soil, which contains a non-uniform moisture content, while a laboratory sample is dried before analysis. The uncontaminated moisture adds mass to the in situ soil that decreases the reported activity per gram.

For the intercomparison study, the soil activity concentration, reported in Table 4-2 above, was adjusted to account for soil moisture at the time of collection in 1997 , i.e., the reported results are for moist soil, not dry. Since the ASTD readings were performed in 1999, some of the difference may be related to different soil moisture, but the values were close enough that further investigation of moisture effects were not deemed worthwhile.

4.1.5 Assessment 5: Analytical Accuracy through Intercomparison. One characteristic of quality sample analysis is the appropriate performance in an intercomparison program. For the baseline of laboratory analysis, intercomparison involves measuring blind samples of calibrated activity and submitting analytical results to the comparison organizer. Both the EPA and the EML coordinate a program of blind sample distribution and intercomparison of laboratory analysis results. For an in situ intercomparison, participants mobilize their portable instruments to a common site that has been characterized by the organizer. They then perform the indicated measurements, and submit analytical results for comparison with other participants.

The ASTD project participated in a modified intercomparison by performing measurements at a field site on BNL, where EML conducted an in situ intercomparison study in the fall of 1997 [ ref 7 ]. The accuracy of the ASTD in situ measurements for the "field counting geometry" category was assessed by comparison to in situ measurements performed by other organizations in the same area. In the 1997 study at this site, measurements were performed on a $5 \mathrm{~m}$ triangular grid by different pairs of the six participants at each apex of a regular hexagon of $5 \mathrm{~m}$ sides. Thus each of the six positions had two reported analyses, a "higher" value and a "lower" value.

The ASTD project accumulated in situ spectra for 20 minutes at each of the six locations used in the prior study. The BEGe detector was mounted on the mobile cart and oriented to look vertically downward from a
Table 4-2. Analytical Accuracy for a Large Area Source

\begin{tabular}{|l|c|c|}
\hline $\begin{array}{l}\text { Cs-137 Activity } \\
\text { in Surface Soil } \\
\text { (pCi/g) }\end{array}$ & $\begin{array}{c}\text { ASTD Project } \\
\text { in situ } \\
\text { measurements } \\
\text { at six locations }\end{array}$ & $\begin{array}{c}\text { EML } \\
\text { analysis of } \\
\text { 19 soil } \\
\text { samples }\end{array}$ \\
\hline Mean & 0.194 & 0.216 \\
\hline Median & 0.188 & 0.211 \\
\hline $\begin{array}{l}\text { Standard } \\
\text { Deviation }\end{array}$ & 0.026 & 0.027 \\
\hline $\begin{array}{l}\text { Maximum } \\
\text { Observed }\end{array}$ & 0.243 & 0.281 \\
\hline $\begin{array}{l}\text { Minimum } \\
\text { Observed }\end{array}$ & 0.174 & 0.181 \\
\hline
\end{tabular}

Note: Laboratory analysis results from the EML study report [ref 7].

distance of 1 meter (39.4 inches) above the soil surface. The detector was shielded by $44 \mathrm{~mm}$ (1.7 in) lead annular side shields for a 180 E FOV. Surface soil activity at each spectrum accumulation location was quantified using the uniform, circular plane geometry template, (contaminated layer $15 \mathrm{~cm}$ thick, $10 \mathrm{~m}$ diameter, with soil density of 1.6 $\left.\mathrm{g} / \mathrm{cm}^{3}\right)$. For data comparison, the ASTD ISOCS measurements were corrected for decay during the time elapsed between the original intercomparison study in Fall 1997 and the ASTD measurements in Fall 1999. Figure 4-5 displays for each of the six positions, the BNL ISOCS measurement as well as the two measurements reported by the EML study.

The BNL-ASTD results were greater than the higher measurement at one position, between the two measurements for three positions, and less than the lower measurement for two positions. For the area as a whole, the ASTD in situ measurements determined a mean concentration (and 2 sigma uncertainty) of $0.19 \pm 0.05$ $\mathrm{pCi} / \mathrm{g}$, while the intercomparison participants average concentration (and 2 sigma uncertainty) was $0.20 \pm 0.04$ $\mathrm{pCi} / \mathrm{g}$. The 5\% lower response of the ASTD measurement could be due to differences in the soil moisture due to the time elapsed between measurements. The ASTD performance is in line with other participants performance and demonstrates the capability to perform in situ analysis of a large source geometry. 


\section{Comparison of Cs-137 Analysis in situ Analysis vs in situ Analysis}

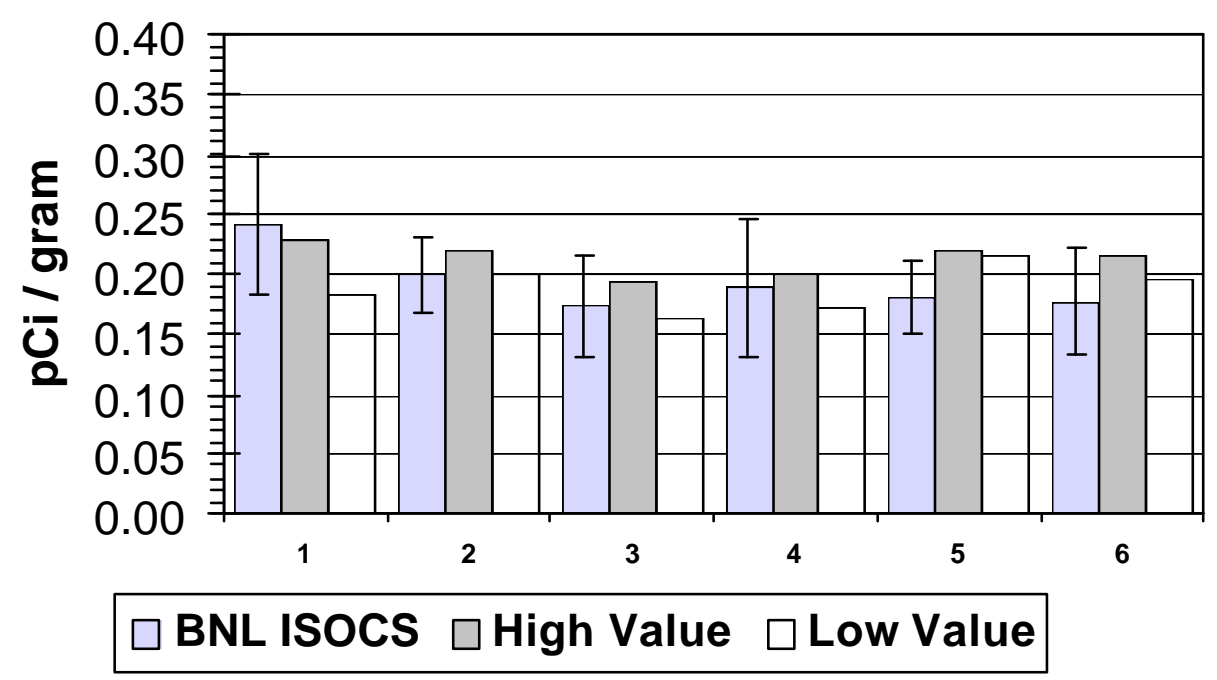

Figure 4-5. Comparison of ISOCS in situ analysis to inter-comparison study

\begin{abstract}
4.1.6 Assessment 6: Analytical Precision Over an Extended Period. An important QC indicator of data quality is analytical precision over an extended time period. Often referred to as "reproducibility", this aspect of precision evaluates the day-to-day stability of the instrument and/or the analysis method for periods of months to years. The data is often graphed as a control chart with bounds indicated for awareness and intervention.
\end{abstract}

To assess ISOCS system stability the spectrum from a nominal 1 microCurie source of Eu-152 is acquired in a fixed geometry each day of operation. The DQIs tracked and the limits on each are identified in the QAPP [ref 8] and are listed in Table 4-3. The energy calibration and detector resolution elements track the electronic stability. The detector efficiency element is a higher order indicator that includes the analysis software operation, as well as electronic stability of the instrument. An electronic control chart for each of the QC elements is produced following the daily QC procedure, and is reviewed on line at the laptop computer. An example of a typical control chart is provided in Figure 4-6.

The control chart in Figure 4-6 illustrates the stability and precision of the ISOCS system. The chart shows response in a narrow band (average $=1.117 \mathrm{FCi}$, standard deviation $=0.008 \mathrm{FCi}$ ) and an absence of trends. The outliers are few and occur randomly, and were usually corrected by repeating the QC check. Note that the \pm 3 sigma intervention limit is only a $\pm 2.1 \%$ variation in the activity measurement, indicating that the ISOCS system response is very stable.

Table 4-3. In Situ Quality Control Indicators and Limits

\begin{tabular}{|l|c|c|}
\hline QC Element & $\begin{array}{c}\text { Investigation } \\
\text { Limit }\end{array}$ & $\begin{array}{c}\text { Action } \\
\text { Limit }\end{array}$ \\
\hline $\begin{array}{c}\text { Energy Calibration Low } \\
-122 \mathrm{keV}\end{array}$ & $\pm 1 \mathrm{keV}$ & $\pm 2 \mathrm{keV}$ \\
\hline $\begin{array}{l}\text { Energy Calibration High } \\
-1408 \mathrm{keV}\end{array}$ & $\pm 1 \mathrm{keV}$ & $\pm 2 \mathrm{keV}$ \\
\hline $\begin{array}{l}\text { Detector Resolution Low } \\
-122 \mathrm{keV}\end{array}$ & $\pm 1 \mathrm{keV}$ & $\pm 2 \mathrm{keV}$ \\
\hline $\begin{array}{c}\text { Detector Resolution High } \\
-1408 \mathrm{keV}\end{array}$ & $\pm 1 \mathrm{keV}$ & $\pm 2 \mathrm{keV}$ \\
\hline $\begin{array}{c}\text { Detector Efficiency Low } \\
-122 \mathrm{keV}\end{array}$ & \pm 2 sigma & $\pm 3 \mathrm{sigma}$ \\
\hline $\begin{array}{c}\text { Detector Efficiency High } \\
-1408 \mathrm{keV}\end{array}$ & \pm 2 sigma & $\pm 3 \mathrm{sigma}$ \\
\hline
\end{tabular}




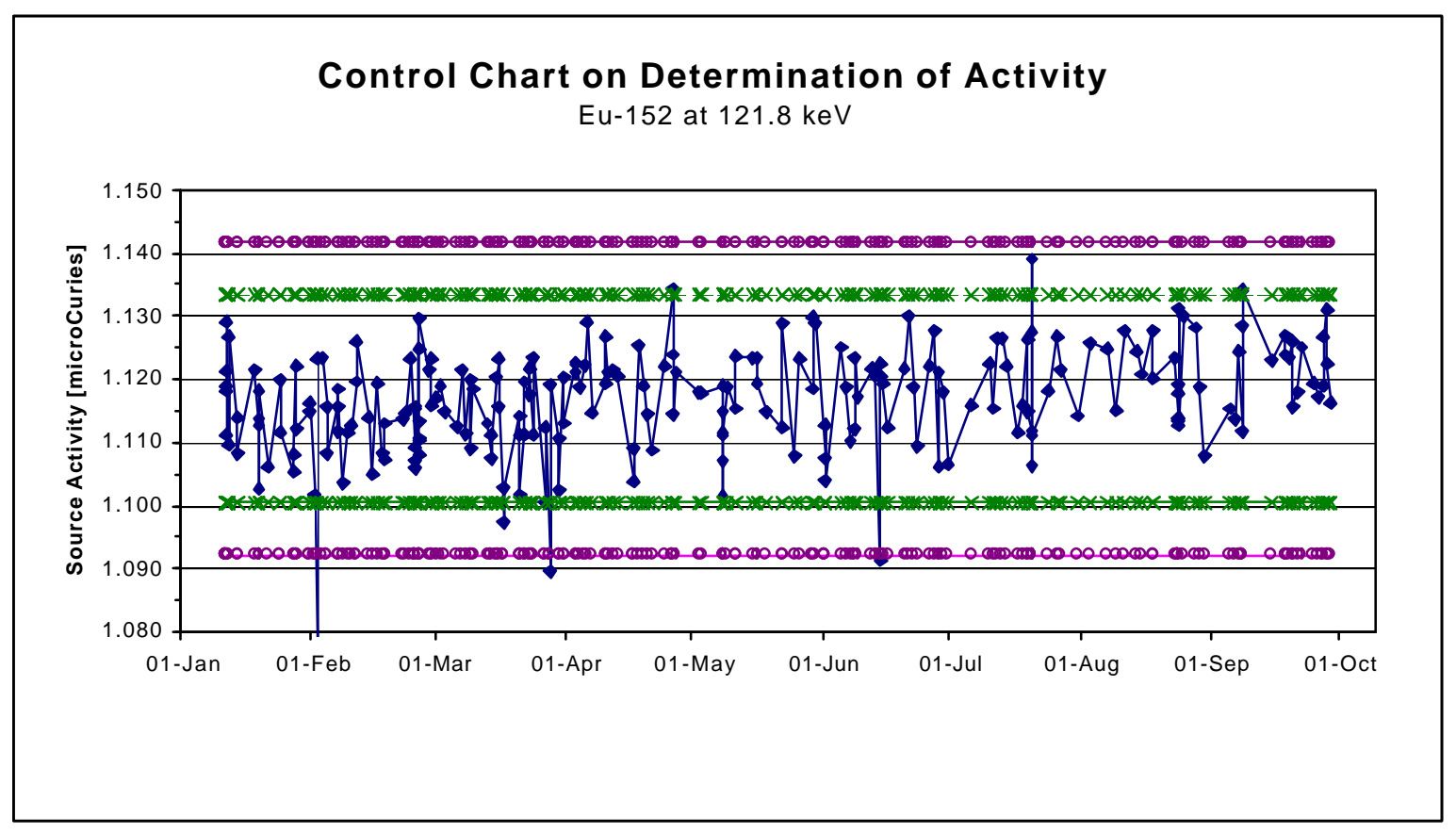

Figure 4-6. ISOCS analytical precision over extended time period

4.1.7 Assessment 7: Analytical Precision in Duplicate Analyses. Precision is a measure of agreement among replicate measurements of the same property, under prescribed similar conditions. Intralaboratory precision represents the agreement expected when a single laboratory uses the same method to make repeated measurements of the same sample. The precision may be expressed as a percentage of the mean of the measurements, the relative percent difference (RPD) [ref 12 ]. The BNL-ASTD Project QAPP stipulates a repeat analysis at least once per every 20 scans, with the QC action level of an RPD greater than $20 \%$.

The analytical precision of the ISOCS instrument is illustrated by the results of repeat analyses performed during a remedial excavation of a contaminated sump. The ISOCS system deployed to the excavation site and provided rapid analysis on soil contamination, allowing the excavation manager to make real-time decisions on advancing the excavation and on disposition of spoils. To expedite the excavation, samples of suspect soil in 1 liter bottles were analyzed adjacent to the construction site, rather than moving the instrument in and out of the active excavation zone. The samples were modeled prior to the operation using the simple cylinder geometry template for four sample sizes (1/4 ful. 2/4 full. 3/4 full and $4 / 4$ full). Gamma spectra were acquired for 5 minutes, the proper model of bottle fullness selected, and the activity concentration was calculated immediately, available on the screen and stored for later printout.

During the excavation support, 600 samples were analyzed of which 25 were QC repeat analyses. Of the 25 repeat samples, 9 were "Non Detect" on both measurements, one was borderline ("Non Detect" vs $0.3 \pm 0.2 \mathrm{pCi} / \mathrm{g}$ ), and 15 samples had measurable activity. The original and repeat measurements for the 15 samples are provided in Table 4-4.

The results in the table indicate that the ISOCS system is capable of measurements as precise as those performed in a laboratory situation. All values of RPD were within the criteria of the Project QAPP. The largest values of RPD occurred when the activity was small $(5 \sim 6 \mathrm{pCi} / \mathrm{g}$ or less), otherwise the RPD was less than $10 \%$ for the sample set. 
Table 4-4. Analytical Precision in Repeat Sample Analyses by ISOCS

\begin{tabular}{|c|c|c|c|}
\hline \multirow{3}{*}{$\begin{array}{l}\text { ASTD } \\
\text { Analysis } \\
\text { ID }\end{array}$} & \multirow{2}{*}{\multicolumn{2}{|c|}{$\begin{array}{c}\text { Measured Activity } \\
\text { Concentration (pCi/gram) }\end{array}$}} & \multirow{3}{*}{$\begin{array}{r}\text { Relative } \\
\text { percent } \\
\text { difference }\end{array}$} \\
\hline & & & \\
\hline & Results & MDC & \\
\hline SAM00181 & $93.0 \pm 8.7$ & 0.6 & \multirow{2}{*}{$1.07 \%$} \\
\hline SAM00202 & $94.0 \pm 8.8$ & 0.7 & \\
\hline SAM00183 & $19.9 \pm 2.0$ & 0.4 & \multirow{2}{*}{$0.50 \%$} \\
\hline SAM00203 & $19.8 \pm 2.0$ & 0.4 & \\
\hline SAM00185 & $3.5 \pm 0.5$ & 0.2 & \multirow{2}{*}{$12.12 \%$} \\
\hline SAM00201 & $3.1 \pm 0.5$ & 0.2 & \\
\hline SAM00328 & $204.7 \pm 15.9$ & 1.2 & \multirow{2}{*}{$2.92 \%$} \\
\hline SAM00335 & $198.8 \pm 15.4$ & 0.9 & \\
\hline SAM00336 & $50.2 \pm 4.1$ & 0.5 & \multirow{2}{*}{$0.80 \%$} \\
\hline SAM00358 & $49.8 \pm 4.1$ & 0.8 & \\
\hline SAM00356 & $2169 \pm 165$ & 3.8 & \multirow{2}{*}{$0.23 \%$} \\
\hline SAM00357 & $2164 \pm 165$ & 4.0 & \\
\hline SAM00368 & $5.7 \pm 0.6$ & 0.3 & \multirow{2}{*}{$15.09 \%$} \\
\hline SAM00391 & $4.9 \pm 0.6$ & 0.3 & \\
\hline SAM00548 & $356 \pm 27.3$ & 1.3 & \multirow{2}{*}{$2.77 \%$} \\
\hline SAM00561 & $366 \pm 28.0$ & 1.1 & \\
\hline SAM00563 & $33.9 \pm 2.8$ & 0.6 & \multirow{2}{*}{$6.39 \%$} \\
\hline SAM00577 & $31.8 \pm 2.7$ & 0.5 & \\
\hline SAM00562 & $325 \pm 25$ & 1.4 & \multirow{2}{*}{$0.61 \%$} \\
\hline SAM00578 & $327 \pm 25$ & 1.6 & \\
\hline SAM00605 & $75.1 \pm 6.0$ & 0.5 & \multirow{2}{*}{$2.84 \%$} \\
\hline SAM00608 & $73.0 \pm 5.8$ & 0.6 & \\
\hline SAM00619 & $0.5 \pm 0.2$ & 0.1 & \multirow{2}{*}{$0.00 \%$} \\
\hline SAM00625 & $0.5 \pm 0.2$ & 0.2 & \\
\hline SAM00645 & $0.5 \pm 0.2$ & 0.2 & \multirow{2}{*}{$0.00 \%$} \\
\hline SAM00646 & $0.5 \pm 0.2$ & 0.2 & \\
\hline SAM00715 & $14.1 \pm 1.3$ & 0.3 & \multirow{2}{*}{$5.84 \%$} \\
\hline SAM00716 & $13.3 \pm 1.2$ & 0.3 & \\
\hline SAM00680 & $88.8 \pm 7.1$ & 0.6 & \multirow{2}{*}{$4.62 \%$} \\
\hline SAM00684 & $93.0 \pm 7.4$ & 0.6 & \\
\hline
\end{tabular}

4.1.8 Assessment 8: Analytical Minimum Detectable Concentration. An indicator that typically substantiates the data quality of a laboratory method is the limit of detection. The limit of detection is the minimum concentration of an analyte in a specific matrix that can be identified with high probability (usually 95\%) when it is present at that concentration. The ISOCS software uses an algorithm based on the Currie method of determining minimum detectable activity (MDA). The Currie method is widely accepted and used as the basis for much of the laboratory analysis software used in industry [ref 6, ref 4].

The Currie method is based on treating the number of counts, $B$, in the Compton continuum beneath a gamma radiation photo-peak as a Poisson random variable, and the standard deviation of this number is then the square root of $B$. The minimum number of counts above the Compton continuum which results in an interpretation of detected radioactivity is then a function of the standard deviation (typically about four times the square root of $B$ ). Applying the instrument efficiency calibration curve, for the matrix and geometry of the spectrum acquisition, to this minimum count produces the MDA or the minimum detectable concentration (MDC), depending on the definition of the efficiency calibration.

Typical MDCs for the ISOCS system are provided in Table 4-5. These values are for common ISOCS uses or geometries that occurred during the program duration. The tabulated values are the averages of MDCs reported from 5 different positions/samples in each category in which none of the four radionuclides was detected.

Table 4-5. ISOCS Minimum Detectable Concentrations for Various Geometries

\begin{tabular}{|c|c|c|c|c|}
\hline \multirow{2}{*}{$\begin{array}{l}\text { Spectrum } \\
\text { Acquisition } \\
\text { Conditions and Area } \\
\text { or Volume Analyzed }\end{array}$} & \multicolumn{4}{|c|}{$\operatorname{MDC}(p \mathrm{pi} / \mathrm{g})$} \\
\hline & Co-60 & Cs-137 & Am-241 & K-40 \\
\hline $\begin{array}{l}\text { in situ, } 90 \mathrm{E} \text { FOV } \\
@ 0.5 \mathrm{~m}, 1200 \mathrm{sec} \\
4.9 \mathrm{~m}^{2} \text { or } 735 \text { liters } \\
\text { of surface soil }\end{array}$ & 0.09 & 0.12 & 0.71 & 0.78 \\
\hline \begin{tabular}{|l} 
in situ, $180 \mathrm{E}$ FOV \\
$@ 1.0 \mathrm{~m}, 1200 \mathrm{sec}$ \\
$20 \mathrm{~m}^{2}$ or 3000 liters of \\
surface soil
\end{tabular} & 0.04 & 0.07 & 0.30 & 0.40 \\
\hline $\mid \begin{array}{l}\text { in situ, } 180 \mathrm{E} \text { FOV } \\
@ 1.0 \mathrm{~m}, 600 \mathrm{sec} \\
20 \mathrm{~m}^{2} \text { or } 3000 \text { liters of } \\
\text { surface soil }\end{array}$ & 0.04 & 0.08 & 0.36 & 1.5 \\
\hline $\begin{array}{l}\text { sample in shielded } \\
\text { cavity, } 300 \mathrm{sec} \\
1 \text { liter of soil }\end{array}$ & 0.30 & 0.30 & 0.40 & 2.0 \\
\hline
\end{tabular}


The results in the table are indicative of the detection limits of the ISOCS in typical in situ and sample counting geometries that occurred in the D\&D project. The magnitude of the MDCs are small, and much less than typical levels of clean-up goals. The MARSSIM recommends that measurement techniques should be capable of measuring levels below the established clean up goals, and $10-50 \%$ of the clean up goal should be the target [ref 13]. The results in the Table 4-5 illustrate that the ISOCS can achieve this target.

It should be noted that the MDC values in Table 4-5 are for samples that have no activity detected. Due to the incomplete interaction in the detector, scattered or partially absorbed high energy gamma rays are detected in the Compton continuum at lower energies, raising the Currie method detection limit for radionuclides with low energy gamma rays. For example, for a soil sample measured in a 1 liter bottle for 300 second acquisition, the MDC for Am-241 shifts from $~ 0.4 \mathrm{pCi} / \mathrm{g}$ when Cs-137 is "not detected" to $\sim 1.0 \mathrm{pCi} / \mathrm{g}$ when $\mathrm{Cs}-137$ is present at $100 \mathrm{pCi} / \mathrm{g}$. This phenomena is common to any gamma spectrometer, both ISOCS and laboratory systems.

\subsection{Assessment of Comparability}

Comparability is the qualitative term that expresses the confidence that two data sets can contribute to a common analysis and interpretation. Comparability must be carefully evaluated to establish whether two data sets can be considered equivalent in regard to the measurement of a specific variable or groups of variables. In a laboratory analysis, the term comparability focuses on method type comparison, holding times, stability issues, and aspects of overall analytical quantitation.

There are a number of issues that can make two data sets comparable, and the presence of each of the following items enhances their comparability:

- two data sets should contain the same set of variables of interest;

- units in which these variables were measured should be convertible to a common metric;

- $\quad$ similar analytic procedures and quality assurance should be used to collect data for both data sets;

- time of measurements of certain characteristics (variables) should be similar for both data sets;

- $\quad$ measuring devices used for both data sets should have approximately similar detection levels;

- $\quad$ rules for excluding certain types of observations from both samples should be similar;

Comparability of ISOCS Instrument
- $\quad$ samples within data sets should be selected in a similar manner;

- $\quad$ sampling frames from which the samples were selected should be similar; and

- number of observations in both data sets should be of the same order or magnitude.

These characteristics vary in importance depending on the final use of the data. The closer two data sets are with regard to these characteristics, the more appropriate it will be to compare them. Large differences between characteristics may be of only minor importance, depending on the decision that is to be made from the data.

Two data sets obtained during the performance of the BNL-ASTD Project can be used to demonstrate the assessment of comparability:

- $\quad$ ISOCS analysis of ex situ samples, in a field laboratory set-up; and

- $\quad$ ISOCS analysis of in situ surface soil, the most common use for in situ gamma spectrometry.

4.2.1 ISOCS Sample Analysis vs Laboratory Sample Analysis. A convenient use of the portable gamma spectrometer is in the on-site, ex situ measurement of radioactivity in physical samples. In many locations or areas of interest, an in situ measurement is impractical:

- the material of interest is in an area with adjacent radiation sources that interfere with an in situ measurement,

- $\quad$ the material of interest is from an area, such as an excavation or in a sump, where moving the in situ instrument requires strenuous efforts and/or impractical delays, or

- the material of interest is in an area where in situ operators do not have the training, medical evaluation, or security clearance to enter.

In these situations, on site field laboratory analysis of $e x$ situ samples provides a rapid, economical alternative to shipping to a remote or off-site laboratory. The ASTD project performed a direct comparison of on site field laboratory sample analysis to remote laboratory analysis to demonstrate comparability of the ISOCS system.

4.2.1.1 Sample Collection. A total of twenty-five samples of surface soil were collected from four contaminated locations on the BNL site. The locations were selected for historical knowledge of the wide range of contamination level in the soil. Each sample consisted of 2 liters of material from the surface layer $(0-15 \mathrm{~cm})$ which 
was sieved to remove organic material, rocks and items larger than $6 \mathrm{~mm}(1 / 4 \mathrm{in})$. Each sample component of sieved soil was combined, thoroughly mixed together and used to fill a 1 liter container. The liter bottles of sample were analyzed on the ISOCS instrument and then packaged and sent off-site for analysis at an analytical laboratory.

4.2.1.2 ISOCS Sample Analysis. The analysis was performed by accumulating in situ a gamma radiation spectrum using an ISOCS BEGe detector attached to a computer-based, multi-channel gamma spectroscopy system. The detector, portable cryostat and lead shielding collimators were mounted on the mobile cart support, allowing consistent sample positioning in a vertically upward orientation. The detector was configured using $44 \mathrm{~mm}$ lead annular side shields around the detector and $19 \mathrm{~mm}$ annular shields above the detector, creating a low-background counting cavity for the 1 liter sample bottles. The sample analysis geometry is illustrated in Figure 4-7 . The gamma spectrum from each sample was evaluated using the ISOCS software,

Figure 4-7. ISOCS instrument configured for sample analysis

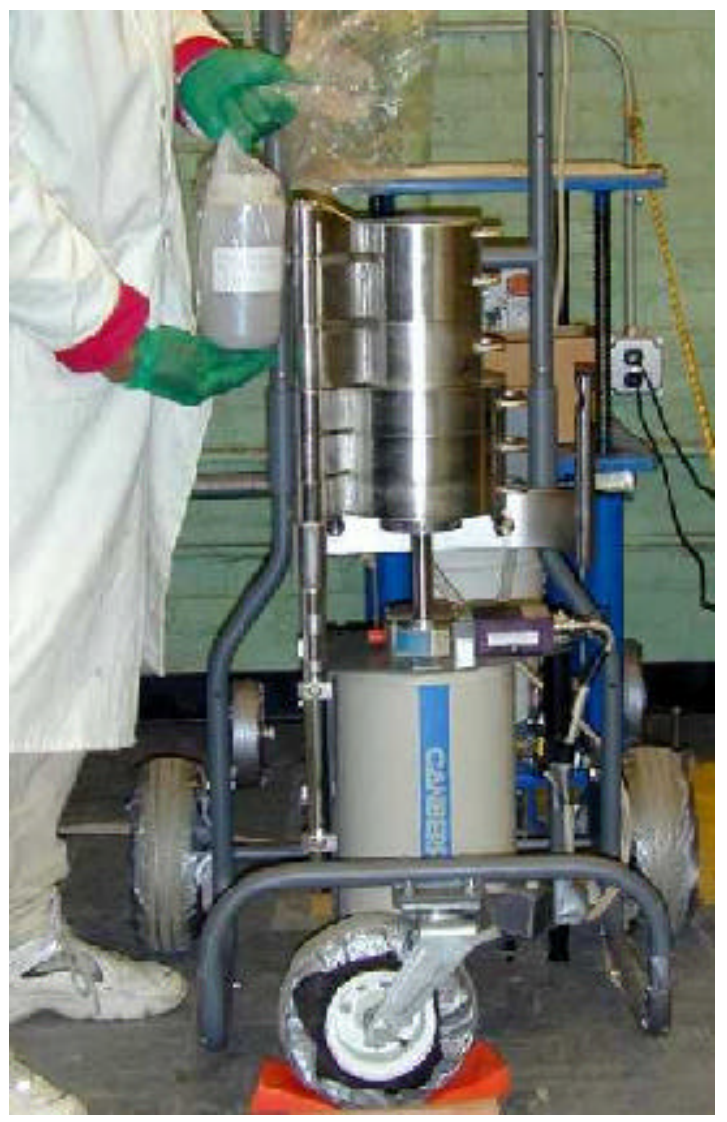

modeling the sample as a uniformly-contaminated, simple cylinder of soil, with density of $1.6 \mathrm{~g} / \mathrm{cm}^{3}$. Results were reported as picoCuries/gram $(\mathrm{pCi} / \mathrm{g})$.

4.2.1.3 Laboratory Analysis. Analysis of samples by the analytical laboratory was performed in a low-background shielded cavity, with a Hyperpure germanium detector attached to a computer-based, multichannel gamma spectroscopy system. Prior to analysis, samples were dried, tumbled with steel shot to homogenize the matrix, and a 150-gram aliquot was sealed in an aluminum/tin can to isolate contaminants and facilitate sample handling. Results were reported as picoCuries/gram (pCi/g).

4.2.1.4 Results. Analysis results for Cs-137 in the samples by the ISOCS instrument and the off site laboratory are provided in Table 4-6. The only contaminant observed was Cs-137. A plot of the ISOCS results versus the laboratory results is provided in Figure 4-8.

4.2.1.6 Discussion. The graph in Figure 4-8 demonstrates the excellent agreement of BNL ISOCS sample analysis with the laboratory sample analysis results. Indicated on the graph of Figure 4-8 is the least-squares linear regression line with slope 1.00 and correlation coefficient of 0.99. The regression slope indicates that the ISOCS result is equivalent to the laboratory reported result (no bias), with a very strong correlation $\left(\mathrm{R}^{2}=0.99\right.$. 1.0) reflecting little non-random error.

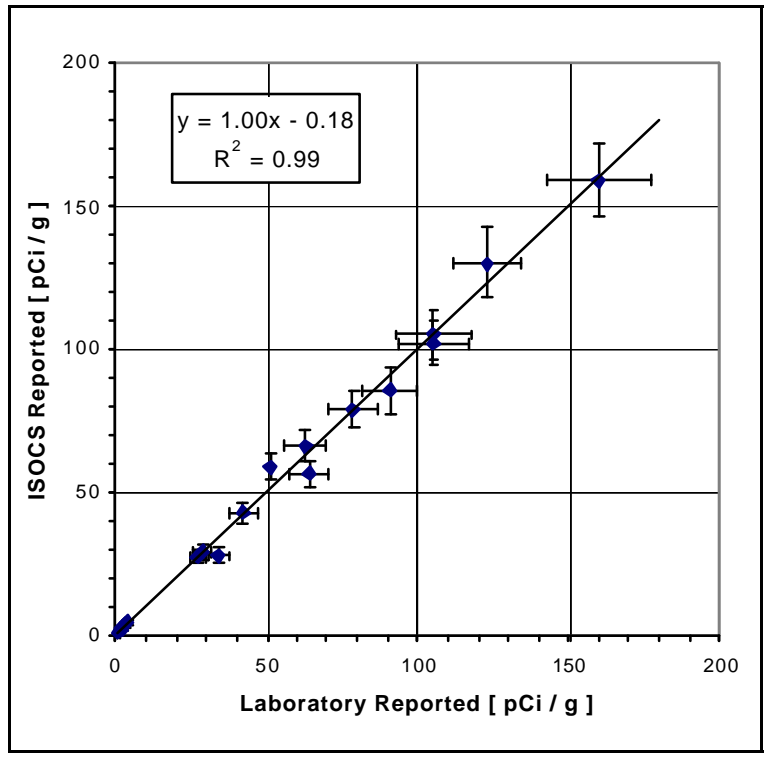

Figure 4-8. Correlation between ISOCS sample and laboratory sample analysis 
The absence of bias reflects the conditioning of the samples before analysis:

- extraneous non-contaminated biomass was separated from the matrix by sieving in the field, so both systems analyzed only soil;

- Samples were surface soil from open fallow fields, collected in early March before spring rains, so moisture content was very low; soil drying at the remote lab did little to alter the mass of the sample from what was analyzed on site; and

- Ball milling by the remote laboratory was effective in homogenizing the soil.

Table 4-6. Precision in Sample Analysis: ISOCS to Laboratory

\begin{tabular}{|c|c|c|c|c|c|}
\hline \multicolumn{5}{|c|}{ Cs-137 Activity Concentration (pCi/g) } \\
\hline \multirow{2}{*}{$\begin{array}{c}\text { Sample } \\
\text { No. }\end{array}$} & \multicolumn{2}{|c|}{ ISOCS } & \multicolumn{2}{c|}{ Remote Lab } & Percent \\
\cline { 2 - 6 } & activity & 2 sigma & activity & 2 sigma & Difference \\
\hline 1 & 0.65 & 0.4 & 0.76 & 0.09 & $-14.5 \%$ \\
\hline 2 & 0.80 & 0.3 & 0.85 & 0.10 & $-5.7 \%$ \\
\hline 3 & 1.8 & 0.3 & 1.73 & 0.23 & $4.0 \%$ \\
\hline 4 & 2.4 & 0.4 & 1.99 & 0.20 & $20.6 \%$ \\
\hline 5 & 3.3 & 0.5 & 2.69 & 0.29 & $22.7 \%$ \\
\hline 6 & 4.5 & 0.6 & 4.01 & 0.41 & $12.2 \%$ \\
\hline 7 & 27.1 & 2.3 & 27.2 & 2.68 & $-0.4 \%$ \\
\hline 8 & 27.6 & 2.8 & 34.0 & 3.30 & $-18.8 \%$ \\
\hline 9 & 28.9 & 2.5 & 28.6 & 3.08 & $1.0 \%$ \\
\hline 10 & 42.8 & 3.6 & 42.1 & 4.70 & $1.7 \%$ \\
\hline 11 & 56.2 & 4.6 & 64.0 & 6.67 & $-12.2 \%$ \\
\hline 12 & 58.6 & 4.8 & 51.3 & 6.08 & $14.2 \%$ \\
\hline 13 & 66.1 & 5.3 & 62.6 & 7.18 & $5.6 \%$ \\
\hline 14 & 78.7 & 6.3 & 78.4 & 8.1 & $0.4 \%$ \\
\hline 15 & 85.3 & 7.9 & 90.8 & 9.3 & $-6.1 \%$ \\
\hline 16 & 102 & 8.1 & 105 & 11.4 & $-2.9 \%$ \\
\hline 17 & 105 & 8.3 & 105 & 12.4 & $0.0 \%$ \\
\hline 18 & 130 & 12.1 & 123 & 11.4 & $5.7 \%$ \\
\hline 19 & 159 & 12.5 & 160 & 17.4 & $-0.6 \%$ \\
\hline 20 & 256 & 19.7 & 317 & 30.8 & $-19.2 \%$ \\
\hline 21 & 307 & 23.7 & 328 & 44.0 & $-6.4 \%$ \\
\hline 22 & 324 & 29.8 & 270 & 26.4 & $20.0 \%$ \\
\hline 23 & 457 & 41.9 & 418 & 39.2 & $9.3 \%$ \\
\hline 24 & 494 & 38.0 & 441 & 47.6 & $11.9 \%$ \\
\hline
\end{tabular}

Comparability of ISOCS Instrument
4.2.2 ISOCS In Situ Analysis vs Laboratory Sample Analysis. An optimum use of the in situ technique is in the evaluation of large areas of surface soil, prior to or following remediation. Because of the field of view and ability to average heterogeneous distributions, the in situ technique provides a rapid, economical alternative to conventional sampling methods. The ASTD project performed a direct comparison of in situ analysis to laboratory analysis to demonstrate comparability.

4.2.2.1 Area Evaluated. A $90 \mathrm{~m}$ by $40 \mathrm{~m}$ irregular area of landscape soil adjacent to the BNL medical facility parking area known to be contaminated with Cs-137 was selected for the comparison. Ten positions were chosen to provide a variety of contamination levels across the range of interest, see Figure 4-9.

4.2.2.2ISOCS Instrument. The analysis was performed by accumulating in situ a gamma radiation spectrum using an ISOCS BEGe detector attached to a computer-based, multi-channel gamma spectroscopy system. The detector, portable cryostat and lead shielding collimators were mounted on the mobile cart support, allowing consistent 1 meter distance and vertical orientation at each position. The detector was configured using $44 \mathrm{~mm}$ lead annular side shields and $180^{\circ}$ field of view, with 5-20 minute accumulation. The gamma spectrum from each position was evaluated using the ISOCS software, modeling the surface as a uniformly-contaminated, circular plane of surface soil, $10 \mathrm{~m}$ diameter and $15 \mathrm{~cm}(6$ in) thick. Results were reported as $\mathrm{pCi} / \mathrm{g}$.

4.2.2.3 Samples for Laboratory Analysis. At each in situ measurement position, soil samples were obtained from four locations: immediately below the ISOCS position and at three equidistant positions 2 meters out, see Figure 410. Each component sample consisted of $1 / 2$ liter of soil from the surface layer $(0-15 \mathrm{~cm})$ which was sieved to remove organic material, rocks and items larger than $6 \mathrm{~mm}$ (1/4 in). The four components were combined, thoroughly mixed together and placed into a 1 liter container for shipment.

Analysis of samples by the analytical laboratory was performed in a low-background shielded cavity, with a HPGe detector attached to a computer-based, multichannel gamma spectroscopy system. Prior to analysis, samples were dried, tumbled with steel shot to homogenize the matrix, and a 150-gram aliquot was sealed in an aluminum/tin can to isolate contaminants and facilitate sample handling during analysis. Results were reported as $\mathrm{pCi} / \mathrm{g}$. 


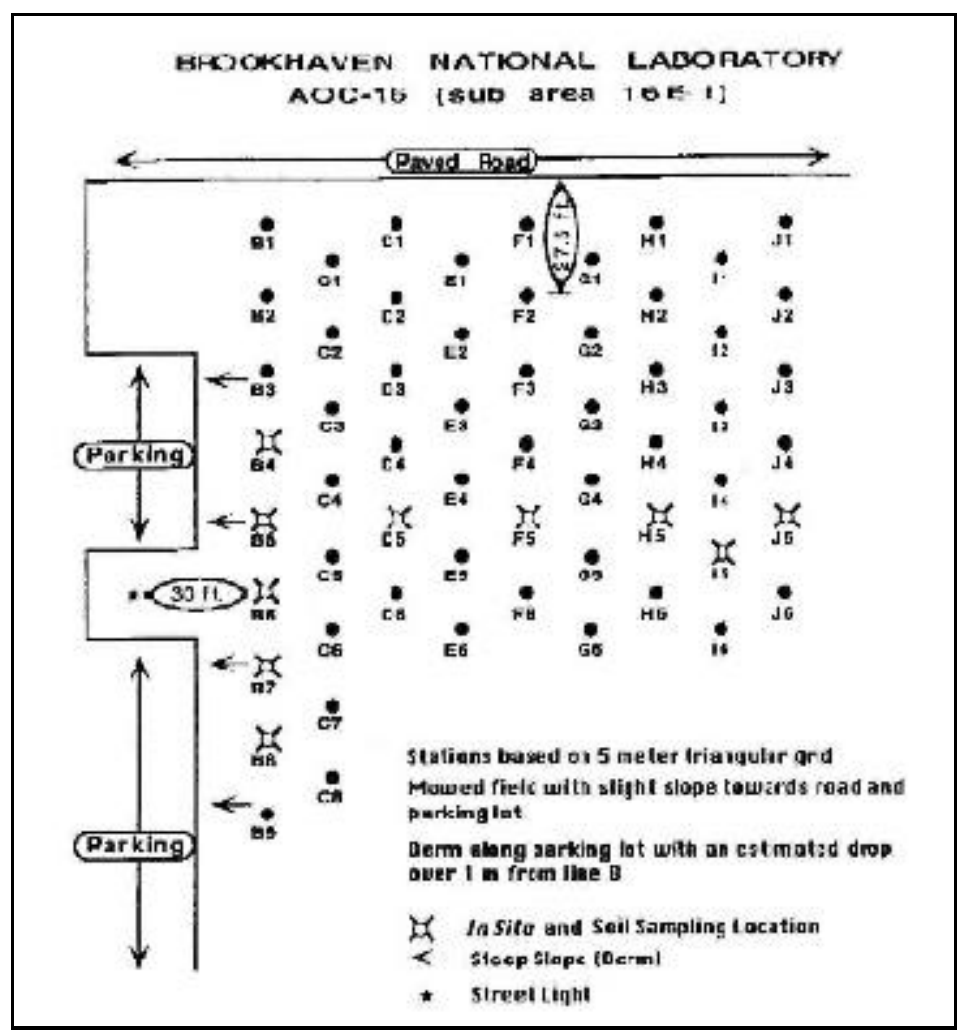

Figure 4-9. Analysis positions for in situ vs laboratory comparability

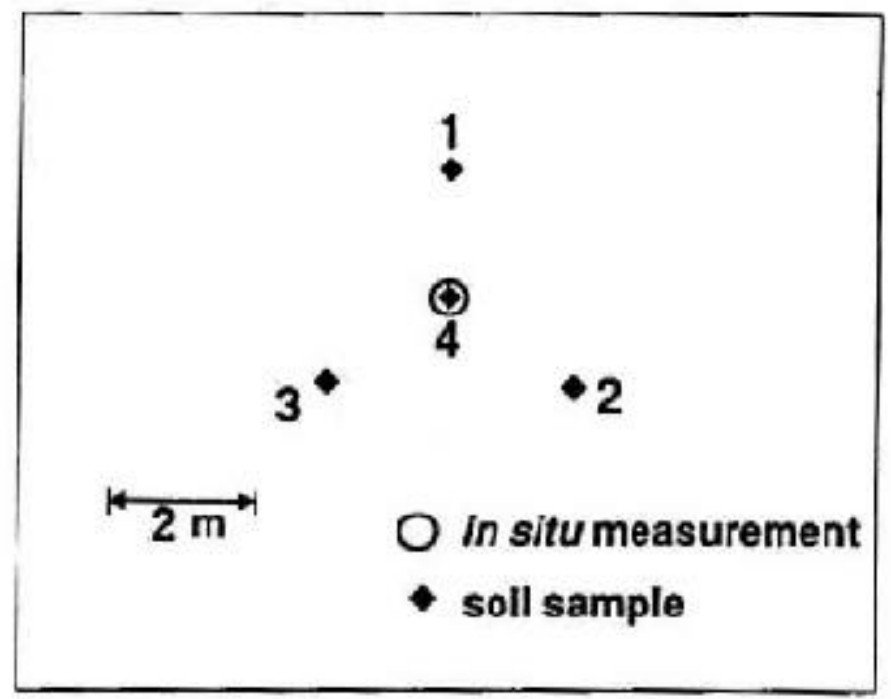

Figure 4-10. Locations of samples for composite at each analysis position 
4.2.2. Results. A plot of the ISOCS results versus the laboratory results is provided in Figure 4-11. The only contaminant observed was Cs-137.

4.2.2.5Discussion. In situ measurements with the ISOCS instrument were generally lower than the results reported by the laboratory. Indicated on the graph of Figure 4-11 is the least-squares linear regression line with slope 0.70 and correlation coefficient of 0.98 . The regression indicates that the ISOCS result is $70 \%$ of the laboratory reported result, with a very strong correlation $\left(\mathrm{R}^{2}=0.98\right.$ . 1.0 ) reflecting little non-random error. The low response bias of the ISOCS instrument can be partially explained by considering the following points that apply to any in situ measurement:

a. The in situ result is for as found soil, which contains a non-uniform moisture content, while the laboratory sample is dried before analysis. The uncontaminated moisture adds mass to the in situ soil that decreases the reported activity per gram. For a typical range of soil moisture of 5-15\%, the in situ result would be $5-18 \%$ lower than the concentration reported by the laboratory. b. The in situ result is for as found soil, which contains a non-uniform distribution of uncontaminated rocks and organic material. This material is removed from the sample before laboratory analysis. The uncontaminated material adds mass to the in situ soil that decreases the reported activity per gram. For a typical range of non-soil components of 10-20\%, the in situ result would be 11-25\% lower than the concentration reported by the laboratory.

4.2.2.6Conclusions. The ISOCS in situ analysis provides an analytical process that yields interpreted results rapidly to support remediation decisions. The in situ analysis is correlated directly to sampling and remote laboratory analysis. The in situ results are biased low, due to inclusion of moisture, rocks, and biomass that is removed prior to laboratory analysis. The linear regression correlation provides a numerical coefficient that allows a prediction of laboratory results from the in situ results. This coefficient can be used to adjust in situ field data to be comparable to data that would result from conventional laboratory analysis. While the in situ measurement more accurately reflects activity concentrations as they exist in the field, prior reliance on and acceptance of the laboratory value may predicate adjustment of in situ data.

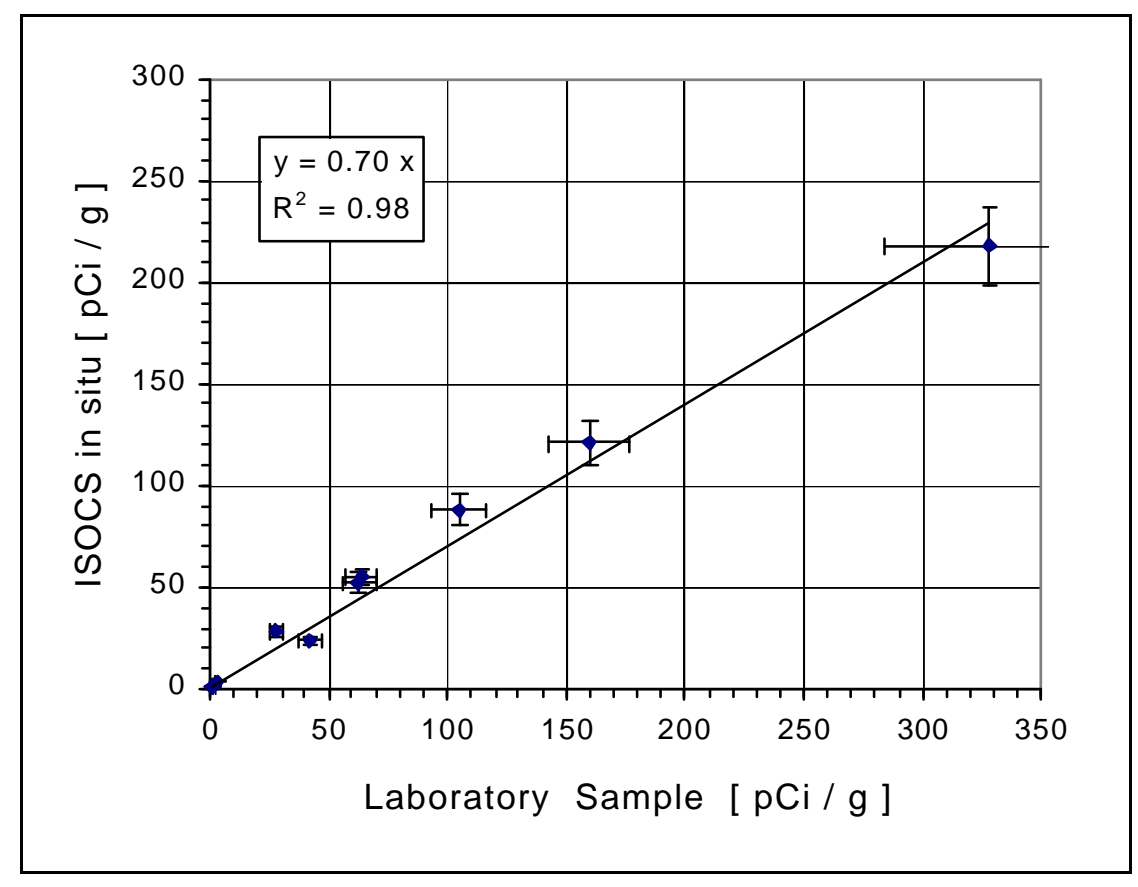

Figure 4-11. Correlation between ISOCS in situ and laboratory sample analysis 


\subsection{ANALYSIS OF DISTINCTIVE OBJECTS NOT EASILY EVALUATED BY CONVENTIONAL METHODS}

One of the strengths of the ISOCS mathematical calibration and geometry templates is the capability to quantify objects of all shapes and sizes, without the expense of designing, fabricating and disposing calibration standards in the same geometry and matrix. This capability is demonstrated in the following discussion of analyses performed on distinctive objects during the D\&D of the BGRR.

\subsection{BGRR Fan House Fans}

A typical ISOCS application can be illustrated by reviewing the characterization of core-cooling exhaust fans, prior to their removal, volume reduction, and shipment from the site. Each fan is a massive squirrelcage type blower, nominally $8 \mathrm{ft}$ x $10 \mathrm{ft}$ x $12 \mathrm{ft}$, and 14,000 lbs. The fans became internally contaminated, likely as a result of fuel element failure, but the identity, extent, and quantity of radioactive material in the fan internals were unknown. External surveys revealed non-uniform internal deposition with highest readings in the vicinity of the fan volutes, where entrained dust particles would have had a higher probability of settling out due to eddies and dead spaces in air flow currents. Three of the five fans had been upgraded/replaced during the operating life of the reactor. Thus, physical configurations, dimensions, and radionuclide quantities were different from those in the other two fans.

The ISOCS was mobilized to the Fan House containing the five contaminated fans and in situ gamma spectra were acquired from Fan \#5 (representative of Fans \#5 and 4) and Fan \#3 (representative of Fans \#3, 2, and 1). Figure 5-1 is a photograph of the ISOCS deployed at the BGRR Fan House. Each fan housing was scanned using $44 \mathrm{~mm}$ annular shields and $90 \mathrm{E}$ field of view collimators to reduce interference as much as possible from adjacent contaminated structures. Because of the equipment layout, there was no position where gamma spectra could be acquired without structural components (concrete supports and carbon steel struts) shielding a portion of the field of view.

The ISOCS cart was positioned so that the detector was oriented diagonally downwards at the fan housing volute bottom, where surveys indicated an accumulation of radioactivity. Spectra were accumulated for 15 minutes each from two symmetric positions: NE of the housing facing SW and NW of the housing facing SE. Equipment setup, spectrum acquisition and equipment-breakdown required less than two hours, with only minimal health and safety oversight and without breaching of contamination containment barriers.

Radioactivity in the fan housing was modeled as a layer of surface dust, uniformly covering the interior of the carbon steel fan volute (horizontal or diagonal rectangular plane). Due to the complex geometry with intervening structural members, several alternative geometry models were defined. The intervening structural members were adjusted in the models until the results from the symmetric scans were similar. The modeling and analysis of both fans required about six hours.

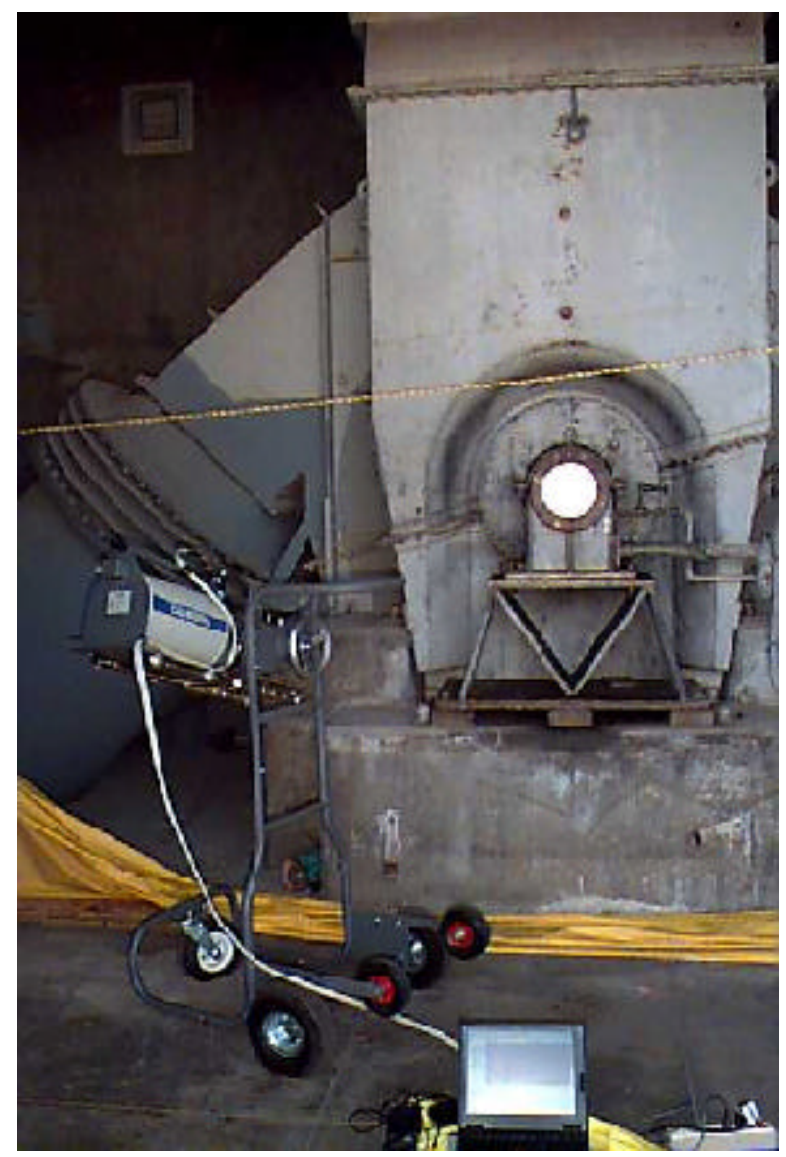

Figure 5-1. In situ measurement of Fan No. 3 
Table 5-1. Results of In Situ Measurements at BGRR Fan House

\begin{tabular}{|c|c|c|c|c|}
\hline \multirow{3}{*}{ Fan Unit } & \multicolumn{4}{|c|}{ Measured Activity, $\mu \mathrm{Ci}$} \\
\hline & \multicolumn{2}{|c|}{ Cs-137 } & \multirow{2}{*}{ Co-60 } & \multirow{2}{*}{ Am-241 } \\
\hline & low estimate & high estimate & & \\
\hline Fan No 5 & $75 \pm 3$ & $600 \pm 20$ & \#0.1 & \#180 \\
\hline Fan No 3 & $114 \pm 10$ & $330 \pm 30$ & $4.8 \pm 0.5$ & \#800 \\
\hline
\end{tabular}

Note: The uncertainties in the table represent \pm 2 s counting error; values expressed as "\#'represent an estimate of the bound on the activity and indicate that the radionuclide was not detected.

The results of the analysis are provided in Table 5-1. The range in the value is representative of the uncertainty in the analysis, and is primarily associated with assumptions on unobserved inner structures of the fan.

The results in Table 5-1 demonstrates that even when using a BEGe detector with enhanced low-energy response, the detection level can still be high when the source is shielded by a highly attenuating medium such as this example, inside a carbon steel fan housing. With the use of the ISOCS modeling software, a quantitative estimate of the activity in the fan was provided in approximately eight hours, without fabricating a physical radioisotope calibration standard, without breaching contaminated barriers, and without handling and transporting contaminated samples.

\subsection{Graphite Pile Internals}

A complex in situ analysis application involved the characterization of the BGRR graphite pile internals to support the determination of pile disposition. The characterization data was also needed for planning radioactive, hazardous, and mixed waste disposal, assessing potential health and safety hazards during stabilization D\&D work, determining ALARA controls, and accurately scheduling the work. The analysis of experimental port penetrations illustrates the use of the ISOCS instrument in this survey, as well as some of the strengths and limitations of the application.

The pile is a 25 -ft cube of refined graphite surrounded on all sides by a five-foot-thick, high-density concrete biological shield. Between the shield and pile are air gaps to allow the flow of cooling air. The interior of the biological shield is faced with steel plates, 6 inches thick, providing structural support and thermal shielding, protecting the concrete from excessive dehydration due to the heat from the core and air. The graphite pile was de-fueled in 1968, with the final fuel shipment being made in 1972.

Access to the pile internals for collecting characterization data was through the penetration openings that exist on each face of the pile biological shield wall. The east and west faces are penetrated horizontally at 30 positions by 4.5-inch square ports for experimental access to the pile interior. Figure 5-2 is a view of the West face of the reactor, the location of several experimental ports visible by the dark, round port covers.

In situ experimental port measurements were performed by aiming the detector, aligned with and centered on the centerline of the experimental port, at each port opening located on the West face of the pile. The steel port covers and plugs were removed prior to each measurement, to minimize structural absorption of gamma rays along the analysis pathway. The resulting exposure condition was analogous to a 4.5-inch diameter borehole through the concrete shielding into the pile interior. Figure 5-3 is a photograph of an Experimental Port on the West Face (No. W-54) with the ISOCS instrument in place for spectrum acquisition. 


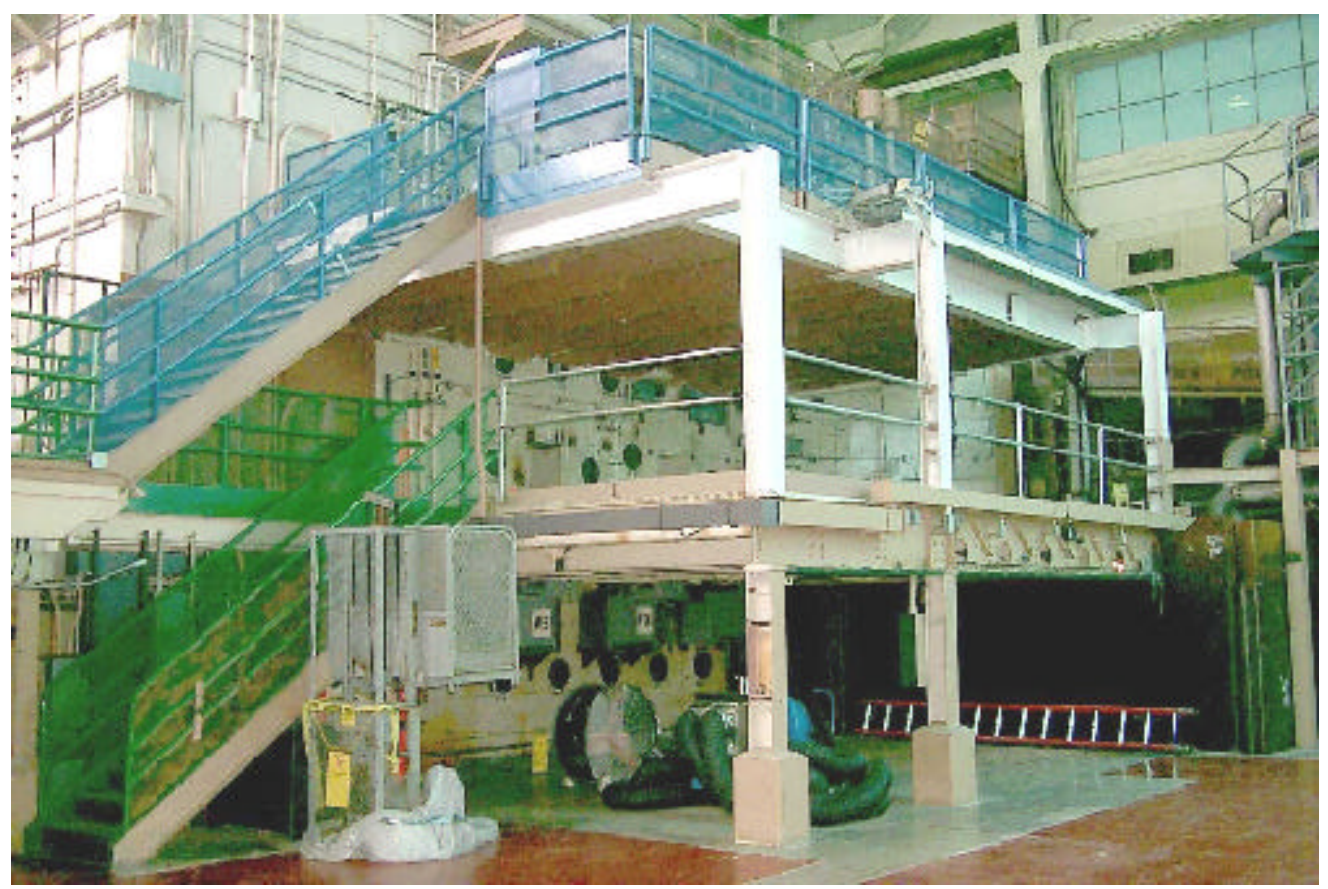

Figure 5-2. West face of the BGRR showing access to experimental port locations

Physical restrictions near the pile face precluded the optimal geometry of a single, reproducible distance from the face at all ports. The in situ measurements were performed in conjunction with physical sampling and radiological surveys of the ports, so that radiological controls were in force during the spectrum acquisition. Instrument surveys along the experimental ports indicated maximum exposure rates at the position of the steel plate on the inside face of the biological shield.

The complex geometry of the spectrum acquisition necessitated several simplifying assumptions of the components scanned. The ISOCS geometry template method allowed the assumptions to be logically defined and consistently applied.

Assumptions concerning the geometry model included:

- The use of the thick, dense steel source and the intervening dense concrete absorber in the model causes an individual ISOCS efficiency calculation to take an extended amount of computer processing time, up to 200 minutes or more. Although the physical source resembles a slice of Swiss cheese (a $25 \mathrm{ft} \times 25 \mathrm{ft} \times 6$ inch slab with 30 , 4.5 inch holes), the source "seen" by the BEGe

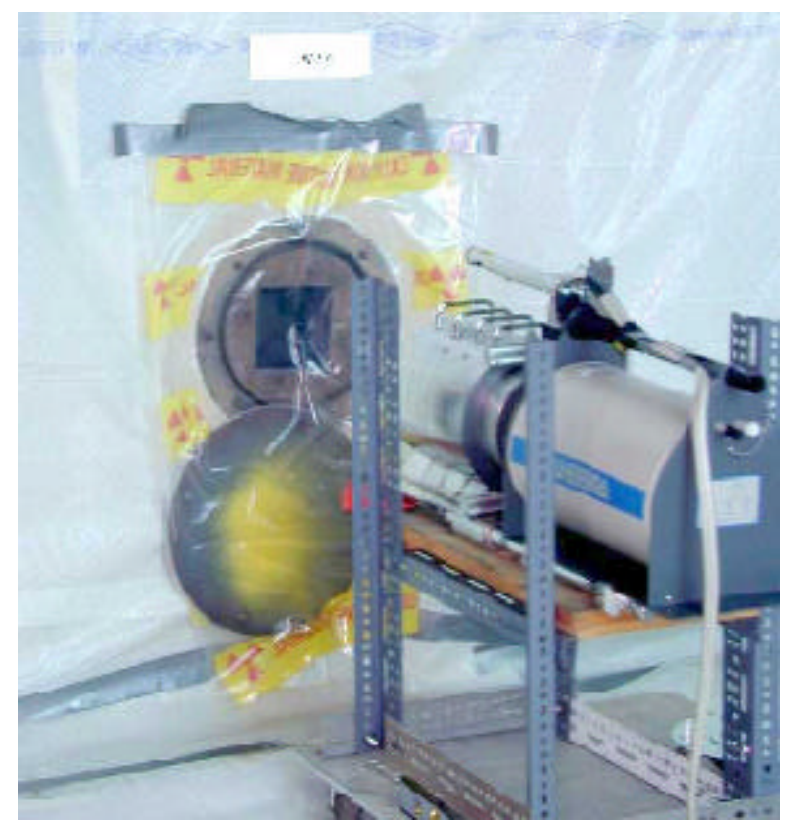

Figure 5-3. In situ measurement of pile internals at Experimental Port No W-54. 
detector in a scan through an individual port is much less. As discussed in sections 4.1.1 and 4.1.2 above, there are "effective" source dimensions, based on source parameters and FOV collimators; greater dimensions contribute to the "exact" mathematical calculation, but contribute little to the effective activity measurement. Several alternative models of the geometry were performed to establish the "effective" source dimensions in order to reduce the analysis time for individual evaluations.

- The source activity was modeled as an activated, annular, carbon steel ring or pipe, with "effective" dimensions of an inside diameter of 4.5 inches (11.5 $\mathrm{cm})$, a wall thickness of 2 inches $(5.08 \mathrm{~cm})$, and a length into the pile of 6 inches $(15.24 \mathrm{~cm})$. The steel ring is positioned at the end of the experimental port, 6 feet $(183 \mathrm{~cm})$ into the shield and flush to the concrete shielding around the port.

- The model assumes a homogenous distribution of activity throughout the steel source. Activity was calculated as concentration ( $\mathrm{pCi} / \mathrm{g}$ ) in the steel to enable extrapolation to the total activity in the entire steel liner.

- The intervening concrete biological shielding around the port was modeled as an external field of view collimator, 4.5 inches inner diameter, 9 inches $(23 \mathrm{~cm})$ outer diameter, and 6 feet $(183 \mathrm{~cm})$ in length. The ISOCS software allows the definition of external collimators, as well as two external absorbing layers.

The use of the "effective" dimensions for the steel source and the concrete collimator/absorber in the model reduced the individual ISOCS efficiency calculation times to between 20 and 40 minutes. Different acquisition distances necessitated individual efficiency calculations for each port evaluation. The initial evaluation of several alternative models of the geometry to establish the "effective" dimensions required 10-12 hours - 10-15 minutes of set-up time and 1.0-1.5 hours of computer run time per alternative. The modeling and analysis for 12 experimental ports averaged approximately 3 hours per port. Typical results of the analysis are illustrated in Table 5-2.

Table 5-2. In situ Analysis at West Face of BGRR Graphite Pile Gamma Spectrum Analysis with the ISOCS Instrument

\begin{tabular}{|c|c|c|c|c|}
\hline Experimental Port & $\mathrm{W}-51$ & $\mathrm{~W}-54$ & $\mathrm{~W}-56$ & $\mathrm{~W}-30$ \\
\hline ASTD Sample No & IG01231 & IG01233 & IG01229 & IG01220 \\
\hline Radionuclide & \multicolumn{4}{|c|}{ Activity Concentration $(\mathrm{pCi} / \mathrm{g}) \quad$ note 1} \\
\hline Am-241 & $\begin{array}{c}\mathrm{ND} \\
{[185,000]}\end{array}$ & $\begin{array}{c}\mathrm{ND} \\
{[222,000]}\end{array}$ & $\begin{array}{c}\text { ND } \\
{[189,000]}\end{array}$ & $\begin{array}{l}243,000 \pm 226,000 \\
{[370,000] \quad \text { note } 2}\end{array}$ \\
\hline Cs-137 & $\begin{array}{c}\mathrm{ND} \\
{[6,800]}\end{array}$ & $\begin{array}{c}\mathrm{ND} \\
{[7,200]}\end{array}$ & $\begin{array}{c}\mathrm{ND} \\
{[7,200]}\end{array}$ & $\begin{array}{l}1,200,000 \pm 104,000 \\
{[20,500] \quad \text { note } 2}\end{array}$ \\
\hline Co-60 & $\begin{array}{c}306,000 \pm 12,500 \\
{[3,650]}\end{array}$ & $\begin{array}{c}413,000 \pm 16,700 \\
{[4,300]}\end{array}$ & $\begin{array}{c}346,000 \pm 14,200 \\
{[4,200]}\end{array}$ & $\begin{array}{c}960,000 \pm 38,000 \\
{[7,650]}\end{array}$ \\
\hline Eu-152 & $\begin{array}{c}261,000 \pm 10,400 \\
{[8,400]}\end{array}$ & $\begin{array}{c}316,000 \pm 12,600 \\
{[9,300]}\end{array}$ & $\begin{array}{c}221,000 \pm 10,200 \\
{[7,020]}\end{array}$ & $\begin{array}{c}153,000 \pm 11,500 \\
{[11,100]}\end{array}$ \\
\hline Eu-154 & $\begin{array}{c}68,100 \pm 4,700 \\
{[8,800]} \\
\end{array}$ & $\begin{array}{c}108,600 \pm 6,600 \\
{[12,800]} \\
\end{array}$ & $\begin{array}{c}69,400 \pm 5,000 \\
{[8,400]} \\
\end{array}$ & $\begin{array}{c}30,300 \pm 17,500 \\
{[39,200]} \\
\end{array}$ \\
\hline
\end{tabular}

Notes: ND = Not Detected

[ $]=$ Minimum Detectable Concentration in $\mathrm{pCi} / \mathrm{g}$

1. Uncertainties reported in the table are counting errors (1.96s); additional uncertainties due to volume, mass, and density estimates could be approximately $\pm 50 \%$ and should be added to the results shown.

2. Am-241 and Cs-137 activity on Port W-30 is more probably surface contamination than volume activation, as indicated in the table. 
The results in Table 5-2 provide the measured activity for Ports W-51, W-54 and W-56, experimental ports that are vertically 8 feet $(250 \mathrm{~cm})$ above the pile centerline, and that run West to East from 8 feet South (No W-51) to 8 Feet North (No W-56) of the centerline. The relative locations of these experimental ports are illustrated in Figure 5-4. The radionuclides identified in the measurements are those expected in activated steel. Comparing the activities for Port W-51 and W-56, it is seen that the concentrations are symmetrical about the centerline. Note that the high detector response, due to the presence of large amounts of Co-60, has elevated the minimum detectable concentration of the low-energy radionuclide Am-241. This is due to scattered Co-60 gammas increasing the Compton continuum in the energy range of the $59.5 \mathrm{keV}$ Am-241 gamma.

For Port W-30 which passes through the pile center, the results identify additional radionuclides and different activity ratios among the radionuclides. Historical operations and survey data indicated the presence of radioactive contamination in the Port infiltrated from failed fuel events in adjacent fuel channels. The analysis modeled the Cs-137 and Am-241 in the gamma spectrum as a volume activated source. To interpret the observed spectrum as surface activity would require that a different model be analyzed, with judgement applied to determine which portion of the spectrum belongs to which of the interpreted geometries. Since alternative methods were available to directly measure the removable contamination through a surface wipe, this effort was not considered necessary.

In situ analysis enabled the rapid evaluation of portions of the graphite pile and its internal components, without the expense and effort of core boring or dismantling the contaminated and activated pile. The modeling computation routine developed quantified estimates of internal activation. There were some ambiguities in the results, due to inconsistencies between the assumptions of the distribution of radionuclides and their physical location on or in the pile internal components.

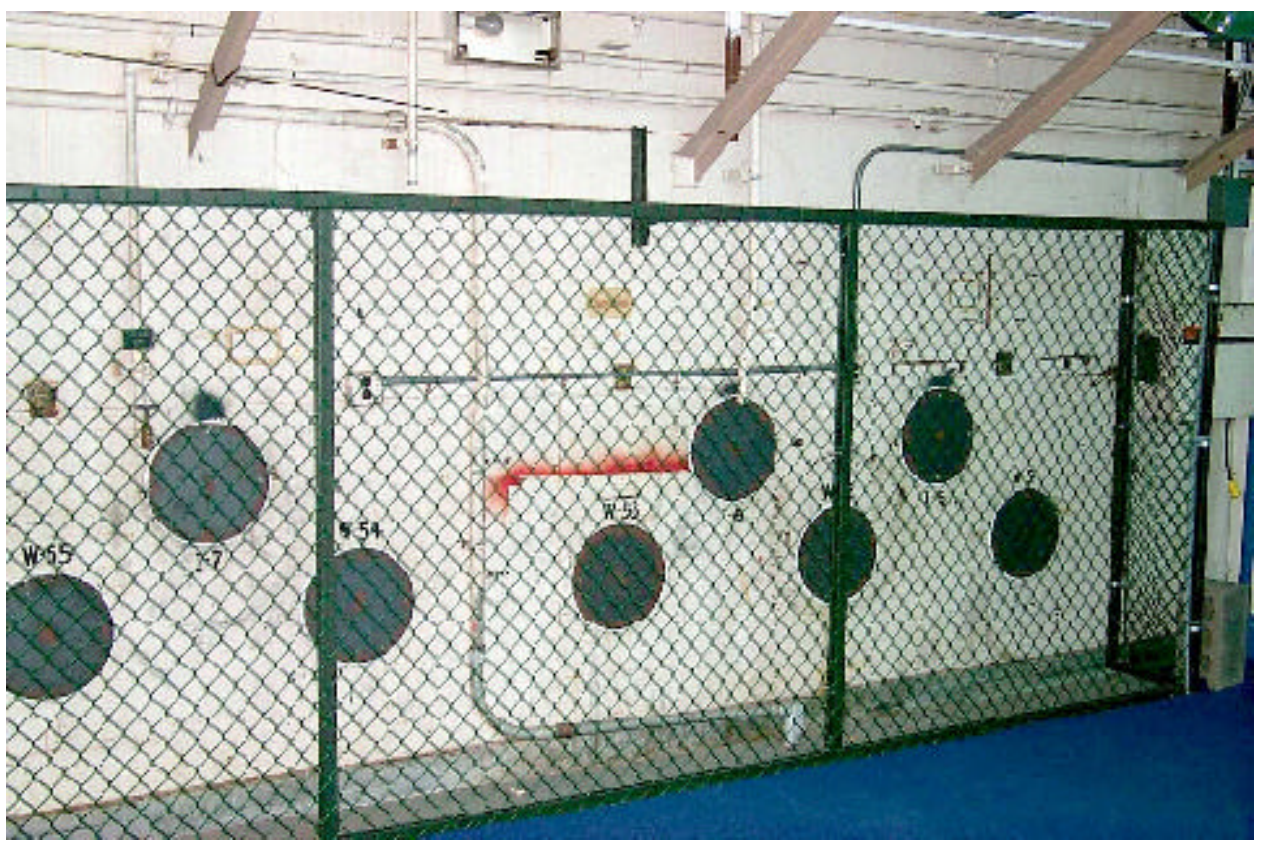

Figure 5-4. Relative location of Experimental Ports 51-55, west face of BGRR 


\subsection{COST COMPARISON OF ISOCS AND BASELINE CHARACTERIZATION TECHNOLOGIES}

This section provides a basis for comparing relative costs of the In Situ Object Counting System (ISOCS) deployed for characterizing gamma emitting radionuclides at the BNL BGRR with the conventional baseline approach of taking discrete physical samples for off-site analyses.

\subsection{Categorization for Cost Comparison}

Since the ISOCS system was deployed in numerous configurations and varying locations at BNL under this ASTD project, the cost analysis has been broken down into several broad categories to facilitate comparison.

- The first distinction for examining the cost breakdown is in situ vs. ex situ. The ISOCS system is well suited to conduct both in situ measurements of objects and areas requiring characterization and ex situ measurements of discrete samples when configured as an analytical field laboratory. Ex situ samples were further categorized as either soil or debris, sludge, and miscellaneous materials.

- The next distinction relates to the surface area being analyzed. In situ measurements were conducted on large areas (e.g., walls, floors, soil) and smaller unique samples (e.g., concrete cores, reactor components).

- The third and final category is related to the radiological conditions in which the samples were taken, i.e., whether the workers would be required to enter a radiologically controlled area in order to obtain the samples for analysis. One of the major advantages of the ISOCS system is the ability to conduct scans remotely, thus often avoiding the need to enter radiologically controlled areas. This reduces radiological exposure to workers, reduces cost, and reduces the time required to gather the analytical data. However, ISOCS analyses that would have required entry into radiologically controlled areas are identified to facilitate cost comparison with the baseline approach.

The ten general categories used for this cost comparison are summarized in Table 6-1.

All 920 of the ex situ samples analyzed for this deployment are summarized in Table A-1 of Appendix A. Of the total, 815 ex situ samples analyzed were soil and 105 were sludge, debris, or other materials. A total of 352 in situ measurements were conducted and are
Table 6-1. General Categories for BGRR ISOCS Characterization

\begin{tabular}{|c|l|}
\hline & Description of Characterization Category \\
\hline 1 & Ex Situ Sample Analysis of Soil \\
\hline 2 & $\begin{array}{l}\text { Ex Situ Sample Analysis of Debris, Sludge, and } \\
\text { Miscellaneous Samples }\end{array}$ \\
\hline 3 & $\begin{array}{l}\text { In Situ Analysis of Large Uniform Areas } \\
\text { (entry into Radiologically Controlled Area } \\
\text { required for conventional sampling) }\end{array}$ \\
\hline 4 & $\begin{array}{l}\text { In Situ Analysis of Large Uniform Areas } \\
\text { (no entry into Radiologically Controlled Area } \\
\text { required for conventional sampling) }\end{array}$ \\
\hline 5 & $\begin{array}{l}\text { In Situ Analysis of Small Uniform Areas } \\
\text { (entry into Radiologically Controlled Area } \\
\text { required for conventional sampling) }\end{array}$ \\
\hline 6 & $\begin{array}{l}\text { In Situ Analysis of Small Uniform Areas } \\
\text { (no entry into Radiologically Controlled Area } \\
\text { required for conventional sampling) }\end{array}$ \\
\hline 7 & $\begin{array}{l}\text { In Situ Analysis of Large Heterogeneous Solid } \\
\text { (entry into Radiologically Controlled Area } \\
\text { required for conventional sampling) }\end{array}$ \\
\hline 8 & $\begin{array}{l}\text { In Situ Analysis of Large Heterogeneous Solid } \\
\text { (no entry into Radiologically Controlled Area } \\
\text { required for conventional sampling) }\end{array}$ \\
\hline 9 & $\begin{array}{l}\text { In Situ Analysis of Small Heterogeneous Solid } \\
\text { (entry into Radiologically Controlled Area } \\
\text { required for conventional sampling) }\end{array}$ \\
\hline 10 & $\begin{array}{l}\text { In Situ Analysis of Small Heterogeneous Solid } \\
\text { required for conventional sampling) }\end{array}$ \\
\hline
\end{tabular}

summarized in Table A-2 of Appendix A, where they are further identified in terms of the categories described above. A total of 215 separate in situ scans were taken in which entry into radiologically controlled areas would have been required using the conventional baseline approach, and a total of 137 scans were taken in areas that would not require radiological controls for removal of characterization samples.

When comparing ISOCS with conventional analyses it is important to note that a single ISOCS measurement is not 
necessarily equivalent to just one conventional analysis, so that a simple one-to-one comparison of ISOCS in situ measurements with conventional baseline samples is overly conservative. For example, a single in situ ISOCS measurement can potentially evaluate an area up to several square meters. In the case of heterogeneously contaminated solids, one ISOCS scan can provide an accurate report of average concentration values, whereas, numerous samples would be needed to derive a similar average value using the baseline approach. Thus, the overall savings associated with ISOCS is based on fewer samples to gather, prepare, ship, analyze, and evaluate.

In order to bracket a range of potential cost savings for this comparison, in situ measurements were categorized in terms of the approximate number of equivalent baseline analyses they potentially represent. In situ scans of large areas and objects were assumed to be equivalent to ten conventional samples and smaller areas and objects were assumed to be equivalent to five conventional samples.

Using this approach, 1760 baseline samples would be necessary to provide equivalent characterization data for samples in radiologically controlled areas and 1360 baseline samples in non-radiologically controlled areas. These represent the maximum estimated cost savings resulting from in situ characterization. Minimum cost savings are determined based on a 1:1 ratio for comparing baseline and in situ characterization analyses, i.e., 215 samples for radiologically controlled areas and 137 samples for non-radiologically controlled areas.

\subsection{Methodology}

Cost estimates were developed by preparing work breakdown structures (WBS) for in situ measurements and equivalent baseline measurements in a manner similar to the cost analysis prepared following the technology demonstration of the ISOCS at the Chicago Pile 5 Research Reactor [ref 15]. In situ sampling categories were grouped according to whether or not the work required sampling within radiologically controlled areas. The resulting WBS data sheets for the scenarios evaluated are identified in Table 6-2. The actual data tables are provided in Appendix $\mathrm{C}$ as Tables $\mathrm{C}-1$ through C-10.

Estimates for the times required to conduct ISOCS measurements were based on actual deployment experience at the BNL BGRR. Times required to conduct the baseline activities were based on engineering estimates and information in the literature. Certain costs (e.g., capital equipment for innovative or baseline technologies, institutional overhead costs, training,
Table 6-2. Identification of Cost Comparison Scenario Data Tables

\begin{tabular}{|l|c|}
\hline $\begin{array}{l}\text { Work Breakdown Structure Categories } \\
\text { for Cost Comparison }\end{array}$ & $\begin{array}{c}\text { Table } \\
\text { Number }\end{array}$ \\
\hline $\begin{array}{l}\text { Baseline Ex Situ Sampling and Analyses } \\
\text { Soil Samples }\end{array}$ & C-1 \\
\hline $\begin{array}{l}\text { ISOCS Ex Situ Sampling and Analyses } \\
\text { Soil Samples }\end{array}$ & C-2 \\
\hline $\begin{array}{l}\text { Baseline Ex Situ Sampling and Analyses } \\
\text { Debris, Sludge, Misc. Samples }\end{array}$ & C-3 \\
\hline $\begin{array}{l}\text { ISOCS Ex Situ Sampling and Analyses } \\
\text { Debris, Sludge, and Misc. Samples }\end{array}$ & C-4 \\
\hline $\begin{array}{l}\text { Baseline Sampling and Analyses in place } \\
\text { of In Situ ISOCS for All Radiologically } \\
\text { Controlled Areas } \\
\text { (Maximum Cost Savings Assumptions) }\end{array}$ & C-5 \\
\hline $\begin{array}{l}\text { Baseline Sampling and Analyses in place } \\
\text { of In Situ ISOCS for All Radiologically } \\
\text { Controlled Areas } \\
\text { (Minimum Cost Savings Assumptions) }\end{array}$ & C-6 \\
\hline $\begin{array}{l}\text { In Situ ISOCS Sampling and Analyses of } \\
\text { All Radiologically Controlled Areas }\end{array}$ & C-7 \\
\hline $\begin{array}{l}\text { Baseline Sampling and Analyses in place } \\
\text { of In Situ ISOCS for all Non- } \\
\text { Radiologically Controlled Areas } \\
\text { (Maximum Cost Savings Assumptions) }\end{array}$ \\
\hline $\begin{array}{l}\text { Baseline Sampling and Analyses in place } \\
\text { of In Situ ISOCS for all Non- } \\
\text { Radiologically Controlled Areas } \\
\text { (Minimum Cost Savings Assumptions) }\end{array}$ \\
\hline $\begin{array}{l}\text { In Situ ISOCS Sampling and Analyses of } \\
\text { All Non-Radiologically Controlled Areas }\end{array}$ & C-9 \\
\hline
\end{tabular}

Note: Individual Cost data tables are provided in Appendix $\mathrm{C}$ of this report.

project management) were not included to simplify the comparison and to facilitate comparison at other sites. It was assumed that these types of costs would be incurred regardless of the approach used and would be quickly amortized through future deployments.

Work conducted in radiologically controlled areas requires the use of personal protective equipment (PPE) with associated loss in productivity which is estimated by the Productivity Loss Factor (PLF). This factor is an 
historically based estimate of the non-productive portion of the work day due to PPE changes, work rules based on As Low As Reasonably Achievable (ALARA) considerations, additional work breaks, etc. According to methodology developed by the Atomic Industrial Forum, tasks that are conducted within radiologically controlled areas are adjusted by a loss factor of 1.27 , the product of factors of 1.15 to account for PPE and 1.10 to account for adjusted work-rest cycles [ref 16]. The additional costs associated with losses in productivity are calculated as the product of the amount of time required in radiologically controlled areas and the PLF. Other specific assumptions for each cost evaluation are provided as footnotes to the data tables.

\subsection{Actual ASTD Project Costs}

In order to evaluate the cost effectiveness of this deployment, project costs for completion of this two year ASTD project are presented in the following sections and summarized in Table 6-3. Many of the costs are one-time expenses, and others are unrelated to the cost of deploying ISOCS and thus are not considered in this analysis. A more rigorous Life Cycle Analysis to determine amortization of these expenses was not conducted. The costs presented here are actual costs, including all overhead burdens.

6.3.1 Capital and Other One-Time Costs. The ISOCS unit deployed at BNL was purchased for a cost of \$ 148,800 . Other one-time costs included training and consulting for initial unique characterizations. On-site training of BNL staff and specialized consulting provided by Canberra for implementation of the system cost $\$ 27,000$. Maintenance/service contract support cost of $\$ 10,694$ is a recurring expense and thus is not discounted.

6.3.2 Project Costs Unrelated to ISOCS Deployment. This ASTD project included support for other activities related to in situ characterization, but not directly related to deployment of the ISOCS technology at BNL. These included support to project collaborators including $\$ 150,000$ to DOE EML for participation on MARSSIM implementation and $\$ 55,000$ to Bechtel Hanford to assist in secondary deployment activities. Support for deployment of BetaScint, a fiber optic sensor for near real-time analysis of Sr-90 was also part of the ASTD budget. Purchase of the BetaScint hardware cost $\$ 87,500$ with an additional $\$ 30,200$ for training and on-site demonstration. An estimated $\$ 120,000$ in BNL labor and support was devoted to the BetaScint activities. Travel costs were discounted since they were programmatic in nature. The cost of travel to support presentations at meetings, symposiums, mid-year review, etc. totaled $\$ 64,000$ for the life of the two year project. Likewise, project management costs are not technology-specific and are required for either innovative or baseline characterization. Thus, the total available for the ISOCS deployment was $\$ 806,300$. When one-time capital equipment costs are subtracted out, a total of $\$ 631,300$ remains available for routine characterization of the facility, so that a more direct comparison with the baseline analytical approach is possible.

\subsection{Results and Conclusions}

This cost comparison quantifies relative costs for ISOCS and baseline sampling/analysis at BNL's BGRR Decommissioning Project and related activities. Actual costs for baseline analyses are highly dependent on sitespecific conditions and the types of analyses that are required. In order to make reasonable comparisons with the conventional baseline approach and establish a range of potential cost savings, assumptions were made about the number of baseline analyses that would be displaced. While there is considerable uncertainty in projecting the number of baseline samples equivalent to in situ characterization scans, this approach serves to bracket potential cost savings in terms of minimum and maximum levels. A summary of the cost comparison is presented in Table 6-3 and graphically in Figures 6-1 and 6-2. Based on the assumptions described above, the relative cost of ISOCS characterization at BNL was $\$ 81,769$. Corresponding relative costs for baseline sampling/analysis ranged from a minimum of $\$ 292,065$ to a maximum of $\$ 1,074,976$. Discounting ASTD project investment costs, the resulting net cost savings of $\$ 210,296$ to $\$ 993,207$ represents savings ranging from $72 \%$ to $92 \%$ over the cost of the baseline technology. If the total ASTD project costs outlined in Table 6-3 are included, the cost comparisons range from $-\$ 339,235$ (loss) to $+\$ 443,676$ (savings). Average cost per sample for ISOCS characterization was $\$ 76$ compared with $\$ 252$ for baseline characterization.

While both the cost per sample and overall costs are significantly lower using ISOCS in situ and field laboratory characterization, perhaps the greatest cost savings associated with this innovative technology are "hidden" savings that are more difficult to quantify. These include savings associated with project schedule acceleration, the ability to characterize non-standard systems, and improved health and safety for D\&D 
workers. Many engineering decisions during D\&D operations are dependent on radiological characterization of facilities and waste generated. For example, excavation of contaminated soils below the Pile Fan Sump and contaminated BNL Landscape Soils were greatly accelerated by the availability of near real-time analyses. Rapid analytical turn-around enabled project engineers to quickly determine when targeted clean-up levels were reached so that equipment and personnel could be efficiently staged. Net cost savings resulted from accelerated completion of the activities and minimization of non-productive use of resources. In addition, non-standard equipment and facilities were readily characterized using ISOCS, where no comparable technique was available using the baseline approach. For example, the large fan motors and plenums which contained inaccessible areas of contamination were evaluated through external in situ ISOCS scans and related modeling. Finally, numerous characterization activities of areas with significant levels of contamination were successfully completed without the necessity of extracting manual sub-samples, thereby avoiding radiological exposure to workers.
Both the documented cost savings and anticipated "hidden" cost savings demonstrated during this ASTD project were implemented over the course of about 1.5 years. Based on this success, use of ISOCS characterization has been integrated into the on-going D\&D and environmental restoration activities at BNL and will continue to generate additional cost savings as these projects progress towards completion. For example, BNL's Environmental Restoration Division has successfully deployed ISOCS for final status surveys of the excavation of contaminated Landscape Soils. BGRR continues to support the use of ISOCS for numerous ongoing characterization activities required during facility decommissioning. Investment in this technology has also been leveraged for a second ASTD initiative at BGRR beginning in FY01 in which contamination in subsurface soils will be characterized and modeled. If this approach can demonstrate that subsurface contamination is localized, some or all of the large below grade facilities (e.g., duct work) can be decontaminated and left in place, resulting in cost savings estimated to total over $\$ 3.4$ million. Additional deployments planned at Hanford (Canyon Disposition Initiative) and Nevada Test Site (D\&D of former nuclear Rocket Test Facility) promise to further increase return on investment for cleanup of DOE sites. 
Table 6-3. Actual Costs to Implement ISOCS for Characterization of BGRR

\begin{tabular}{|c|c|c|c|}
\hline Category & FY 1999 & FY 2000 & Total \\
\hline ASTD Budget & $\$ 742,000$ & $\$ 802,000$ & $\$ 1,544,000$ \\
\hline \multicolumn{4}{|l|}{ Non BNL-Collaborators: } \\
\hline EML & $\$ 100,000$ & $\$ 50,000$ & $\$ 150,000$ \\
\hline Bechtel Hanford & $\$ 30,000$ & $\$ 25,000$ & $\$ 55,000$ \\
\hline \multicolumn{4}{|l|}{ BetaScint } \\
\hline Capital Equipment & & $\$ 87,500$ & $\$ 87,500$ \\
\hline Training & & $\$ 30,200$ & $\$ 30,200$ \\
\hline Labor & & $\$ 120,000$ & $\$ 120,000$ \\
\hline Travel & $\$ 44,000$ & $\$ 20,000$ & $\$ 64,000$ \\
\hline Project Management & $\$ 111,000$ & $\$ 120,000$ & $\$ 231,000$ \\
\hline $\begin{array}{l}\text { Subtotal Available for ISOCS } \\
\text { Deployment }\end{array}$ & $\$ 457,000$ & $\$ 349,300$ & $\$ 806,300$ \\
\hline \multicolumn{4}{|l|}{ One-Time Expenses: } \\
\hline Equipment & $\$ 148,000$ & & $\$ 148,000$ \\
\hline ISOCS Training & $\$ 27,000$ & & $\$ 27,000$ \\
\hline \multicolumn{4}{|c|}{ Total Available for ISOCS Deployment: } \\
\hline & $\$ 282,000$ & $\$ 349,300$ & $\$ 631,300$ \\
\hline
\end{tabular}


Table 6-4. Cost Comparison Summary

Minimum Savings over Baseline:

\section{Characterization Description}

Soil Samples, Ex Situ

Debris, Sludge, Misc. Samples, Ex Situ

Rad Controlled Areas

(1:1 ratio of baseline: ISOCS)

Non Rad Controlled Areas

(1:1 ratio of baseline: ISOCS)

Total

Average Cost/sample

Maximum Savings over Baseline:

Characterization Description

Soil Samples, Ex Situ

Debris, Sludge, Misc. Samples, Ex Situ

Rad Controlled Areas

(1:1 ratio of baseline: ISOCS)

Non Rad Controlled Areas

(1:1 ratio of baseline: ISOCS)

Total

Average Cost/sample

\section{Baseline Sampling Analysis}

Total

Per Sample

$\$ 164,710$

$\$ 26,759$

$\$ 202$

$\$ 69,647$

$\$ 255$

$\$ 324$

$\$ 30,949$

$\$ 226$

$\$ 292,065$

$\$ 252$
ISOCS

Total

$\$ 45,040$

$\$ 10,456$

$\$ 15,497$

$\$ 10,776$

$\$ 81,769$

Per Sampl
$\$ 5$
$\$ 100$
$\$ 7$
$\$ 77$

\section{Baseline Sampling Analysis}

Total

Per Sample

$\$ 164,710$

$\$ 26,759$

$\$ 202$

$\$ 576,444$

$\$ 255$

\$307,063

$1,074,976$

$\$ 1,074,976$ $\underline{\text { ISOCS }}$

Total Per Sample

$\$ 45,040$

$\$ 10,456$

$\$ 15,497$

$\$ 10,776$

$\$ 81,769$

\section{$\underline{\text { Savings }}$}

Total Per Sample $\$ 119,670 \quad \$ 146$ $\$ 16,303 \quad \$ 155$

$\$ 54,150 \quad \$ 252$

$\$ 20,173 \quad \$ 147$

$\$ 210,296$

$\$ 175$

$\$ 76 \quad \$ 175$




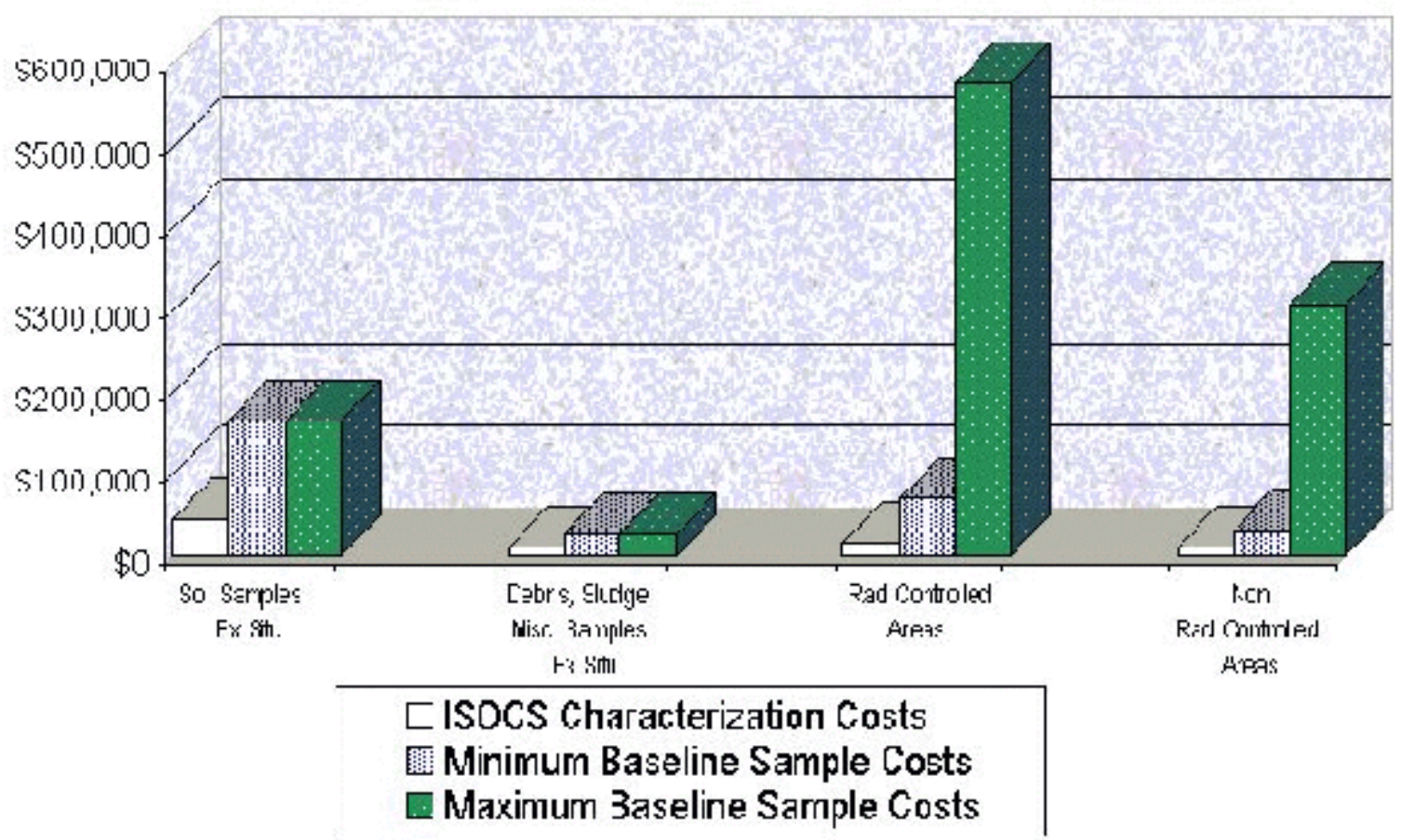

Figure 6-1. Comparison of ISOCS and baseline characterization costs by category

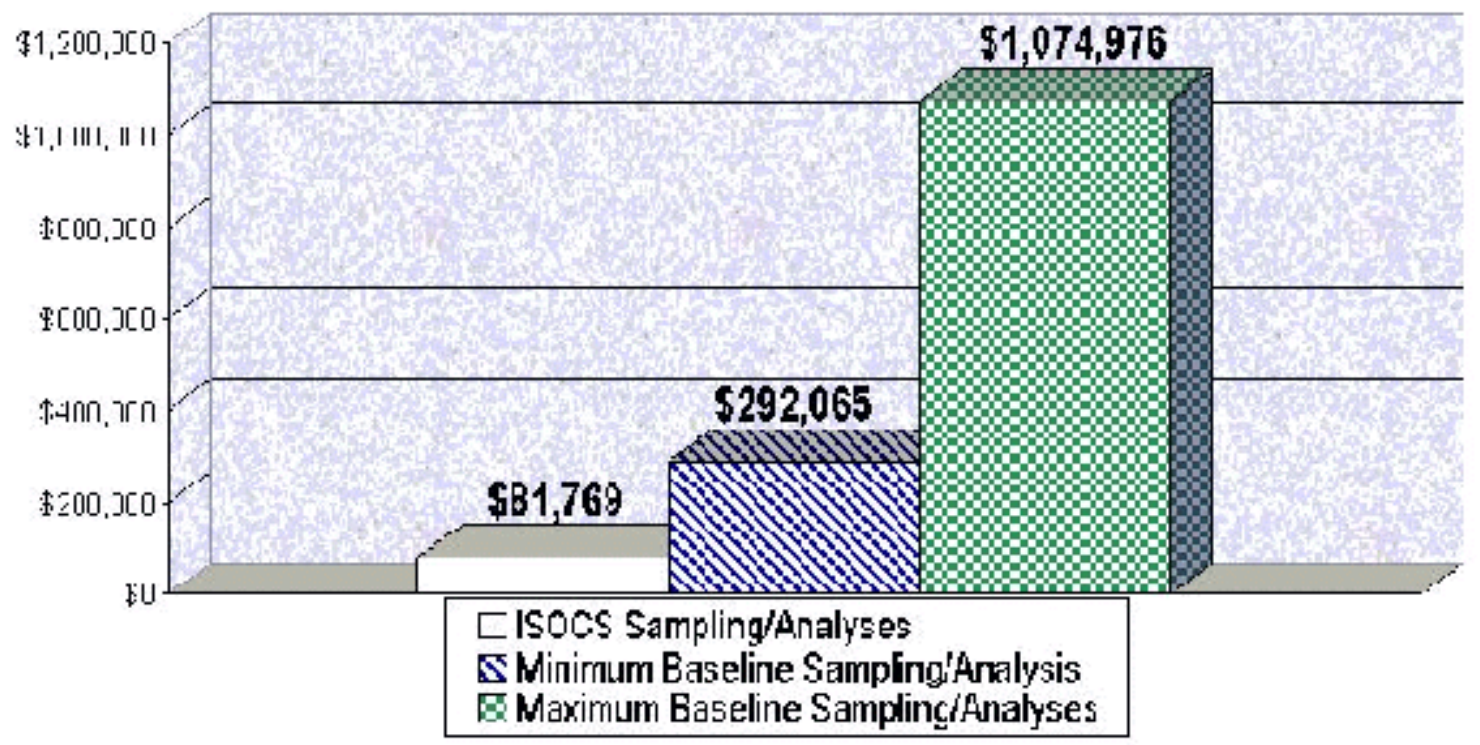

Figure 6-2. Comparison of total ISOCS and baseline characterization costs 


\subsection{REGULATORY/INSTITUTIONAL ISSUES}

Decommissioning of the BGRR is being conducted as a CERCLA removal action and thus prior to initiating work incorporates a logical progression of establishing Data Quality Objectives (DQOs), Sampling and Analysis Plan (SAP), Engineering Evaluation/Cost Analysis (EE/CA), and period of public review and comment. At each stage, BGRR-DP engages the regulatory community (EPA Region II, NYS Department of Environmental Conservation (NYSDEC), and Suffolk County Department of Health) for review and comment, so that their input is incorporated prior to review/approval of the final Record of Decision (ROD). This dialogue allows for better insurance that the final ROD will be acceptable upon completion. The community is also kept informed as the project progresses so that their input can be considered prior to the final decision-making process.

This dialogue is accomplished in several ways. First, the BGRR-DP issues weekly status reports that are available to the regulators and the public via the BGRR web site (http://www.bnl.gov/bgrr/Default.html). Monthly status reports to the DOE EM program are also made available.

Progress on the ASTD project is incorporated into both of these report formats. Regulators are then specifically

\subsection{SUMMARY}

The versatility of the ISOCS system has been demonstrated in numerous situations during initial characterization and decommissioning efforts at the BGRR. Guidance from the MARSSIM and the Data Quality Objectives process provided direction for survey planning and data quality assessment. Surface soil detection sensitivities of less than $1 \mathrm{pCi} / \mathrm{g}$ have been attained with count times as short as 10 minutes for common gamma emitters such as Cs-137. Final results have been reported the same day, following data review and validation. Lower activities or more difficult to measure objects, such as enclosed systems, buried sources, and low-level surface contamination, can take longer to measure and evaluate. However, large surface areas or volumes with heterogeneous material distri-butions can be assayed with a single in situ measurement, thus saving time over other, more manual, methods, such as sampling and remote laboratory analysis.

\subsection{Comparability Assessment}

This assessment of the in situ data quality using the DQIs engaged as part of the DQO process by evaluating documentation and dialogue through face-to-face meetings. Several DQO meetings have been held on separate removal sub-actions (e.g., Pile Fan Sump). As part of this process, the ASTD project team prepared documentation on comparability of in situ characterization technologies for the regulators and were available to brief the regulators. In Situ characterization techniques were found to be acceptable and were then incorporated into the BGRR-DP Sampling and Analysis Plan(s). This form of regulatory "buy-in" is a major performance metric to demonstrate the success of the ASTD effort.

Community involvement has been incorporated through a formal process by BGRR-DP. A series of roundtable meetings open to the general public were held to discuss overall project goals and schedules and solicit input. A standing BGRR Working Group consisting of volunteer community members has been established. The BGRR Working Group meets monthly to be briefed in depth on current BGRR decommissioning status and provide input on issues of concern to the public. The ASTD team has briefed this group on specific activities associated with the project. has demonstrated that the ISOCS data quality can be comparable to definitive level laboratory analysis when the field instrument is supported by an appropriate Quality Assurance Project Plan developed using the DQO process. Analytical results were used to calculate data quality indicators (DQI) were accuracy, precision, and bias.

a. The analytical accuracy of the BNL ISOCS instrument, expressed in terms of the percent difference (\%D) was demonstrated in several modes:

- for a point source, the $\% \mathrm{D}$ was $-2.1 \%$,

- for an extended source, the $\% \mathrm{D}$ was $-10.2 \%$, and

- for an intercomparison to other in situ gamma spectrometers, the $\% \mathrm{D}$ was $-5.0 \%$.

b. The periodic re-measurement of a single source demonstrated the precision of the instrument over an extended period. The relative standard deviation was only $\pm 0.7 \%$, a variation in the activity measurement indicating that the ISOCS system response is very stable. 
c. The analytical precision of the ISOCS instrument was illustrated by the results of repeat analyses per-formed on soil samples. For a series of paired original and repeat analyses on 25 samples, all values of the relative percent difference were within the criteria of the Project QAPP (RPD < 20\%). The largest values of RPD occurred when the activity was small (5 6 pCi/g or less), otherwise the RPD was less than $10 \%$ for the sample set.

d. Very strong correlation was demonstrated between the ISOCS and laboratory results for ex situ $\left(\mathrm{R}^{2}=0.99\right)$ and in situ $\left(\mathrm{R}^{2}=0.98\right)$ analyses.

e. Analysis results for in situ surface soils were usually lower than the corresponding laboratory sample values. This low response "bias" is actually a demonstration that the instruments are analyzing different "samples": the in situ measurement looks at a wide area of soil in its native condition, while the laboratory analyzes a small aliquot, that is perturbed by preparation for analysis (drying and sieving). The bias in the laboratory values is usually very linear and can be adjusted to be more directly comparable to the in situ analysis, or vice versa.

\subsection{Benefits}

The successful implementation of this device provides many advantages over the traditional methodology, which is sampling followed by laboratory analysis.

a. Results are available nearly instantaneously, which allows better decisions to be made. The results can be used to guide the selection of the next measurement for a more complete survey without the necessity to re-mobilize the sampling crew. Or the results can be used to guide the conduct of a decontamination activity to know when to stop. The quick and reliable results are also very useful to advise interested members of the public and/or regulatory bodies on the extent of contamination and the effectiveness of the cleanup operation.

b. Most situations of radiological contamination do not result in uniform deposition of the offending material. Consequently, the selection of a small sample to send to the laboratory is a difficult and imprecise task. One solution is to take very large samples. And this is just what in situ measurement generally does. This large sample averages the non-homogeneity of the sample deposition over the entire object or area. Where the contamination on or in an object is not homogeneous, the ISOCS total activity results are probably more accurate than conventional samples, since a very large fraction of the sample is measured. In situ minimum detection limits are generally as low or lower than laboratory samples, since a very large sample size is used.

c. In many situations taking samples is difficult and/or presents health and safety hazards. Common examples are contaminated concrete, activated steel, radioactive liquids, corrosive or high temperature fluids, dusts and powders, sludge on the bottom of a tank, tightly adhered surface contamination, gaseous samples, etc. In these cases once samples are successfully collected, they must be properly packaged and transported to the laboratory, where additional handling is required. In situ measurements can avoid this in many cases.

d. Conventional sampling and analysis is expensive. The cost comparison discussed in section 6, above, describes estimates of the cost of taking a sample, processing it, and laboratory spectroscopy. The same analysis is also provided for in situ gamma spectroscopy. The sampling/laboratory analysis process is approximately three times more expensive than in situ gamma spectroscopy, on a sample-to-sample basis. And, because of the non-uniform nature of the contamination in most cases, more samples must be taken than for in situ measurements.

\subsection{Limitations}

There are limitations on the implementation and use of the ISOCS system

a. The 30E FOV collimator can not be effectively used with the BEGe. The $30 \mathrm{E}$ FOV collimator is designed for use with a standard "co-axial" HPGe detector, and the wide, squat shape of the BEGe results in the $30 \mathrm{E} F O V$ collimator shielding over $80 \%$ of the active BEGe detector region. This limitation could be rectified by the manufacturer producing a re-designed collimator for use with the BEGe detector

b. Analysis results for in situ surface soils are usually lower than the corresponding laboratory sample values. The bias in the laboratory values is usually very linear and can be adjusted to be more directly comparable to the in situ analysis, or vice versa. Samples should be weighed before and after drying so that an adjustment for soil moisture can be made. In addition, the weight of any material, such as rocks or biomass, that are removed from the sample should also be recorded so that a similar 
adjustment can be made. Without such adjustments, laboratory measurements are biased towards higher concentrations than actually exist at the sampling site. It is after all, the in situ concentration that is needed as input to a dose or risk model. The adjustment of laboratory results to be in line with physical site conditions is often ignored in an effort to be "conservative" in estimating risks. However, this practice should not be allowed to prejudice the comparison of in situ results to soil samples. Data Quality Objectives dictate that the measurement which is most closely related to risk should be preferred.

c. The use and application of the ISOCS geometry templates to generate instrument efficiency from the parameters of the spectrum acquisition can be daunting, especially for complex source objects. The system can be programmed to rapidly analyze recurring geometries, such as in the final status survey of remediated open fields. But when characterizing singular components, such as during a reactor decommissioning, the time to model individual pieces can add up quickly. In such cases it is the DQO process that can help to decrease the analysis setup time, by identifying less stringent precision or accuracy needs, allowing previous geometry models that are "close enough" to be used, without the necessity to refine the model to achieve unnecessary precision.

\subsection{Conclusions}

The ISOCS is an effective instrument for decontamination surveys, environmental measurements, operational radiation protection surveys, and waste assay measurements. This study demonstrated that in situ measurements can meet the QC acceptance criteria established by the project QAPP. Definitive level data may be generated by field instruments, as long as the project DQOs and QA/QC requirements are satisfied. The assessment of the total data quality in the study, and not just the instrument used in the analysis, will establish the confidence in the analysis and will determine the quality level of the data.

The success of this ASTD project is measured on several levels. First, the deployment of this innovative approach using in situ characterization, portable field laboratory measurements, and implementation of MARSSIM was successfully established for all three phases of D\&D characterization, i.e., pre-job scoping, on-going disposition of waste, and final status surveys upon completion of the activity. Unlike traditional D\&D projects, since the BGRR-DP is operating on an accelerated schedule, much of the work is being carried out simultaneously. Rather than complete a full characterization of the facility before D\&D work begins, specific removal actions require characterization as the activity progresses. Thus, the need for rapid and costeffective techniques for characterization is heightened.

Secondly, since the approach used for this ASTD project was not thoroughly proven prior to deployment, a large effort was devoted to demonstrating technical comparability to project managers, regulators and stakeholders. During the initial phases, large numbers of replicate samples were taken and analyzed by conventional baseline techniques to ensure that BGRRDP quality assurance standards were met. ASTD project staff prepared comparisons of data gathered using ISOCS and BetaScint with traditional laboratory methods and presented this information to BGRR-DP staff and regulators from EPA Region II, NYS Department of Environmental Conservation, and the Suffolk County Board of Health. As the results of comparability evaluations became available, approval for these methods was received and the techniques associated with in situ characterization, portable field laboratory measurements, and implementation of MARSSIM were gradually integrated into BGRR-DP procedures.

Clearly, a significant metric for success is cost effectiveness. Integration of this approach and displacement of traditional baseline characterization at BGRR-DP resulted in far fewer samples that needed to be taken, packaged for transport to an off-site laboratory and analyzed. In addition, because samples are analyzed rapidly on-site, cost per sample is drastically reduced. For example, cost per sample for ISOCS measurements was calculated to be $\$ 76$, compared with $\$ 252$ per sample for conventional measurement, a savings of $\$ 175$ per sample. Discounting programmatic costs, the relative cost of deploying ISOCS for BGRR characterization in FY 99 and FY 00 was $\$ 82,000$. The cost for equivalent conventional baseline characterization was estimated to range from a minimum of $\$ 292,000$ to a maximum of $\$ 1,075,000$ depending on the number of analyses displaced. This represents net cost savings ranging from $\$ 210,000$ to $\$ 993,000$. If the total ASTD project cost associated with ISOCS deployment is included, the maximum cost savings range from $-\$ 339,000$ (loss) to $\$ 443,000$ (gain). While both the cost per sample and overall costs are significantly lower using ISOCS in situ and field laboratory characterization, perhaps the greatest cost savings associated with this innovative technology are "hidden" savings that are more difficult to quantify. These include savings associated with project schedule acceleration, the ability to characterize non-standard systems, and improved health and safety for D\&D workers. 
Finally, the most significant criterion for success of this ASTD effort is associated with continued deployment as part of the BGRR-DP and other projects at BNL as well as additional deployments at sites throughout the DOE complex. Investment in the initial ASTD project will continue to see dividends as the inherent cost savings continue to be realized. For example, based on proven success at BGRR (both technical and reduced cost), the BNL Environmental Restoration Division (BNL ERD) deployed ISOCS for cleanup of a large volume of contaminated landscape soils. ASTD team members provided both guidance and technical support for this deployment. In FY 01, BNL is engaged in another ASTD project to characterize subsurface soils beneath structures at the BGRR. Both ISOCS and BetaScint have been incorporated into the project plan for that activity, facilitated through cost savings associated with this project. In addition, ISOCS and MARSSIM are currently being deployed for characterization of the Canyon Disposition Initiative at Hanford, based partly on support from this activity. A new effort to deploy ISOCS and MARSSIM is underway at the Nevada Test Site, as part of a large effort to D\&D their former nuclear rocket test facilities. Based on expertise developed through this ASTD project, BNL is providing technical support and technology transfer assistance to DOE NV.

\subsection{ACKNOWLEDGMENTS}

The authors gratefully acknowledge the U.S. Depart-ment of Energy Office of Science and Technology Decontamination and Decommissioning Focus Area

\subsection{REFERENCES}

1 Briesmeister, J. F. (ed.), MCNP - A General Monte Carlo N-Particle Transport Code, Version 4a. Report LA-12625-M, Los Alamos National Laboratory, November 1993.

2 Bronson, F.L. ISOCS, A Laboratory Quality Ge Gamma Spectroscopy System That You Can Take to the Source for Immediate High Quality Results, Proceedings of Conference on Rapid Radioactivity Measurements in Emergency and Routine Situations, London, October, 1997.

3 Canberra Industries, ISOCS Efficiency Calibration, Validation, and Internal Consistency Document, Publication No. 9231205C. Canberra Industries, Meriden, CT. September 1999.

4 Canberra Industries, Model S573 ISOCS Calibration Software for Genie-2000: User's Manual, Publication No. 9231013B, Canberra Industries, Meriden, CT. August 1999.

5 Kalb, P.D., Luckett, L., Watters, D., Gogolak, C., and Milian, L. Deployment of In Situ Measurement Techniques and the MARSSIM Process for Characterization of the Brookhaven Graphite Research Reactor, Proceedings of Waste Management 2000 Conference, Tucson, AZ. March 2000 . Miller, K. M., P. Shebell and G. Klemic, In Situ and the Brookhaven BGRR Decommissioning Project for their support of this effort.
Gamma Ray Spectrometry for the Measurement of Uranium in Surface Soils, Health Physics, Vol. 67, No. 2, February, 1994.

7 Miller, K.M., Shebell, P., et. al. An Intercomparison of in situ Gamma-Ray Spectrometers, Radioactivity \& Radiochemistry, Vol. 9, No. 4, 1998.

8 In Situ Analysis Quality Assurance Project Plan, Accelerated Site Technology Deployment Project FY99/00, Brookhaven National Laboratory, Upton, NY. July 1999.

9 U. S. EPA, EPA Environmental Technology Verification Report: Field Portable X-ray Fluorescence Analyzer, EPA/600/R-97/150, U. S. Environmental Protection Agency, Washington, DC. March 1998.

10 U. S. EPA, EPA Guidance for the Data Quality Objectives Process (EPA $Q A / G-4$ ), EPA/600/R96/055, U. S. Environmental Protection Agency, Washington, DC. August 2000.

11 U. S. EPA, EPA Guidance for Quality Assurance Project Plans (EPA $Q A / G-5$ ), EPA/600/R-98/018, U. S. Environmental Protection Agency, Washington, DC. February 1998.

12 U. S. EPA, Guidance for Data Quality Assessment 
(EPA QA/G-9), EPA/600/R-96/084, U. S. Environmental Protection Agency, Washington, DC. January 1998.

13 U. S. EPA, U. S. NRC, U. S. DOE, and U. S. Department of Defense, Multi-Agency Radiation Survey and Site Investigation Manual (MARSSIM), EPA 402-R-97-016. Washington, DC. December 1997; revised August 2000. [also issued by U. S. Nuclear Regulatory Commission as NUREG-1575 and by U. S. Department of Energy as DOE/EH-0624].

14 U. S. DOE, Comparability of In-Situ Gamma Spectrometry and Laboratory Data, Rep No 20701-RP-0001, U.S. Department of Energy Fernald Area Office, Fernald, OH, January 1999.
15 U. S. DOE, Innovative Technology Summary Report: In-Situ Object Counting System (ISOCS), U. S. Department of Energy, Federal Energy Technology Center - D\&D Focus Area, Morgantown, WV, February 1998 (DRAFT).

16 Atomic Industrial Forum, Guidelines for Producing Commercial Nuclear Power Plant Decommissioning Cost Estimates, National Environmental Studies Project of the AIF, Bethesda, MD, May 1986.

17 U. S. EPA, Data Quality Objectives for Remedial Response Activities -- Development Process, EPA/540/G-87/003, U. S. Environmental Protection Agency, Washington, DC. March 1987. 
APPENDICES 
APPENDIX A. Summary List of Project Measurements and Scans 
Table A-1. ISOCS Ex Situ Sample Measurements

\begin{tabular}{|c|c|c|c|}
\hline Sample Description & $\begin{array}{l}\text { No. of } \\
\text { Samples }\end{array}$ & Sample Description & $\begin{array}{l}\text { No. of } \\
\text { Samples }\end{array}$ \\
\hline AGD Concrete dust from cutting down comers & 3 & AGD Concrete, Sludge, and Debris & 22 \\
\hline AGD Cutting residuals & 5 & AGD North Duct Joint & 6 \\
\hline AGD South Duct Joint & 6 & AGD Water from cutting down comers & 3 \\
\hline Animal Tunnel East Debris & 1 & Background/Calibration/Source check & 13 \\
\hline BGD and Cooler Drain Sludges & 6 & BGD Cooler Coils & 3 \\
\hline BGD Filter Media & 3 & Canal Core Borehole Soil & 78 \\
\hline Canal Debris & 4 & Canal House drill shavings & 1 \\
\hline Canal Joint & 1 & Canal Sump & 4 \\
\hline Canal Walk-way East & 1 & Canal Walk-way South & 9 \\
\hline ERD Landscape Soil (pre-excavation surveys) & 10 & $\begin{array}{l}\text { ERD Landscape Soil (post-excavation } \\
\text { surveys) }\end{array}$ & 51 \\
\hline ERD Soil from Sewage Treatment Plant & 8 & Fan House 1 Soil & 1 \\
\hline Fuel Channel Extraction Tool & 1 & Graphite Plug stud section & 1 \\
\hline PFS Asphalt (pre-excavation) & 6 & PFS Drainline Soil & 7 \\
\hline $\begin{array}{l}\text { PFS Drainline Soil and asphalt } \\
\text { (post-excavation) }\end{array}$ & 12 & $\begin{array}{l}\text { PFS Drainline Soil and asphalt } \\
\text { (pre-excavation) }\end{array}$ & 4 \\
\hline $\begin{array}{l}\text { PFS Excavation Soil (during and post } \\
\text { excavation) }\end{array}$ & 606 & PFS Soil (pre-excavation) & 5 \\
\hline Soil for BetaScint Demo & 30 & Water Treatment House Debris & 8 \\
\hline Water Treatment House Debris (west) & 3 & & \\
\hline TOTAL & \multicolumn{2}{|c|}{ NON-SOIL TOTAL } & 817 \\
\hline
\end{tabular}

Acronyms:

AGD $=$ Above Ground Ducts

BGD $=$ Below Ground Ducts

ERD $=$ Environmental Restoration Division
PFS = Pile Fan Sump

$\mathrm{WMD}=$ Waste Management Division 
Table A-2. ISOCS In Situ Scan Measurements

\begin{tabular}{|c|c|c|c|c|c|}
\hline Scan Location & \begin{tabular}{|c|} 
No. of \\
Scans \\
\end{tabular} & Category & Sample Location & \begin{tabular}{|l|} 
No. of \\
Scans \\
\end{tabular} & Category \\
\hline AGD (N\&S hatch) & 6 & $\mathrm{a}-1$ & AGD Concrete Debris (from demob) & 2 & b-1 \\
\hline AGD (roof hatch) & 3 & $\mathrm{a}-1$ & Animal Tunnel East Debris & 1 & b-1 \\
\hline Canal House & 1 & a-1 & Canal Sump Debris & 3 & b-1 \\
\hline ERD Waste Container & 5 & $a-1$ & Canal walkway sludge & 2 & b-1 \\
\hline Experimental Port E23 (w cover) & 2 & a-1 & ERD Chem Holes lead & 1 & $\mathrm{~b}-1$ \\
\hline Experimental Port W15 (w cover) & 2 & a-1 & ERD C-magnets & 11 & b-1 \\
\hline Experimental Port E23 & 3 & $\mathrm{a}-1$ & PFS cover closed & 3 & b-1 \\
\hline Experimental Port E30 & 2 & $\mathrm{a}-1$ & PFS cover open & 3 & b-1 \\
\hline Experimental Port E24 & 3 & $a-1$ & Reactor sump cover & 1 & b-1 \\
\hline Experimental Port E26 & 3 & $\mathrm{a}-1$ & TOTAL Category b-1 & \multicolumn{2}{|l|}{27} \\
\hline Experimental Port N5 & 2 & $a-1$ & Canal Sump Debris (south bottom gate) & 1 & $\mathrm{c}-1$ \\
\hline Experimental Port N6 & 2 & a-1 & Control Rod Guide Mechanism (SE) & 2 & $\mathrm{c}-1$ \\
\hline Experimental Port N8 & 2 & $a-1$ & Control Rod Guide Mechanism (SW) & 2 & $\mathrm{c}-1$ \\
\hline Experimental Port W12 & 1 & $a-1$ & Experimental Port W12 Graphite Debris & 3 & $\mathrm{c}-1$ \\
\hline Experimental Port W12 (w cover) & 1 & $\mathrm{a}-1$ & Experimental Port W16 Debris & 1 & $\mathrm{c}-1$ \\
\hline Experimental Port W15 & 1 & a-1 & Fan House 1 & 1 & $\mathrm{c}-1$ \\
\hline Experimental Port W16 & 1 & $a-1$ & Fan House 3 & 3 & $\mathrm{c}-1$ \\
\hline Experimental Port W30 & 1 & $\mathrm{a}-1$ & Fan House 5 & 2 & $\mathrm{c}-1$ \\
\hline Experimental Port W31 & 2 & a-1 & Filter Bank media & 4 & $\mathrm{c}-1$ \\
\hline Experimental Port W36 & 2 & $a-1$ & Glass block & 1 & $\mathrm{c}-1$ \\
\hline Experimental Port W5 & 2 & $\mathrm{a}-1$ & Graphite from Port 12 & 4 & $\mathrm{c}-1$ \\
\hline Experimental Port W51 & 2 & $a-1$ & Graphite from Port 30 & 5 & $\mathrm{c}-1$ \\
\hline Experimental Port W54 & 2 & a-1 & Graphite from Port 42 & 6 & $\mathrm{c}-1$ \\
\hline Experimental Port W56 & 3 & $a-1$ & Graphite from Ports $31 \& 36$ & 5 & $\mathrm{c}-1$ \\
\hline Northwest Side Scanner Slot & 6 & a-1 & Rad Waste Bags (BLIP) & 9 & $\mathrm{c}-1$ \\
\hline South Scanner Slot Samples (SE) & 4 & $\mathrm{a}-1$ & TOTAL Category c-1 & \multicolumn{2}{|l|}{49} \\
\hline South Scanner Slot Samples (SW) & 6 & $a-1$ & Excavated asphalt & 11 & $\mathrm{c}-2$ \\
\hline Water Treatment House East & 2 & $\mathrm{a}-1$ & TOTAL Category c-2 & \multicolumn{2}{|l|}{11} \\
\hline WMD Waste Box 1 & 4 & a-1 & AGD plug & 1 & $\mathrm{~d}-1$ \\
\hline WMD pig & 9 & a-1 & AGD Sidewall Concrete Cores & 4 & $\mathrm{~d}-1$ \\
\hline WMD Waste Box 2 (bldg938) & 3 & $\mathrm{a}-1$ & Bioshield graphite plug & 2 & $\mathrm{~d}-1$ \\
\hline TOTAL Category a-1 & \multicolumn{2}{|l|}{88} & ExperimentalPort W16 Graphite Powder & 1 & d-1 \\
\hline 701 Parking lot & 2 & $a-2$ & Fan House 3 dust & 3 & $\mathrm{~d}-1$ \\
\hline Agricultural Field Intercomparison Study & 15 & $\mathrm{a}-2$ & Fan House 5 dust & 3 & $\mathrm{~d}-1$ \\
\hline Bldg 703 floors & 6 & $a-2$ & Instrument Tunnel East Debris & 1 & d-1 \\
\hline ERD Landscape soil & 2 & $\mathrm{a}-2$ & Interior Pile Debris (Port W32) & 12 & d-1 \\
\hline ERD lanscape soil (phyto) & 8 & $\mathrm{a}-2$ & Interior Pile Graphite Dust and Shavings & 9 & $\mathrm{~d}-1$ \\
\hline Fan House soils & 27 & $a-2$ & North Scanner Slot Samples & 14 & $\mathrm{~d}-1$ \\
\hline PFS pipeline soil & 59 & $\mathrm{a}-2$ & PFS sludge & 1 & $\mathrm{~d}-1$ \\
\hline WMD Liquid Waste Tanker & 5 & $a-2$ & TOTAL Category d-1 & \multicolumn{2}{|l|}{51} \\
\hline TOTAL Category a-2 & \multicolumn{2}{|l|}{124} & ERD Phyto plant & 2 & $\mathrm{~d}-2$ \\
\hline TOTAL Category b-2 & \multicolumn{2}{|l|}{$\overline{0}$} & TOTAL Category d-2 & \multicolumn{2}{|l|}{2} \\
\hline
\end{tabular}

a-1) large uniform area (homogeneity assumed). Controlled area entry for baseline sampling

a-2) large uniform area (homogeneity assumed). No controlled area entry for baseline sampling

b-1) small uniform area (homogeneity assumed). Controlled area entry for baseline sampling

b-2) small uniform area (homogeneity assumed). No controlled area entry for baseline sampling

c-1) large heterogeneous solid. Controlled area entry for baseline sampling

c-2) large heterogeneous solid. No controlled area entry for baseline sampling

d-1) small heterogeneous solid. Controlled area entry for baseline sampling

d-2) small heterogeneous solid. No controlled area entry for baseline sampling 
APPENDIX B. Project Participants 


\section{Accelerated Site Technology Deployment (ASTD) Project Organization Chart}

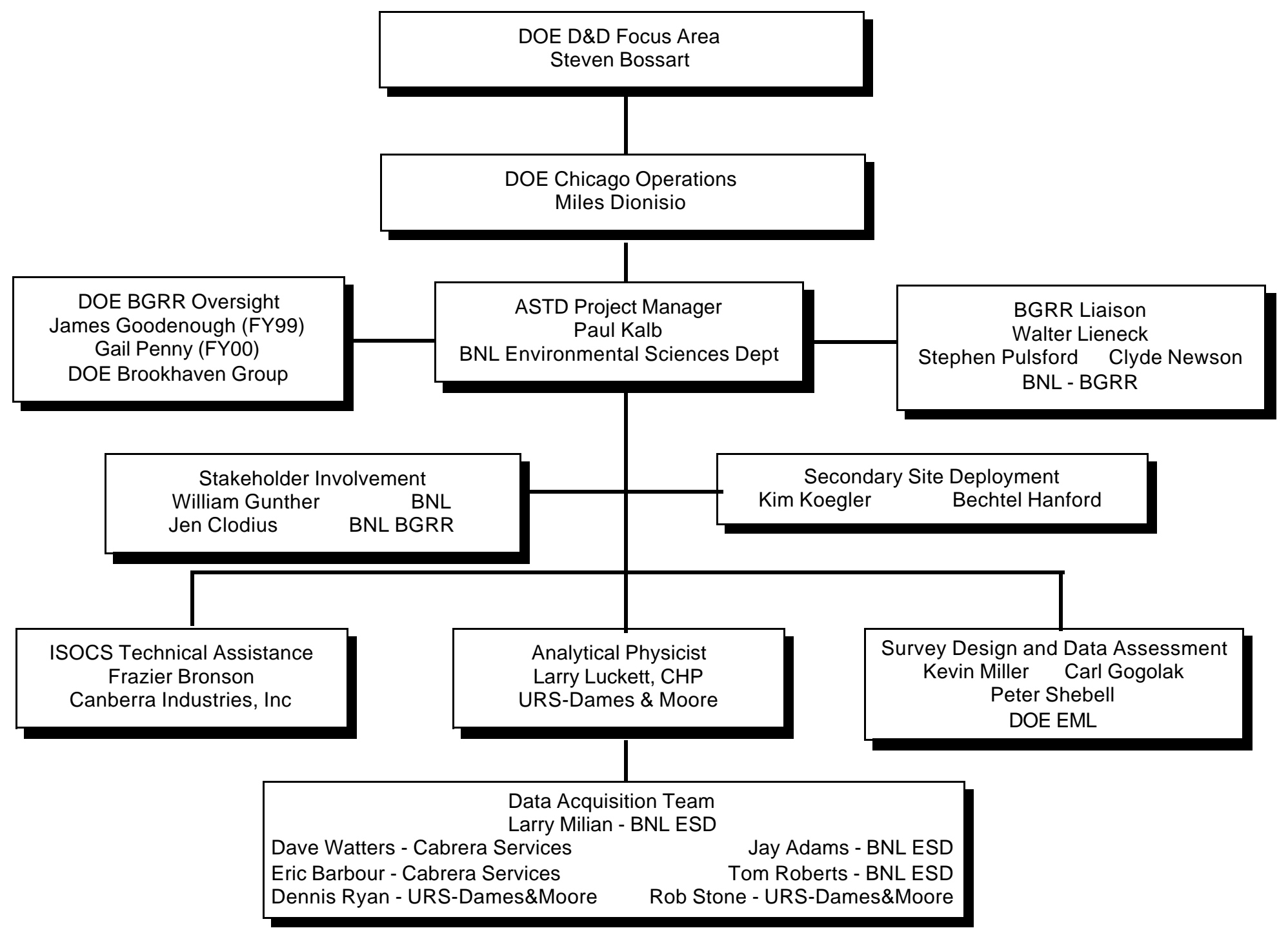


APPENDIX C. Cost Analysis Data Tables 


\section{Table C-1}

WBS for Baseline Ex Situ Sampling and Analyses

\section{Soil Samples}

\section{Mobilization}

Transport equipment to work area

Prepare equipment for use

\begin{tabular}{|c|c|c|c|c|c|c|c|}
\hline \multirow{2}{*}{$\begin{array}{l}\text { Labor } \\
\text { Hours }\end{array}$} & \multirow[b]{2}{*}{ Rate } & \multicolumn{2}{|c|}{ Materials } & \multirow{2}{*}{$\begin{array}{l}\text { Total } \\
\text { Unit Cost }\end{array}$} & \multirow{2}{*}{$\begin{array}{l}\text { Total } \\
\text { Quantity }\end{array}$} & \multirow{2}{*}{$\begin{array}{l}\text { Unit of } \\
\text { Measure }\end{array}$} & \multirow{2}{*}{$\begin{array}{l}\text { Total } \\
\text { Cost }\end{array}$} \\
\hline & & Quantity & Rate & & & & \\
\hline 0.5 & $\$ 45$ & & & $\$ 22.50$ & 30 & work days & $\$ 675$ \\
\hline .5 & $\$ 45$ & & & $\$ 22.50$ & 30 & work days & $\$ 675$ \\
\hline
\end{tabular}

\section{Characterization}

Set up and move equipment (auger, geoprobe, etc)

Collect sample

$\$ 45$

Decon equip for next sampling

Package Sample

Prepare shipment

Transport, Analyze, Dispose of samples

Review/Evaluate Data

Daily Project/Safety Briefing

Containers

PPE

Productivity Loss Factor

(PLF)

\section{Demobilization}

Survey and Decon equipment

Transport equipment to storage area

$0.1 \$ 45$

$0.25 \$ 45$

$0 \quad \$ 0$

$0.1 \$ 75$

$0.5 \$ 75$

$0 \quad \$ 0$

$\begin{array}{ll}0.5 & \$ 45 \\ 0.5 & \$ 45\end{array}$

$\$ 22.50$

$\$ 22.50$
$\$ 4.50$

$\$ 9.00$

$\$ 4.50$

$\$ 11.25$

$\$ 146$

$\$ 7.50$

$\$ 37.50$

817

2 per day $\$ 50$

0

0
817

817

817

817

817

817

30

$\begin{array}{ll} & \$ 3,677 \\ & \$ 7,353 \\ & \$ 3,677 \\ & \$ 9,191 \\ & \$ 119,28 \\ & \$ 6,128 \\ \text { work days } & \$ 1,125 \\ \text { each } & \$ 4,902 \\ \text { work days } & \$ 3,000\end{array}$

( a )
work days
$\$ 675$
work days \$675
TOTAL: $\quad \$ 164,710$
Cost/sample: $\$ 201.60$

\section{Notes:}

(a) Avg cost for off-site gamma analyses (14d turnaround) is $\$ 121+\$ 25$ shipping/handling $=\$ 146$

(b) One CHP evaluates 10 data sets/hr

(c) Adjusts for changes, breaks, respiratory protection, and ALARA

(PLF is calculated by multiplying time spent applied to work within controlled areas by the adjustment factor of 27\%) 
Table C-2

WBS for ISOCS Ex Situ Sampling and Analyses

Soil Samples

\section{Mobilization}

Transport sampling equipment to work area

$\begin{array}{lll}\text { Labor } & \text { Materials } \\ \text { Hours Rate } & \text { Quantity Rate }\end{array}$

Prepare sampling equipment for use

$\begin{array}{ll}0.5 & \$ 45 \\ 0.5 & \$ 45 \\ 0.5 & \\ 0.5 & \$ 45\end{array}$

Equipment Maintenance

$0.5 \$ \$ 45$

ISOCS Liquid Nitrogen

\section{Characterization}

Set up and move equipment (auger, geoprobe, etc) $\quad 0.1$

Collect sample

Decon equip for next sampling

Package Sample

Analyze samples at ISOCS field lab

$0.1 \$ 45$

Archive Files/Print Data

$0.13 \$ 75$

Daily Project/Safety Briefing

Containers

PPE

$0.05 \$ \$ 75$

Productivity Loss Factor (PLF)

$0.5 \$ \$ 75$

$\begin{array}{llll}\text { Total } & \text { Total } & \text { Unit of } & \text { Total } \\ \text { Unit Cost } & \text { Quantity } & \text { Measure } & \text { Cost }\end{array}$

Comment

\section{Demobilization}

\section{Survey and Decon equipment}

Transport equipment to storage area

work days

$\begin{array}{llll} & \$ 4.50 & 817 & \text { each } \\ \$ 4.50 & 817 & \text { each } & \$ 3,677 \\ \$ 9.00 & 817 & \text { each } & \$ 7,353 \\ \$ 4.50 & 817 & \text { each } & \$ 3,677 \\ \$ 9.75 & 817 & \text { each } & \$ 7,966 \\ \$ 3.75 & 817 & \text { each } & \$ 3,064 \\ \$ 3.75 & 817 & \text { each } & \$ 3,064 \\ \$ 37.50 & 30 & \text { work days } & \$ 1,125 \\ & & \text { each } & \$ 4,902 \\ \$ 50 & 30 & \text { work days } & \$ 3,000\end{array}$

\section{Notes:}

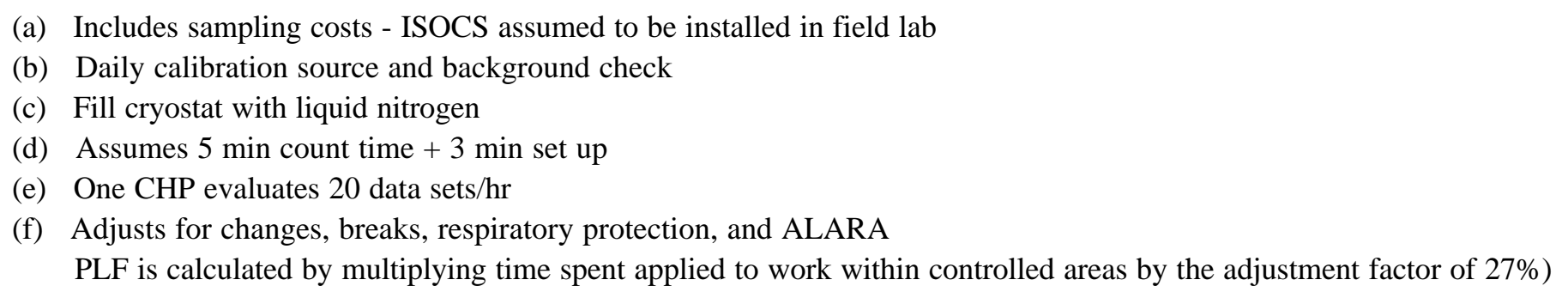


Table C-3

WBS for Baseline Ex Situ Sampling and Analyses

Debris, Sludge, Misc. Samples

\section{Mobilization}

Prepare area for sampling

\begin{tabular}{|c|c|c|c|c|c|c|c|c|}
\hline \multirow{2}{*}{$\begin{array}{l}\text { Labor } \\
\text { Hours }\end{array}$} & \multirow[b]{2}{*}{ Rate } & \multicolumn{2}{|c|}{ Materials } & \multirow{2}{*}{$\begin{array}{l}\text { Total } \\
\text { Unit Cost }\end{array}$} & \multirow{2}{*}{$\begin{array}{l}\text { Total } \\
\text { Quantity }\end{array}$} & \multirow{2}{*}{$\begin{array}{l}\text { Unit of } \\
\text { Measure }\end{array}$} & \multirow{2}{*}{$\begin{array}{l}\text { Total } \\
\text { Cost }\end{array}$} & \multirow[b]{2}{*}{ Comment } \\
\hline & & Quantity & Rate & & & & & \\
\hline 0.5 & $\$$ & & & $\$ 22.50$ & 10 & work days & $\$ 225$ & (a) \\
\hline
\end{tabular}

\section{Characterization}

Collect sample

Decon equip for next sampling

Package Sample

Prepare shipment for off-site analyses

Transport, Analyze, Dispose of samples

Review/Evaluate Data

Daily Project/Safety Briefing

Containers

PPE

Productivity Loss Factor (PLF)

$\begin{array}{ll}0.25 & \$ 45 \\ 0.2 & \$ 45 \\ 0.1 & \$ 45 \\ 0.25 & \$ 45 \\ 0 & \$ 0 \\ 0.1 & \$ 75 \\ 0.5 & \$ 75 \\ 0 & \$ 0 \\ 0 & \\ 0.885 & \$ 45\end{array}$

\section{Demobilization}

Survey and Decon equipment

$\begin{array}{lllll} & \$ 11.25 & 105 & \text { each } & \$ 1,181 \\ & \$ 9.00 & 105 & \text { each } & \$ 945 \\ & \$ 4.50 & 105 & \text { each } & \$ 473 \\ & \$ 11.25 & 105 & \text { each } & \$ 1,181 \\ & \$ 146 & 105 & \text { each } & \$ 15,330 \\ & \$ 7.50 & 105 & \text { each } & \$ 788 \\ & \$ 37.50 & 10 & \text { work days } & \$ 375 \\ \text { per day } & \$ 50 & 10 & \text { each } & \$ 630 \\ & \$ 39.83 & 105 & \text { work days } & \$ 1,000 \\ & & & & \$ 4,182 \\ & & & & \\ & \$ 45.00 & 10 & \text { work days } & \$ 450 \\ & & & \text { TOTAL: } & \$ 26,759 \\ & & & \text { Cost/sample: } & \$ 254.85\end{array}$

\section{Notes:}

(a) Prepare buffer area and assemble sampling equipment; assume 10 samples/day rate

(b) Avg cost for off-site gamma analyses (14d turnaround) is $\$ 121+\$ 25$ shipping/handling $=\$ 146$

(c) One CHP evaluates 10 data sets/hr

(d) Adjusts for changes, breaks, respiratory protection, and ALARA

(PLF is calculated by multiplying time spent applied to work within controlled areas by the adjustment factor of 27\%) 
Table C-4

WBS for ISOCS Ex Situ Sampling and Analyses

Debris, Sludge, and Misc. Samples

\section{Mobilization}

Prepare area for sampling

ISOCS Quality Assurance Procedures

Equipment Maintenance

ISOCS Liquid Nitrogen

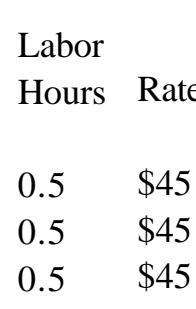

\section{Characterization}

Collect sample

Package Sample

Analyze samples at ISOCS field lab

Archive Files/Print Data

Review/Evaluate Data

Daily Project/Safety Briefing

Containers

PPE

Productivity Loss Factor (PLF)

\section{Demobilization}

Survey and Decon equipment

Materials
Quantity Rate

$\begin{array}{llll}\text { Total } & \text { Total } & \text { Unit of } & \text { Total } \\ \text { Unit Cost } & \text { Quantity } & \text { Measure } & \text { Cost }\end{array}$

Comment

$\begin{array}{ll}\$ 22.50 & 10 \\ \$ 22.50 & 10 \\ \$ 22.50 & 2 \\ & 10\end{array}$

work days

$\$ 225$

work day

$\$ 225$

week

$\$ 45$

$\$ 0.90$

work day

$\$ 9$

( a )

(b)

(c)

$\begin{array}{lll}0.25 & \$ 45 & \\ 0.1 & \$ 45 & \\ 0.13 & \$ 75 & \\ 0.05 & \$ 75 & \\ 0.05 & \$ 75 & \\ 0.5 & \$ 45 & \\ 0 & \$ 0 & 105 \\ 0 & & 2 \\ 0.885 & \$ 45 & \end{array}$

$\begin{array}{ll} & \$ 11.25 \\ & \$ 4.50 \\ & \$ 9.75 \\ & \$ 3.75 \\ & \$ 3.75 \\ & \$ 22.50 \\ \$ 6 & \\ \text { per day } & \$ 50 \\ & \\ & \$ 39.83\end{array}$

\section{5}

each

$\$ 1,181$

$\$ 473$

$\$ 1,024$

each

$\$ 394$

each

$\$ 394$

each

$\$ 225$

each \$630

work days $\$ 1,000$

each \$4,182

( e )

10

105

\section{Notes:}

(a) Prepare buffer area and assemble sampling equipment; assume 10 samples/day rate

(b) Daily calibration source and background check

(c) Fill cryostat with liquid nitrogen

(d) Assumes 5 min count time +3 min set up

(e) One CHP evaluates 20 data sets/hr

(f) Adjusts for changes, breaks, respiratory protection, and ALARA

(PLF is calculated by multiplying time spent applied to work within controlled areas by the adjustment factor of $27 \%$ ) 


\section{Table C-5}

WBS for Baseline Sampling and Analyses in place of In Situ ISOCS for All Radiologically Controlled Areas;

\section{Maximum Cost Savings Assumptions}

(Assuming 10:1 ratio of Baseline Sampling to ISOCS for Large Areas and 5:1 Ratio for Small Areas)

\section{Mobilization}

Transport equipment to work area
Prepare equipment for use

$\begin{array}{ll}\text { Labor } & \\ \text { Hours } & \text { Rate } \\ 0.5 & \$ 45 \\ 0.5 & \$ 45\end{array}$

Materials

Quantity Rate

$0.5 \$ 45$
Set up and move equipment (auger, geoprobe, etc)

Collect sample

Decon equip for next sampling

Package Sample

Prepare shipment for off-site analyses

Transport, Analyze, Dispose of samples

Review/Evaluate Data

Daily Project/Safety Briefing

Containers

PPE

Productivity Loss Factor (PLF)

\section{Demobilization}

Survey and Decon equipment

Transport equipment to storage area

$\begin{array}{ll}\text { ( b ) } & \\ 0.25 & \$ 45 \\ 0.2 & \$ 45 \\ 0.25 & \$ 45 \\ 0.25 & \$ 45 \\ 0 & \$ 0 \\ 0.1 & \$ 75 \\ 0.5 & \$ 75 \\ 0 & \$ 0 \\ 0 & \\ 1.27 & \$ 45\end{array}$

$0.5 \$ \$ 45$

$0.5 \$ 45$

$\begin{array}{ll}\text { Total } & \text { Total } \\ \text { Unit Cost } & \text { Quantity } \\ \$ 22.50 & 440 \\ \$ 22.50 & 440\end{array}$

$\$ 11.25$

Unit of

Measure

work days

work days

1760

each

each

each

each

each

each

work days

each

work days

$\begin{array}{ll}440 & \text { work } \\ 1760 & \text { each }\end{array}$

$\$ 57.15$

$\$ 22.50$

$\$ 22.50$
440
440 work days
Total

Cost

$\$ 9,900$

$\$ 9,900$

each

$\$ 19,800$

$\$ 15,840$

$\$ 19,800$

$\$ 19,800$

$\$ 256,960$ (c )

$\$ 13,200 \quad(\mathrm{~d})$

$\$ 16,500$

$\$ 10,560$

$\$ 44,000$

$\$ 100,584$ ( e )
Comment

(a)

$\$ 19,800$

work days $\quad \$ 9,900$

Total: $\quad \$ 576,444$

Cost/sample: $\$ 328$

Notes:

(a) With $4.5 \mathrm{hrs}$ for set up, prep, PL factor, survey, decon \& demob, Assume 4 samples/ day; 440 work days required

(b) Assuming 10 conventional baseline samples required for each ISOCS scan of large homogeneous areas; 5 conventional baseline samples required for each ISOCS scan of small homogeneous areas

(c) Avg cost for off-site gamma analyses (14d turnaround) is $\$ 121+\$ 25$ shipping/handling $=\$ 146$

(d) One CHP evaluates 10 data sets/hr

(e) Adjusts for changes, breaks, respiratory protection, and ALARA

(PLF is calculated by multiplying time spent applied to work within controlled areas by the adjustment factor of $27 \%$ )

[This analysis assumes no compositing of analytical samples] 
Table C-6

WBS for Baseline Sampling and Analyses in place of In Situ ISOCS for All Radiologically Controlled Areas;

\section{Minimum Cost Savings Assumptions}

(Assuming 1:1 ratio of Baseline Sampling to ISOCS for All Samples)

\section{Mobilization}

\begin{tabular}{lll} 
Labor & & \multicolumn{2}{c}{ Materials } \\
Hours & Rate & Quantity Rate \\
0.5 & $\$ 45$ & \\
0.5 & $\$ 45$ &
\end{tabular}

$\begin{array}{ll}\text { Total } & \text { Total } \\ \text { Unit Cost } & \text { Quantity } \\ \$ 22.50 & 54 \\ \$ 22.50 & 54\end{array}$

\section{Unit of} Measure

Total

Transport equipment to work area

Prepare equipment for use

\section{Characterization}

Set up and move equipment (auger, geoprobe, etc)

$\quad 0.25$

Collect sample

$0.25 \$ 45$

Decon equip for next sampling

$\$ 45$

$\begin{array}{ll} & \\ & \$ 11.25 \\ & \$ 9.00 \\ & \$ 11.25 \\ & \$ 11.25 \\ & \$ 146 \\ & \$ 7.50 \\ \text { per day } & \$ 37.50 \\ & \\ & \$ 57.15 \\ & \\ & \$ 22.50 \\ & \$ 22.50\end{array}$

$\$ 11.25$
215
215
215
215
215
215
54
215
54
215

work days

Cost

work days

Comment

$\$ 1,215$

( a )

Package Sample

$0.2 \$ 45$

Prepare shipment for off-site analyses

Transport, Analyze, Dispose of samples

$0.25 \$ 45$

Review/Evaluate Data

$0.25 \$ 45$

$0 \quad \$ 0$

Daily Project/Safety Briefing

Containers

PPE

Productivity Loss Factor (PLF)

$0.1 \$ 75$

$0.5 \$ 75$

$0 \$ \$$

77

$\begin{array}{ll}0 & \\ 1.27 & \$ 45\end{array}$

\section{Demobilization}

Survey and Decon equipment

$\begin{array}{ll}0.5 & \$ 45 \\ 0.5 & \$ 45\end{array}$

$\$ 22.50$

$\begin{array}{lll}\$ 11.25 & 215 & \text { each } \\ 215 & \text { each } & \$ 2,419 \\ 215 & \text { each } & \$ 1,935 \\ 215 & \text { each } & \$ 2,419 \\ 215 & \text { each } & \$ 2,419 \\ 215 & \text { each } & \$ 31,390 \\ 215 & \text { each } & \$ 1,613 \\ 54 & \text { work days } & \$ 2,025 \\ 215 & \text { each } & \$ 462 \\ 54 & \text { work days } & \$ 5,400 \\ 215 & \text { each } & \$ 12,287 \\ & & \\ & & \$ 1,215 \\ 54 & \text { work days } & \$ 1,215 \\ 54 & \text { work days } & \\ & & \$ 69,647 \\ & \text { Total: } & \mathbf{3 2 4}\end{array}$

Notes:

(a) With $4.5 \mathrm{hrs}$ for set up, prep, PL factor, survey, decon \& demob, Assume 4 samples/ day; 54 work days required
(b) Avg cost for off-site gamma analyses (14d turnaround) is $\$ 121+\$ 25$ shipping/handling $=\$ 146$
(c) One CHP evaluates 10 data sets/hr
(d) Adjusts for changes, breaks, respiratory protection, and ALARA
(PLF is calculated by multiplying time spent applied to work within controlled areas by the adjustment factor of $27 \%$ ) 
Table C-7

WBS for In Situ ISOCS Sampling and Analyses of All Radiologically Controlled Areas

\begin{tabular}{|c|c|c|c|c|c|c|c|c|c|}
\hline & Labor & & Mater & & Total & Total & & Total & \\
\hline Mobilization & Hours & Rate & Quantity & Rate & Unit Cost & Quantity & Measure & Cost & Comment \\
\hline Transport ISOCS equipment to work area & 0.5 & $\$ 45$ & & & $\$ 22.50$ & 27 & work day & $\$ 608$ & ( a ) \\
\hline Prepare equipment for use & 0.5 & $\$ 45$ & & & $\$ 22.50$ & 27 & work day & $\$ 608$ & \\
\hline Quality Assurance Procedures & 0.5 & $\$ 45$ & & & $\$ 22.50$ & 27 & work day & $\$ 608$ & ( b ) \\
\hline Equipment Maintenance & 0.5 & $\$ 45$ & & & $\$ 22.50$ & 6 & week & $\$ 135$ & ( c ) \\
\hline Liquid Nitrogen & & & & $\$ 0.90$ & & 27 & work day & $\$ 24$ & \\
\hline \multicolumn{10}{|l|}{ Characterization } \\
\hline Set up and move equipment (ISOCS) & 0.1 & $\$ 75$ & & & $\$ 7.50$ & 215 & each & $\$ 1,613$ & \\
\hline Acquire data & 0.25 & $\$ 75$ & & & $\$ 18.75$ & 215 & each & $\$ 4,031$ & ( d ) \\
\hline Model Data & 0.25 & $\$ 75$ & & & $\$ 18.75$ & 215 & each & $\$ 4,031$ & \\
\hline Archive Files/Print Data & 0.05 & $\$ 75$ & & & $\$ 3.75$ & 215 & each & $\$ 806$ & \\
\hline Review/Evaluate Data & 0.05 & $\$ 75$ & & & $\$ 3.75$ & 215 & each & $\$ 806$ & ( e ) \\
\hline Daily Project/Safety Briefing & 0.5 & $\$ 75$ & & & $\$ 37.50$ & 27 & work day & $\$ 1,013$ & \\
\hline PPE & 0 & & 0 & per day & $\$ 50$ & 0 & & $\$ 0$ & \\
\hline Productivity Loss Factor (PLF) & 0 & $\$ 45$ & & & $\$ 0$ & 0 & & $\$ 0$ & ( f ) \\
\hline \multicolumn{10}{|l|}{ Demobilization } \\
\hline Equipment Disassembly & 0.5 & $\$ 45$ & & & $\$ 22.50$ & 27 & work day & $\$ 608$ & \\
\hline \multirow[t]{3}{*}{ Transport equipment to storage area } & 0.5 & $\$ 45$ & & & $\$ 22.50$ & 27 & work day & $\$ 608$ & \\
\hline & & & & & & & Total: & $\$ 15,497$ & \\
\hline & & & & & & & Cost/sample: & $\$ 72$ & \\
\hline
\end{tabular}

\section{Notes:}

(a) With 2.5 hrs for set up, prep, \& demob, Assume 8 samples/ day; 27 work days required

(b) Daily calibration source and background check

(c) Fill cryostat with liquid nitrogen

(d) Assumes 15 min count time

(e) One CHP evaluates 20 data sets/hr

(f) Adjusts for changes, breaks, respiratory protection, and ALARA

Assumes ISOCS data acquisition is conducted from outside controlled area 


\section{Table C-8}

WBS for Baseline Sampling and Analyses in place of In Situ ISOCS for all Non-Radiologically Controlled Areas

Maximum Cost Savings Assumptions

(Assuming 10:1 ratio of Baseline Sampling to ISOCS for Large Areas and 5:1 Ratio for Small Areas )

\section{Mobilization}

Transport equipment to work area

Prepare equipment for use

\begin{tabular}{lllll} 
Labor & \multicolumn{2}{c}{ Materials } & Total & Total \\
Hours & Rate & Quantity Rate & Unit Cost & Quantity \\
0.5 & $\$ 45$ & & $\$ 22.50$ & 227 \\
0.5 & $\$ 45$ & & $\$ 22.50$ & 227
\end{tabular}

\section{Characterization}

Set up and move equipment (auger, geoprobe, etc)

Collect sample

Package Sample

Prepare shipment for off-site analyses

Transport, Analyze, Dispose of samples

Review/Evaluate Data

Daily Project/Safety Briefing

Containers

PPE

Productivity Loss Factor (PLF)

\section{Demobilization}

Survey and Decon equipment

Transport equipment to storage area

$0.25 \$ 45$

$\begin{array}{lll} & & \\ & & \\ & \$ 111.25 & 1360 \\ & \$ 11.25 & 1360 \\ & \$ 11.25 & 1360 \\ & \$ 146 & 1360 \\ & \$ 7.50 & 1360 \\ \text { per day } & \$ 37.50 & 227 \\ & & 1360 \\ & & 0 \\ & & 0 \\ & & \\ & \$ 22.50 & 227 \\ & \$ 22.50 & 227\end{array}$

$\$ 22.50$

Unit of
Measure
work days
work days

Total

Cost

$\$ 5,108$

$\$ 5,108$

Comment

( a )

1360

each

each

each

each

each

$\$ 15,300$

$\$ 15,300$

$\$ 15,300$

$\$ 15,300$

$\$ 198,560$ each

work days

each

$\$ 10,200$

$\$ 8,513$

$\$ 8,160$

$\$ 0$

$\$ 0$

\section{(c )}

$\begin{array}{ll}\text { work days } & \$ 5,108 \\ \text { work days } & \$ 5,108 \\ \text { Total: } & \$ 307,063 \\ \text { Cost/sample: } & \mathbf{\$ 2 2 6}\end{array}$

\section{Notes:}

(a) With 1.5 hrs for set up, prep, decon \& demob, Assume 6 samples/ day; 227 work days required

(b) Assuming 10 conventional baseline samples required for each ISOCS scan of large homogeneous areas; 5 conventional baseline samples required for each ISOCS scan of small homogeneous areas

(c) One CHP evaluates 10 data sets/hr

(d) No Productivity Loss Factor for work in Non-Radiologically Controlled areas 


\section{Table C-9}

WBS for Baseline Sampling and Analyses in place of In Situ ISOCS for all Non-Radiologically Controlled Areas

Minimum Cost Savings Assumptions

(Assuming 1:1 ratio of Baseline Sampling to ISOCS for All Samples)

\section{Mobilization}

$\begin{array}{ll}\text { Labor } & \\ \text { Hours } & \text { Rate } \\ 0.5 & \$ 45 \\ 0.5 & \$ 45\end{array}$

Materials

Transport equipment to work area

Prepare equipment for use

$\begin{array}{ll}\text { Total } & \text { Total } \\ \text { Unit Cost } & \text { Quantity } \\ \$ 22.50 & 23 \\ \$ 22.50 & 23\end{array}$

Unit of

Measure

work days

Total

$\$ 518$

work days $\$ 518$

\section{Characterization}

Set up and move equipment (auger, geoprobe, etc)

Collect sample

$\begin{array}{lll}0.25 & 0.25 & \$ 45 \\ 0.25 & \$ 45 & \\ 0.25 & \$ 45 & \\ 0 & \$ 0 & \\ 0.1 & \$ 75 & \\ 0.5 & \$ 75 & \\ 0 & \$ 0 & \\ 0 & & 0 \\ 0 & \$ 45 & \end{array}$

$\$ 45$

Package Sample

Prepare shipment for off-site analyses

Transport, Analyze, Dispose of samples

Review/Evaluate Data

Daily Project/Safety Briefing

Containers

PPE

Productivity Loss Factor (PLF)

\section{Demobilization}

Survey and Decon equipment

Transport equipment to storage area

$\begin{array}{ll}0.5 & \$ 45 \\ 0.5 & \$ 45\end{array}$

$\begin{array}{ll} & \$ 11.25 \\ \$ 11.25 & 137 \\ \$ 11.25 & 137 \\ \$ 11.25 & 137 \\ \$ 146 & 137 \\ \$ 7.50 & 137 \\ \$ 37.50 & 23 \\ & 137 \\ \$ 50 & 0 \\ \$ 0 & 0\end{array}$

137

each

each

$\$ 1,541$

each

$\$ 1,541$

each

$\$ 1,541$

each

$\$ 20,002$

each

$\$ 1,028$

work days $\$ 863$

each

$\$ 822$

$\$ 0$

$\$ 0$

Comment

(a)

$\$ 1,541$

(b)

$\$ 6$
per day $\$ 50$

0

\begin{tabular}{|c|c|}
\hline work days & $\$ 518$ \\
\hline work days & $\$ 518$ \\
\hline & $\$ 30,949$ \\
\hline ost/sample: & $\$ 226$ \\
\hline
\end{tabular}

Notes:
(a) With $1.5 \mathrm{hrs}$ for set up, prep, decon \& demob, Assume 6 samples/ day; 23 work days required
(b) One CHP evaluates 10 data sets/hr
(c) No Productivity Loss Factor for work in Non-Radiologically Controlled areas 
Table C-10

WBS for In Situ ISOCS Sampling and Analyses of All Non-Radiologically Controlled Areas

\section{Mobilization}

Transport ISOCS equipment to work area

$\begin{array}{ll}\text { Labor } & \\ \text { Hours } & \text { Rate } \\ & \\ 0.5 & \$ 45 \\ 0.5 & \$ 45 \\ 0.5 & \$ 45 \\ 0.5 & \$ 45\end{array}$

Materials
Quantity Rate

Prepare equipment for use

Quality Assurance Procedures

Equipment Maintenance

Liquid Nitrogen

\section{Characterization}

Set up and move equipment (ISOCS)

Acquire data

$\begin{array}{ll}0.1 & \$ 75 \\ 0.25 & \$ 75 \\ 0.25 & \$ 75 \\ 0.05 & \$ 75 \\ 0.05 & \$ 75 \\ 0.5 & \$ 75 \\ 0 & \\ 0 & \$ 45\end{array}$

Model Data

Archive Files/Print Data

Review/Evaluate Data

Daily Project/Safety Briefing

PPE

Productivity Loss Factor (PLF)

$0 \quad \$ 45$

Total

Unit Cost

\section{Total}

Unit of

Total

Quantity Measure Cost

Comment

\section{Demobilization}

Equipment Disassembly

Transport equipment to storage area

$\begin{array}{ll}0.5 & \$ 45 \\ 0.5 & \$ 45\end{array}$

$\begin{array}{ll}\$ 22.50 & 23 \\ \$ 22.50 & 23 \\ \$ 22.50 & 23 \\ \$ 22.50 & 5 \\ & 23\end{array}$

work days

$\$ 518$

work days $\$ 518$

work days $\$ 518$

work week \$113

work days \$21

$\$ 0.90$

$\begin{array}{ll}\text { each } & \$ 1,028 \\ \text { each } & \$ 2,569 \\ \text { each } & \$ 2,569 \\ \text { each } & \$ 514 \\ \text { each } & \$ 514 \\ \text { work days } & \$ 863 \\ & \$ 0 \\ & \$ 0\end{array}$

$\begin{array}{ll}\$ 7.50 & 137 \\ \$ 18.75 & 137 \\ \$ 18.75 & 137 \\ \$ 3.75 & 137 \\ \$ 3.75 & 137 \\ \$ 37.50 & 23 \\ \$ 50 & 0 \\ \$ 0 & 0\end{array}$

\section{Notes:}

a) With 3 hrs for set up, meeting, prep, \& demob, Assume 6 samples/ day; 23 work days required

b) Daily calibration source and background check

c) Fill cryostat with liquid nitrogen

d) Assumes 15 min count time

e) One CHP evaluates 20 data sets/hr

f) Adjusts for changes, breaks, respiratory protection, and ALARA

Assumes ISOCS data acquisition is conducted from outside controlled area 
APPENDIX D.

Glossary 


\section{GLOSSARY}

accuracy is a measure of the closeness of an individual measurement or the average of a number of measurements to the true value. Accuracy includes a combination of random error (precision) and systematic error (bias) components that result from sampling and analytical operations.

bias - the systematic or persistent distortion of a measurement process that causes errors in one direction (i.e., the expected sample measurement is different from the sample's true value).

boundaries - the spatial and temporal conditions and practical constraints under which environmental data are collected. Boundaries specify the area of volume (spatial boundary) and the time period (temporal boundary) to which a decision will apply.

comparability is the qualitative term that expresses the confidence that two data sets can contribute to a common analysis and interpolation. Comparability must be carefully evaluated to establish whether two data sets can be considered equivalent in regard to the measurement of a specific variable or groups of variables.

completeness is a measure of the amount of valid data obtained from a measurement system, expressed as a percentage of the number of valid measurements that should have been collected (i.e., measurements that were planned to be collected).

data quality assessment (DQA) - a statistical and scientific evaluation of the data set to determine the validity and performance of the data collection design and statistical test, and to determine the adequacy of the data set for its intended use.

data quality objectives (DQOs) - qualitative and quantitative statements derived from the DQO Process that clarify study objectives, define the appropriate type of data, and specify tolerable levels of potential decision errors that will be used as the basis for establishing the quality and quantity of data needed to support decisions.

data quality objectives process is a systematic planning tool to facilitate the planning of environmental data collection activities. Data quality objectives are the qualitative and quantitative outputs from the DQO Process.

error is the difference between the true value and the measured value of a quantity or parameter.

false acceptance decision error - the error that occurs when a decision maker accepts the baseline condition when it is actually false. Statisticians usually refer to the limit on the possibility of a false acceptance decision error as beta (B) and it is related to the power of the statistical test used in decision making. An alternative name is false negative decision error.

false negative decision error - see false acceptance decision error.

false positive decision error - see false rejection decision error.

false rejection decision error - the error that occurs when a decision maker rejects the baseline condition (null hypothesis) when it actually is true. Statisticians usually refer to the limit on the possibility of a false rejection decision error as alpha, (a), the level of significance, or the size of the critical region, and it is expressed numerically as a probability. An alternative name is false positive decision error.

matrix is the predominant material of which the sample to be analyzed is composed. Matrix is not synonymous with phase (liquid or solid).

percent difference (\%D) is used to compare two values; the percent difference indicates both the direction and the magnitude of the comparison, i.e., the percent difference may be either negative, positive, or zero. (In contrast, see relative percent difference.)

performance-basedmeasurement system - a process in which the data quality needs or limitations of a program or project are specified and serve as a criterion for selecting appropriate analytical methods. Under the PBMS framework, the performance of the method employed is emphasized rather than the specific technique or procedure used in the analysis.

precision - a measure of mutual agreement among individual measurements of the same property, usually under prescribed similar conditions expressed generally in terms of the standard deviation. It may also be expressed as a percentage of the mean of the measurements, such as relative range (RR) (for duplicates) or relative standard deviation (RSD).

productivity loss factor (PLF) is an historically based estimate of the non-productive portion of the work day due to PPE changes, work rules based on As Low As Reasonably Achievable considerations, additional work breaks, etc, when working in an area of radioactive contamination.

quality assurance (QA) - an integrated system of management activities involving planning, implementation, documentation, assessment, reporting, and quality improvement to ensure that a process, item, or service is of the type and quality needed and expected by the customer. 
QA Project Plan (QAPP) - a document describing in comprehensive detail the necessary quality assurance, quality control, and other technical activities that should be implemented to ensure that the results of the work performed will satisfy the stated performance criteria.

quality control (QC) - the overall system of technical activities that measure the attributes and performance of a process, item, or service against defined standards to verify that they meet the stated requirements established by the customer; operational techniques and activities that are used to fulfill requirements for quality.

random errors vary in a non-reproducible way around the limiting mean. These errors can be treated statistically by use of the laws of probability.

relative percent difference (RPD) - used to compare two values, the relative percent difference is based on the mean of the two values, and is reported as an absolute value, i.e., always expressed as a positive number or zero. In contrast, see percent difference.

representativeness is a measure of the degree to which data accurately and precisely represent a characteristic of a population parameter at a sampling point or for a process condition or environmental condition. Representativeness is a qualitative term that should be evaluated to determine whether in situ and other measurements are made and physical samples collected in such a manner that the resulting data appropriately reflect the media and phenomenon measured or studied.

support - the support of a physical sample is the volume from which an individual sample is drawn. For a grab sample the physical support is exactly equal to the size of the physical sample. Arises when assessing the representativeness of results for a heterogenous population or distribution.

systematic errors are errors that are reproducible and tend to bias a result in one direction. Their causes can be assigned, at least in principle, and they can have both constant and variable components. Generally, these errors cannot be treated statistically.

type I error - the statistical term for false rejection decision error.

type II error - the statistical term for false acceptance decision error.

uncertainty is the range of values within which the true value is estimated to lie. It is a best estimate of possible inaccuracy due to both random and systematic errors. 


\section{Section 4}




\title{
COMPARABILITY OF BETASCINT ${ }^{\mathrm{TM}}$ INSTRUMENT IN Sr-90 CHARACTERIZATION AT BROOKHAVEN NATIONAL LABORATORY*
}

\author{
PAUL D. KALB \\ Brookhaven National Laboratory \\ LARRY W. LUCKETT \\ URS Corporation \\ DAVID WATTERS \\ Cabrera Services, Inc \\ LAURENCE W. MILIAN \\ Brookhaven National Laboratory \\ THOMAS ROBERTS \\ Brookhaven National Laboratory
}

\begin{abstract}
This report describes a DOE Accelerated Site Technology Deployment project being conducted at Brookhaven National Laboratory to deploy innovative, radiological, in situ analytical techniques. The technologies are being deployed in support of efforts to characterize the Brookhaven Graphite Research Reactor (BGRR) facility, which is currently undergoing decontamination and decommissioning.

This report focuses on the deployment of the BetaScint Industries Strontium-90 (Sr-90) Spectrometer and assesses its data comparability to baseline methods of sampling and laboratory analysis. The BetaScint ${ }^{\mathrm{TM}}$ system consists of a multi-layer beta scintillation detector array, with a beta radiation entrance window measuring $30-\mathrm{cm}$ by $60-\mathrm{cm}$. Soil samples are prepared, transferred to large area counting trays, and positioned beneath the system entrance window for analysis. Beta particles that pass through the entrance window will excite electrons in the scintillating ribbons resulting in the emission of light pulses, which are counted by photomultiplier tubes. Concentration of $\mathrm{Sr}-90$ in the soil (pCi/g) can be determined in minutes using the field instrument, providing rapid, reliable analysis results and mabling expedited decisions on the remediation status.
\end{abstract}

The Project used the Multi-Agency Radiation Survey and Site Investigation Manual guidance and the Data Quality Objectives process to provide direction for survey planning and data quality assessment. Analytical results have been used to calculate data quality indicators (DQI) for the BetaScint measurements. Among the DQIs assessed in the report are sensitivity, accuracy, precision, bias, and influence of soil moisture. The assessment of the data quality using the DQIs demonstrates that the BetaScint instrument data quality can be comparable to definitive level laboratory analysis when the field instrument is supported by an appropriate Quality Assurance Project Plan.

\footnotetext{
*This work was performed under the auspices of the U.S. Department of Energy.
} 


\section{COMPARABILITY OF THE BETASCINT ${ }^{\text {TM }}$ INSTRUMENT IN SR-90 CHARACTERIZATION AT BROOKHAVEN NATIONAL LABORATORY}

Current Status

Substantial soil excavation efforts will be required to complete the D\&D of many BGRR systems. Based on previous evaluations, the primary potential radionuclide contaminants in these soils are cesium-137 (Cs-137) and strontium-90 (Sr-90). In some areas these contaminants are surficially deposited, while in other locations, such as soils beneath failed underground piping, contamination is expected in subsurface soils covered by clean soil overburden. The relative distribution of Cs-137 and Sr-90 in subsurface soils has been found to vary considerably; Sr-90 contamination has been identified in soils deeper than Cs-137 in many locations. This is due to the high mobility of strontium in soil relative to cesium, which often results in an increase in the ratio of Sr-90 to Cs-137 contamination levels with depth, that is it makes it difficult to establish a ratio to use in quantifying Sr-90 by measuring Cs- 137.

Soil contaminated above site-specific derived concentration guideline levels (DCGLs) will be removed during D\&D of contaminated BGRR underground piping and systems. During such remediation actions, rapid and accurate quantification of Cs-137 and Sr-90 is essential. Results of these measurements are used to confirm that overburden is not contaminated, to determine if soil removal is necessary, and to establish the lower boundary of contamination in excess of site closure criteria (i.e., to determine when to stop digging.) Lack of timely data regarding radionuclide contaminants in the soil results in operational delays which substantially increase costs associated with heavy excavation equipment and remediation personnel.

Rapid quantification of Cs-137 activity concentrations in soil samples has been accomplished using the ISOCS system described previously, with turnaround times on the order of 20 minutes. Although this data can be used to determine whether Cs-137 concentrations are in excess of site closure criteria, Sr-90 activity concentrations cannot be inferred from the results due to the variable relative distribution of these contaminants. Sr-90 is a pure beta emitter with no direct photon emissions, and thus cannot be quantified using the ISOCS gamma spectroscopy system.

Quantification of Sr-90 using conventional EPA laboratory methods typically takes a minimum of two weeks (accelerated turnaround) or a month (standard turnaround). As a potential solution to this time delay, use of the BetaScint ${ }^{\mathrm{TM}}$ fiber-optic sensor has been applied and tested at the BGRR as a technique to rapidly quantify $\mathrm{Sr}-90$ in soil samples. The preliminary results of this evaluation, summarized herein, indicate that the BetaScint ${ }^{\mathrm{TM}}$ system produces accurate and precise results with a quick turnaround time (approximately 20-30 minutes) with a detection sensitivity of approximately $1 \mathrm{pCi} / \mathrm{gram}$. 


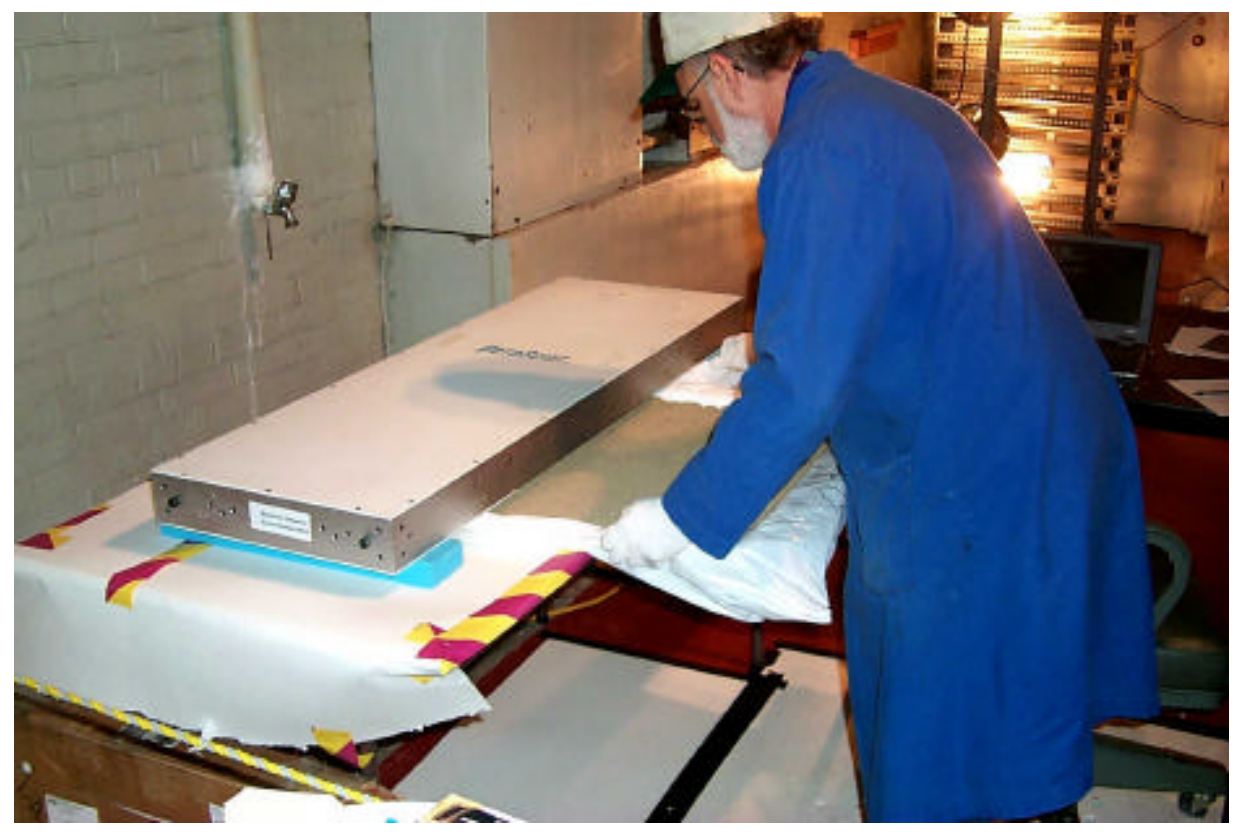

Figure 1. Illustration of BetaScint ${ }^{T M}$ Spectrometer and Soil Sample in Tray

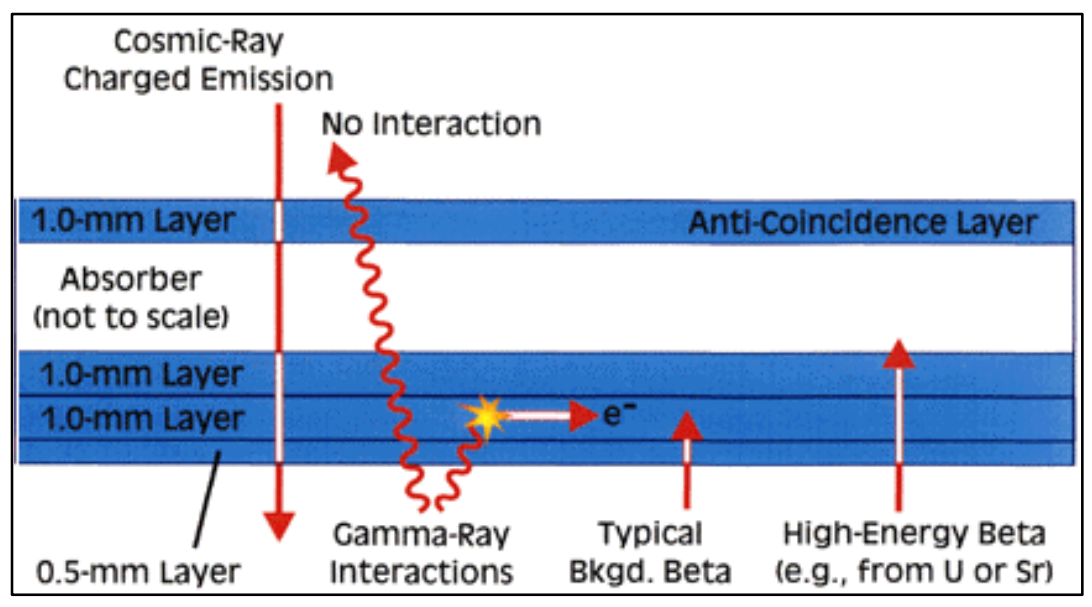

Figure 2 - Schematic Cross-section of BetaScint ${ }^{\mathrm{TM}}$ System 


\section{Technology Description}

The BetaScint ${ }^{\mathrm{TM}}$ system consists of a multilayer beta scintillation detector array, with a beta radiation entrance window measuring $30-\mathrm{cm}$ by $60-\mathrm{cm}$. Scintillating fibers are fashioned into ribbons, which are stacked vertically as shown in Figure 2. Soil samples are prepared, transferred to large area counting trays, and positioned beneath the system entrance window for analysis. Beta particles that pass through the entrance window will excite electrons in the scintillating ribbons resulting in the emission of light pulses, which are counted by photomultiplier tubes.

The BetaScint ${ }^{\mathrm{TM}}$ system relies on the relatively high energy of the beta particle emitted from Y$90\left(\mathrm{E}_{\max }=2.3 \mathrm{MeV}\right)$ a product of Sr-90 decay to quantify Sr-90 in the presence of other betaemitting radionuclides and ambient background radiation, whose beta energies are lower. It should be noted that the BetaScint ${ }^{\mathrm{TM}}$ would also respond to uranium-238 contamination, due to the decay of $\mathrm{Pa}-234 \mathrm{~m}\left(\mathrm{E}_{\max }=2.29 \mathrm{MeV}\right)$; however, uranium-238 is not a significant radionuclide of concern at the BGRR and is not addressed in this paper.

The basic principles of the BetaScint ${ }^{\mathrm{TM}}$ technology to measure Sr-90 are as follows:

- Beta particles that interact and simultaneously produce light pulses in all three lower scintillation ribbons (i.e., one $0.5-\mathrm{mm}$ thick ribbon and two $1.0-\mathrm{mm}$ thick ribbons), but not in the upper anti-coincidence layer, are registered as detection events.

- Any other combinations of simultaneous interactions in any of the scintillation ribbons, including single interactions, are rejected as background (non-sample) events.

This configuration eliminates the system's response to low energy beta particles from naturally occurring background radioactivity and substantially reduces the system's response to cosmic rays and ambient gamma rays. Low energy betas are eliminated because they do not have sufficient energy to penetrate both the $0.5-\mathrm{mm}$ thick layer and the first $1.0-\mathrm{mm}$ layer; thus it is impossible for such beta particles to simultaneously produce light pulses in all three lower scintillation ribbons because they cannot reach the second $1.0-\mathrm{mm}$ layer. Cosmic ray interference is reduced because cosmic events typically result in simultaneous interactions in all four scintillation ribbons, including the upper anti-coincidence layer. Ambient gamma ray interference is reduced because the probability that an incident gamma interacts in the three lower scintillation ribbons is much smaller than the probability of an interaction by a beta particle of comparable energy.

\section{System Operation}

1. For calibration and operation, a two-pound soil sample is typically dried, sieved to remove organic matter and rocks over 0.25 inches in size, and spread evenly over a large area (18" x 30") counting tray. The tray is then positioned beneath (within 1/4" of) the radiation entrance window of the detector and counted for five minutes. Following the analysis, the system reports the number of coincident events occurring in the three scintillating layers during the counting period. This count is converted to Sr-90 activity 
concentration in the soil, based on the detection efficiency correlation established using the spiked site soils.

2. Initially, the Sr-90 detection efficiency of the BetaScint ${ }^{\mathrm{TM}}$ system is established by measuring its response to site-specific calibration standards. These calibration standards are prepared by spiking clean (non-contaminated) site soils with known quantities of Sr90. The net system response is directly proportional to Sr-90 activity concentration because it is almost entirely due to Sr-90 beta interactions.

3. Routine daily operations of the BetaScint ${ }^{\mathrm{TM}}$ system include the performance of daily quality control checks and background measurements.

- Quality control checks consist of analysis of a calibration standard of known activity. The results of the quality control checks are compared against established acceptance criteria to determine whether the instrument is functioning properly.

- Background checks consist of counting the sample tray without a sample in place. These measurements, which are performed daily at a minimum, are subtracted from gross sample counts to establish net detector response.

Implementation at BNL

The BetaScint ${ }^{\mathrm{TM}}$ system was initially deployed at Brookhaven for a two week demonstration during the period of December 6 - 17, 1999. Soil samples from various environmental restoration areas at the Brookhaven site were collected and analyzed using the system.

\section{System Calibration}

Four calibration standards were prepared from an NIST-traceable Sr-90 solution and site soils collected from an area that has not been impacted by site operations. Prior to spiking the standards, the soils were analyzed using the ISOCS gamma spectroscopy system to assist in determining whether the soils were impacted by site operations. The results of these analyses did not indicate the presence of gamma emitting radionuclide contaminants in excess of background levels. Following preparation, the calibration standards were analyzed by the BetaScint ${ }^{\mathrm{TM}}$ system and a correlated Sr-90 detection efficiency was established. Results are indicated in Figure 3.

\section{Analytical Stability}

Daily, or more frequent, quality control checks were performed (a total of 25 QC checks) by analyzing the $22.5 \mathrm{pCi} /$ gram calibration standard that was prepared. The average result of these analyses was $22.2 \mathrm{pCi} /$ gram (see Figure 4). All results were within \pm 2 sigma of the average value, with the exception of one result that was slightly less than 2 sigma, indicating that the system response is stable over time and exhibits acceptable levels of precision. Duplicate analyses were also performed on most samples to evaluate the precision of the system. In general, the results of duplicate analyses were within acceptable statistical bounds. 


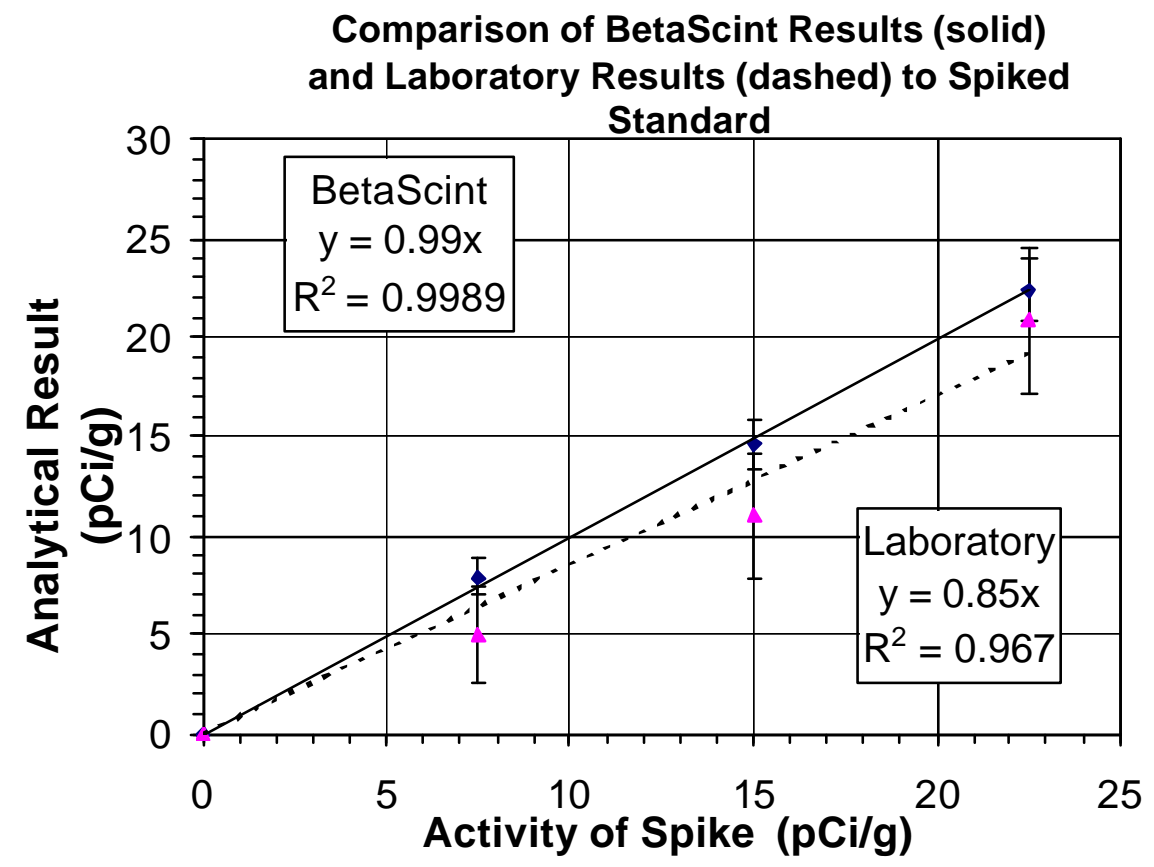

Figure 3. BetaScint and Laboratory Analysis of Spiked Standards

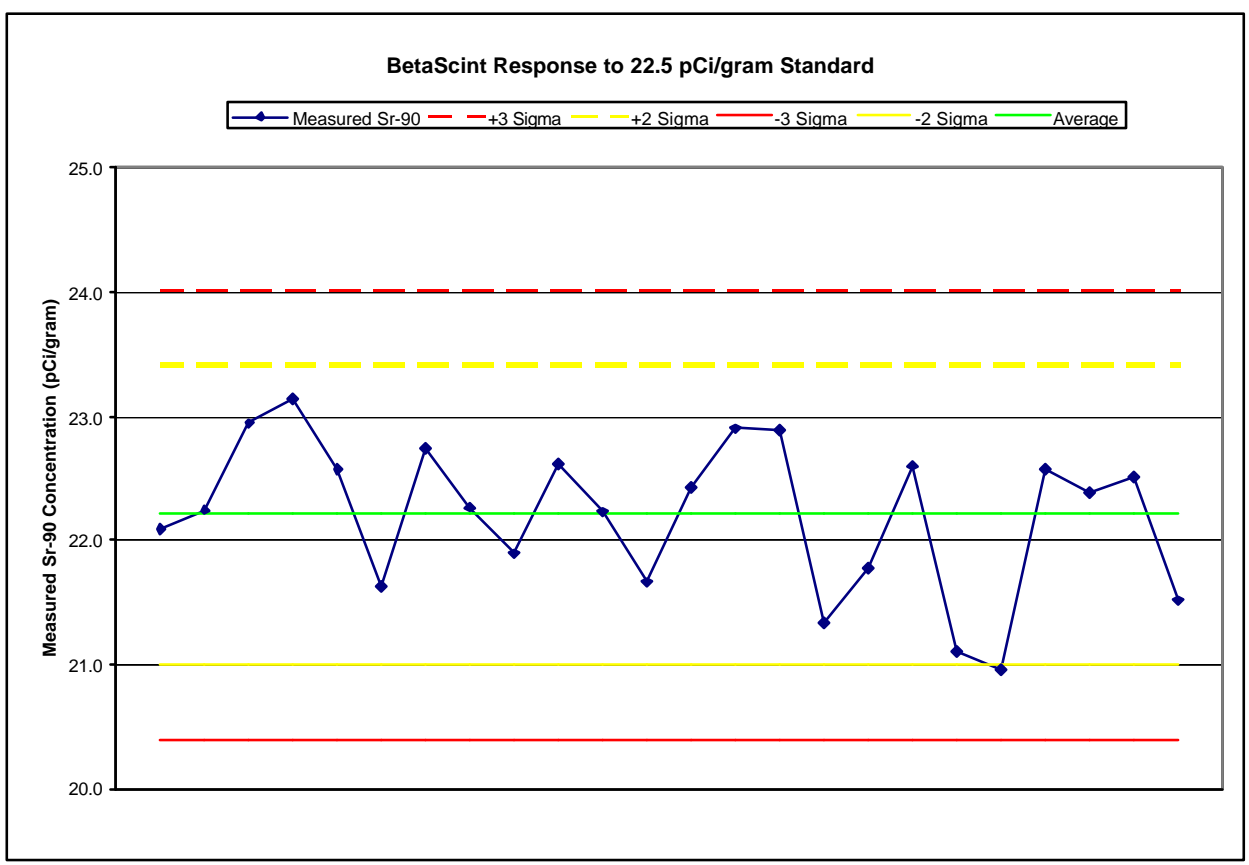

Figure 4. - Results of Quality Control Measurements 


\section{Analysis Variability}

In order to evaluate the accuracy of the BetaScint ${ }^{\mathrm{TM}}$ analyses, the calibration standards were reanalyzed on the BetaScint ${ }^{\mathrm{TM}}$ following system calibration. The results of these analyses are summarized in Table 1. As can be seen, the BetaScint ${ }^{\mathrm{TM}}$ results were within $\pm 8 \%$ of the calibration standard activity concentrations, indicating that the system exhibits acceptable levels of accuracy.

Table 1

Results of Calibration Standard Measurements

\begin{tabular}{|c|c|c|}
\hline $\begin{array}{c}\text { Spiked Sr-90 } \\
\text { Concentration } \\
(\mathrm{pCi} / \mathrm{g})\end{array}$ & $\begin{array}{c}\text { Measured Sr-90 } \\
\text { Concentration } \\
(\mathrm{pCi} / \mathrm{g})\end{array}$ & \% Difference \\
\hline 7.5 & $7.9 \pm 1$ & +5.4 \\
\hline 15 & $16 \pm 2$ & +7.7 \\
\hline 22.5 & $22 \pm 2$ & -0.30 \\
\hline 610 & $562 \pm 40$ & -7.9 \\
\hline
\end{tabular}

* Errors reported at the $95 \%$ confidence level

\section{Analytical Intercomparison}

To support the evaluation of system accuracy, 7 soil samples and aliquots from the 4 calibration standards were sent off-site for conventional baseline Sr-90 analysis. The results, shown in Figure 3, indicate a slight over response of the BetaScint instrument (slope $=1.11$ ) and an acceptable correlation coefficient $\left(\mathrm{R}^{2}=0.81\right)$. It should be noted, however, that off-site Sr-90 analyses are based on a very small sample size (\#1 g), whereas BetaScint evaluates $2 \mathrm{~kg}$ samples of soil. Thus, if contamination is not $100 \%$ homogeneously distributed, BetaScint may provide a more representative characterization.

\section{Influence of Soil Moisture}

Samples were prepared for analysis in accordance with BetaScint ${ }^{\mathrm{TM}}$ guidance. This involved sifting soil using a 0.25 -inch mesh sieve, spreading the soil onto counting trays, and the drying the soil using heat lamps. During performance of this process, it was determined that the sample drying time was excessive and could adversely affect the objective of quick sample result turnaround. In order to determine whether sample drying was necessary, a cursory evaluation of the effects of soil moisture content on the system was performed. De-ionized water was added to the $610 \mathrm{pCi} / \mathrm{gram}$ calibration standard, the standard was thoroughly mixed, its moisture content was measured, and it was analyzed using the system. This process was repeated for moisture contents of $0,4,9.5$, and $14.3 \%$. At $14.3 \%$ moisture content the soil became saturated, as the site soil is sandy and does not absorb much water. The results of this evaluation are plotted in Figure 6. As can be seen, the system response was reduced by less than $20 \%$ for saturated soil compared to dried soil. Based on these results, a more rigorous analysis of the effects of moisture content could be used to develop a correction curve for un-dried samples. This would significantly increase the throughput of the system, eliminating the need for drying and only requiring a brief moisture analysis be performed. Although this correction would adversely 
affect the detection sensitivity of the system, based on these results it is unlikely that it would be greater than $2 \mathrm{pCi} / \mathrm{gram}$ for a 5-minute count of saturated soil.

\section{Sample Analysis}

During the two-week demonstration, a total of 145 evaluations were performed on 35 samples. The analytical count time for each analysis was 5-minutes. Based on the BetaScint ${ }^{\mathrm{TM}}$ results, $\mathrm{Sr}$ 90 activity concentrations in these samples ranged from not detectable to approximately 70 pCi/gram. The 5 minute count time yielded a minimum detectable activity concentration of approximately $1.2 \mathrm{pCi} /$ gram at the $95 \%$ confidence level, which is considerably less than the BGRR DGCL of $15 \mathrm{pCi} / \mathrm{gram}$.

\section{Conclusions}

The BetaScint ${ }^{\mathrm{TM}}$ system was initially deployed on the Brookhaven site for a two-week field demonstration prior to integration into on-going characterization activities. Evaluation of the system indicates that it can provide accurate and repeatable analyses of $\mathrm{Sr}-90$ in soil with an acceptable detection sensitivity and a throughput of approximately 20-30 minutes per sample. This throughput could be adversely affected by the need to dry samples prior to analysis. However, preliminary data indicates that soil moisture correction factors can be applied (if necessary) to eliminate the need to dry samples.

\section{$\underline{\text { References }}$}

U. S. EPA, EPA Guidance for the Data Quality Objectives Process (EPA QA/G-4), EPA/600/R96/055, U. S. Environmental Protection Agency, Washington, DC. August 2000.

U. S. EPA, EPA Guidance for Quality Assurance Project Plans (EPA QA/G-5), EPA/600/R98/018, U. S. Environmental Protection Agency, Washington, DC. February 1998.

U. S. EPA, Guidance for Data Quality Assessment (EPA QA/G-9), EPA/600/R-96/084, U. S. Environmental Protection Agency, Washington, DC. January 1998.

U. S. EPA, U. S. NRC, U. S. DOE, and U. S. Department of Defense, Multi-Agency Radiation Survey and Site Investigation Manual (MARSSIM), EPA 402-R-97-016. Washington, DC. December 1997; revised August 2000. [also issued by U. S. Nuclear Regulatory Commission as NUREG-1575 and by U. S. Department of Energy as DOE/EH-0624].

U. S. DOE, Innovative Technology Summary Report: BetaScint ${ }^{T M}$ Fiber-Optic Sensor for Detecting Strontium-90 and Uranium-238 in Soil, U. S. Department of Energy, Office of Science and Technology, December 1998. 


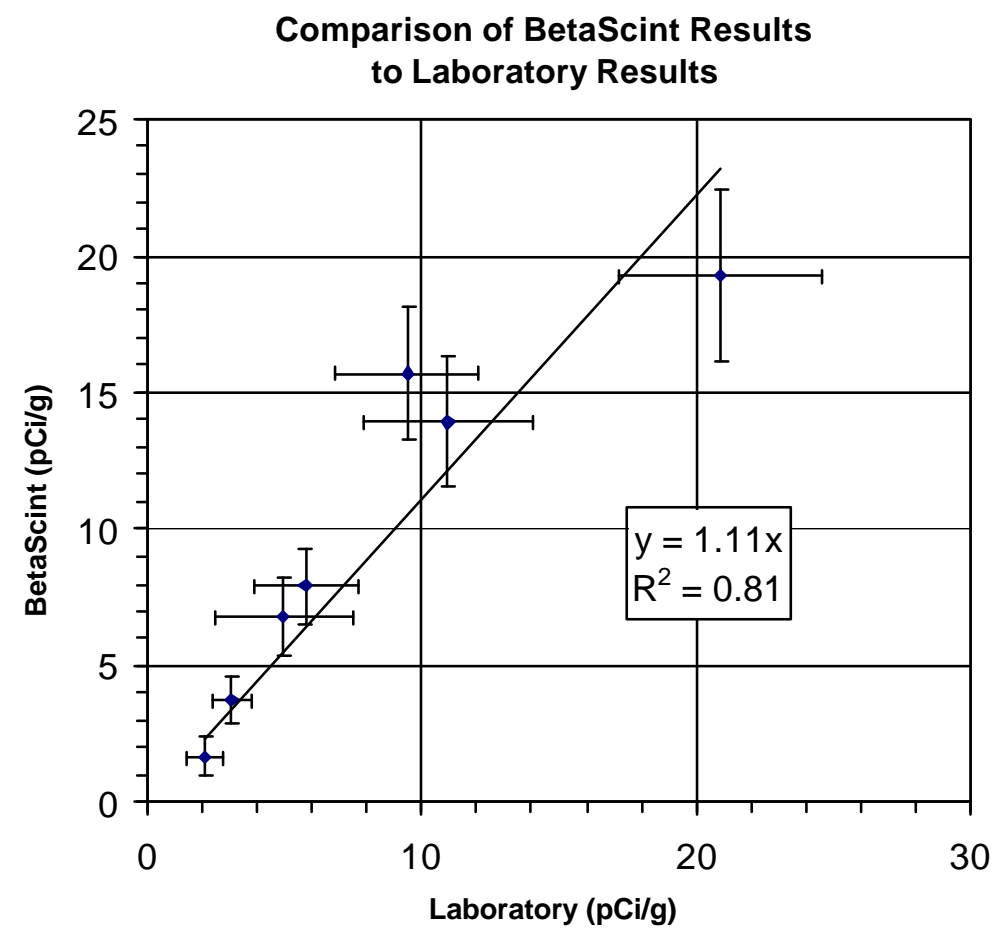

Figure 5. Comparison of field samples on two analysis systems.

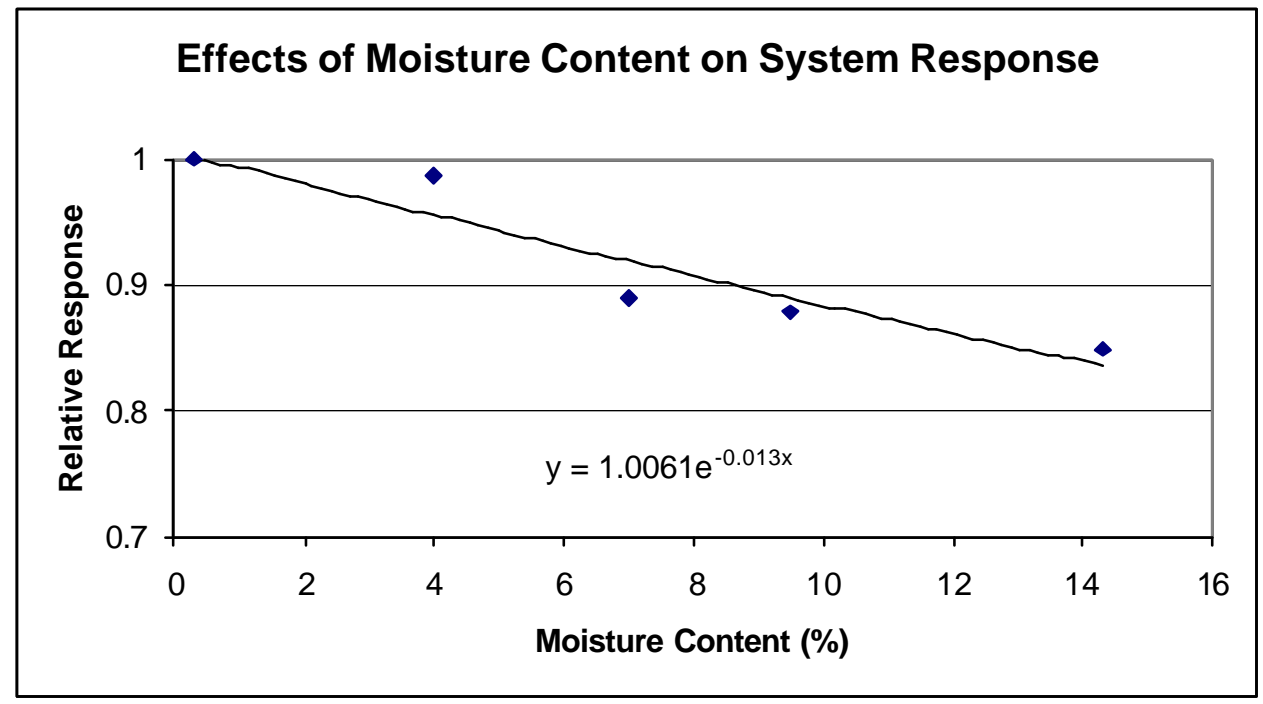

Figure 6. - Effects of Moisture Content on System Response 
Section 5 


\title{
BRDDKTDYTEN \\ NATIONAL LABORATORY
}

\section{Standard Operating Procedure}

\author{
Analysis of Gamma Spectrum Files \\ Using Canberra ISOCS System \\ [software ver 3.0] \\ SOP - DAT2
}

for the

Brookhaven National Laboratory

Accelerated Site Technology Deployment Project

\section{DEPLOYMENT OF \\ INNOVATIVE CHARACTERIZATION TECHNOLOGIES \\ AND IMPLEMENTATION OF THE MARSSIM PROCESS \\ AT RADIOLOGICALLY CONTAMINATED SITES}

Version 3

February 23, 2000

[replaces version 1, dated August 27, 1999]

APPROVED

Larry W. Luckett, CHP

Project Analytical Physicist, BNL-DAT 


\title{
SOP-DAT2 Analysis of Gamma Spectrum Files Using Canberra ISOCS System [software ver 3.0]
}

\author{
Table of Contents
}

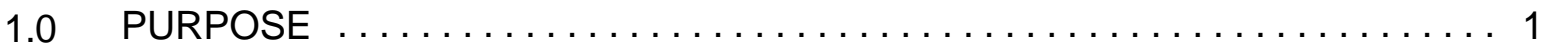

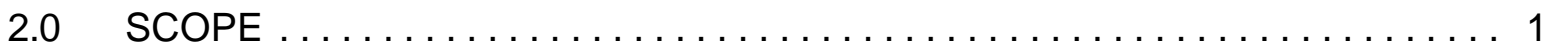

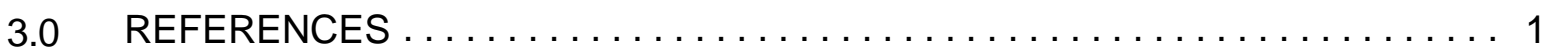

4.0 DEFINITIONS $\ldots \ldots \ldots \ldots \ldots \ldots \ldots \ldots \ldots \ldots \ldots \ldots \ldots \ldots \ldots \ldots \ldots \ldots$

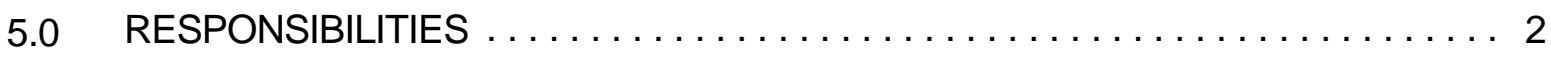

6.0 OPERATIONAL PRECAUTIONS $\ldots \ldots \ldots \ldots \ldots \ldots \ldots \ldots \ldots \ldots \ldots \ldots \ldots \ldots \ldots$

7.0 EQUIPMENT AND TECHNICAL REQUIREMENTS $\ldots \ldots \ldots \ldots \ldots \ldots \ldots \ldots$.

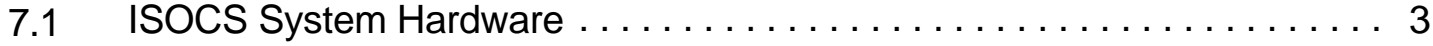

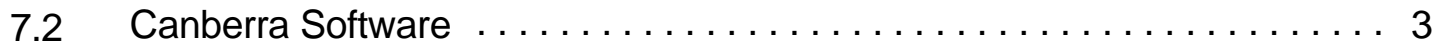

8.0 PREREQUISITE KNOWLEDGE AND ACTIONS $\ldots \ldots \ldots \ldots \ldots \ldots \ldots \ldots \ldots 4$

8.1 Correspondence between Sample Number and Spectrum Data File . . . . 4

8.2 Locating Spectrum Data Files on the Workstation Computer . . . . . . . 4

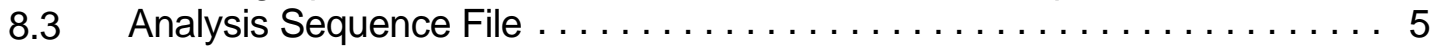

8.4 Canberra Software Inter-Communication $\ldots \ldots \ldots \ldots \ldots \ldots \ldots \ldots \ldots$

8.5 Geometry Template Worksheet Forms $\ldots \ldots \ldots \ldots \ldots \ldots \ldots \ldots \ldots$

8.6 Physical Dimensions and Materials $\ldots \ldots \ldots \ldots \ldots \ldots \ldots \ldots \ldots \ldots \ldots \ldots \ldots \ldots \ldots$

9.0 QUANTITATIVE OBJECT ANALYSIS PROCEDURES $\ldots \ldots \ldots \ldots \ldots \ldots \ldots \ldots$

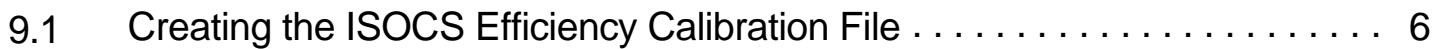

9.2 Gamma Spectrum Analysis using the ISOCS Efficiency File. . . . . . . . 10

10.0 DATA FILE BACKUP AND TRANSFER $\ldots \ldots \ldots \ldots \ldots \ldots \ldots \ldots \ldots \ldots \ldots$

11.0 MAINTENANCE $\ldots \ldots \ldots \ldots \ldots \ldots \ldots \ldots \ldots \ldots \ldots \ldots \ldots \ldots \ldots \ldots \ldots \ldots$

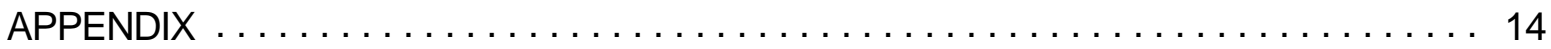




\section{SOP-DAT2 Analysis of Gamma Spectrum Files Using Canberra ISOCS System [software ver 3.0]}

\subsection{PURPOSE}

This procedure describes the steps necessary for quantitative gamma spectrum analysis and reporting using the Canberra In Situ Object Counting System (ISOCS ). Instructions are provided for software environment setup, routine spectrum analysis, software modifications for specific acquisition and analysis requirements, and spectrum file management.

\subsection{SCOPE}

This procedure addresses operation of the Canberra ISOCS software system for quantitation of gamma emitting radionuclides in situ and in samples collected during remediation activities at the Brookhaven National Laboratory.

This procedure addresses operation of the ISOCS software, ver 3.0, distributed in September, 1999. The previous version of this procedure (ver 1, August 1999) addressed the operation of ISOCS software, version 1.2E.

Gamma radiation spectra will be accumulated in documented measurement configurations (geometries), using a high purity germanium (HPGe) detector. Procedures for spectrum acquisition are addressed in a separate procedure (SOP-DAT1, ref 3.6). Analysis activities and results will be documented in the Project files.

This procedure addresses the analysis of gamma spectra using the ISOCS system. The actual surfaces, items, and/or samples to be assessed are identified in a Project Specific Survey Plan (PSSP) that should be available to the instrument operator. The PSSP can vary in complexity from a verbal briefing by the Project Manager to a formally approved document specifying items, location/sample identifiers, locations, instrument positioning, and set-up parameters. At appropriate steps, this procedure identifies when reference to the PSSP is indicated.

\subsection{REFERENCES}

3.1 Model S503 PROcount-2000: User's Manual, No. 9231025B. Canberra Industries, Meriden, CT. June 1999. ^

3.2 Model S500 GENIE-2000 Spectroscopy System: Operations, No. 9230846E. Canberra Industries, Meriden, CT. June 1999. ^ 
3.3 Model S505 Genie-2000 QA Software: User's Manual, No. 9230871C Canberra Industries, Meriden, CT. June 1999. ^

3.4 Model S573 ISOCS Calibration Software for Genie-2000: User's Manual, No. 9231013B, Canberra Industries, Meriden, CT. August 1999.

3.5 ISOCS Efficiency Calibration, Validation, and Internal Consistency Document, No. 9231205C. Canberra Industries, Meriden, CT. September 1999.

3.6 BNL SOP-DAT1. Gamma Spectrum Acquisition Using Canberra ISOCS System. Department of Advanced Technology, BNL, Upton, NY. August 19, 1999.

3.7 BNL SOP-DAT3. Quality Control Measurements When Using Canberra ISOCS System. Department of Advanced Technology, BNL, Upton, NY. Under Development.

NOTE: References marked $\left({ }^{\wedge}\right)$ are available as electronic files on the Documentation portion of the Genie-2000 software distribution $\mathrm{CD}-\mathrm{ROM}$ and should be available for on-line review on the workstation computer.

\subsection{DEFINITIONS.}

ISOCS In situ object counting system, the Canberra Industries name for the quantitative gamma spectroscopy analysis system

in situ

Performed in the natural or normal place; at the site of origin without invasive procedures or disruption of the media

PSSP Project specific survey plan

System Manager an individual with knowledge, training, or experience capable of setting up and modifying the software operating environment of the Canberra ISOCS.

\subsection{RESPONSIBILITIES}

5.1 The System Manager is responsible for

- maintaining the ISOCS instrument and accessories referred to in this procedure, and

- ensuring that the instrument is operational and calibrated for routine and nonroutine geometries, as needed. 
5.2 Personnel qualified on this procedure are responsible for

- reviewing the PSSP to ensure knowledge of the survey objective prior to performing the analysis,

$\mathrm{C}$ analyzing gamma radiation spectra in the several routine geometries specified this procedure, and

C transferring electronic data files upon completion of the analysis.

\subsection{OPERATIONAL PRECAUTIONS}

This procedure addresses the processing of electronic files on a computer work station. The operational hazards are those associated with routine computer use in an office location.

Processing of electronic files may also be performed on the laptop computer connected directly to the Canberra Industries ISOCS System. The system is a mobile instrument and can be taken to and used in locations with a variety of physical, environmental, health, and safety hazards. When performing in the field, the instrument operator should coordinate with BNL safety personnel to become familiar with any hazards and controls associated with the location being surveyed.

\subsection{EQUIPMENT AND TECHNICAL REQUIREMENTS}

\subsection{ISOCS System Hardware}

The Canberra Industries ISOCS hardware for gamma spectrum acquisition is identified in SOP-DAT1, ref 3.6. The only portion of the hardware required for this analysis procedure is the laptop computer or a separate computer workstation with the ISOCS software system loaded. Access to a printer from the computer workstation is necessary if hard copy reports are required.

\subsection{Canberra Software}

Required software programs and the setup of the operational environment are discussed in Appendix 1 of this procedure. These setup actions are only required when re-installing the software, or upon establishing the software on a new computer workstation. The need to perform or change any of these system components should be discussed with the System Manager. 


\subsection{PREREQUISITE KNOWLEDGE AND ACTIONS}

\subsection{Correspondence between Sample Number and Spectrum Data File}

During spectrum acquisition, the Canberra operating system assigns a file name to the spectrum data file that is separate and independent of any sample number or identification assigned by the operator.

The name of the file will be of the form : STCnnnnn.CNF where STC is the Sample Type Code, nnnnn is the Sample Sequence Number, and $C N F \quad$ is the file identifier for any spectrum data file.

8.1.1 To perform the analysis, one must know the name of the spectrum data file that corresponds to the sample or object description of interest. The spectrum data file name should have been recorded in the field logbook at the time of acquisition, and may be found in that notebook.

8.1.2 Alternatively, the lines of descriptive text entered in a file during spectrum acquisition can be observed using Genie2000 Gamma Acquisition and Analysis (GAA) to verify that the spectrum file corresponds to the sample or object of interest.

a. Start the GAA program by double clicking on the Gamma Acquisition \& Analysis icon or by choosing Programs, Genie-2000, and Gamma Acquisition \&

Analysis from the Start Menu. The main spectrum display screen is displayed.

b. Click on File and then Open Datasource to obtain the file directory dialog box.

c. Change the directory to the location of the *..nf file to be reviewed.

d. Highlight the file to be reviewed and press $\langle O K>$ to display that file.

e. Click Edit and then Sample Info to display the Sample information dialog box. The sample ID number is listed in a field on the upper right corner of the dialog box. The sample description is displayed in the left center of the dialog box.

f. Click Cancel to return to the main spectrum display screen.

At this point additional spectrum data files may be reviewed until the sample of interest is found.

g. To exit GAA, click File and Exit.

8.2 Locating Spectrum Data Files on the Workstation Computer.

8.2.1 Ensure that the spectrum file you wish to analyze is in the appropriate directory:

Spectrum data files acquired under PROcount are stored in a sample-type subdirectory within the directory:

C:|pcnt2klcamfiles $\mid$

The name of the file will be of the form as shown in $§ 8.1$, above. 
8.2.2 If the spectrum was acquired directly in Genie2000 GAA, rather than using PROcount, the spectrum file will be stored in the directory:

C:Igenie2klcamfiles।

Copy/move the file to the appropriate sub-directory within the directory C:|pcnt2klcamfiles\ for use in this procedure.

\subsection{Analysis Sequence File}

The name of the appropriate pre-defined analysis sequence must be known prior to performing the analysis. This information will be needed in Step 9.2.10, below. For the BNL ASTD project, the typical analysis sequence is entitled: "ASTD Default Analysis with MDA", or a specific analysis may be specified in the PSSP.

The Canberra operating system uses an analysis sequence file ( ${ }^{*}$.asf) to define the steps in analyzing and in reporting the results of an analysis. The files are found in the directory C:|pcnt2klasfiles|

The Analysis Sequence File Editor is used to define and edit an analysis sequence file. This operation defines such aspects as report format, reporting steps, algorithms for calculating error and minimum detectable activity, units and scale factors/multipliers, and the energy/decay library for radionuclide identification. The use of the Analysis Sequence File Editor is described in the Genie-2000 Users Manual, ref 3.2 .

\subsection{Canberra Software Inter-Communication}

To enable communication and data transfer between the various Canberra programs, the Genie2000 Virtual Data Manager must be running in background on the analytical computer. If it is not already running, start the Virtual Data Manager by choosing Programs, Genie-2000, and Virtual Data Manager from the Start Menu. A button indicating "Genie 2000 VDM" should appear on the Windows Application Bar at the bottom of the screen.

\subsection{Geometry Template Worksheet Forms}

Use of this procedure is dependent on a familiarity with ISOCS methods and with the analysis geometries defined in the ISOCS models. The availability of ISOCS Geometry Template Worksheet Forms eases the visualization of the model geometry. The appropriate ISOCS Geometry Template Worksheet form should be filled-in with the chosen parameter values during the analysis and filed with the final data analysis document package upon completion. 
NOTE: Additional copies of the Geometry Template Worksheets can be printed from the MS Word document file C:lisocsltemplate.libltemplates.doc

\subsection{Physical Dimensions and Materials}

Accurate quantitative evaluation relies on knowledge of the constituents and physical dimensions of the object in the detector field of view at the time of spectrum acquisition. Access to the field notebook and/or photographs and notes recorded during spectrum acquisition are necessary to performing the analysis. Additional information on material composition and dimensions may be provided in the PSSP.

\subsection{QUANTITATIVE OBJECT ANALYSIS PROCEDURES}

\subsection{Creating the ISOCS Efficiency Calibration File}

Prior to performing this procedure, see Section 8.0, prerequisite knowledge and actions.

9.1.1 Start the ISOCS Program by double clicking on the ISOCS icon or choosing Programs, Genie-2000 and ISOCS from the Start Menu. The ISOCS Main Menu screen is displayed with a Header at the top and a Status Bar at the bottom.

NOTE: The mouse is not operable under ISOCS; use arrow keys to maneuver around menu and to highlight your choice. use $<$ Enter $>$ to accept a selection use $<\mathrm{Esc}>$ to exit to previous level

9.1.2 To identify the Detector and Collimator used in the spectrum acquisition:
a. Highlight Equipment on the Main Menu Header and
b. Highlight Detector on the drop-down menu and
Press <Enter>
c. Highlight the specific detector used in the analysis and
Press <Enter $>$
d. Highlight Circular Collimator on the drop-down menu and
Press $<$ Enter $>$
e. Highlight the specific collimator on the drop-down menu and
Press $<$ Enter $>$
You can now use the arrow to go to another Header on the Main Menu

9.1.3 To choose the Geometry Template for the analysis:

a. Highlight In Situ Template on the Main Menu Header and

$$
\begin{aligned}
& \text { Press < Enter }> \\
& \text { Press < Enter }>
\end{aligned}
$$

b. Highlight the specific geometry template on the drop-down menu and

NOTE: At this point, to retrieve a previously saved ISOCS parameter file for the specific combination of detector-collimator-geometry, highlight File on the Main Menu Header, press <Enter>, highlight Load from the drop down menu, press $<$ Enter $>$. A list of previously saved calibrations is displayed. If the list is too long, $<$ Page Up $>$ or $<$ Page Down $>$ is used to scroll to 
additional file names. Highlight the specific file and press <Enter>. The previous physical parameter data is loaded and may be modified by the following steps.

9.1.4 To Enter Physical Data for the analysis:

NOTE: The current units for the various dimensions are displayed on the status bar at the bottom of the screen. When entering data, to change the units highlight Parameter input on the Main Menu Header, press <Enter>, highlight Dimension Units on the drop down menu, press <Enter>, highlight the unit of choice in the dimension category, and press <Enter $>$.
a. Highlight Parameter input on the main Menu Header and
Press <Enter $>$

b. Highlight Source Dimensions on the drop-down menu and

Press <Enter>

NOTE: Use the ISOCS Geometry Template Worksheet Form for the chosen geometry model as a guide for which data positions require values.

c. Use arrow keys to move to the data entry position for the parameter of interest and type in a value. Note that the units for the various dimensions are displayed on the status bar at the bottom of the screen.

d. Use the arrow keys to move to the next data entry position and type in the value.

e. With the highlight in the Material column, press <Enter> to display a list of previously defined materials. You must select one from this list: use the arrow keys to highlight the specific choice and press <Enter>.

NOTE: To edit the material list and define a new material, navigate to Parameter Input on the Main menu header and select Library Materials Edit from the drop down menu. [Defining materials is discussed in Section 4.4.5, of the ISOCS User's Manual, ref 3.4]. If using a new definition, write the material definition on the Worksheet form.

f. When all data have been entered on the screen form, write the values and units on the Worksheet form.

g. Press $<$ Esc $>$ to return to the Main Menu Screen.

9.1.5 To perform the detector Efficiency Calculation for the geometry chosen:
a. Highlight File on the Main Menu Header and
Press <Enter $>$

b. Highlight Calc+Save on the drop-down menu and

Press < Enter>

NOTE: The highlight should re-appear in a file save dialog box directly above the status bar at the bottom of the screen.

c. Use arrow keys to move to the FILENAME data entry position; type in a name limited to eight alphanumeric characters (do not use "." or a blank space; use underscore for space). The FILENAME may be the sample number identified in the PSSP.

NOTE: This FILENAME will be used to save the template dimensions in a geometry definition file and later is the default name for the efficiency calculation file. This is the Filename used to recall the geometry data for reanalysis, as discussed in the note at $\S 9.1 .3$, above. This filename will also be used in the quantitative analysis, at $§ 9.2 .8$, below. 
d. Write the FILENAME on the Geometry Template Worksheet Form.

e. Use arrow keys to move to the DESCRIPTION data entry position; type in a description of up to 16 alphanumeric characters.

NOTE: This description appears on the PROcount Default Analysis Report, so it should be descriptive and unique. Type in the FILENAME as part of this description to provide an audit link from the calibration file to the analysis report.

f. Write the description text on the Geometry Template Worksheet Form.

g. Use arrow keys to move to the COMMENTS data entry position; type in a text string of up to 48 alphanumeric characters.

h. When all data has been entered, press <Enter $>$ to begin calculation.

NOTE: The ISOCS program performs a review of entered values, and displays a screen message identifying errors, if any. Take heed of where the errors have occurred and press <Esc> to return to the Main Menu Screen. Use the procedure in the previous steps to edit values and enter data until the calculation will progress.

i. The program displays the ELAPSED TIME to show the progress in completion of the Efficiency Computation and displays the convergence values attained on each iteration of the computation.

NOTE: When the estimated calculation time will be longer than a few minutes, ISOCS provides an option to abort the calculation. Press $\langle\mathbf{Y}>$ to continue the calculation, or any other key to stop.

Upon completion of the calculation, the message appears that states:

Press $<\mathrm{Y}>$ to see full listing or $<\mathrm{Esc}>$ to continue Press $<$ Esc $>$

The highlight returns to the File menu position on the Main Menu Header.

j. Use the down arrow to move the highlight to Exit and Press <Enter>

The program exits the calculation module and enters a module for editing the file description information and saving the efficiency calibration file.

\subsubsection{Saving the Efficiency Calibration File}

When the program exits the ISOCS efficiency calculation module, it enters a module of dialog boxes for editing and saving the efficiency file. In this module, the mouse is again active and may be used to re-position the pointer/highlight.

a. The first dialog box offers a choice of Efficiency Options which determines the units for the quantitative output of the analysis. Refer to the PSSP for guidance in choice of units.

Press $<$ Efficiency $>\quad$ to choose units of total activity $[\mu \mathrm{Ci}]$ - the analysis will be performed to generate a report that quantifies the total radioactivity detected in the field of view of the instrument and reports it in units of activity $[\mu \mathrm{Ci}]$.

Press $<$ Efficiency ${ }^{*}$ Mass $>$ to choose units of activity concentration $[\mu \mathrm{Ci} / \mathrm{g}]$ in solid 
media or objects, such as soil or waste in a container the analysis will be performed to generate a report that quantifies the concentration of activity detected in the material defined in the efficiency file and reports it in units of activity/mass $[\mu \mathrm{Ci} / \mathrm{g}]$.

Press $<$ Efficiency ${ }^{\star}$ Area $>$ to choose units of areal activity concentration $\left[\mu \mathrm{Ci} / \mathrm{m}^{2}\right]$ in a surface such as open ground, walls or floors - the analysis will be performed to generate a report that quantifies the concentration of radioactivity per unit area detected in the geometry surface defined in the efficiency file and reports it in units of activity/area $\left[\mu \mathrm{Ci} / \mathrm{m}^{2}\right]$.

Press $<$ Efficiency ${ }^{*}$ Length $>$ to choose units of linear activity concentration $[\mu \mathrm{Ci} / \mathrm{m}]$ in a cylindrical object, such as a pipe, rod or tank - the analysis will be performed to generate a report that quantifies the concentration of radioactivity per unit length detected in the object defined in the efficiency file and reports it in units of activity/length $[\mu \mathrm{Ci} / \mathrm{m}]$.

NOTE: While this choice will select the units to be used in the calculation, the actual units will not appear in the final printed report. Failure to choose the appropriate units or failure to record the choice on the Worksheet form will result in mis-interpreting the analytical report.

Write the efficiency mode on the Geometry Template Worksheet Form.

After pressing one of the buttons, the system displays a message:

"Building Efficiency Results Table. Please Wait..."

b. The next dialog box displays the ISOCS: Efficiency Results tabulated at the predetermined energy values.

- $\quad$ to choose a different efficiency option Press < Reselect >

The system returns to the previous dialog box.

- to accept the efficiency results Press < Ok >

The system displays a message

"Creating CAM file. Please Wait..."

c. The next dialog box is the Select Efficiency Function that allows several options for reviewing or changing the results of the efficiency calculation

Press < Exit > to quit the program without saving the calibration file.

Select "View Efficiency Plot' and Press $<\mathbf{O k}>$ to display the Efficiency Calibration Curves screen with several options for modifying or accepting efficiency curve coefficients. To accept the displayed efficiency curve data Press $<\mathbf{O k}>$ 
Select "Save Efficiency File" and Press < Ok > to accept the results of the efficiency calculation.

d. The next dialog box is the Comment Edit screen which displays the COMMENTS field entered in \$9.1.5.e, above, with the text modified to reflect the units of the output chosen in \$9.1.6.a, above.

- If the initial text in the comment field is "ISOCS", then the units in the analysis reports will be in activity.

- If the initial text in the comment field is "ISOCS UNITS=ACT/G", then the units in the analysis reports will be in activity concentration.

- If the initial text in the comment field is "ISOCS UNITS=ACT/M2", then the units in the analysis reports will be in areal activity concentration.

- If the initial text in the comment field is "ISOCS UNITS=ACT/M", then the units in the analysis reports will be in linear activity concentration .

Write the units text on the Geometry Template Worksheet Form.

To accept the displayed information Press $<\mathbf{O k}>$.

e. The next dialog box is the ISOCS File Menu screen, which displays the eight character FILENAME assigned in §9.1.5.c, above, and allows assignment of a new name.

NOTE: At this point, the name of the efficiency calibration file may be edited to contain in excess of eight characters, so that a more descriptive title may be assigned. However, the name of the geometry definition file, saved at \$9.1.5.c, above, will not be changed by editing the filename here.

Write any new FILENAME on the Geometry Template Worksheet Form.

To accept the displayed information Press $<\mathbf{O k}>$.

Displays a message "Processing...Please Wait" and then exits to Windows. The calibration file is saved as c:Igenie2klcalfiles\FILENAME.cal

\subsection{Gamma Spectrum Analysis using the ISOCS Efficiency File.}

Prior to performing this procedure, see Section 8.0, prerequisite knowledge and actions. This analysis can only be performed following the creation of the ISOCS calibration file using the procedure in $\$ 9.1$, above.

9.2.1 Start PROcount software package by double clicking on the PROcount 2000 icon or by choosing Programs, Genie-2000, and PROcount 2000 from the Start Menu.

9.2.2 LOGON to the system by typing your Username and Password, and Press < ENTER > or < Ok $>$.

Displays Genie PROcount Main Selection Screen, showing selections "A-H". 
9.2.3 Select $<$ G. System Maintenance $>$ and Press $<$ Ok $>$. Displays the System Maintenance Menu Screen, showing selections "A-F".

9.2.4 Select $<$ A. Analyze Sample Data File $>$ and Press $<$ Ok $>$. Displays the Analyze Sample Data File Screen

9.2.5 Highlight/select the sample type < ISOCS Generic > and Press < Choose by Sample Type > .

Displays a dialog box/file list of sample files with Sample ID, Description and Acquisition date/time displayed

9.2.6 Use the arrow and/or page down key to highlight the sample to be analyzed and Press < Select $>$.

Displays the Re-Analyze a PROcount Sample Menu, showing selections "A-G". NOTE: The spectrum data file name (stcnnnnn.cnf) is displayed in the header line of the menu screen. This is the name the system will use to save the report file when it is generated. [See $\$ 9.2 .11$, below].

9.2.7 Highlight $<$ B. Select Alternate External Efficiency Calibration $>\quad$ and Press $<$ Ok $>$.

Displays a dialog box/file list of saved geometry efficiency calibrations. In the column "Filename" are available geometries that may be recalled for use in this analysis.

9.2.8 Use the arrow and/or PgDn (page down) key to scroll through the list and reveal additional geometry efficiency filenames. One of the filenames in the list should be the eight character alphanumeric name that was entered as the filename in \$9.1.5.c, above. Highlight the desired efficiency filename and Press $<\mathbf{O k}>$.

Re-displays the Re-Analyze a PROcount Sample Menu.

9.2.9 Highlight $<$ C. Select Alternate Analysis Sequence File $>$ and Press < Ok $>$.

Displays a dialog box identifying the detector and geometry and a drop-down list of alternate analysis sequence files.

9.2.10 Highlight on the drop-down menu the desired analysis to be performed. For the BNL ASTD project, the typical analysis sequence is entitled: "ASTD Default Analysis with MDA". Refer to the PSSP for any specific analysis sequence.

Press $<$ Ok $>$.

Re-displays Re-Analyze a PROcount Sample Menu, showing selections "A-G".

9.2.11 Highlight < F. Perform Analysis, Show Report $>$ and Press $<$ Ok $>$.

After a few moments, the Report Window appears in the upper half of the display. Use the arrow keys and the scroll bar to review the report.

NOTE: A copy of the analysis report is saved as an ASCII text file under:

C: :pcnt2k \repfiles/stcnnnnn.rpt

where stcnnnnn is the spectrum data file name of the spectrum in analysis. Any re-analysis of the spectrum file stcnnnnn.cnf will overwrite this report file, so if the report is wanted, it should be renamed 
or copied to another disk location prior to performing another analysis on the same spectrum data file.

9.2.12 When finished reviewing the report, Press $<$ Ok $>$.

Closes the Report Window and Re-displays the Re-Analyze a PROcount Sample Menu, showing selections "A-G".

9.2.13 Press < Cancel $>$.

Re-Displays the System Maintenance Menu Screen, showing selections "A-F".

9.2.14 Press < Return to Main >

Re-displays Genie PROcount Main Selection Screen, showing selections "A-H".

9.2.15 Press < Exit > . System returns to Windows.

\subsection{DATA FILE BACKUP AND TRANSFER}

Daily, or at the end of each spectrum analysis session, the Data Acquisition Technical Team member will assemble data and files for transfer to the Analytical Physicist. The data transfer and records retention activities include:

10.1 Fill out the Data Acquisition and File Control Form (Form DAT-02) for the scans analyzed; this is the chain-of-custody for the following electronic files:

a. Geometry Definition files created by the system during \$9.1.6.c are stored in c: isocsigeometry $\backslash$ filename.n Where " $n$ " is a digit from 1 to 7

C Copy each geometry definition file (filename.n) to a labeled diskette.

b. Efficiency Calibration files, created by the system during \$9.1.7.d, are stored in c:Igenie2klcalfiles〉filename.cal

C Copy each efficiency calibration file (filename.cal) to a labeled diskette.

c. Analyzed Data Report, created by the system during \$9.2.11, are stored in:

C: Ipcnt2k\repfiles Istcnnnnn.rpt

C Copy each analyzed data report file (STCnnnnn.rpt) to a labeled diskette.

10.2 Assemble the annotated hard copy of the ISOCS Geometry Template Worksheet for each analysis and the hard copy of reports, if printed.

10.3 Transfer to the Project Analytical Physicist.

11.0 MAINTENANCE

NOTE: Any maintenance performed on the ISOCS System shall be recorded in the ISOCS Laboratory/Field Notebook. 
11.1 Routine maintenance is not required on the Canberra Software operating environment.

11.2 Non-routine maintenance on the electronics should be performed by the BNL Cognizant Environmental Scientist or designated alternate.

11.3 The Canberra Industries customer service department should be consulted should problems arise which cannot be handled by site personnel.

APPENDIX: Installing the ISOCS Software and Establishing the ISOCS Operating Environment 


\section{APPENDIX : Installing ISOCS Software and Establishing the ISOCS Operating Environment}

Prior to the analysis of a gamma spectrum, the Canberra PROcount software program environment must be created on the system computer. These functions are explained, in detail, in Chapter 2 and Chapter 4 of the PROcount-2000 Users Manual (ref 3.1). The following system functions must be performed by the System Manager prior to routine spectrum acquisition and analysis.

1.0 ISOCS System Software. The following are components of the software programs supplied by Canberra Industries for the ISOCS Inspector multichannel analysis system. Each software program is supplied on a single $3.5 \mathrm{inch} / 1.44 \mathrm{Mb}$ disk, except as indicated.

$\begin{array}{lllll}\text { a. } & \text { S504 } & \text { Genie-2000 Basic Spectroscopy (CD ROM) } & \text { Model G2KV13 } & \text { v } 1.3 \\ \text { b. } & \text { S501 } & \text { Genie-2000 Gamma Analysis } & \text { Model 501J-6 } & \text { v } 1.3 \mathrm{~A} \\ \text { c. } & \text { S503 } & \text { PROcount-2000 } & \text { Model 503J-3 } & \text { v } 1.1 \\ \text { d } & \text { S505 } & \text { Genie-2000 Quality Assurance } & \text { Model 505J-5 } & \text { v } 1.3 \\ \text { e. } & \text { S506 } & \text { Interactive Peak Fit } & \text { Model 506J-4 } & \text { v } 1.2 \\ \text { f. } & \text { S561 } & \text { Batch Programming Support } & \text { Model 561J-4 } & \text { v } 1.2 \\ \text { g. } & \text { S573 } & \text { ISOCS Calibration Software (2 disks) } & \text { Model 573J-5 } & \text { v 3.0 } \\ \text { h. } & & \text { Detector-Specific Characterization Disk } & & \end{array}$

2.0 Initial Software Installation.

2.1 Procedures for loading the software to the workstation computer are provided in the appropriate Canberra manuals for the individual programs. In general:

2.1.1 Insert the distribution disk (CD ROM or 3.5 inch) into the drive.

2.1.2 Select the "RUN" command.

2.1.3 Type "A:lsetup.exe" in the dialog box.

2.1.4 Select "Run" and follow the screen commands to complete the setup.

2.2 The Detector Specific Characterization File is loaded to the workstation computer by using the COPY command, rather than a Setup routine. Instructions for the files transfer are provided in a file README.txt found on the distribution disk.

2.3 After installing the Canberra ISOCS Software, the program may not run ISOCS from the ISOCS icon nor from the Start Menu, due to a mismatch with the Entrexx batch mode processor. The path for the target file in the ISOCS Icon Shortcut must be revised. 


\subsubsection{In the Windows Explorer, open the following folder:}

C:IWINDOWSIStart MenulProgramsiGenie-2000. There should be a shortcut icon for ISOCS in this folder.

2.3.2 With your mouse Right click on the ISOCS icon

2.3.3 Select "Properties" from the pop-up menu.

2.3.4 Select the "Shortcut" tab

2.3.5 In the Target entry line type in the following :

2.3.6 Select "OK".

C:lentrexx\rexx.exe C:lisocs\runisocs.rex INSI

You should now be able to execute ISOCS from the icon or from the Start Menu.

3.0 ISOCS System Management Components. Several system functions are rarely, if ever, changed following the initial set-up actions.

\section{System Component or Function}

Setting up the Calibration Function

Setting up the Quality Control Function

Organizing the Software Security System

\section{$\underline{\text { Reference }}$}

$\S 4.8$, PROcount Users Manual $\S 4.9$, PROcount Users Manual

$\S 4.2$, PROcount Users Manual

4.0 ISOCS System Analysis Components. Several system functions may be modified more frequently, based on requirements of the Project Specific Survey Plan.

System Component or Function

Setting Operating Defaults

Defining Acquisition Geometries

Defining the Sample Types

Developing Analysis Sequence Files

Creating and maintaining radionuclide libraries

\section{Reference}

§4.7, PROcount Users Manual \$4.4, PROcount Users Manual $\$ 4.6$, PROcount Users Manual §7, Genie-2000 Users Manual $\S 5$, Genie-2000 Users Manual 
Section 6 
Fri, May. 18, 2001 ONLINE COPY - ERD OPERATIONS PROCEDURES MANUAL

VALID FOR FIVE (5) WORKING DAYS

ERD Operations Procedures Manual

4.3 PROCEDURE FOR ASTD SAMPLE PROCESSING
TO SUPPORT BGRR DECOMMISSIONING OPERATIONS

Text Pages 1 through 5

No Attachments

Approved: $\quad$ /s/ Stephen K. Pulsford

Date: July 12, 2000

Stephen K. Pulsford, Manager

BGRR Decommissioning Project

Preparer: L. Luckett/P. Kalb, ASTD Project

ERD-OPM-4.3, Revision 0 


\section{PROCEDURE FOR ASTD SAMPLE PROCESSING TO SUPPORT BGRR DECOMMISSIONING OPERATIONS}

\subsection{PURPOSE AND SCOPE}

This procedure provides guidance and describes the sample handling sequence for Accelerated Site Technology Deployment (ASTD) Project personnel performing sample analysis in support of BGRR. The procedure discusses the field analysis of samples using two identified instruments: (1) the Canberra Industries, Inc. ISOCS gamma radiation spectrometer, and (2) the BetaScint, Inc. beta radiation spectrometer.

\subsection{RESPONSIBILITIES}

2.1 ASTD Project provides trained and experienced personnel to operate a field analysis laboratory to perform rapid analysis of samples during BGRR decommissioning operations. Project personnel may include contractor/vendor instrument operators during initial field trials or instrument demonstrations.

2.2 BGRR Project obtains the physical samples during decommissioning operations and provides health and safety and radiological control support for the field laboratory operation.

\subsection{PREREQUISITES}

3.1 BGRR Project will evaluate anticipated sample contamination levels during the project planning and use that information to determine the need for and to develop a radiation work permit (RWP) for the field sample analysis laboratory.

3.2 Special Training and Qualifications for ASTD operators include manufacturer's training on a specific instrument and/or prior experience in operating the instrument in the field. Personnel will have appropriate, current qualifications to meet requirements identified in the RWP.

3.3 ASTD Operators will perform instrument checks and calibrations at the frequency identified in manufacturer's literature or operating procedures to assure confidence in instrument operations. Quality control criteria for the Canberra ISOCS instrument are addressed in Section 4.0 of the ASTD Project Quality Assurance Project Plan (QAPP), Reference 7.1. 
3.4 BGRR Project will designate a location for the ASTD field laboratory, convenient to the operations to provide timely support but not where it would unduly interfere with the anticipated operations. The routine operational location is in the former physics shop area on the 110' level of Building 701.

\subsection{PRECAUTIONS AND LIMITATIONS}

4.1 The samples obtained from decommissioning operations during the BGRR Decommissioning Project are contaminated, or potentially contaminated, with radioactive materials. Anticipated or previously identified levels of contamination will be discussed in project planning documents.

4.2 Work permits (hazardous or radiological) shall specify protective equipment and measures for personnel protection against injury or exposure, and may provide levels of contaminant that will trigger additional control measures. Adherence to requirements of the work permits is mandatory. Failure to follow requirements of the work permit may expose the individual unnecessarily to hazardous materials, could lead to personal contamination, and will result in suspension of the work.

4.3 The instruments being used and evaluated by the ASTD Project are extremely sensitive and respond to low levels of radioactivity. Instrument contamination leading to invalid analysis can result if contamination control procedures are not carefully followed.

\subsection{PROCEDURE}

\subsection{Analysis of Gross Soils by ISOCS and BetaScint Instruments}

5.1.1 Receive the sample and chain of custody (COC) from BGRR radiological control technician (RCT).

5.1.2 Record the sample description identification in the ASTD logbook.

5.1.3 Prepare labels for poly bottle (ISOCS) and mixing pan (BetaScint).

5.1.4 Position the $1 / 4$ " sieve over a 5-gallon deep sided mixing pan with a clean plastic bag liner.

5.1.5 Transfer the sample to the sieve.

5.1.5.1 Shake the sieve slightly to mobilize the sample through the sieve into the plastic bag lining the mixing pan.

5.1.5.2 Return those sample components that do not pass through the sieve into the original sample container.

NOTE: If ISOCS results are already available for this sample, or if the sample is only to be analyzed by the BetaScint instrument, jump to Step 5.1.15 
5.1.6 Extract approximately $750 \mathrm{ml}$ of sample from the plastic bag liner, and place into the labeled 1 liter poly bottle.

5.1.7 Place the poly bottle into a clean plastic bag and seal with tape.

5.1.8 Weigh the bagged and bottled sample and record the weight in the logbook.

5.1.9 Transfer the bagged and bottled sample to the ISOCS instrument.

NOTE: Procedure for acquiring a gamma spectrum analysis with the Canberra ISOCS instrument is provided in DAT - SOP1, reference 7.2

5.1.10 Acquire a gamma spectrum analysis on the ISOCS instrument.

5.1.11 Observe the gamma analysis results and record in the logbook.

5.1.12 Compare the results to values in the RWP and notify the BGRR RCT if a hold point level has been triggered.

5.1.13 Retrieve the bagged and bottled sample from the ISOCS instrument and return the sample contents to the corresponding labeled, plastic bag lined mixing pan.

5.1.14 Discard the empty poly bottle and corresponding plastic bag into contaminated waste receptacle.

5.1.15 Close the plastic bag liner and seal with a "J seal", place the sealed bag into a clean, secondary bag (heavy duty trash compactor style). Tie a label to the clean secondary bag, with the sample identification number clearly written on the label. Place the double lined plastic bag within a clean 5 gallon plastic bucket and install lid in preparation for sample transfer. Obtain HP smear on secondary plastic bag and transfer bucket, and obtain clearance to move the container from the preparation area to the BetaScint counting area. Complete chain of custody data sheet and signatures.

5.1.16 Dampen lightly a paper towel with distilled water. Wipe the container exterior, the mixing pan, the sieve and scoops with the dampened paper towel(s) until items are visually clean. Discard used paper towels into contaminated waste receptacle.

5.1.17 Deliver samples in transfer bucket to BetaScint counting area, obtain chain of custody signatures. Open transfer bucket and remove selected sample (confirm sample ID number if several samples are contained in the transfer bucket). Place the clean sample bag on a shallow aluminum or plastic "Baker's tray, place the inner sample bag on top, cut open the inner sample bag and discard as radwaste. Spread the sample on the plastic lined Baker's tray in preparation for BetaScint analysis.

NOTE: The operation and interpretation of the beta radiation spectrometer will be performed according to the BetaScint instrument procedure.

5.1.18 Obtain a beta radiation spectrum analysis on the BetaScint instrument.

5.1.19 Observe the beta analysis results and record in the logbook.

5.1.20 Compare the results to values in the RWP and notify the BGRR RCT if a hold point level has been triggered. 
Fri, May. 18, 2001 ONLINE COPY - ERD OPERATIONS PROCEDURES MANUAL

VALID FOR FIVE (5) WORKING DAYS

NOTE: At this point, the preliminary analytical results may be verbally reported to the BGRR Engineer.

5.1.21 Retrieve the sample from the BetaScint instrument by placing it back in the plastic bag liner. Note that this bag originally served as the secondary containment, but is now being used as the primary containment. Re-seal the bag with a "J seal", and place in a new, clean, secondary containment bag. Replace the RAM tag, which clearly identifies the sample ID number on the secondary bag, replace the sample within the 5-gallon plastic bucket, and replace lid in preparation for storage.

5.1.22 Obtain HP smear on secondary plastic bag and transfer bucket, and obtain clearance to move the container from the BetaScint counting area. Complete chain of custody data sheet and signatures. Place the sample container into the post-analysis staging area for BGRR disposition.

\subsection{ISOCS Analysis of Samples}

5.2.1 Receive the bagged or bottled sample and COC from BGRR radiological control technician (RCT).

5.2.2 Record the sample description identification in the ASTD logbook.

5.2.3 Place the sample or poly bottle into a clean secondary plastic bag and seal with tape.

5.2.4 Weigh the bagged and/or bottled sample and record the weight in the logbook.

5.2.5 Transfer the bagged and/or bottled sample to the ISOCS instrument.

NOTE: Procedure for acquiring a gamma spectrum analysis with the Canberra ISOCS instrument is provided in DAT - SOP1, reference 7.2

5.2.6 Acquire a gamma spectrum analysis on the ISOCS instrument.

5.2.7 Observe the gamma analysis results and record in the logbook.

5.2.8 Compare the results to values in the RWP and notify the BGRR RCT if a hold point level has been triggered.

NOTE: At this point, the preliminary analytical results may be verbally reported to the BGRR Engineer. Procedure for interpreting a gamma spectrum analysis with the Canberra ISOCS instrument is provided in DAT - SOP3, reference 7.3

5.2.9 Retrieve the bagged and/or bottled sample from the ISOCS instrument.

5.2.10 Discard any empty plastic bag into contaminated waste receptacle.

5.2.11 Complete the chain of custody data sheet and signatures. Place the sample into the post-analysis staging area for BGRR disposition. 
Fri, May. 18, 2001 ONLINE COPY - ERD OPERATIONS PROCEDURES MANUAL

VALID FOR FIVE (5) WORKING DAYS

\subsection{RECORDS}

The ASTD Project operator shall record sample data, observations, and analytical results in the field logbook. The ASTD operator shall transfer electronic files from the computer/workstation to removable disk for archiving with Project records as discussed in Section 6.0 of the ASTD Project QAPP, Reference 7.1.

\subsection{REFERENCES}

7.1 In Situ Analysis Quality Assurance Project Plan, version 1, July 2, 1999.

7.2 SOP-DAT1, Gamma Spectrum Acquisition Using Canberra ISOCS System, version 1, August 19, 1999.

7.3 SOP-DAT2, Analysis of Gamma Spectrum Files Using Canberra ISOCS System [software ver 3.0], version 3, February 23, 2000.

\subsection{ATTACHMENTS}

None.

\subsection{DEFINITIONS}

ASTD Accelerated Site Technology Deployment

BGRR Brookhaven Graphite Research Reactor

COC chain of custody

ISOCS in-situ object counting system

RCT radiological control technician

RWP radiation work permit

QAPP Quality Assurance Project Plan

\section{PLEASE CLICK HERE TO COMPLETE READING ACKNOWLEDGEMENT FORM}




\section{Section 7}




\section{ASTD Project-Specific Survey Plan No. 2k-01 \\ Use of ISOCS in Support of BGRR Fan House Drain Pipeline Excavation and Pile Fan Sump Removal}

\subsection{PURPOSE}

Perform ISOCS scans of disturbed surface soils in the area between the BGRR Exhaust Stack, the Fan House, and the Pile Fan Sump to

(i) monitor progress of excavation (have we excavated far enough to identify the limits of any contaminated pipe/soil?)

(ii) assist with determination of soil disposition (which pile does this soil go into?)

NOTE: The use of the BetaScint instrument to support this BGRR excavation by the field analysis of samples for $\mathrm{Sr}-90$ activity is addressed in a separate ASTD Project Specific Survey Plan (PSSP No. 2K-02, in press).

\subsection{DATA QUALITY OBJECTIVES}

\subsection{State the Problem}

Using the Canberra ISOCS instrument, in contrast to baseline technology, provides the opportunity to obtain data on radionuclide identification and quantification quickly, without having a delay for transportation and preparation of the sample. An area of interest for this application is the BGRR Fan House Pipeline (FHP), a drain pipe that runs from the BGRR Exhaust Stack, to the Fan House, Bldg 704, to the Pile Fan Sump, and into Bldg 801 as well as the Pile Fan Sump and surrounding soils. Data are needed to determine, with the combination of activity and shielding present,

(a) the radionuclide content of the surface and subsurface soils during excavation;

(b) whether the residual radioactivity in the pipeline is such that it can be detected or bounded by in situ measurements;

\subsection{Identify the decision.}

The decision to be made is essentially a simple detection limit decision. What radionuclides does the ISOCS instrument detect in the soil and from the pipeline? If the pipeline scans are not different from the non-pipeline scans, can an upper bound on the activity present be quantified?

\subsection{Identify inputs.}

Information is available on the geometry and constituents of the Fan House Pipeline and the Pile Fan Sump from construction drawings. Plant Engineering has attempted to mark the pipe location using sounding techniques with some success near the ends, but not in the center of the run. Results of prior analysis of water and sludge samples from the Pile Fan Sump are available for review. Prior analysis has detected different radionuclides in the water and sludge phases (see Annex A) 
The DCGL (derived concentration guideline level) for radionuclides of interest have been identified by BGRR (see Annex B).

Additional direct surface readings and soil samples will be obtained by BGRR staff, and the analytical results will be available at a later date to use in interpreting the ISOCS analysis.

\section{$2.4 \quad$ Define the boundaries.}

The pipeline from BGRR Exhaust Stack to the east end of the Fan House (Bldg 704, on the hill SE of reactor), and from the Fan House to the Pile Fan Sump (in the parking lot drive E of the reactor and S of Bldg 801) is 4-in diameter, cast iron of approximately 40 meters (130 feet) in length. The surface over the pipeline is approximately $60 \%$ earth and grass and $40 \%$ asphalted. The pipeline from the Sump to Building 801 is 2-in diameter, stainless steel of approximately $15 \mathrm{~m}(50 \mathrm{ft})$ in length, all asphalt covered. Approximately $40 \mathrm{~m}$ of pipeline below Bldg 704 will not be removed at this time.

The area of interest on the sub-surface is a corridor of overburden soil along the pipeline, the pipe itself, and any contaminated soil that may be delineated under the pipe. The pipeline, where it exits from Bldg 704 running northward, is at approximately $8 \mathrm{ft}$ depth, so that a significant amount of overburden will be removed to expose the pipe and to slope the sides of the excavation. From this location, the pipeline does not drop as rapidly as the surface contour, so that the pipe enters the sump at only approximately $2 \mathrm{ft}$ depth and the trench width can be narrowed as the excavation progresses towards the sump. The pipeline between the stack and Bldg 704, and between the sump and Bldg 801 is only 2-4 ft below grade so that extensive excavation and sloping will not be required.

2.5 Develop decision rules. If there is an identifiable gamma peak in the ISOCS spectrum that can be attributed to a source location in the ISOCS field of view, the activity will be quantified using an planar distribution geometric model representing the soil surface. Otherwise, it will be concluded that the combination of source activity and shielding is such that it is below the detection capability of the ISOCS.

\subsection{Specify the tolerable limits on decision errors.}

The decision error of most concern would be to conclude that the instruments cannot detect the activity, when perhaps with a longer counting time, it might have been able to. The consequence of counting longer than necessary would primarily be the eventual loss in resolution caused by electronic instrument drift, or the delay of excavation progress due to overly-conservative counting times. To provide an indication of instrument analysis variability, performance stability, and drift, duplicate and replicate analysis of samples will be performed:

- $\quad$ Field Replicate - 1 in 20 (5\%) samples will be counted twice

- Field Duplicate/Split - 1 in 20 (5\%) samples will be collected as double volume, composited, split, and counted separately

- $\quad$ Field Consistency - each day of sampling, one sample should be recounted after a period of two hours has elapsed since the initial count 


\subsection{Optimization.}

2.7.1 in situ considerations. The use of the ISOCS instrument to directly scan soils and pipes uncovered in situ during in the excavation is complicated by two aspects:

- the large field of view of the detector without collimators does not allow the distinction between contaminated materials still inside the pipe from those in the soil surrounding the pipe, and

- when collimators are added to restrict the field of view, the weight of the instrument and cart makes it difficult to maneuver over uneven excavation surfaces.

2.7.2 Sample scanning. The primary analysis mode used in support of the excavation will be the field screening/analysis of soil samples in a reproducible, shielded geometry. The Canberra annular collimators will be arranged to construct a shielded counting cavity around the detector that accepts a 1 liter poly bottle. Soil sample bottle must be filled to the upper crown to meet the description of the geometry model.

2.7.3 Detection sensitivity. The primary information need for the control of excavation is the identity of radionuclides present and whether they are present at levels near or above the DCGL. The gamma spectrum will be accumulated for a time that assures that the minimum detectable concentration is less than 50\% of the DCGL for the gamma emitters identified in the BGRR list (Annex B).

- for soil sample counted in the shielded cavity, the acquisition time will be 5 minutes (300 seconds)

- for analysis of finite objects such as sections of pipe, acquisition time will be 10 minutes (600 seconds)

- for analysis of trench wall/bottom the acquisition time will be 16.6 minutes (1000 seconds) to maintain consistency with previous surface soil evaluations.

2.7.4 Sample Sequencing. For this project, samples will be analyzed by both the ISOCS and Betascint instruments. Because the BetaScint analysis requires manipulation of the potentially contaminated soil in an un-contained geometry, special sample handling procedures and a radiological material handling area have been specified. ISOCS operators will be familiar with these procedures and comply with requirements.

\subsection{Equipment}

\section{ISOCS Hardware}

a. the InSpector portable gamma spectroscopy interface,

b. a broad energy germanium (BEGe) detector with preamp,

c. Multi-Attitude Cryostat with extended detector to allow use of a back-shield, d. notebook computer with Canberra Genie, PROcount-2000 and ISOCS software,

e. assorted connecting cables, power cords, batteries and battery chargers, and

f. a cart for relocating and positioning the detector and shield assembly, and

i. wheel chocks. 
Annular shields and field of view collimators
a. Set of 2-inch thick annular shields (3 pieces),
b. 2-inch thick back shield (2 pieces),
c. 1-inch annular shields (3 pieces),
d. 1-inch thick end cap, and
e. Collimator frame extensions

Additional Equipment and Instruments

a. Calibrated microR or microRem meter

b. Digital camera or Polaroid camera w/ film

c. Tape measure, 100 foot or $50 \mathrm{~m}$

d. Field notebook

e. 3.5 inch disk for file transfer

f. DAT vehicle

g. $50 \mathrm{ft}$ extension cords

\subsection{COORDINATION}

4.1 Health and Safety BGR Health and Safety POC: Reggie Suga x-8248

(i) Samples may contain radioactive material contamination. There is a Radiation Work Permit (RWP) for the handling of contaminated soil samples during the performance of this analysis. Operators must comply with the requirements of the RWP.

(ii) Sample handling procedures are specified in a separate soil handling/processing procedure. Personnel should read and be familiar with that procedure prior to performing soil analysis.

(iii) When working in parking lots and driveways be aware of traffic, and use vehicle flashers or cones to warn drivers and increase your visibility.

(iv) Some analysis positions are on a sloped hillside. Choose your footing carefully, and brace the instrument carefully to avoid falls or tip-overs.

(v) Be aware of heat/cold stress concerns when working in open uncovered areas. A lightweight, pop-up awning for shade and cover is available and should be used. Fluids should be consumed regularly to replace body losses.

\subsection{Facility Access}

Primary: Steve Masciulli x-8247 Alternate: Manni Lilimpakis x-7628

\subsection{SPECIFIC SCANS AND PARAMETERS}

Specific areas of interest are identified in the BGRR survey plan (Ref 3). Individual targets or scans within the areas may be added at the discretion of the operator when in the area. A project sample identification scheme is described.

\subsubsection{ASTD Project Sample Numbers.}

Targets for gamma spectrum acquisition will be identified with a sample number of the form: aaaxnnnz

where aaa a three character code identifying the portion of the excavation

(FPE) for Fan Pipe Excavation Sample

(FSE) for Fan Sump Excavation Sample 
a single character code identifying the scan target

S For a sample counted within the field sample analysis cavity

P For a section of pipeline

T For a section of the excavated trench

C For a section of the concrete sump

nnn is a three digit number incrementing in sequence indicating a sample sequence number for the project

$\mathrm{z} \quad$ is a single letter indicating a subsequent scan of the same sample, such as at a different target center, or from a different angle or position

For example: FPES012b is the second scan $(\mathbf{b})$ of sample $(\mathbf{S})$ number $12(\mathbf{0 1 2})$ obtained during the fan house pipeline excavation (FPE). The code $\mathbf{S}$ for sample indicates it was counted in the field analysis cavity.

The ASTD Project Sample Number will be entered into the scan description by the instrument operator during scan acquisition, to tie the sample number to the scan record file. The BGRR sample number will also be entered into the scan description field and the field notebook. The ASTD Sample Number will also be cross-referenced with the default scan filename on the File Custody Record Form.

\subsubsection{Scan Acquisition}

a. Scans should be accumulated to detect the radioactivity and to investigate the impact of ISOCS configuration on the analytical results.

b. Initial scan time of 300 seconds; longer if necessary to see activity peaks especially in highly shielded objects such as through the pipe wall

c. ISOCS codes for sample type and geometry
Sample Type ISOCS Generic
Geometry ISOCS

Table 5-1. Studies of the Fan Pipeline Excavation, BGRR

\begin{tabular}{|c|c|c|c|c|c|c|}
\hline $\begin{array}{c}\text { Sample } \\
\text { No }\end{array}$ & $\begin{array}{l}\text { Annular } \\
\text { Shield }\end{array}$ & $\begin{array}{l}\text { Field of } \\
\text { View }\end{array}$ & $\begin{array}{l}\text { Initial } \\
\text { Count } \\
\text { Time }\end{array}$ & $\begin{array}{l}\text { Sample } \\
\text { Size }\end{array}$ & Orientation & Note \\
\hline FPESnnna & \multirow{2}{*}{$\begin{array}{l}2 \text { inch around } \\
\text { detector } \\
1 \text { inch around } \\
\text { sample }\end{array}$} & \multirow{2}{*}{$\begin{array}{l}180^{\circ} \text { inside } \\
\text { with cavity } \\
\text { capped }\end{array}$} & $300 \mathrm{sec}$ & 1 liter & \multirow{2}{*}{$\begin{array}{l}\text { Vertical } \\
\text { sample count } \\
\text { configuration }\end{array}$} & $\begin{array}{l}\text { Fan Pipe } \\
\text { Excavation Sample }\end{array}$ \\
\hline FSESnnna & & & $300 \mathrm{sec}$ & 1 liter & & $\begin{array}{l}\text { Fan Sump } \\
\text { Excavation Sample }\end{array}$ \\
\hline FPETnnna & $\begin{array}{l}2 \text { inch around } \\
\text { detector }\end{array}$ & $\begin{array}{l}90^{\circ} \text { field of } \\
\text { view }\end{array}$ & $600 \mathrm{sec}$ & $\begin{array}{l}1 \text { sq meter } \\
\text { field of } \\
\text { view }\end{array}$ & $\begin{array}{l}\text { Vertical down towards } \\
\text { trench bottom or } \\
\text { perpendicular to } \\
\text { surface }\end{array}$ & \\
\hline
\end{tabular}




\subsection{REFERENCES}

6.1 BNL-DAT, In Situ Analysis Quality Assurance Project Plan, Version 1, July 7, 1999.

6.2 BNL-DAT SOP-DAT1, In Situ Gamma Spectroscopy Using the Canberra ISOCS System, version 1, August 19, 1999.

6.3 BGRR Sampling and Analysis Plan for Pile Fan Sump Excavation (in press).

6.4 BGRR Procedure for Handling Contaminated Soil Samples (in press). 


\section{ANNEX A Previous Analytical Results}

1 Surface Activity Scans. A summary of the results of the in situ analysis of surface soils is provided in Table 1.1. Detailed listings of each sample analysis are provided in the Appendix.

Table 1.1. Average Radioactivity in Surface Soils (in pCi/g) in the Vicinity of the Pipeline Between the BGRR Fan House (Bldg 704) and the Hot Laboratory (Bldg 801)

\begin{tabular}{|c|c|c|c|}
\hline \multirow[b]{2}{*}{$\begin{array}{l}\text { Radio- } \\
\text { nuclide }\end{array}$} & \multicolumn{3}{|c|}{ Ground Surface Facing the Detector } \\
\hline & Grass $(\mathrm{N}=11)$ & $\begin{array}{l}\text { Asphalt near Bldg } 704 \text { and } \\
\text { Diagonal Drive }(N=11)\end{array}$ & $\begin{array}{l}\text { Asphalt near } \\
\text { Bldg } 801 \quad(\mathrm{~N}=9)\end{array}$ \\
\hline $\mathrm{K}-40$ & $4.6 \pm 1.3 \quad(10)$ & $9.7 \pm 1.8 \quad(10)$ & $11.7 \pm 2.6$ \\
\hline Cs-137 & $0.43 \pm 0.26$ & $0.9 \pm 0.8 \quad(11)$ & $0.5 \pm 0.6$ \\
\hline $\mathrm{Pb}-212$ & $0.56 \pm 0.27$ & $1.0 \pm 0.7$ & $1.2 \pm 0.8$ \\
\hline $\mathrm{Pb}-214$ & $0.39 \pm 0.15$ & $0.8 \pm 0.2 \quad(11)$ & $1.0 \pm 0.3$ \\
\hline Ac-228 & $0.5 \pm 0.5$ & $0.6 \pm 0.3$ & $0.9 \pm 0.6$ \\
\hline Am-241 & mda: $\# 0.8$ & mda: \#8 & mda: \#8 \\
\hline Co-60 & mda: \#0.005 & mda: \#0.08 & mda: \#0.08 \\
\hline
\end{tabular}

NOTE: (*) is the number of samples in the ground surface category that reported detection of the radionuclide Errors are reported as $\pm 2 \mathrm{~s}$.

The analysis consistently identified naturally occurring radionuclides (K-40, Uranium series, and Thorium series) and Cs-137 in the gamma spectra. The activity concentration of Cs-137 in the grass area (the area not covered by asphalt) is consistent with global fall-out levels. The minimum detectable activities of other radionuclides are indicated.

2 Pipeline. Possible contaminants in the pipeline, or in the soil if the pipeline had leaked, can be inferred from the analysis of the sludge and water in the Pile Fan Sump, where pipeline constituents accumulated. Results of prior analysis of water and sludge samples from the Pile Fan Sump are available for review. Prior analysis has detected different radionuclides in the water and sludge phases.

2.1 Sampling and analysis results of the Pile Fan Sump from March 1997 are summarized in Table 2.1. The sampling identified elevated concentrations of Tritium, Sr-90, Cs-137, and Ra-226 in sump water; analyses of sump sludge identified elevated concentrations of Cs-137, Ra-226, Am-241, and Co-60. 
Table 2.1. Contaminants Observed in the Pile Fan Sump Contents in 1997 Sampling

\begin{tabular}{|l|c|c|}
\hline Radionuclide & $\begin{array}{c}\text { Concentration in water } \\
\text { (pCi/liter) }\end{array}$ & $\begin{array}{c}\text { Concentration in sludge } \\
\text { (pCi/liter) }\end{array}$ \\
\hline Tritium (H-3) & 260,000 & NR \\
\hline Gross beta & 6,600 & NR \\
\hline Cs-137 & 2,000 & 15,700 \\
\hline Ra-226 & 2,300 & 365 \\
\hline Am-241 & NR & 71 \\
\hline Co-60 & NR & 3.1 \\
\hline Sr-90 & 2,270 & NR \\
\hline
\end{tabular}

NR $=$ Not Reported

Ref: Root Cause Analysis Summary Form, Occurrence CH-BH-BNL-1997-0012, Apr 1997.

2.2 The PFS was opened on August 12, 1999 following a significant rainfall on August 11. Results of analysis of a water sample obtained from the volume in the sump (sample 9908527-02) are provided in Table 2.2.

Table 2.2. Contaminants Observed in Pile Fan Sump Contents in Aug 1999 sampling

\begin{tabular}{|l|c|}
\hline Radionuclide & $\begin{array}{c}\text { Concentration in water } \\
\text { (pCi/liter) }\end{array}$ \\
\hline $\mathrm{U}-238 / 234$ & $23.0 \pm 3.4$ \\
\hline $\mathrm{Pu}-239 / 240$ & $13.5 \pm 2.8$ \\
\hline $\mathrm{Cs}-137$ & $102,000 \pm 9,500$ \\
\hline Am-241 & $3.0 \pm 1.0$ \\
\hline Na-22 & $19.3 \pm 5.5$ \\
\hline Sr-90 & $76,500 \pm 40$ \\
\hline
\end{tabular}

2.3 While the PFS was open on August 12, 1999, an in situ gamma spectrum was obtained using the ISOCS instrument (ASTD Sample PFS2123b). The analysis identified Cs-137 in the gamma spectrum. The analysis did not detect any other gamma-emitting radionuclides observed in the water (Ra-226) or in the sludge (Am-241, Co-60 and Ra-226). Estimated activity concentrations and minimum detectable concentrations are provided in Table 2.3 for each ISOCS geometry model that was evaluated. 
Table 2.3. Activity Concentrations in PFS Determined by ISOCS Analysis-Open Sump Cover

\begin{tabular}{|c|c|c|c|c|c|c|c|}
\hline \multirow{2}{*}{ Medium } & \multirow{2}{*}{$\begin{array}{c}\text { Assumed } \\
\text { Thickness }\end{array}$} & \multicolumn{3}{|c|}{ Activity Cs-137 } & \multicolumn{3}{|c|}{$\begin{array}{l}\text { Total Activity in the sump } \\
(\mu \mathrm{Ci})\end{array}$} \\
\hline & & $\left(\mathrm{dpm} / 100 \mathrm{~cm}^{2}\right)$ & $\left(\mu \mathrm{Ci} / 100 \mathrm{~cm}^{2}\right)$ & $(\mu \mathrm{Ci} / \mathrm{g})$ & Cs-137 & Am-241 & Co-60 \\
\hline $\begin{array}{l}\text { Residue on } \\
\text { Sump Floor }\end{array}$ & $\begin{array}{c}0.05 \text { in } \\
\text { evenly over } \\
\text { surface }\end{array}$ & $\begin{array}{c}4.9 \mathrm{E}+06 \pm \\
0.6 \mathrm{E}+06\end{array}$ & $2.2 \pm 0.3$ & $0.11 \pm 0.014$ & $378 \pm 42$ & $<4.72$ & $<0.7$ \\
\hline Sludge pool & 10 in deep; $1.5 \mathrm{ft}^{3}$ & --- & --- & $0.019 \pm 0.001$ & & & \\
\hline $\begin{array}{l}\text { Residue on } \\
\text { Sump Floor }\end{array}$ & $\begin{array}{l}0.05 \text { in } \\
\text { evenly over } \\
\text { surface }\end{array}$ & $\begin{array}{c}1.6 \mathrm{E}+06 \pm \\
0.2 \mathrm{E}+06\end{array}$ & $0.73 \pm 0.10$ & $0.035 \pm 0.005$ & $1,280 \pm 180$ & ND & $<1.92$ \\
\hline $\begin{array}{l}\text { Residue on } \\
\text { Upper S Wall }\end{array}$ & $\begin{array}{l}0.05 \text { in } \\
\text { evenly over } \\
\text { surface }\end{array}$ & $7600 \pm 4900$ & $0.0034 \pm 0.0022$ & $\begin{array}{c}170 \pm 110 \\
\mathrm{pCi} / \mathrm{g}\end{array}$ & - & $\begin{array}{r}<0.004 \\
\mu \mathrm{Ci} /\end{array}$ & $\begin{array}{l}<0.003 \\
00 \mathrm{~cm}^{2}\end{array}$ \\
\hline
\end{tabular}

$\mathrm{ND}=$ not determined due to absorption attenuation in thick constituents.

--- = not calculated for the assumed geometry

Errors are reported as $\pm 2 \mathrm{~s}$.

2.4 The PFS was opened again on August 23, 1999 and samples of the sludge and smears of removable contamination of the sump interior were obtained. Analysis of the sludge sample (No. 99082309-01) had Cs-137 reported as $0.104 \mu \mathrm{Ci} / \mathrm{g}$ with 1-sigma error of $8.5 \%$ and Am241 was not detected. Five smears (No 990823-01 to -05) were reported as detecting Cs-137 (0.6-1.3E-03 $\mu \mathrm{Ci} / \mathrm{smear})$ and Am-241 (8.5E-05 $\mu \mathrm{Ci} / \mathrm{smear})$. Am-241 was detected on 3 of 5 smears, and Am-241 was not detected when the Cs-137 activity was below 7E-04 $\mu \mathrm{Ci} / \mathrm{smear}$. 


\section{Section 8}




\section{Analysis of Surface Soil Radioactivity BGRR Stack to Fan House Drain Pipeline Excavation Area}

\section{Purpose}

In situ gamma spectroscopy measurements with the ISOCS instrument were performed on undisturbed surface soils and asphalt in the area between the BGRR Fan House, Building 704, and the Exhaust Stack near Building 802 The measurements were performed to characterize surface soils above the Stack Drain Pipeline prior to excavation, and to establish baseline conditions of adjacent surface areas prior to laying down soil excavated during the pipeline removal. This report addresses measurements in areas that had exposed grass or soil at the surface; areas covered by asphalt pavement will be addressed in a subsequent report.

\section{Background.}

The Fan House Pipeline is an underground pipe that runs approximately 40 meters (130 feet) from the BGRR Fan House, Bldg 704 in an easterly direction, under Building 715 to a point between Building 802 and the Stack. (See figure 1). The pipeline collects rainwater from the exhaust stack (actively shared with the HFBR), carries it to the Fan House drain systemand then to the Pile Fan Sump. The BGRR is presently planning an excavation of the pipeline (and the sump), as part of the decommissioning program at the BGRR.

\section{Known Contaminants}

3.1 Surface soils. Analytical results from previous sampling of the ground surface in this specific location were not provided. BGRR will perform sampling of the soils as part of the baseline characterization to support the excavation planning.

3.1.1 In a cooperative effort between BNL and the Suffolk County Department of Health Services, soil samples from farms in the vicinity of the Laboratory are collected annually. In data for 1996 provided in a recent BNL Site Environmental Report, the analysis of five surface soil samples for three off-site farms confirmed the presence of natural radionuclides such as K-40 (5.9 - $8.0 \mathrm{pCi} / \mathrm{g}$ ) and $\mathrm{Pb}-212$ (0.7 - $1.4 \mathrm{pCi} / \mathrm{g}$ ), as well as the globally-distributed Cs-137 (non detect to $0.4 \mathrm{pCi} / \mathrm{g})$.

3.1.2 Surface soils in the area north of Building 704 were evaluated in situ by the ASTD Project in September 1999. In that evaluation the analysis consistently identified naturally occurring radionuclides (K-40, Uranium series, and Thorium series) and Cs-137 in the gamma spectra. The activity concentration of Cs-137 in the grass area (the area not covered by asphalt) was consistent with global fall-out levels. The results reported are summarized in Table 1. 
Table 1. Average Radioactivity in Surface Soils (in pCi/g) in the Vicinity of the Pipeline Between the BGRR Fan House (Bldg 704) and the Hot Laboratory (Bldg 801)

\begin{tabular}{|c|cc|cc|cc|}
\hline \multirow{2}{*}{$\begin{array}{c}\text { Radio- } \\
\text { nuclide }\end{array}$} & \multicolumn{5}{|c|}{ Ground Surface Facing the Detector } \\
\cline { 2 - 7 } & Grass (N=11) & $\begin{array}{c}\text { Asphalt near Bldg 704 and } \\
\text { Diagonal Drive (N=11) }\end{array}$ & \multicolumn{2}{|c|}{$\begin{array}{c}\text { Asphalt near } \\
\text { Bldg 801 }\end{array}$} \\
K-40 & $4.6 \pm 1.3$ & $(10)$ & $9.7 \pm 1.8$ & $(10)$ & $11.7 \pm 2.6$ & $(9)$ \\
\hline $\mathrm{Cs}-137$ & $0.43 \pm 0.26$ & $(9)$ & $0.9 \pm 0.8$ & $(11)$ & $0.5 \pm 0.6$ & $(8)$ \\
\hline $\mathrm{Pb}-212$ & $0.56 \pm 0.27 \quad(10)$ & $1.0 \pm 0.7$ & $(11)$ & $1.2 \pm 0.8$ & $(9)$ \\
\hline $\mathrm{Pb}-214$ & $0.39 \pm 0.15 \quad(11)$ & $0.8 \pm 0.2$ & $(11)$ & $1.0 \pm 0.3$ & $(8)$ \\
\hline $\mathrm{Ac}-228$ & $0.5 \pm 0.5$ & $(5)$ & $0.6 \pm 0.3$ & $(2)$ & $0.9 \pm 0.6$ & $(6)$ \\
\hline $\mathrm{Am}-241$ & mda: \#0.8 & mda: \#8 & mda: \#8 \\
\hline $\mathrm{Co}-60$ & mda: \#0.005 & mda: \#0.08 & mda: \#0.08 \\
\hline
\end{tabular}

NOTE: $\quad(*)$ is the number of samples in the ground surface category that reported detection of the radionuclide Errors are reported as $\pm 2 \mathrm{~s}$.

3.2 Pipeline. Possible contaminants in the pipeline, or in the soil if the pipeline had leaked, can be inferred from the analysis of the sludge and water in the Pile Fan Sump, where pipeline constituents accumulated.

\section{Pipeline Geometry}

Information is available on the geometry and constituents of the Fan House Pipeline from construction drawings.

4.1 Plant Engineering has attempted to mark the pipe location using sounding techniques, with some success near the ends where the pipe exits Bldg 704 and enters the PFS. In the center of the run, the pipe location was lost amid the noise of crossing pipes and interference.

4.2 Between the Fan House, Building 704, and the sump, the pipeline is a 4-inch diameter cast iron pipe at approximately 2-4 ft depth. An asphalt apron extends from the Fan House for approximately 30 feet. Midway to the sump, an asphalt access drive crosses over the pipeline on a diagonal. The area where the pipe enters the sump and the area over the sump itself are also asphalt. The remainder of the surface is rough grass over surface soil with steep local grades.

4.3 Between the PFS and Building 801 the line is a 2-inch diameter, stainless steel line, running adjacent to the 14-inch acid off-gas line. The surface area over this pipeline is asphalted. 


\section{ISOCS Scan Acquisition and Analysis}

5.1 Personnel Gamma scan acquisition was performed by Larry Milian, and Tom Roberts, while spectrum analysis and ISOCS geometry modeling were performed by Dave Watters. The report generation and data interpretation were performed by Dave Watters and Larry Luckett. All individuals are members of the ASTD Project Data Acquisition Team under the direction of the Project Analytical Physicist, Larry Luckett, CHP.

5.2 Surface Activity Scans. Scans were acquired on a 5-m equilateral triangular grid at 24 locations (12 asphalt and 11 grass and 1 horizontal pipe) along and either side of the apparent pipeline run between Bldg 704 and the Exhaust stack Base near Bldg 802. A drawing showing the general location of the survey area is provided as Figure 1. The ISOCS measurements were performed using the $180^{\circ}$ field of view collimator with the 1.75 in $(4.4 \mathrm{~cm})$ annular lead side shields. The detector was positioned perpendicular to the local ground surface and followed the ground surface as terrain slopes varied. The distance from the face of the detector to the ground surface was 39.4 inches $(100 \mathrm{~cm})$. The spectrum at each location was accumulated for 1000 seconds (16.7 minutes).

5.3 Spectrum Analysis. Analysis was performed assuming that detected radionuclides were distributed uniformly in a 6-inch $(15-\mathrm{cm})$ thick layer of soil with a density of $1.6 \mathrm{~g} / \mathrm{cm}^{3}$.

\subsection{Results}

6.1 Surface Activity Scans. A summary of the results of the in situ analysis of surface soils is provided in Table 2. Detailed listings of each sample analysis are provided in the Appendix.

6.2 Anomalous Radionuclides. The analysis did not identify any locations where the local spectrum deviated from the nominal set of naturally occurring radionuclides seen throughout the area.

\subsection{Conclusions}

The ISOCS was capable of detecting and quantifying gamma-emitting radionuclides in the surface soils at sensitive levels. Small but detectable levels of Cs-137, consistent with global fall-out, were observed, along with naturally occurring radionuclides. Several locations of possible interference from sources in adjacent structures were identified.

\subsection{References}

8.1 ASTD Project-Specific Survey Plan No. 99-04, Surface Trace of BGRR Fan House Drain Pipeline, Version 1, August 10, 1999.

8.2 BNL-DAT, In Situ Analysis Quality Assurance Project Plan, Version 1, July 7, 1999. 
8.3 BNL-DAT SOP-DAT1, In Situ Gamma Spectroscopy Using the Canberra ISOCS System, version 1 (Draft) of August 19, 1999.

8.4 BNL Site Environmental Report for Calendar Year 1996, Report BNL-52543, January 1998.

8.5 ASTD Project Data Report No 99-04-01, Analysis of Surface Soil Radioactivity -- BGRR Fan House Drain Pipeline Excavation Area, September 27, 1999 


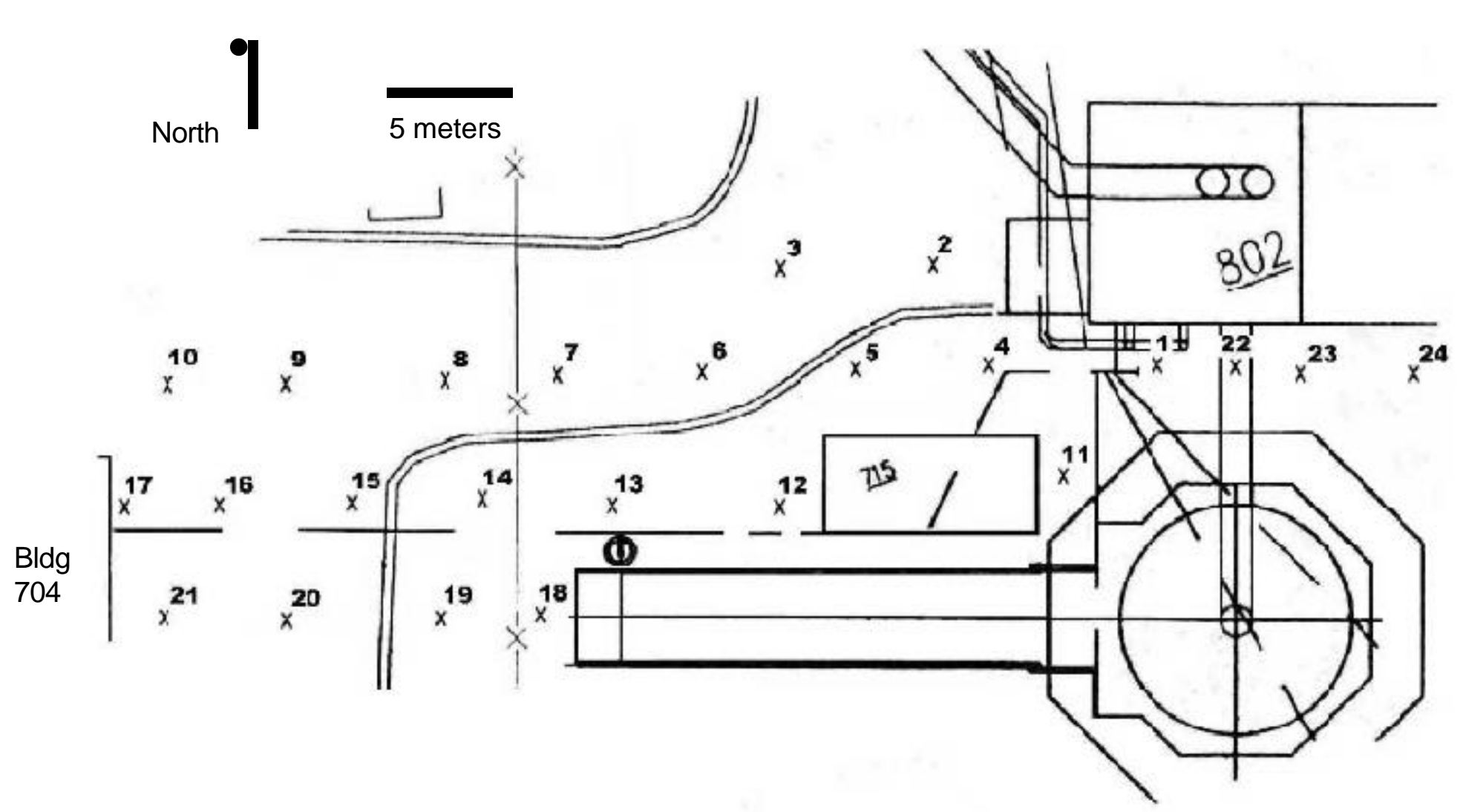

Figure 1. Locations of in situ gamma spectrum acquisition in the area between Bldg 704 and the Exhaust Stack. 


\section{Appendix 1. Prior Analysis of Water and Sludge Samples from the Pile Fan Sump}

A1. Sampling and analysis results of the Pile Fan Sump from March 1997 are summarized in Table A1. The sampling identified elevated concentrations of Tritium, Sr-90, Cs-137, and Ra-226 in sump water; analyses of sump sludge identified elevated concentrations of Cs-137, Ra-226, Am-241, and Co-60.

Table A1. Contaminants Observed in the Pile Fan Sump Contents in 1997 Sampling

\begin{tabular}{|l|c|c|}
\hline Radionuclide & $\begin{array}{c}\text { Concentration in water } \\
(\mathbf{p C i} / \text { liter })\end{array}$ & $\begin{array}{c}\text { Concentration in sludge } \\
(\mathbf{p C i} / \text { liter })\end{array}$ \\
\hline Tritium (H-3) & 260,000 & $\mathrm{NR}$ \\
\hline Gross beta & 6,600 & $\mathrm{NR}$ \\
\hline Cs-137 & 2,000 & 15,700 \\
\hline Ra-226 & 2,300 & 365 \\
\hline Am-241 & $\mathrm{NR}$ & 71 \\
\hline Co-60 & $\mathrm{NR}$ & 3.1 \\
\hline Sr-90 & 2,270 & $\mathrm{NR}$ \\
\hline
\end{tabular}

NR $=$ Not Reported

Ref: Root Cause Analysis Summary Form, Occurrence CH-BH-BNL-1997-0012, Apr 1997.

A.2 The PFS was opened on August 12, 1999 following a significant rainfall on August 11. Results of analysis of a water sample obtained from the volume in the sump (sample 9908527-02) are provided in Table A2.

Table A2. Contaminants Observed in Pile Fan Sump Contents in Aug 1999 sampling

\begin{tabular}{|l|c|}
\hline Radionuclide & $\begin{array}{c}\text { Concentration in water } \\
\text { (pCi/liter) }\end{array}$ \\
\hline \hline U-238/234 & $23.0 \pm 3.4$ \\
\hline Pu-239/240 & $13.5 \pm 2.8$ \\
\hline Cs-137 & $102,000 \pm 9,500$ \\
\hline Am-241 & $3.0 \pm 1.0$ \\
\hline Na-22 & $19.3 \pm 5.5$ \\
\hline Sr-90 & $76,500 \pm 40$ \\
\hline
\end{tabular}


While the PFS was open on August 12, 1999, an in situ gamma spectrum was obtained using the ISOCS instrument (ASTD Sample PFS2123b). The analysis identified Cs-137 in the gamma spectrum. The analysis did not detect any other gamma-emitting radionuclides observed in the water (Ra-226) or in the sludge (Am-241, Co-60 and Ra-226). Estimated activity concentrations and minimum detectable concentrations are provided in Table A3 for each ISOCS geometry model that was evaluated.

Table A3. Activity Concentrations in PFS Determined by ISOCS Analysis-Open Sump Cover

\begin{tabular}{|c|c|c|c|c|c|c|c|}
\hline \multirow[b]{2}{*}{ Medium } & \multirow{2}{*}{$\begin{array}{c}\text { Assumed } \\
\text { Thickness }\end{array}$} & \multicolumn{3}{|c|}{ Activity Cs-137 } & \multicolumn{3}{|c|}{ Total Activity in the sump $(\mu \mathrm{Ci})$} \\
\hline & & $\left(\mathrm{dpm} / 100 \mathrm{~cm}^{2}\right)$ & $\left(\mu \mathrm{Ci} / 100 \mathrm{~cm}^{2}\right)$ & $(\boldsymbol{\mu} \mathbf{C i} / \mathbf{g})$ & Cs-137 & $\begin{array}{lll}A \quad m & - \\
241 & \end{array}$ & Co-60 \\
\hline $\begin{array}{l}\text { Residue on } \\
\text { Sump Floor }\end{array}$ & $\begin{array}{c}0.05 \text { in } \\
\text { evenly over } \\
\text { surface }\end{array}$ & $\begin{array}{c}4.9 \mathrm{E}+06 \pm \\
0.6 \mathrm{E}+06\end{array}$ & $2.2 \pm 0.3$ & $0.11 \pm 0.014$ & $378 \pm 42$ & $<4.72$ & $<0.7$ \\
\hline Sludge pool & 10 in deep; $1.5 \mathrm{ft}^{3}$ & --- & --- & $0.019 \pm 0.001$ & & & \\
\hline $\begin{array}{l}\text { Residue on } \\
\text { Sump Floor }\end{array}$ & $\begin{array}{l}0.05 \text { in } \\
\text { evenly over } \\
\text { surface }\end{array}$ & $\begin{array}{c}1.6 \mathrm{E}+06 \pm \\
0.2 \mathrm{E}+06\end{array}$ & $0.73 \pm 0.10$ & $0.035 \pm 0.005$ & $1,280 \pm 180$ & ND & $<1.92$ \\
\hline $\begin{array}{l}\text { Residue on } \\
\text { Upper S Wall }\end{array}$ & $\begin{array}{c}0.05 \text { in } \\
\text { evenly over } \\
\text { surface }\end{array}$ & $7600 \pm 4900$ & $0.0034 \pm 0.0022$ & $\begin{array}{c}170 \pm 110 \\
\mathrm{pCi} / \mathrm{g}\end{array}$ & --- & $\begin{array}{r}<0.004 \\
\mu \mathrm{Ci} / 1\end{array}$ & $\begin{array}{l}<0.003 \\
00 \mathrm{~cm}^{2}\end{array}$ \\
\hline
\end{tabular}

$\mathrm{ND}=$ not determined due to absorption attenuation in thick constituents.

--- = not calculated for the assumed geometry

Errors are reported as $\pm 2 \mathrm{~s}$.

A.4 The PFS was opened again on August 23, 1999 and samples of the sludge and smears of removable contamination of the sump interior were obtained. Analysis of the sludge sample (No. 99082309-01) had Cs-137 reported as $0.104 \mu \mathrm{Ci} / \mathrm{g}$ with 1-sigma error of $8.5 \%$ and Am241 was not detected. Five smears (No 990823-01 to -05) were reported as detecting Cs-137 (0.6-1.3E-03 $\mu \mathrm{Ci} / \mathrm{smear})$ and Am-241 (8.5E-05 $\mu \mathrm{Ci} / \mathrm{smear})$. Am-241 was detected on 3 of 5 smears, and Am-241 was not detected when the Cs-137 activity was below 7E-04 $\mu \mathrm{Ci} / \mathrm{smear}$.

A.5 Additional direct surface readings and soil samples will be obtained by BGRR staff. The analytical results will be available at a later date for use in interpreting the ISOCS analysis. 


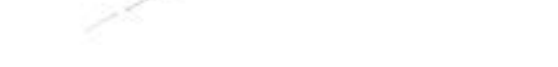

ACTION

Connie Simiele - BGRR INFO

Paul Kalb - ASTD Project Steve Masciulli - BGRR

Topical Data Reports

FROM Larry Luckett, Analytical Physicist, ASTD Project

DATE December 1, 1999

SUBJECT: $\quad$ Analysis of Soil Samples, Fan House Pipeline Test-Dig

1. On October 20,1999 the BGRR transferred to the ASTD Project 12 samples obtained from the Fan House Pipeline test dig pit adjacent to Building 704. The samples, six labeled as soil and six labeled as asphalt, were in 1 liter poly bottles.

The samples were individually analyzed in Building 830 using the ISOCS gamma spectrometer. The lead shielding was arranged on the instrument cart for field sample analysis, providing a 1.75 inch annular shield around the detector and a 1 inch annular shield around and on top of the sample bottle. Each sample was weighed, a gamma spectrum accumulated for 900 seconds, corrected for ambient background in the shielded enclosure, modeled using the ISOCS software, and reported as activity per gram of sample. The results of the analysis of the soil samples is provided in the table.

Table 1. Radioactivity concentration in soil samples from test dig adjacent to the Fan House.

\begin{tabular}{|c|c|c|c|c|}
\hline \multirow{2}{*}{$\begin{array}{c}\text { ASTD } \\
\text { Sample No }\end{array}$} & Sample Description & \multicolumn{3}{|c|}{ Activity (pCi/g) } \\
\cline { 3 - 5 } & & Cs-137 & Am-241 & K-40 \\
\hline FHS0120a & Soil at 1 ft depth & $\# 0.11$ & $\# 0.19$ & $3.5 \pm 1$ \\
\hline FHS0220a & Soil at 2 ft depth & $\# 0.11$ & $\# 0.19$ & $2.8 \pm 1$ \\
\hline FHS0320a & Soil under pipe joint & $43 \pm 4$ & $\# 0.48$ & $2.1 \pm 1$ \\
\hline FHS0420a & Soil 6" below joint & $38 \pm 3$ & $\# 0.41$ & $2.4 \pm 1$ \\
\hline FHS0520a & Soil 6"-12" below joint & $60 \pm 6$ & $\# 0.55$ & $1.8 \pm 1$ \\
\hline FHS0620a & Soil 12"-18" below joint & $57 \pm 5$ & $\# 0.50$ & $2.5 \pm 1$ \\
\hline
\end{tabular}

2. On October 211999 the ASTD Project used the ISOCS instrument to count soil and asphalt samples during a excavation adjacent to the Pile Fan Sump to uncover pipe joints for observation. Samples were provided in 1 liter poly bottles without a chain of custody.

The samples were individually analyzed in Building 701 using the ISOCS gamma spectrometer. The lead shielding was arranged on the instrument cart for field sample analysis, providing a 1.75 inch annular shield around the detector and a 1 inch annular shield around and on top of the sample bottle. Each sample was weighed, a gamma spectrum accumulated for 900 seconds, corrected for ambient background in the shielded enclosure, modeled using the ISOCS software, 
and reported as activity per gram of sample. The results were reported to BGRR personnel as the results were calculated in the field. The results of the analysis of the soil samples is provided in Table 2:

Table 2. Radioactivity concentration in soil samples from test dig adjacent to the Pile Fan Sump

\begin{tabular}{|l|l|c|c|c|}
\hline \multirow{2}{*}{$\begin{array}{c}\text { ASTD } \\
\text { Sample No }\end{array}$} & \multicolumn{1}{c|}{$\begin{array}{c}\text { BGRR } \\
\text { Sample Description }\end{array}$} & \multicolumn{3}{c|}{ Activity (pCi/g) } \\
\cline { 3 - 5 } & \multicolumn{1}{|c|}{ Cs-137 } & Am-241 & K-40 \\
\hline FSS0100a & 4 ft depth close to sump & $<0.15$ & $<0.26$ & $3.9 \pm 2$ \\
\hline FSS0200a & $\begin{array}{l}\text { Asphalt pieces, south side of } \\
\text { PFS (A-7) }\end{array}$ & $<0.19$ & $<0.24$ & $<3.7$ \\
\hline FSS0300a & $\begin{array}{l}\text { Asphalt pieces, north side of } \\
\text { PFS (A-8) }\end{array}$ & $<0.24$ & $<0.33$ & $1.8 \pm 2$ \\
\hline FSS0400a & $\begin{array}{l}\text { soil at 2.5' below 14" pipe } \\
\text { south side PFS }\end{array}$ & 638 & $<1.6$ & $2.4 \pm 1.5$ \\
\hline
\end{tabular}

3. On November 2, 1999 the BGRR transferred to the ASTD Project 2 samples obtained from the Fan House Pipeline test dig pit adjacent to the Pile Fan Sump.

The samples were individually analyzed in Building 830 using the ISOCS gamma spectrometer. The lead shielding was arranged on the instrument cart for field sample analysis, providing a 1.75 inch annular shield around the detector and a 1 inch annular shield around and on top of the sample bottle. Each sample was weighed, a gamma spectrum accumulated for 900 seconds, corrected for ambient background in the shielded enclosure, modeled using the ISOCS software, and reported as activity per gram of sample. The results were reported to BGRR personnel as the results were calculated. The results of the analysis of the soil samples is provided in the table.

Table 3. Radioactivity concentration in additional soil samples from test dig adjacent to the Pile Fan Sump

\begin{tabular}{|c|c|c|c|c|}
\hline \multirow{2}{*}{$\begin{array}{c}\text { ASTD } \\
\text { Sample No }\end{array}$} & \multirow{2}{*}{$\begin{array}{c}\text { BGRR } \\
\text { Sample Description }\end{array}$} & \multicolumn{3}{|c|}{ Activity (pCi/g) } \\
\hline & & Cs-137 & Am-241 & K-40 \\
\hline FSS0500a & $\begin{array}{l}\text { 10/22/99@1310 } \\
\text { PFS - 4" inlet line at joint } \\
\text { before sump wall }\end{array}$ & $<0.13$ & $<0.24$ & 3.71 \\
\hline $\begin{array}{l}\text { FSS0600a } \\
\text { [may be same } \\
\text { as FSS0100a] }\end{array}$ & $\begin{array}{l}10 / 21 / 99 \\
\text { PFS, } 4 \text { ' next to sump }\end{array}$ & $<0.19$ & $<0.36$ & 6.2 \\
\hline
\end{tabular}


4. On November 9, 1999 the BGRR transferred to the ASTD Project 2 samples obtained from the Fan House Pipeline test dig pit adjacent to the Pile Fan Sump.

The samples were individually analyzed in Building 830 using the ISOCS gamma spectrometer. The lead shielding was arranged on the instrument cart for field sample analysis, providing a 1.75 inch annular shield around the detector and a 1 inch annular shield around and on top of the sample bottle. Each sample was weighed, a gamma spectrum accumulated for 900 seconds, corrected for ambient background in the shielded enclosure, modeled using the ISOCS software, and reported as activity per gram of sample. The results were reported to BGRR personnel as the results were calculated. The results of the analysis of the soil samples is provided in the table.

Table 4. Radioactivity concentration in further soil samples from test dig adjacent to the Pile Fan Sump

\begin{tabular}{|l|l|c|c|c|c|}
\hline \multirow{2}{*}{$\begin{array}{c}\text { ASTD } \\
\text { Sample No }\end{array}$} & \multicolumn{1}{|c|}{$\begin{array}{c}\text { BGRR } \\
\text { Sample Description }\end{array}$} & \multicolumn{4}{c|}{ Activity (pCi/g) } \\
\cline { 3 - 6 } & \multicolumn{1}{|c|}{ Cs-137 } & Co-60 & Am-241 & K-40 \\
\hline FSD0100a & $\begin{array}{l}\text { PFS N. side under 18" pipe } \\
\text { and at depth 0-2' soil }\end{array}$ & 271 & $<0.22$ & $<1.34$ & 9.28 \\
\hline FSD0200a & $\begin{array}{l}\text { PFS N. side under 18" pipe } \\
\text { repeat analysis }\end{array}$ & 125 & $<0.27$ & $<0.99$ & 10.4 \\
\hline
\end{tabular}




\begin{tabular}{|c|c|c|}
\hline NATIONAL LA & MEMO & $\begin{array}{l}\text { Bldg } 830 \text {, Railroad Ave } \\
\text { Brookhaven National Laboratory } \\
\text { Upton, NY } 11973 \\
\text { Voice } 516-344-2777 \\
\text { Fax } \quad 516-344-2217\end{array}$ \\
\hline ACTION & INFO (w/o encl) & ASTDProject \\
\hline Matt Lebarge - BGRR & $\begin{array}{l}\text { Paul Kalb, Proj Mgr } \\
\text { Stephen Pulsford - BGRR } \\
\text { Kevin Miller - DOE-EML }\end{array}$ & $30822-262-023$ \\
\hline
\end{tabular}

FROM Larry Luckett, ASTD Proj
DATE Mar 29, 2000

SUBJECT: $\quad$ Results of Soil Analysis during PFS Excavation

1. Enclosed is a tabulation of the data results from the ISOCS analysis of soil samples during the excavation of the Pile Fan Sump. This tabulation compiles and summarizes the analysis results that were available at the time of analysis in the ISOCS instrument logbook and transmitted verbally to BGRR staff as they needed the information.

2. Samples were provided by BGRR personnel in a 1-liter poly bottle and were counted on the ISOCS instrument in the sample analysis configuration using 1" and 2" lead annular side shields and 1" lead end cap. Samples were counted in the ISOCS support area established on the Main level (110' elevation) of Building 701. All samples were received from and have been transferred back to BGRR control under appropriate chains of custody record.

3. The table provides data on Co-60, Cs-137 and Am-241 (BGRR radionuclides of concern) and K-40 (a naturally-occurring radionuclide). Results are sorted in the table by the BGRR sample number identified on the chain of custody provided with the sample. Results for sample numbers with '*' or ' $\mathrm{R}^{*}$ ' indicate a recount of a sample in accordance with the provisions of the ASTD Project QAPP. Full gamma spectroscopy analysis reports for each sample are on file with ASTD Project records.

4. The data set includes 581 primary samples and 25 quality recounts for a total of 606 samples analyzed.

- All 581 samples were reported as Non Detected for Co-60, with a minimum detectable concentration typically $0.2 \mathrm{pCi} / \mathrm{g}$.

- All 581 samples were reported as Non Detected for Am-241, with a minimum detectable concentration typically $0.4 \mathrm{pCi} / \mathrm{g}$.

- The 581 samples exhibited a range of Cs-137: 414 samples reported as Non Detected with a minimum detectable concentration typically $0.4 \mathrm{pCi} / \mathrm{g}, 52$ samples detected \# $1.0 \mathrm{pCi} / \mathrm{g}, 73$ samples detected between 1 and $23 \mathrm{pCi} / \mathrm{g}, 25$ samples reported between 23 and $100 \mathrm{pCi} / \mathrm{g}$, and 17 samples reported with activity concentration above $100 \mathrm{pCi} / \mathrm{g}$.

- All quality recounts of samples confirmed the initial analysis.

4. Should you have any questions, please contact me at x-2777. 


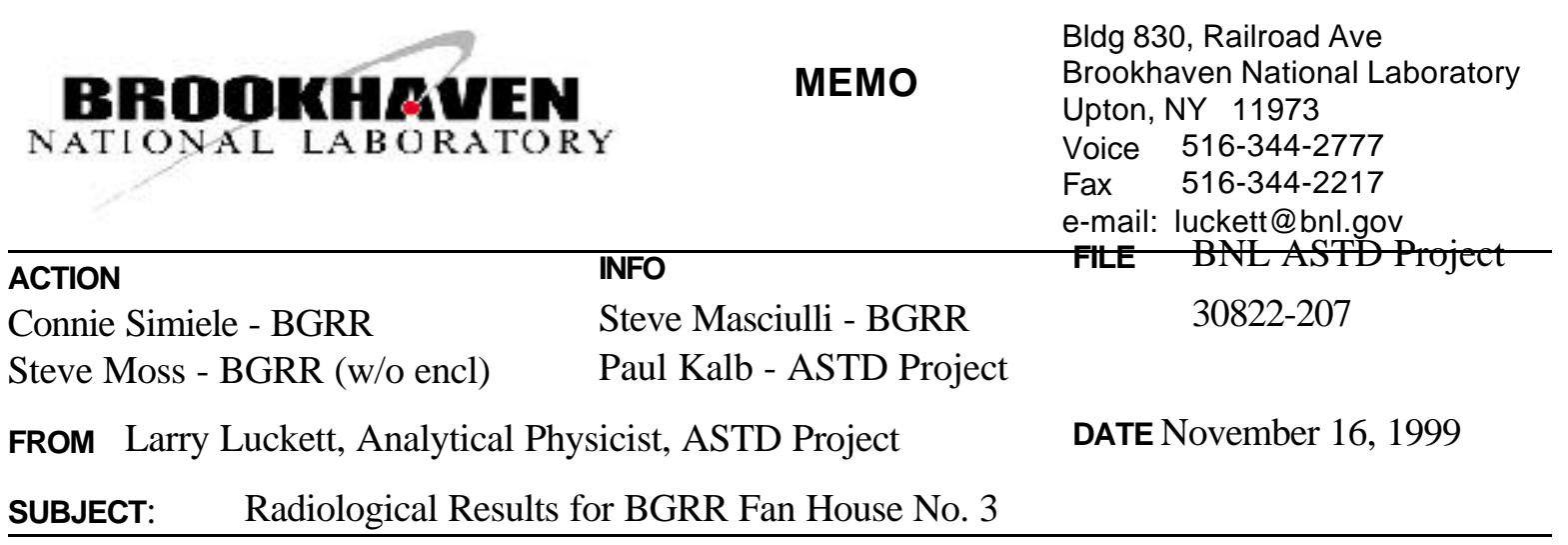

1. Dust Sample Analysis. On September 16, 1999, BGRR provided two samples of dust, identified as extracted from the North face volute housing of Fan No 3. The samples were scanned in the field at Bldg 701, using 1.75" annular shields and $90^{\circ}$ field of view collimators on the detector to reduce interference as much as possible. Results of the analysis are provided in Table 1.

\section{In Situ Analysis at Fan No 3}

a. At your request on November 9, Larry Milian and Tom Roberts, ASTD ISOCS Technical Team, and I used the ISOCS instrument to perform in situ analysis of the fan housing of Fan No 3, located in the BGRR Fan House, Building 704. Because of the dimensions of the housing, physical construction, and the layout of the fan room, there were no access points where the spectrum could be accumulated without interference from fan support structures. BGRR RCT support did allow us into the radiologically controlled area to access the most beneficial angle for spectrum acquisition of the North volute. We could not access nor evaluate the contents of the South volute, but from the fan design the contents should be similar to the North volute, prior to the dust extraction of September 16.

b. Discussion of the analysis: The fan housing was scanned in situ using $1.75^{\prime \prime}$ annular shields and $90^{\circ}$ field of view collimators on the detector to reduce interference as much as possible. The detector was oriented horizontally at the fan housing volute, north face, where surveys indicated an accumulation of radioactivity. Spectra were accumulated from two symmetric positions: East of the housing facing West and West of the housing facing East. Activity was modeled as a layer of surface dust, uniformly covering the fan housing bottom (adjacent rectangular planes). The intervening structural members were adjusted in the model until the results from the symmetric scans were of similar magnitude.

c. Discussion of the results. Results of the in situ analysis are provided in Table 2. Given the uncertainty of internal fan geometry, the total activity remaining in the North volute of Fan No 3 after the dust extraction could be as much as twice the activity indicated in either of the individualin situ analyses. Due to the carbon steel wall thickness and low energy of the gamma photon, the ISOCS model could not realistically quantify a minimum detectable activity for the Am-241; however, the activity detected in the separate dust sample provides an indication of the relative magnitude of Am-241 that might be expected to be still in the fan.

Please contact me if you need further information.

Larry W. Luckett, CHP

Analytical Physicist, ASTD Project 
TABLE 1. Analysis of dust samples extracted from Fan No 3

\begin{tabular}{|c|c|c|c|c|c|c|}
\hline $\begin{array}{l}\text { ASTD Sample } \\
\text { No }\end{array}$ & Sample Description & Cs-137 & Co-60 & Eu-152 & Eu-154 & Am-241 \\
\hline \multirow[t]{3}{*}{ FH3V129a } & $\begin{array}{l}\text { "Heavy"/ Gravity separated fraction } \\
143 \mathrm{~g} \text { in } 0.75 \text { " layer, } 1 \text { liter poly bottle }\end{array}$ & & & & & \\
\hline & Total Activity $(\mu \mathrm{ci})$ & $2025 \pm 140$ & $30 \pm 2$ & $12 \pm 2$ & $4.4 \pm 1.5$ & $10.4 \pm 6.3$ \\
\hline & Activity Concentration $(\mu \mathrm{Ci} / \mathrm{g})$ & $14.2 \pm 1.0$ & $0.21 \pm 0.01$ & $0.085 \pm 0.015$ & $0.031 \pm 0.010$ & $0.073 \pm 0.044$ \\
\hline \multirow[t]{3}{*}{ FH3V229a } & $\begin{array}{l}\text { "Light"/ Filter trapped fraction } \\
49 \mathrm{~g} \text { in } 0.4 \text { " layer, } 1 \text { liter poly bottle }\end{array}$ & & & & & \\
\hline & Total Activity $(\mu \mathrm{ci})$ & $74 \pm 5$ & $1.2 \pm 0.2$ & $<1.5$ & $<1.0$ & $<0.9$ \\
\hline & Activity Concentration $(\mu \mathrm{Ci} / \mathrm{g})$ & $1.50 \pm 0.11$ & $0.024 \pm 0.004$ & $<0.03$ & $<0.02$ & $<0.02$ \\
\hline
\end{tabular}

Notes: $\quad$ Uncertainties in the Table represent \pm 2 s counting error;

Values given as "<" represent the minimum detectable activity (MDA), and indicate the radionuclide was not detected

TABLE 2. in situ Analysis of Fan No 3 in Bldg 704, BGRR

\begin{tabular}{|c|r|r|r|r|c|c|}
\hline $\begin{array}{c}\text { ASTD Sample } \\
\text { No }\end{array}$ & Sample Description & Cs-137 & Co-60 & Eu-152 & Eu-154 & Am-241 \\
\hline FH30329a & $\begin{array}{l}\text { Fan No 3, North face volute } \\
\text { "Left" side or from East facing West } \\
\text { Total Activity ( } \mu \text { ci) }\end{array}$ & $114 \pm 10$ & $1.6 \pm 0.1$ & $<2.5$ & $<1.7$ & ND/NQ \\
\hline FH30429a & $\begin{array}{l}\text { Fan No 3, North face volute } \\
\text { "Right" side or from West facing East } \\
\text { Total Activity ( } \mu \text { ci) }\end{array}$ & $165 \pm 15$ & $2.4 \pm 0.2$ & $<4.2$ & $<2.9$ & ND/NQ \\
\hline
\end{tabular}

Notes: $\quad$ Uncertainties in the Table represent \pm 2 s counting error;

Values given as "<" represent the minimum detectable activity (MDA), and indicate the radionuclide was not detected.

$\mathrm{ND}=$ Not Detected; a peak for the radionuclide was not observed in the spectrum

$\mathrm{NQ}=$ Non-Quantifiable; the ISOCS model could not quantify a realistic MDA due to

[1] physical constraints of the in situ spectrum acquisition (the fan wall thickness and carbon steel composition), and

[2] the low energy of the radionuclide (Am-241) resulted in significant attenuation in the ISOCS model analysis 


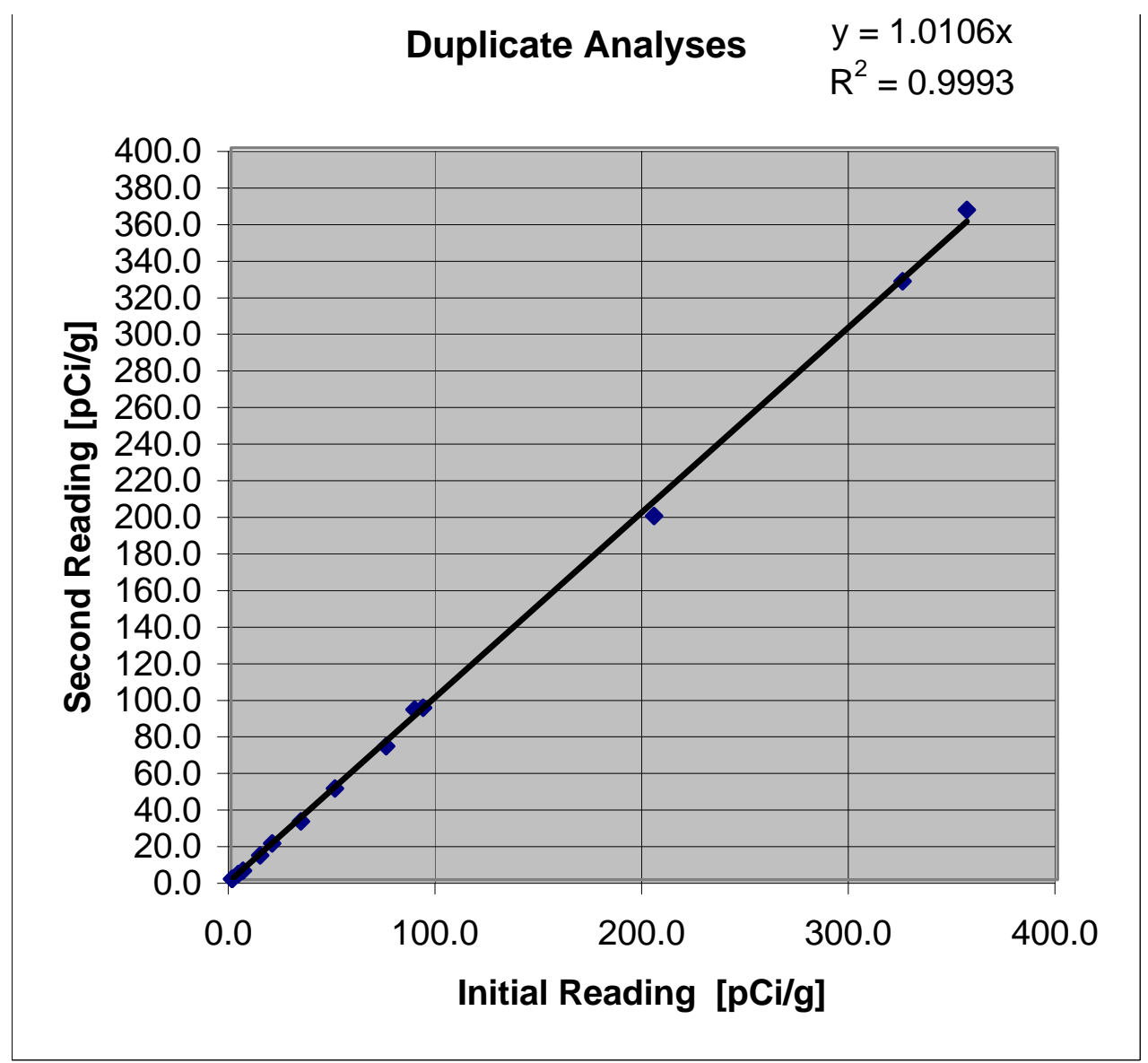

$\begin{array}{rrr} & & \begin{array}{r}\text { Cs-137 } \\ \text { R.P.D. }\end{array} \\ 0.5 & 0.5 & 0.00 \% \\ 0.5 & 0.5 & 0.00 \% \\ 3.5 & 3.1 & 12.90 \% \\ 5.7 & 4.9 & 16.33 \% \\ 14.1 & 13.3 & 6.02 \% \\ 19.9 & 19.8 & 0.51 \% \\ 33.9 & 31.8 & 6.60 \% \\ 50.2 & 49.8 & 0.80 \% \\ 75.1 & 73.0 & 2.88 \% \\ 88.8 & 93.0 & -4.52 \% \\ 93.0 & 94.0 & -1.06 \% \\ 204.7 & 198.8 & 2.97 \% \\ 325 & 327 & -0.61 \% \\ 356 & 366 & -2.73 \% \\ 2169 & 2164 & 0.23 \%\end{array}$




\section{Section 9}




\section{ASTD Project-Specific Survey Plan No. 2K-02 \\ Use of BetaScint Instrument in Support of BGRR Fan House Drain Pipeline Excavation and Pile Fan Sump Removal}

\subsection{PURPOSE}

Perform beta spectroscopy of soil samples from disturbed surface soils in the area between the BGRR Exhaust Stack, the Fan House, and the Pile Fan Sump to

(i) monitor progress of excavation (have we excavated far enough to identify the limits of any contaminated pipe/soil?)

(ii) assist with determination of soil disposition (which pile does this soil go into?)

NOTE: The use of the Canberra ISOCS instrument to support this BGRR excavation by the field analysis of samples for gamma activity is addressed in a separate ASTD Project Specific Survey Plan (PSSP No. 2K-01, Nov, 1999).

\subsection{DATA QUALITY OBJECTIVES}

\subsection{State the Problem}

BetaScint, Inc., has developed an instrument using fiber optics and scintillating phosphor fibers to discriminate high-energy beta particles, as from Sr-90 and U-238, from lower energy betas found in ambient background. Using the BetaScint instrument, in contrast to baseline technology, provides the opportunity to obtain data on radionuclide identification and quantification quickly, without having a delay for transportation and preparation of the sample. An area of interest for this application is the BGRR Fan House Pipeline (FHP), a drain pipe that runs from the BGRR Exhaust Stack, to the Fan House, Bldg 704, to the Pile Fan Sump, and into Bldg 801, as well as the Pile Fan Sump removal. Within the combination of activity present and self-absorption in the soil, data are needed to determine the radionuclide content of the surface and subsurface soils during excavation.

\subsection{Identify the decision.}

The decisions to be made are twofold:

(i) a utility decision: Does the BetaScint instrument detect radionuclides in the soil with a sensitivity sufficient to guide the progress of excavation in a timely manner? and

(ii) a comparability decision: Are the results of analysis by the BetaScint instrument comparable in accuracy and precision

\subsection{Identify inputs.}

Information is available on the geometry and constituents of the Fan House Pipeline and Pile Fan Sump from construction drawings. Plant Engineering has attempted to mark the pipe location using sounding techniques with some success near the ends, but not in the center of the run. 
Results of prior analysis of water and sludge samples from the Pile Fan Sump are available for review. Prior analysis has detected different radionuclides in the water and sludge phases (see Annex A)

The DCGL (derived concentration guideline level) for Sr-90 has been identified by BGRR as 15 $\mathrm{pCi} / \mathrm{g}$.

Additional direct surface readings and soil samples will be obtained by BGRR staff, and the analytical results will be available at a later date to use in interpreting the BetaScint analysis.

\subsection{Define the boundaries.}

The pipeline from BGRR Exhaust Stack to the east end of the Fan House (Bldg 704, on the hill SE of reactor), and from the Fan House to the Pile Fan Sump (in the parking lot drive E of the reactor and S of Bldg 801) is 4-in diameter, cast iron of approximately 40 meters (130 feet) in length. The surface over the pipeline is approximately $60 \%$ earth and grass and $40 \%$ asphalted. The pipeline from the Sump to Building 801 is 2-in diameter, stainless steel of approximately $15 \mathrm{~m}(50 \mathrm{ft})$ in length, all asphalt covered. Approximately $40 \mathrm{~m}$ of pipeline below Bldg 704 will not be removed at this time.

The area of interest on the sub-surface is a corridor of overburden soil along the pipeline, the pipe itself, and any contaminated soil that may be delineated under the pipe. The pipeline, where it exits from Bldg 704 running northward, is at approximately $8 \mathrm{ft}$ depth, so that a significant amount of overburden will be removed to expose the pipe and to slope the sides of the excavation. From this location, the pipeline does not drop as rapidly as the surface contour, so that the pipe enters the sump at only approximately $2 \mathrm{ft}$ depth and the trench width can be narrowed as the excavation progresses towards the sump. The pipeline between the stack and Bldg 704, and between the sump and Bldg 801 is only 2-4 ft below grade so that extensive excavation and sloping will not be required.

2.5 Develop decision rules. If there is a significant instrument response that can be attributed to a source location in the detector field of view, the activity will be quantified using factors derived from correlating instrument response to spiked soil samples. Otherwise, it will be concluded that the combination of source activity and shielding is such that it is below the detection capability of the BetaScint instrument.

\subsection{Specify the tolerable limits on decision errors.}

The decision error of most concern would be to conclude that the instrument cannot detect the activity, when perhaps with a longer counting time or better sample preparation (uniform spread or dryness), it might have been able to. The consequence of longer preparation or counting than is necessary would primarily be the eventual loss in resolution caused by electronic instrument drift, or the delay of excavation progress. To provide an indication of instrument analysis variability, performance stability, and drift, duplicate and replicate analysis of samples will be performed:

- Instrument Replicate - 1 in $10(10 \%)$ samples will be immediately re-counted, without disturbing the soil distribution in the sample tray.

- Field Duplicate/Split - 1 in 10 (10\%) samples will be collected as double volume, composited, split, and counted separately. 
- Instrument Consistency - each day of sampling, two samples should be recounted after a period of two hours has elapsed since the initial count. This involves re-distribution of the soil across the tray and repositioning the tray with respect to the detector.

\subsection{Optimization.}

2.7.1 Instrument considerations. The use of the BetaScint instrument to directly scan soil samples is complicated by two aspects:

- the large field of view of the detector without collimators requires a sample size of approximately $2 \mathrm{~kg}$ ( $5 \mathrm{lbs}$ ). The operator must ensure that sample soil is spread evenly at a uniform thickness across the sample tray.

- the range (energy) of the beta radiation exiting the soil surface is affected by moistur in the soil. The operator must insure that each individual soil sample is dried to the same soil moisture content as in the spiked soil samples used to establish the instrument response correlation.

2.7.2 Sample scanning. The primary analysis mode used in support of the excavation will be the screening/analysis of soil samples in a reproducible geometry. The instrument operator must ensure that adequate soil volume is obtained, and that consistent sample preparation is performed prior to analysis. Otherwise analysis results will be qualified to explain the limitation on use of the data.

2.7.3 Detection sensitivity. The primary information need for the control of excavation is the identity of radionuclides present and whether they are present at levels near or above the DCGL. The Betascint analysis will be accumulated for a time that assures that the minimum detectable concentration is less than $50 \%$ of the DCGL for the Sr-90 identified by the BGRR (50\% of $15 \mathrm{pCi} / \mathrm{g})$.

- for soil sample counted in the field laboratory, the acquisition time will be 5 minutes (300 seconds)

- $\quad$ other analysis times may be identified by the project Analytical Physicist in response to instrument stability observations.

\subsection{Equipment}

BetaScint Hardware

a. the BetaScint beta radiation sensor/detector,

b. DC power supply with A/C cord,

c. cable for power supply to sensor,

d. laptop computer with BetaScint software loaded, and

e. null modem, female/female DB9 cable to connect sensor and computer
Additional Equipment and Instruments

a. Calibrated microR or microRem meter,

b. Digital camera or Polaroid camera w/ film

c. Field notebook

d. Sample counting trays and tray racks,

e. heat lamps for drying samples,

f. zip-lock bags, bottles or buckets for sample packaging,

g. PPE as required by the RWP 


\subsection{COORDINATION}

4.1 Health and Safety BGRR Health and Safety POC: Reggie Suga x-8248

(i) Samples may contain radioactive material contamination. There is a Radiation Work Permit (RWP) for the handling of contaminated soil samples during the performance of the BetaScint analysis. Operators must comply with the requirements of the RWP.

(ii) Sample handling procedures are specified in ERD-OPM-4.3. Personnel should read and be familiar with that procedure prior to performing soil analysis with the BetaScint instrument.

(iii) When working in parking lots and driveways be aware of traffic, and use vehicle flashers or cones to warn drivers and increase your visibility.

(iv) Be aware of heat/cold stress concerns when working in open uncovered areas. A light-weight, pop-up awning for shade and cover is available and should be used. Fluids should be consumed regularly to replace body losses.

\subsection{BGRR Facility Access}

Primary: Steve Masciulli x-8247 Alternate: Manni Lilimpakis X-7628

\subsection{SPECIFIC SCANS AND PARAMETERS}

Specific areas of interest are identified in the BGRR survey plan (Ref 3).Samples and or areas of samples will be determined by the BGRR Field Engineer. BGRR personnel will deliver samples to the ASTD field laboratory or ASTD personnel may be requested to assist with sampling to obtain the soil for analysis.

Samples will be counted on the ISOCS gamma spectroscopy system prior to performing BetaScint analysis. A project sample identification scheme is described in the PSSP for operation of the ISOCS instrument (PSSP No 2K-01). The ASTD Project Sample Number will be entered into the BetaScint analysis log by the instrument operator during analysis. The BGRR sample number will also be entered into the log and the field notebook.

\subsection{REFERENCES}

6.1 BNL-DAT, In Situ Analysis Quality Assurance Project Plan, Version 1, July 7, 1999.

6.2 BNL-DAT SOP-DAT1, In Situ Gamma Spectroscopy Using the Canberra ISOCS System, version 1, August 19, 1999.

6.3 BGRR Sampling and Analysis Plan for Pile Fan Sump Excavation (in press).

6.4 ERD-OPM-4.3, Procedure for ASTD Soil Sample Processing to Support BGRR Excavations, Rev 0 (in press).

6.5 Operational Procedures for Beta Sensor, BetaScint, Inc. 


\section{ANNEX A Previous Analytical Results for Sr-90}

1. Pipeline. Possible contaminants in the pipeline, or in the soil if the pipeline had leaked, can be inferred from the analysis of the sludge and water in the Pile Fan Sump, where pipeline constituents accumulated. Results of prior analysis of water and sludge samples from the Pile Fan Sump are available for review. Prior analysis has detected different radionuclides in the water and sludge phases.

1.1 Sampling and analysis results of the Pile Fan Sump from March 1997 are summarized in Table A.1. The sampling identified elevated concentrations of Tritium, Sr-90, Cs-137, and Ra-226 in sump water; analyses of sump sludge identified elevated concentrations of Cs-137, Ra-226, Am-241, and Co-60.

Table A.1. Contaminants Observed in the Pile Fan Sump Contents in 1997 Sampling

\begin{tabular}{|l|c|c|}
\hline Radionuclide & $\begin{array}{c}\text { Concentration in water } \\
\text { (pCi/liter) }\end{array}$ & $\begin{array}{c}\text { Concentration in sludge } \\
\text { (pCi/liter) }\end{array}$ \\
\hline Tritium (H-3) & 260,000 & NR \\
\hline Gross beta & 6,600 & NR \\
\hline Cs-137 & 2,000 & 15,700 \\
\hline Ra-226 & 2,300 & 365 \\
\hline Am-241 & NR & 71 \\
\hline Co-60 & NR & 3.1 \\
\hline Sr-90 & 2,270 & NR \\
\hline
\end{tabular}

NR = Not Reported

Ref: Root Cause Analysis Summary Form, Occurrence CH-BH-BNL-1997-0012, Apr 1997.

1.2 The PFS was opened on August 12, 1999 following a significant rainfall on August 11. Results of analysis of a water sample obtained from the volume in the sump (sample 990852702) are provided in Table A.2:

Table A.2. Contaminants Observed in Pile Fan Sump Contents in Aug 1999 sampling

\begin{tabular}{|l|c|}
\hline Radionuclide & $\begin{array}{c}\text { Concentration in water } \\
\text { (pCi/liter) }\end{array}$ \\
\hline $\mathrm{U}-238 / 234$ & $23.0 \pm 3.4$ \\
\hline $\mathrm{Pu}-239 / 240$ & $13.5 \pm 2.8$ \\
\hline $\mathrm{Cs}-137$ & $102,000 \pm 9,500$ \\
\hline $\mathrm{Am}-241$ & $3.0 \pm 1.0$ \\
\hline $\mathrm{Na}-22$ & $19.3 \pm 5.5$ \\
\hline $\mathrm{Sr}-90$ & $76,500 \pm 40$ \\
\hline
\end{tabular}

2.4 The PFS was opened again on August 23, 1999 and samples of the sludge and smears of removable contamination of the sump interior were obtained. Analysis of the sludge sample (No. 99082309-01) had Cs-137 reported as $0.104 \mu \mathrm{Ci} / \mathrm{g}$ with 1-sigma error of $8.5 \%$ and Am- 
241 was not detected. Five smears (No 990823-01 to -05) were reported as detecting Cs-137 (0.6-1.3E-03 $\mu \mathrm{Ci} / \mathrm{smear})$ and Am-241 (8.5E-05 $\mu \mathrm{Ci} / \mathrm{smear})$. Am-241 was detected on 3 of 5 smears, and Am-241 was not detected when the Cs-137 activity was below 7E-04 $\mu \mathrm{Ci} / \mathrm{smear}$. 


\section{Section 10}




\begin{tabular}{|c|c|c|}
\hline NATIONAL LABORA & MEMO & $\begin{array}{l}\text { Bldg } 830 \text {, Railroad Ave } \\
\text { Brookhaven National Laboratory } \\
\text { Upton, NY } 11973 \\
\text { Voice } 631-344-2777 \\
\text { Fax } 631-344-4486\end{array}$ \\
\hline ACTION & INFO & ASTD Project \\
\hline Memo for Matt Labarge, BGRR & $\begin{array}{l}\text { Paul Kalb, DAT } \\
\text { Steve Masciulli, BGRR }\end{array}$ & $30822-262$ \\
\hline \multicolumn{2}{|c|}{$\begin{array}{l}\text { FROM Larry Luckett, CHP } \\
\text { ASTD Project Analytical Physicist }\end{array}$} & DATE Apr 10, 2000 \\
\hline BetaScint Analysi & Composited PFS Soil Samples & \\
\hline
\end{tabular}

In his e-mail memo of March 30, 2000, Steve Masciulli identified 30 samples of soil from the Pile Fan Sump (PFS) excavation on which he requested BetaScint analysis. As he suggested, we combined the paired samples in his list to increase the sample volume for BetaScint requirements. We then sieved the soils to remove extraneous objects and organics, weighed each composite, and counted the samples on the BetaScint instrument. Results of the analysis are provided in the Table.

Even after compositing, most (10 of 15) samples were below the requisite mass for definitive BetaScint analysis. To provide you the most information possible, we analyzed each sample, even when the mass was sub-optimal. Results are reported in a "Response Range", indicating that while the actual concentration of Sr-90 could not be quantified, its relative magnitude could be estimated. The response ranges in this analysis are:

Response Range 1: Sr-90 concentration less than $5 \mathrm{pCi} / \mathrm{g}$.

Response Range 2: Sr-90 concentration between $5 \mathrm{pCi} / \mathrm{g}$ and $15 \mathrm{pCi} / \mathrm{g}$.

Response Range 3: Sr-90 concentration greater than $15 \mathrm{pCi} / \mathrm{g}$.

If you have any questions on the analysis or interpretation, please contact me or Larry Milian of the ASTD Project. 


\begin{tabular}{|c|c|c|c|c|}
\hline \multicolumn{5}{|c|}{ Composite PFS Soil Samples Counted on BetaScint Spectrometer } \\
\hline \multirow{2}{*}{$\begin{array}{l}\text { BGRR Soil } \\
\text { Sample I.D. }\end{array}$} & \multirow{2}{*}{$\begin{array}{c}\begin{array}{c}\text { Previous } \\
\text { ISOCS }\end{array} \\
\text { Cs-137 } \\
\text { pCi/g }\end{array}$} & \multicolumn{2}{|c|}{ BetaScint Sr-90 Analysis } & \multirow{2}{*}{$\begin{array}{l}\text { Composite/Sieved } \\
\text { Soil Weight, g }\end{array}$} \\
\hline & & $\begin{array}{l}\text { Response } \\
\text { Range (1) }\end{array}$ & $\begin{array}{l}\text { Indicated } \\
\text { pCi/g (2) }\end{array}$ & \\
\hline PFS- 95 & 93.0 & \multirow[t]{2}{*}{2} & \multirow[t]{2}{*}{6.1} & \multirow[t]{2}{*}{1396.5} \\
\hline PFS- 96 & 29.9 & & & \\
\hline PFS- 209 & 204.7 & \multirow[t]{2}{*}{1} & \multirow[t]{2}{*}{1.1} & \multirow[t]{2}{*}{2250.4} \\
\hline PFS- 210 & 22.5 & & & \\
\hline PFS- 220A & 44.5 & \multirow[t]{2}{*}{1} & \multirow[t]{2}{*}{0.3} & \multirow[t]{2}{*}{2231.1} \\
\hline PFS- 222 & 31.3 & & & \\
\hline PFS- 235 & 2169.0 & \multirow[t]{2}{*}{3} & \multirow[t]{2}{*}{23} & \multirow[t]{2}{*}{1816.5} \\
\hline PFS- 269 & 26.9 & & & \\
\hline PFS- 279 & 365.1 & \multirow[t]{2}{*}{1} & \multirow[t]{2}{*}{4.2} & \multirow[t]{2}{*}{1433.0} \\
\hline PFS- 280 & 230.8 & & & \\
\hline PFS- 347 & 27.9 & \multirow[t]{2}{*}{1} & \multirow[t]{2}{*}{0.2} & \multirow[t]{2}{*}{1728.8} \\
\hline PFS- 349 & 20.8 & & & \\
\hline PFS- 356 & 200.0 & \multirow[t]{2}{*}{2} & \multirow[t]{2}{*}{5.2} & \multirow[t]{2}{*}{1186.2} \\
\hline PFS- 358 & 128.0 & & & \\
\hline PFS- 412 & 131.0 & \multirow[t]{2}{*}{3} & \multirow[t]{2}{*}{26} & \multirow[t]{2}{*}{1867.3} \\
\hline PFS- 413 & 33.9 & & & \\
\hline PFS- 414 & 325.0 & \multirow[t]{2}{*}{2} & 10 & 1708.4 \\
\hline PFS- 416 & 260.0 & & & \\
\hline PFS- 422 & 80.4 & 2 & 6.0 & 1583.8 \\
\hline PFS- 423 & 114.0 & & & \\
\hline PFS- 464 & 21.5 & 1 & 1.9 & 1816.8 \\
\hline PFS- 465 & 33.2 & & & \\
\hline PFS- 507A & 83.2 & 2 & 6.8 & 2445.5 \\
\hline PFS- 508A & 135.0 & & & \\
\hline PFS- 528 & 21.2 & 1 & 0.4 & 1675.0 \\
\hline PFS- 530 & 33.2 & & & \\
\hline PFS- 533 & 14.1 & 1 & 2.3 & 2270.6 \\
\hline PFS- 535 & 88.8 & & & \\
\hline PFS- 539 & 8.8 & 1 & 2.3 & 2530.2 \\
\hline PFS- 543W & 13.1 & & & \\
\hline
\end{tabular}

NOTES: (1) Response Range 1 : Sr-90 concentration less than $5 \mathrm{pCi} / \mathrm{g}$

Response Range 2 : Sr-90 concentration between $5 \mathrm{pCi} / \mathrm{g}$ and $15 \mathrm{pCi} / \mathrm{g}$

Response Range 3 : Sr-90 concentration greater than $15 \mathrm{pCi} / \mathrm{g}$

(2) Due to sub-optimal volumes for soil samples, analytical response of the BetaScint instrument should be considered only semi-quantitative; response ranges are identified to provide interpretation of the instrument response. 
Section 11 


\begin{tabular}{|c|c|c|}
\hline NATIONAL LAB & MEMO & $\begin{array}{l}\text { Bldg 830, Railroad Ave } \\
\text { Brookhaven National Laboratory } \\
\text { Upton, NY } 11973 \\
\text { Voice } 516-344-2777 \\
\text { Fax } 516-344-2217\end{array}$ \\
\hline ACTION & INFO & FILE ASTOProjeet \\
\hline Steve Masciulli - BGRR & Paul Kalb, DAT & $30822-262$ \\
\hline FROM Larry Luckett & & DATE Feb 22, 2000 \\
\hline
\end{tabular}

SUBJECT: Analysis Results : Support Columns of the Above Grade Ducts

OnFebruary 17, 2000 the ASTD Project Technical Team used the ISOCS instrument to perform gamma spectrum analysis of cement columns of the BGRR Above Grade Duct on the rooftop of the Fanhouse, Building 704. These columns had been identified and marked by your surveyors as having surface contamination.

We located the ISOCS instrument with the detector positioned at 9 in $(23 \mathrm{~cm})$ from the marked surface of the concrete support column. The detector was shielded with $45 \mathrm{~mm}$ thick annular lead side-shields, and the field of view was restricted to 90 degrees. The detector was lifted on supports so that the geometry was optimized to have the field of view encompass the indicated active area. The observed field of view of the ISOCS in this geometry is $420 \mathrm{~cm}^{2}$. Spectra were accumulated for 600 seconds. Additional spectra were accumulated at each location with the endcap closed, to account for activity in the duct interfering with the primary area of analysis.

The analysis of each spectrum indicated that the only radionuclide detected was Cs-137. The results are summarized in the table, below.

Surface Activity observed on concrete columns of Above Ground Ducts

\begin{tabular}{|c|c|c|c|c|}
\hline \multirow{2}{*}{$\begin{array}{l}\text { Sample No } \\
\text { Description } \\
\text { Activity } \\
\text { of } \\
\text { Radionuclide }\end{array}$} & \multicolumn{2}{|c|}{$\begin{array}{c}\text { RDS-0229a } \\
\text { Above Ground Support No 5, West }\end{array}$} & \multicolumn{2}{|c|}{$\begin{array}{l}\text { RDS03229a } \\
\text { Above Ground Support No 6, West }\end{array}$} \\
\hline & $\begin{array}{l}\text { Total } \\
\mu \mathrm{Ci}\end{array}$ & $\begin{array}{c}\text { Areal Concentration } \\
\text { averaged over FOV } \\
\mu \mathrm{Ci} / \mathbf{1 0 0} \mathrm{cm}^{2}\end{array}$ & $\begin{array}{l}\text { Total } \\
\mu \mathrm{Ci}\end{array}$ & $\begin{array}{c}\text { Areal Concentration } \\
\text { averaged over FOV } \\
\mu \mathrm{Ci} / 100 \mathrm{~cm}^{2}\end{array}$ \\
\hline Cs-137 & $4.6 \pm 0.4$ & $1.1 \pm 0.1$ & $0.18 \pm 0.02$ & $0.041 \pm 0.004$ \\
\hline Co-60 & \#0.004 & \#0.0009 & \#0.003 & \#0.0007 \\
\hline Eu-154 & \#0.01 & \#0.003 & \#0.008 & \#0.002 \\
\hline Am-241 & \#0.015 & \#0.004 & \#0.007 & \#0.002 \\
\hline
\end{tabular}

Notes: 1. Areal concentrations are averaged over the ISOCS $420 \mathrm{~cm}^{2}$ field of view and are reported per 100 $\mathrm{cm}^{2}$; measurements with an instrument with a smaller detector, or considering only the actual contaminated surface area might be numerically different.

2. Uncertainties ( \pm ) are reported as 1.96 sigma; MDA (\#) is the $95 \%$ confidence level.

Larry W. Luckett, CHP

Senior Health Physicist 
BRDDKADUEN

NATIONAL LABORATORY
MEMO
Bldg 830, Railroad Ave

Brookhaven National Laboratory

Upton, NY 11973

Voice 516-344-2777

Fax 516-344-2217

INFO

Paul Kalb, DAT

30822-262

Memo for Record

FROM Larry Luckett

DATE Sept 21, 1999

SUBJECT: Analysis Results : BGRR Above Grade Ducts

Reference to Preliminary Analysis, September 14, 1999

On August 11 the ASTD ISOCS Technical Team used the ISOCS instrument to perform gamma spectrum analysis of a cement plug identified as having been obtained from the side wall of the BGRR Above Grade Duct, on the rooftop over the fan house. Also on September 2 and September 9, we performed in situ analysis of the interior of the ducts through three opened access portals in each of the duct sections, after the filters but before the fans. The analysis of the spectra are provided in the table below.

\section{Surface Activity Concentration on inner surface of Above Ground Ducts (pCi/cm²)}

\begin{tabular}{|l|c|c|c|c|}
\hline Radionuclide & Plug Surface & North Duct & South Duct & Rooftop Duct \\
\hline Sample No. & AGDp129b & AGDnd23b & AGDsd23a & AGDrd23b \\
\hline Am-241 & $37 \pm 13$ & $11 \pm 2$ & $21 \pm 24$ & $15 \pm 21$ \\
\hline Cs-137 & $8,500 \pm 260$ & $8,850 \pm 600$ & $24,100 \pm 1,600$ & $13,700 \pm 930$ \\
\hline Co-60 & ND & ND & $34.6 \pm 4.4$ & $26 \pm 4.3$ \\
\hline Na-22/Eu-154 & ND & $1.9 \pm 1.5$ & $2.7 \pm 3.3$ & ND \\
\hline & & & & \\
\hline
\end{tabular}

$\mathrm{ND}=$ Not Detected

Larry W. Luckett, CHP

Senior Health Physicist 
BRDDKHAYEN

NATIONAL LABORATORY

ACTION

Memo for Matt Labarge, BGRR

INFO

Paul Kalb, DAT

FROM Larry Luckett, CHP

ASTD Project Analytical Physicist
Bldg 830, Railroad Ave

MEMO Brookhaven National Laboratory

Upton, NY 11973

Voice 631-344-2777

Fax 631-344-4486

FItE ASTDProjeet

30822-262

DATE Apr 5, 2000

SUBJECT: Preliminary Analysis Results : BGRR Above Grade Ducts

On April 5 the ASTD ISOCS Technical Team used the ISOCS instrument to perform gamma spectrum analysis of samples identified as having been obtained from the April 3 entry of the BGRR Above Grade Duct, on the rooftop over the fan house. The analysis of the spectra are summarized in the table below. Full data analysis reports are on file.

\section{Activity Concentration on samples from Above Ground Ducts}

\begin{tabular}{|c|c|c|c|c|c|}
\hline Description & $\begin{array}{l}\text { Sludge from } \\
\text { Expansion Joint } \\
\text { between } \\
\text { Fans \#1 and \#2 }\end{array}$ & $\begin{array}{c}\text { Rust } \\
\text { (4' to bottom) } \\
\text { East side of } \\
\text { Fan \#1 }\end{array}$ & $\begin{array}{l}\text { Concrete dust } \\
\text { from before } \\
\text { Fan \#2 donut }\end{array}$ & $\begin{array}{l}\text { Concrete } \\
\text { from N wall } \\
\text { corner } \\
\text { horizontal } \\
\text { Fan \#1 }\end{array}$ & $\begin{array}{l}\text { Concrete } \\
\text { parts from } \\
\text { scabbling }\end{array}$ \\
\hline $\begin{array}{c}\text { BGRR } \\
\text { Sample No }\end{array}$ & AGD-1 & AGD-2 & AGD-3 & AGD-4 & AGD-5 \\
\hline $\begin{array}{c}\text { ASTD } \\
\text { Sample No }\end{array}$ & SAM00822 & SAM00818 & SAM00819 & SAM00820 & SAM00821 \\
\hline Radionuclide & \multicolumn{5}{|c|}{ Activity Concentration (pCi/g) } \\
\hline Am-241 & $\begin{array}{c}249,000 \pm 246,000 \\
{[165,000]}\end{array}$ & $\begin{array}{l}\text { ND } \\
{[5]}\end{array}$ & $136 \pm 30$ & $50 \pm 11$ & $23 \pm 11$ \\
\hline Cs-137 & $64 \mathrm{E} 6 \pm 4 \mathrm{E} 6$ & $2,850 \pm 200$ & $41,000 \pm 3,000$ & $7,400 \pm 600$ & $6,700 \pm 500$ \\
\hline Co-60 & $115,000 \pm 8,500$ & $7.5 \pm 0.7$ & $260 \pm 10$ & $37 \pm 2$ & $21 \pm 2$ \\
\hline Eu-152 & $\begin{array}{c}\text { ND } \\
{[40,000]}\end{array}$ & \multirow{2}{*}{. $3 \pm 2$} & $120 \pm 10$ & $20 \pm 3$ & \multirow{2}{*}{. $10 \pm 5$} \\
\hline Eu-154 & $\begin{array}{c}\text { ND } \\
{[26,000]}\end{array}$ & & $50 \pm 7$ & $8 \pm 1$ & \\
\hline
\end{tabular}

ND $=$ Not Detected

[ ] = Minimum Detectable Concentration

Uncertainties are counting errors (1.96s);

Additional uncertainties due to volume and density variations are approximately $\pm 30 \%$ and should be added to the tabulated results. 
Section 12 


\begin{abstract}
BRDOMHAYEN
NATIONAL LABORATORY

Brookhaven National Laboratory

Upton, NY 11973

Voice 631-344-2777

Fax 631-344-4486

ACTION

INFO

Matt Labarge- BGRR

Paul Kalb, Proj Mgr

ASTD Projeet

Steve Musolino-BGRR

Stephen Pulsford - BGRR

30822-262-023

Rob Stone-BGRR(URS)

FROM Larry Luckett, CHP

DATE August 3, 2000

ASTD Project Analytical Physicist

SUBJECT: $\quad$ Results of Analysis for Concrete Samples from Duct Core Bores, Bldg 704

1. Enclosed is a tabulation of the results from the ISOCS analyses of four concrete samples collected by BGRR/URS during the evaluation of duct core boring operations, on the ground adjacent to Bldg 704.

2. Concrete samples were provided by BGRR/URS personnel in poly-wrapped bags (dry) and were counted on the ISOCS instrument in an ISOCS counting area established on the ground level (110' elevation) of Building 701. BGRR/URS RCT personnel assisted in identifying the "hot" side of the sample, so that we were assured of appropriate geometry. All samples were received from, and have been transferred back to, BGRR/URS control.

3. Spectrum acquisition was performed by Larry Milian, quantification modeling results were performed by Milian, and results were reviewed by Larry Luckett, both members of the ASTD Project Team.

4. The table provides data on Co-60, Cs-137 and Am-241 (BGRR radionuclides of concern). Full gamma spectroscopy analysis reports for each sample are on file with ASTD Project records and are available upon request.
\end{abstract}

Should you have any questions, please contact me at x-2777. 


\section{Total Activity on Concrete Duct Surface from Duct Cores, Bldg 704 \\ BGRR Duct Removal Project}

Gamma Spectrum Analysis with the ISOCS Instrument

\begin{tabular}{|c|c|c|c|c|}
\hline BGRR Sample No & CB-A-1-N & CB-9A & CB-5A & CB-5B \\
\hline $\begin{array}{l}\text { BGRR Sample } \\
\text { Description }\end{array}$ & $\begin{array}{c}\text { Concrete Chunk } \\
\text { from Core Bore } \\
\text { in Duct }\end{array}$ & $\begin{array}{c}\text { Concrete Chunk } \\
\text { from Core Bore } \\
\text { in Duct Segment } \\
\text { No } 9\end{array}$ & $\begin{array}{c}\text { Concrete Chunk } \\
\text { from Core Bore } \\
\text { in Duct Segment } \\
\text { No } 5\end{array}$ & $\begin{array}{c}\text { Concrete Chunk } \\
\text { from Core Bore } \\
\text { in Duct Segment } \\
\text { No } 5\end{array}$ \\
\hline Sample Mass & $315.7 \mathrm{~g}$ & $178.4 \mathrm{~g}$ & $132 \mathrm{~g}$ & $275 \mathrm{~g}$ \\
\hline $\begin{array}{c}\text { Measured area of } \\
\text { contaminated } \\
\text { surface } \\
\end{array}$ & $33.2 \mathrm{~cm}^{2}$ & $21.2 \mathrm{~cm}^{2}$ & $19.6 \mathrm{~cm}^{2}$ & $28.3 \mathrm{~cm}^{2}$ \\
\hline ASTD Sample No & IG01317 & IG01319 & IG01320 & IG01318 \\
\hline Radionuclide & \multicolumn{4}{|c|}{ Total Activity ( $\mathrm{pCi}$ ) } \\
\hline Am-241 & $\begin{array}{c}2.10 \pm 0.68 \\
{[0.84]}\end{array}$ & $\begin{array}{c}\text { ND } \\
{[1.10 \text { ] }}\end{array}$ & $\begin{array}{l}\text { ND } \\
{[1.15 \text { ] }}\end{array}$ & $\begin{array}{c}1.02 \pm 0.61 \\
{[0.96]}\end{array}$ \\
\hline Cs-137 & $\begin{array}{c}946 \pm 84 \\
{[1.67]}\end{array}$ & $\begin{array}{c}642 \pm 57 \\
{[1.52]}\end{array}$ & $\begin{array}{l}560 \pm 50 \\
{[1.37 .]}\end{array}$ & $\begin{array}{c}693 \pm 61 \\
{[1.37]}\end{array}$ \\
\hline Co-60 & $\begin{array}{c}1.65 \pm 0.29 \\
{[0.50]}\end{array}$ & $\begin{array}{c}\mathrm{ND} \\
{[0.83]}\end{array}$ & $\begin{array}{c}\mathrm{ND} \\
{[0.84]}\end{array}$ & $\begin{array}{c}1.02 \pm 0.29 \\
{[0.59]}\end{array}$ \\
\hline Eu-152 & $\begin{array}{c}\text { ND } \\
{[1.90]}\end{array}$ & $\begin{array}{c}\mathrm{ND} \\
{[1.54]}\end{array}$ & $\begin{array}{c}\text { ND } \\
{[1.62]}\end{array}$ & $\begin{array}{c}\mathrm{ND} \\
{[1.47]}\end{array}$ \\
\hline Eu-154 & $\begin{array}{c}\mathrm{ND} \\
{[1.33 \text { ] }}\end{array}$ & $\begin{array}{c}\mathrm{ND} \\
{[1.08]}\end{array}$ & $\begin{array}{c}\mathrm{ND} \\
{[1.13]}\end{array}$ & $\begin{array}{c}\mathrm{ND} \\
{[1.05]}\end{array}$ \\
\hline
\end{tabular}

$\mathrm{ND}=$ Not Detected

[ ] = Minimum Detectable Activity in $\mathrm{pCi}$

DATA QUALIFIERS:

1. Analysis assumes $1 \mathrm{~mm}$ thin, uniform, homogeneous distribution of contaminants on surface of concrete matrix

2. Note that results are provided in units of TOTAL ACTIVITY on the chunk, to assist in determination of package quantity for shipping purposes. 


\begin{abstract}
BEDOXHCY EN
NATIONAL LABORATORY

Bldg 830, Railroad Ave

Brookhaven National Laboratory

Upton, NY 11973

Voice 631-344-2777

Fax 631-344-4486

ACTION

INFO

Matt Labarge- BGRR

Paul Kalb, Proj Mgr

ASTD Projeet

Steve Musolino-BGRR

Stephen Pulsford - BGRR

30822-262-023

Rob Stone-BGRR(URS)

FROM Larry Luckett, CHP

DATE July 19, 2000

ASTD Project Analytical Physicist

SUBJECT: Results of Analysis for Concrete Dust from Duct Cutting, Bldg 704

1. Enclosed is a tabulation of the results from the ISOCS analyses of two concrete dust samples collected by BGRR during the evaluation of operations from the cutting area for duct section No 6 and 8 , on the roof of Bldg 704 .

2. Concrete samples were provided by BGRR personnel in 1000-ml HDPE bottles (wet) or in polywrapped bags (dry) and were counted on the ISOCS instrument in an ISOCS counting area established on the ground level (110' elevation) of Building 701. All samples were received from, and have been transferred back to, BGRR control.

3. Spectrum acquisition was performed by Larry Milian, quantification modeling results were performed by Milian and Eric Barbour, and results were reviewed by Larry Luckett, all members of the ASTD Project Team.

4. The table provides data on Co-60, Cs-137 and Am-241 (BGRR radionuclides of concern). Full gamma spectroscopy analysis reports for each sample are on file with ASTD Project records and are available upon request.
\end{abstract}

Should you have any questions, please contact me at x-2777. 


\section{Activity Concentration in Concrete Dust from Duct Cutting, Bldg 704}

BGRR Duct Removal Project

Gamma Spectrum Analysis with the ISOCS Instrument

\begin{tabular}{|c|c|c|}
\hline BGRR Sample No & DC6 & DC8 \\
\hline $\begin{array}{l}\text { BGRR Sample } \\
\text { Description }\end{array}$ & $\begin{array}{c}\text { Dry concrete dust } \\
\text { from Downcomer \#6 } \\
\text { in plastic bag }\end{array}$ & $\begin{array}{l}\text { Wet concrete slurry } \\
1 / 2 \text { liquid - } 1 / 2 \text { solids } \\
\text { from Downcomer \#8 }\end{array}$ \\
\hline Sample Mass & $1,372 \mathrm{~g}$ & $1,320 \mathrm{~g}$ \\
\hline ASTD Sample No & SAM00906 & SAM00905 \\
\hline Radionuclide & \multicolumn{2}{|c|}{ Activity Concentration ( $\mathrm{pCi} / \mathrm{g}$ ) } \\
\hline Am-241 & $\begin{array}{c}\text { ND } \\
{[0.37 \text { ] }}\end{array}$ & $\begin{array}{c}\text { ND } \\
{[0.38 \text { ] }}\end{array}$ \\
\hline Cs-137 & $\begin{array}{c}1.04 \pm 0.26 \\
{[0.26]}\end{array}$ & $\begin{array}{c}3.13 \pm 0.46 \\
{[0.26]}\end{array}$ \\
\hline Co-60 & $\begin{array}{c}\text { ND } \\
{[0.24]}\end{array}$ & $\begin{array}{c}\text { ND } \\
{[0.27]}\end{array}$ \\
\hline Eu-152 & $\begin{array}{c}\text { ND } \\
{[0.47 \text { ] }}\end{array}$ & $\begin{array}{c}\mathrm{ND} \\
{[0.53]}\end{array}$ \\
\hline $\mathrm{Eu}-154$ & $\begin{array}{c}\mathrm{ND} \\
{[0.32]} \\
\end{array}$ & $\begin{array}{c}\mathrm{ND} \\
{[0.38]} \\
\end{array}$ \\
\hline
\end{tabular}

$\mathrm{ND}=$ Not Detected

[ ] = Minimum Detectable Concentration in $\mathrm{pCi} / \mathrm{g}$

DATA QUALIFIERS:

1. Analysis assumes uniform, homogeneous distribution of contaminants throughout the sample matrix 


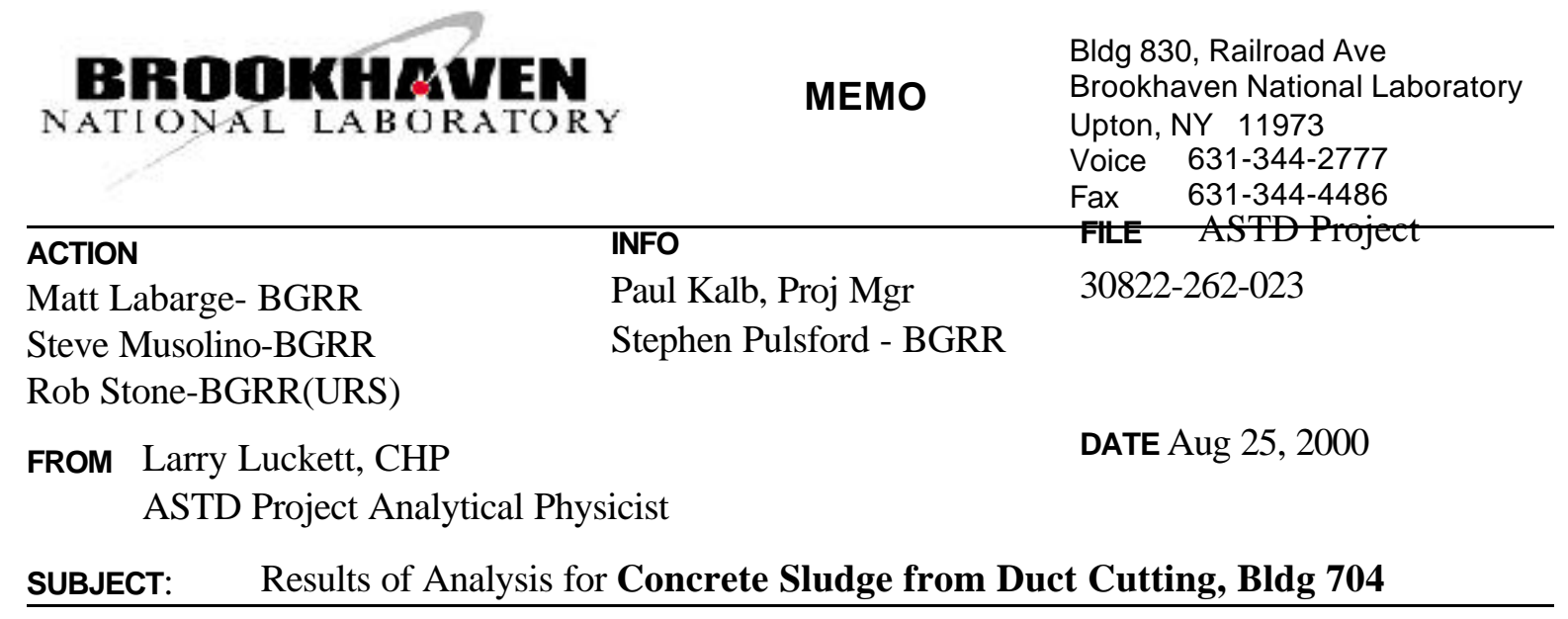

1. Enclosed are tabulation of the results from the ISOCS analyses of five concrete sludge and water samples collected by BGRR during the evaluation of operations from the cutting area for duct section No9, on the ground adjacent to Bldg 704.

2. Sludge and water samples were provided by BGRR personnel and were counted on the ISOCS instrument in an ISOCS counting area established on the ground level (110' elevation) of Building 701. All samples were received from, and have been transferred back to, BGRR control.

3. Spectrum acquisition was performed by Larry Milian, quantification modeling results were performed by Milian, and results were reviewed by Larry Luckett, members of the ASTD Project Team.

4. The table provides data on Co-60, Cs-137 and Am-241 (BGRR radionuclides of concern). Full gamma spectroscopy analysis reports for each sample are on file with ASTD Project records and are available upon request.

Should you have any questions, please contact me at x-2777.

NOTE: Sludge samples were provided by BGRR personnel in 160-ml HDPE containers which is a non-standard geometry for samples. Use of 1-liter wide mouth HDPE bottles would result in more accurate analytical results. 
Activity Concentration in Concrete Dust from Duct Cutting, Bldg 704

BGRR Duct Removal Project

Gamma Spectrum Analysis with the ISOCS Instrument

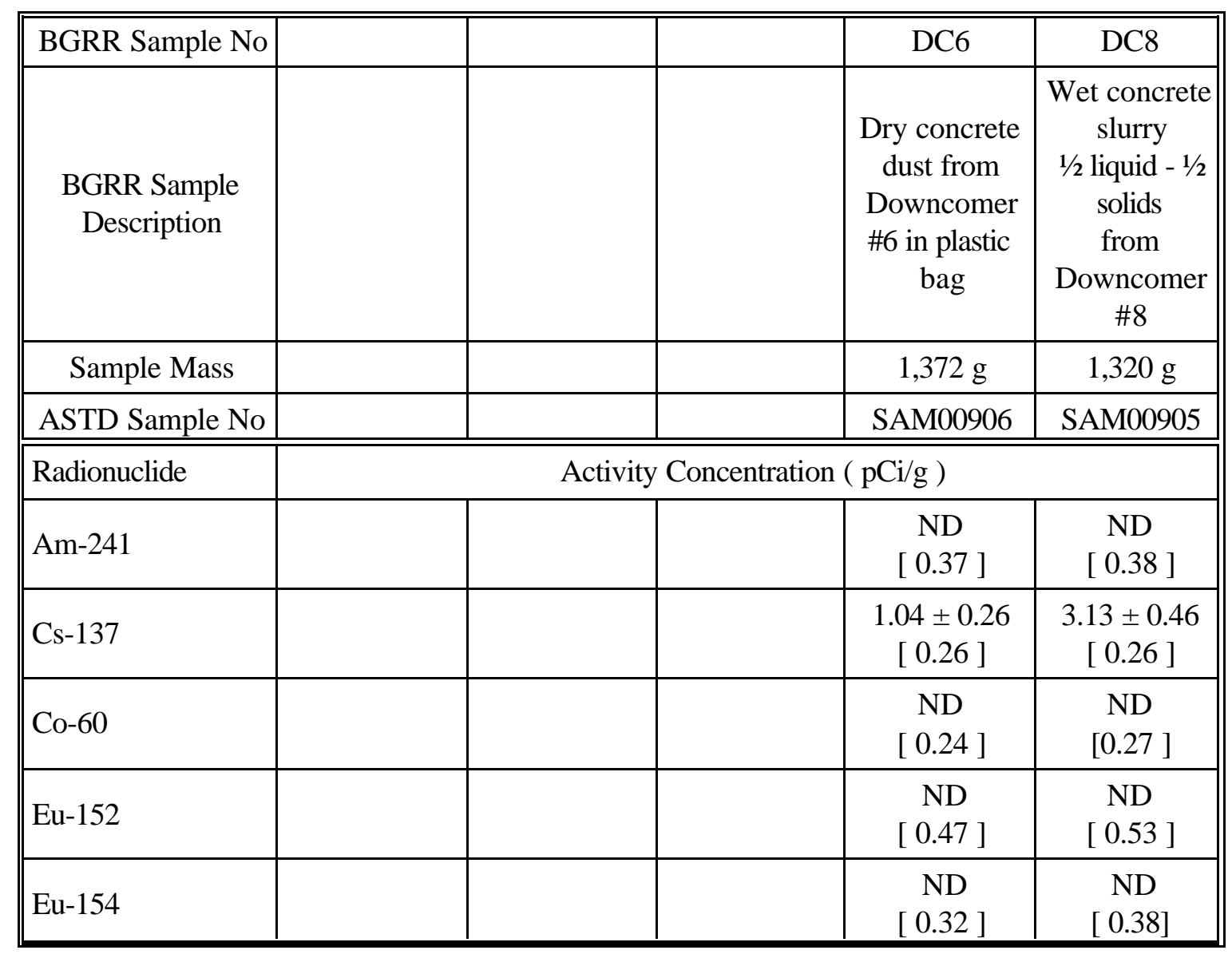

$\mathrm{ND}=$ Not Detected

[ ] = Minimum Detectable Concentration in $\mathrm{pCi} / \mathrm{g}$

DATA QUALIFIERS:

1. Analysis assumes uniform, homogeneous distribution of contaminants throughout the sample matrix 


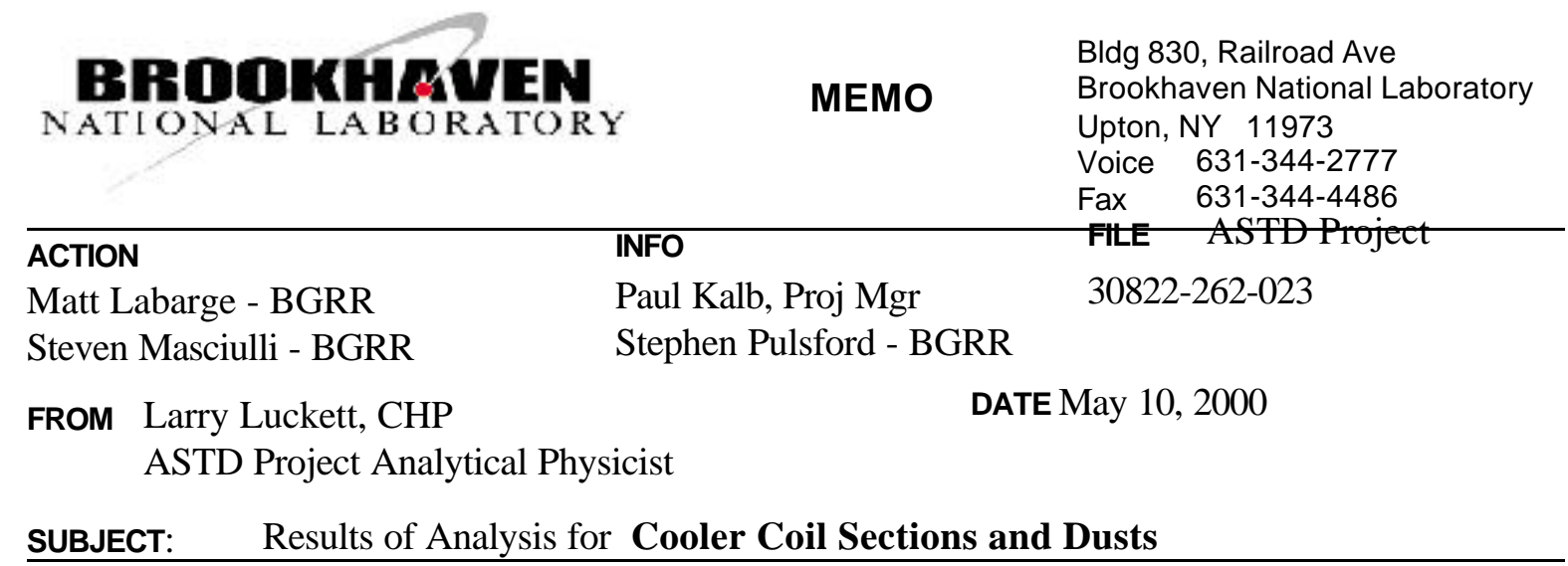

1. Enclosed is a tabulation of the results from the ISOCS analyses of samples collected by BGRR during the duct entry and coil cutting of May 4 to view the air filters.

2. When appropriate to the sample matrix, samples were provided by BGRR personnel in a 1-liter poly bottle and were counted on the ISOCS instrument in the sample analysis configuration using $1 "$ and 2" lead annular side shields and 1" lead end cap. Two bags of odd-sized or large pieces of coil were counted at a measured distance from the ISOCS instrument, and modeled appropriate to the acquisition geometry. All samples were received from, and have been transferred back to, BGRR control under appropriate chain of custody records.

3. Samples were counted in the ISOCS support area established on the Main level (110' elevation) of Building 701. Spectrum acquisition was performed by Larry Milian, quantification modeling results were performed by Milian and Dave Watters, and results were reviewed by Larry Luckett, all members of the ASTD Project Team.

4. The table provides data on Co-60, Cs-137 and Am-241 (BGRR radionuclides of concern). Results are sorted in the table by the BGRR sample number identified on the chain of custody provided with the sample. Full gamma spectroscopy analysis reports for each sample are on file with ASTD Project records and are available upon request.

Should you have any questions, please contact me at x-2777. 


\section{Activity Concentration on samples of Cooler Coil and Dusts \\ from BGRR Below Ground Ducts}

Gamma Spectrum Analysis with the ISOCS Instrument

\begin{tabular}{|c|c|c|c|c|}
\hline BGRR Sample No & AGD-024 & AGD-025 & AGD-026 & AGD-027 \\
\hline Description & $\begin{array}{l}\text { Rust and Fine Dust } \\
\text { from South Duct } \\
\text { Upstream of } \\
\text { cooler coils }\end{array}$ & $\begin{array}{l}\text { Section of cooler coil } \\
\text { in } 11 \text { bottle } \\
\text { from South duct }\end{array}$ & $\begin{array}{l}\text { Bag of } 4 \text { tubes } \\
\text { from South Duct } \\
\text { cooler coils }\end{array}$ & $\begin{array}{l}\text { Bag of } 7 \text { tubes } \\
\text { from North Duct } \\
\text { cooler coils }\end{array}$ \\
\hline Sample Mass & $\begin{array}{c}72.9 \mathrm{~g} \\
\text { in } 11 \text { bottle } \\
1 / 8 \text { full }\end{array}$ & $\begin{array}{c}125 \mathrm{~g} \\
12 \mathrm{~cm} \text { long by } \\
3.5 \mathrm{~cm} \mathrm{dia}\end{array}$ & $2,350 \mathrm{~g}$ & $4,980 \mathrm{~g}$ \\
\hline ASTD Sample No & SAM00870 & SAM00871 & IG01173 & IG01174 \\
\hline Radionuclide & \multicolumn{4}{|c|}{ Activity Concentration ( $\mathrm{pCi} / \mathrm{g}$ ) } \\
\hline Am-241 & $\begin{array}{l}60 \pm 16 \\
{[17.6]}\end{array}$ & $\begin{array}{c}56 \pm 28 \\
{[43]} \\
\end{array}$ & $\begin{array}{c}29 \pm 19 \\
{[30]} \\
\end{array}$ & $\begin{array}{l}\mathrm{ND} \\
{[12]}\end{array}$ \\
\hline Cs-137 & $\begin{array}{c}16,800 \pm 1300 \\
{[21.7]} \\
\end{array}$ & $\begin{array}{c}5,140 \pm 400 \\
{[13.5]} \\
\end{array}$ & $\begin{array}{c}6,600 \pm 500 \\
{[28]} \\
\end{array}$ & $\begin{array}{c}5,100 \pm 400 \\
{[10.4]} \\
\end{array}$ \\
\hline Co-60 & $\begin{array}{l}34 \pm 3 \\
{[4.4]}\end{array}$ & $\begin{array}{l}18 \pm 2.5 \\
{[3.7]}\end{array}$ & $\begin{array}{l}19 \pm 5 \\
{[9.9]} \\
\end{array}$ & $\begin{array}{l}20 \pm 3 \\
{[1.7]}\end{array}$ \\
\hline $\mathrm{Eu}-152$ & $\begin{array}{l}\mathrm{ND}^{*} \\
{[20]}\end{array}$ & $\begin{array}{c}\mathrm{ND} \\
{[18.8]}\end{array}$ & $\begin{array}{c}\mathrm{ND} \\
{[32]}\end{array}$ & $\begin{array}{c}16 \pm 5 \\
{[14.2]}\end{array}$ \\
\hline Eu-154 & $\begin{array}{c}\text { ND } \\
{[14]}\end{array}$ & $\begin{array}{c}\text { ND } \\
{[13.2]}\end{array}$ & $\begin{array}{c}\mathrm{ND} \\
{[23]}\end{array}$ & $\begin{array}{c}\mathrm{ND}^{*} \\
{[12.3]}\end{array}$ \\
\hline
\end{tabular}

$\mathrm{ND}=$ Not Detected

* = Indications of the presence of Eu-152 or Eu-154 at small, non-quantifiable levels

[ ] = Minimum Detectable Concentration in $\mathrm{pCi} / \mathrm{g}$

DATA QUALIFIERS:

Uncertainties reported in the table are counting errors (1.96s); additional uncertainties due to volume and density estimates could be approximately $\pm 30 \%$ and should be added to the tabulated results. 


\begin{tabular}{|c|c|c|}
\hline NATIONAL LABORAT & MEMO & $\begin{array}{l}\text { Bldg 830, Railroad Ave } \\
\text { Brookhaven National Laboratory } \\
\text { Upton, NY } 11973 \\
\text { Voice } 631-344-2777 \\
\text { Fax } 631-344-4486\end{array}$ \\
\hline$\overline{\text { ACTION }}$ & INFO & FItE ASTPProject \\
\hline Matt Labarge - BGRR & Paul Kalb, Proj Mgr & $30822-262-023$ \\
\hline Steven Masciulli - BGRR & Stephen Pulsford - BGRR & \\
\hline \multicolumn{2}{|l|}{ FROM Larry Luckett, ASTD Proj } & DATE May 04, 2000 \\
\hline Results of Sampl & alysis during Duct Entry/Coc & r Characterization \\
\hline
\end{tabular}

1. Enclosed is a tabulation of the data results from the ISOCS analyses of samples collected during the duct entry to evaluate the air coolers. This tabulation compiles and summarizes the analysis results, which were available at the time of analysis in the ISOCS instrument logbook and transmitted verbally to BGRR staff as they needed the information.

2. When appropriate to the sample matrix, samples were provided by BGRR personnel in a 1-liter poly bottle and were counted on the ISOCS instrument in the sample analysis configuration using $1 "$ and 2" lead annular side shields and 1" lead end cap. Some odd-sized or large pieces were counted at a measured distance from the ISOCS instrument, and modeled appropriate to the acquisition geometry. All samples were received from, and have been transferred back to, BGRR control under appropriate chain of custody records.

3. Samples were counted in the ISOCS support area established on the Main level (110' elevation) of Building 701. Spectrum acquisition was performed by members of the ASTD Project Team, Milian or Adams, and quantification modeling results were performed or reviewed by Watters or Luckett.

4. The table provides data on Co-60, Cs-137 and Am-241 (BGRR radionuclides of concern). Results are sorted in the table by the BGRR sample number identified on the chain of custody provided with the sample. Results for sample numbers with ' $R$ ' indicate a recount of a sample. Full gamma spectroscopy analysis reports for each sample are on file with ASTD Project records and are available upon request.

Should you have any questions, please contact me at x-2777. 


\section{Activity Concentration on samples from Below Ground Ducts during Air Cooler Characterization}

Gamma Spectrum Analysis with the ISOCS Instrument

\begin{tabular}{||c|c|c|c|c|c|c||}
\hline \hline BGRR Sample No & DC-1 & DC-1R & DC-2 & DC-2R & SDCSD-001 & NDCSD-001 \\
\hline Description & $\begin{array}{c}\text { N Drain } \\
\text { Cooler } \\
\text { Sump } \\
\text { Water from } \\
\text { Pump } \\
\text { Out Process }\end{array}$ & $\begin{array}{c}\text { DC-1 } \\
\text { shaken and } \\
\text { re-counted }\end{array}$ & $\begin{array}{c}\text { N Drain } \\
\text { Cooler } \\
\text { Sump } \\
\text { Water with } \\
\text { Graphite }\end{array}$ & $\begin{array}{c}\text { DC-2 } \\
\text { shaken and } \\
\text { re-counted }\end{array}$ & $\begin{array}{c}\text { S Drain Cooler } \\
\text { Sump } \\
\text { Debris Sample }\end{array}$ & $\begin{array}{c}\text { N Drain Cooler } \\
\text { Sump } \\
\text { Debris - } \\
\text { Orange Liquid }\end{array}$ \\
\hline Sample Mass & $1018 \mathrm{~g}$ & $1018 \mathrm{~g}$ & $941 \mathrm{~g}$ & $941 \mathrm{~g}$ & 578 g & $682 \mathrm{~g}$ \\
\hline Fractional Fullness \\
of Liter bottle
\end{tabular}

ND $=$ Not Detected

* = Indications of the presence of Eu-152 or Eu-154 at small, non-quantifiable levels

[ ] = Minimum Detectable Concentration in $\mathrm{pCi} / \mathrm{g}$

DATA QUALIFIERS:

Uncertainties reported in the table are counting errors (1.96s); additional uncertainties due to volume and density estimates could be approximately $\pm 30 \%$ and should be added to the tabulated results.

Analytical results are reported in the table assuming samples were homogeneously mixed, with solids re-suspended. As seen in the sample description, several samples were aqueous suspensions; sample activity in the settled solid phase may be significantly different from the activity in the aqueous phase. 


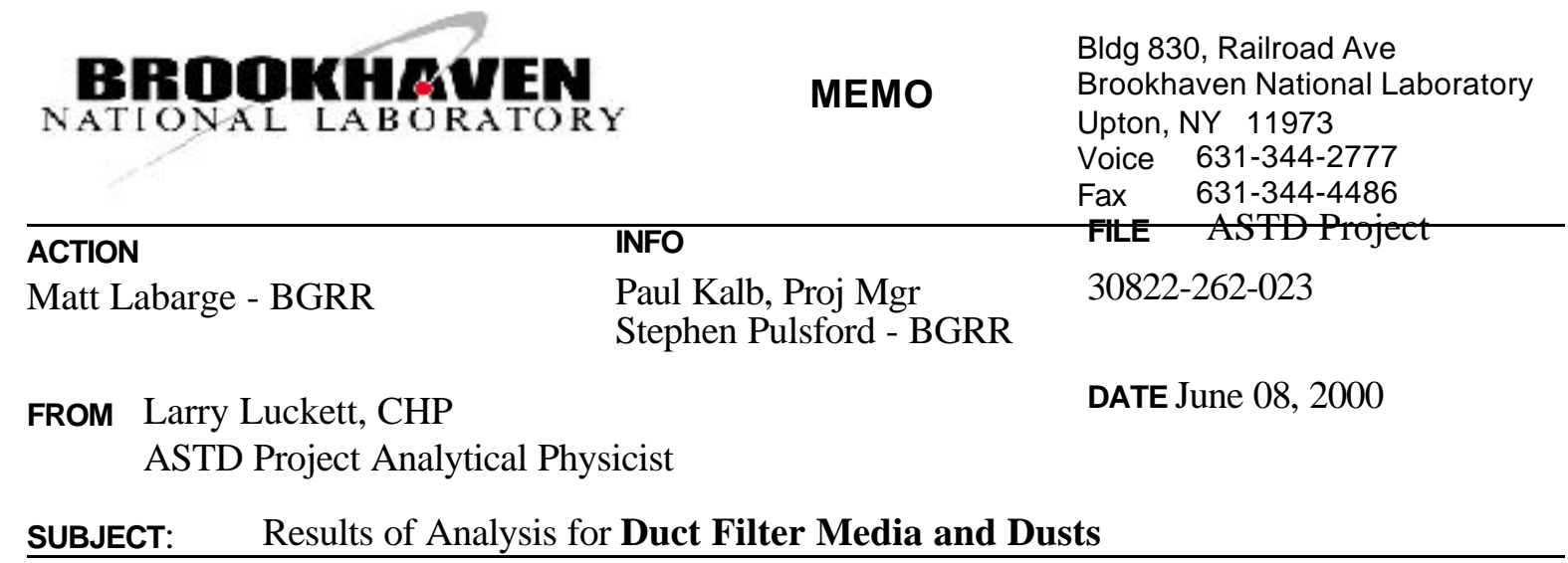

1. Enclosed is a tabulation of the results from the ISOCS analyses of samples collected by BGRR during the collection of samples from the air filters in the underground ducts.

2. When appropriate to the sample matrix, samples were provided by BGRR personnel in a 1-liter poly bottle and were counted on the ISOCS instrument in the sample analysis configuration using $1 "$ and 2" lead annular side shields and 1" lead end cap. All samples were received from, and have been transferred back to, BGRR control under appropriate chain of custody records.

3. Samples were counted in the ISOCS support area established on the Main level (110' elevation) of Building 701. Spectrum acquisition was performed by Larry Milian, quantification modeling results were performed by Milian and Dave Watters, and results were reviewed by Larry Luckett, all members of the ASTD Project Team.

4. The table provides data on Co-60, Cs-137 and Am-241 (BGRR radionuclides of concern). Results are sorted in the table by the BGRR sample number identified on the chain of custody provided with the sample. Full gamma spectroscopy analysis reports for each sample are on file with ASTD Project records and are available upon request.

Should you have any questions, please contact me at x-2777. 


\section{Activity Concentration on samples of Filter Media and Dusts \\ from BGRR Below Ground Ducts}

Gamma Spectrum Analysis with the ISOCS Instrument

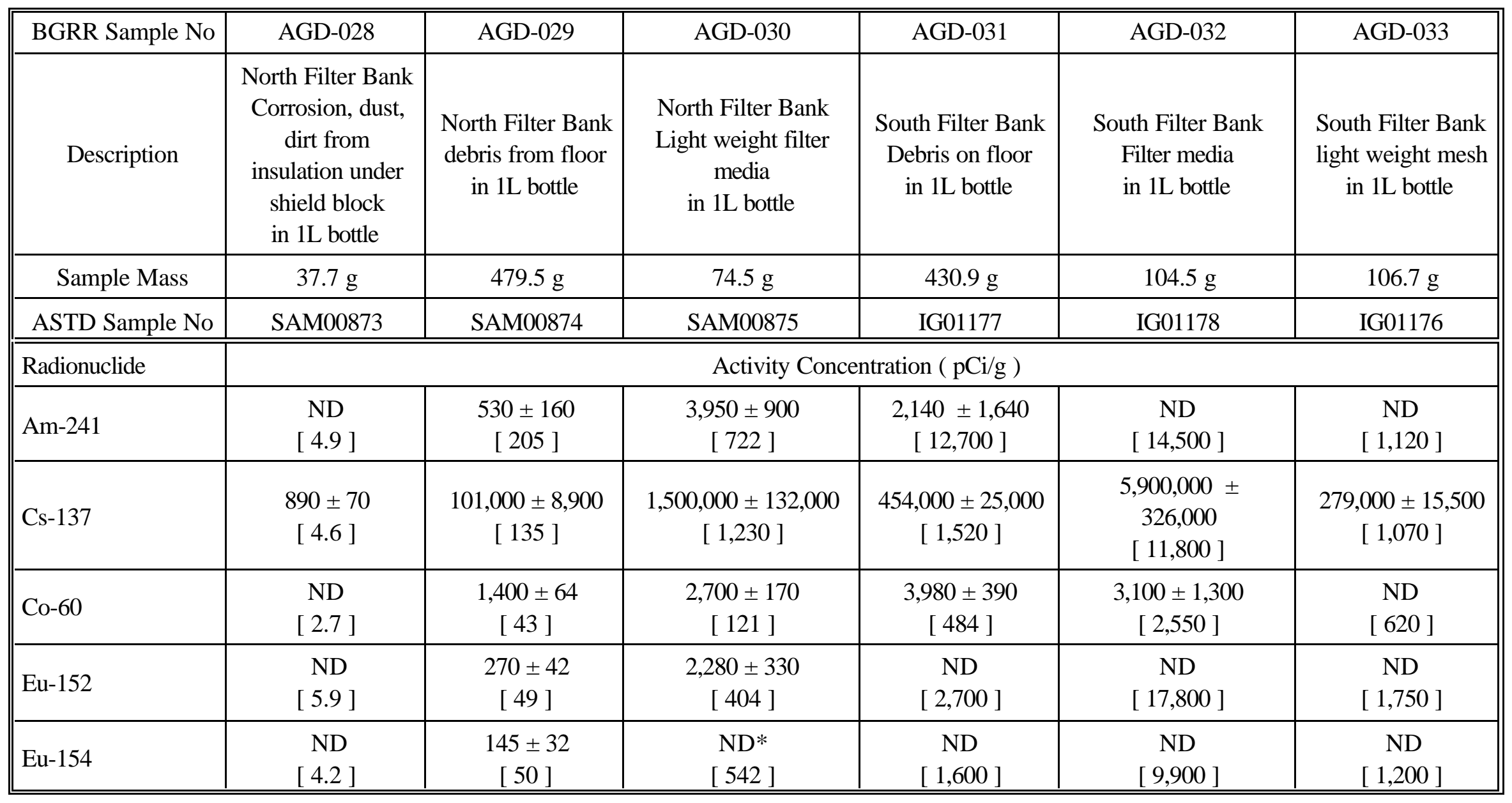

$\mathrm{ND}=$ Not Detected

* = Indications of the presence of Eu-154 at small, non-quantifiable levels

[ ] = Minimum Detectable Concentration in $\mathrm{pCi} / \mathrm{g}$

DATA QUALIFIERS:

Uncertainties reported in the table are counting errors (1.96s); additional uncertainties due to volume and density estimates could be approximately $\pm 30 \%$ and should be added to the tabulated results. 


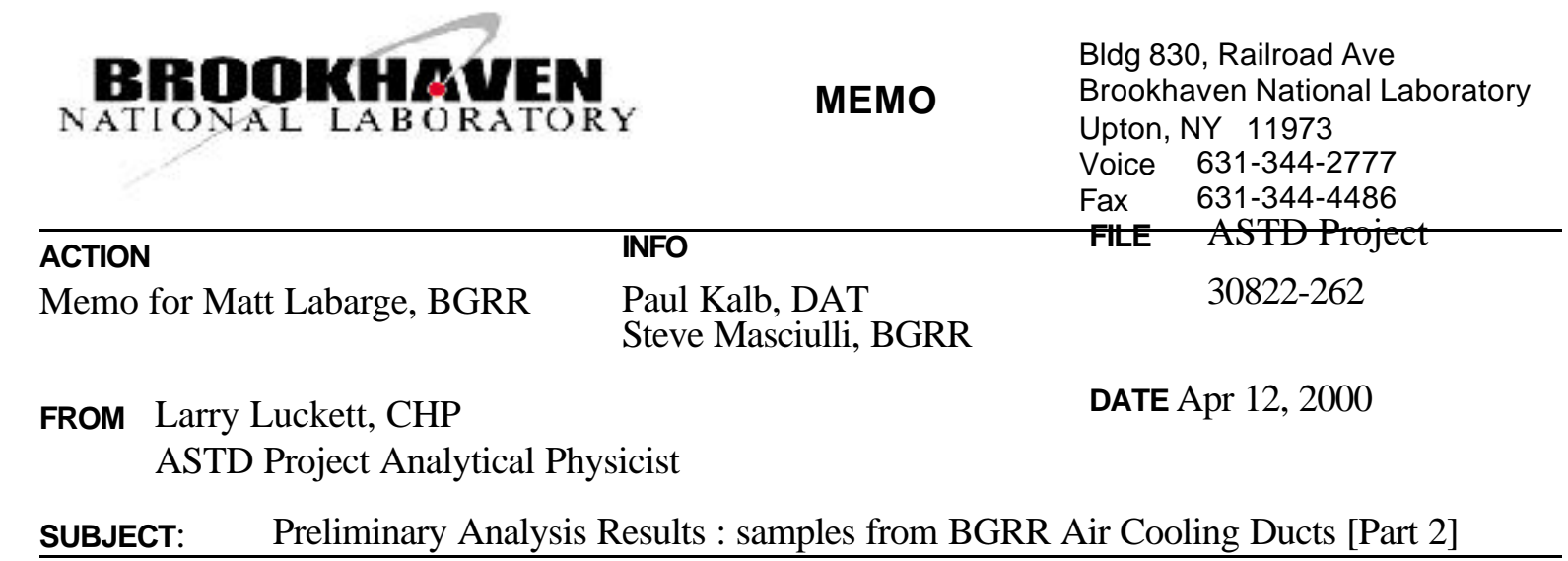

On April 7 and 10, the ASTD ISOCS Technical Team used the ISOCS instrument to perform gamma spectrum analysis of samples identified as having been obtained from the April 6 entry of the BGRR Above Grade Duct, on the diagonal slope down to the east face of the coolers. The analysis of the spectra are summarized in the table below. Full data analysis reports are on file.

\section{DATA QUALIFIERS:}

1. Uncertainties reported in the table are counting errors (1.96s); additional uncertainties due to volume and density estimates could be approximately $\pm 30 \%$ and should be added to the tabulated results.

2. Analytical results are reported in the table as if for homogeneously mixed samples with a density of $1.4 \mathrm{~g} / \mathrm{ml}$ ("homogeneous" $\mathrm{pCi} / \mathrm{g}$ ). As seen in the sample description, the samples provided were of numerous materials, pieces, sizes, and shapes collected during the duct entry.

- For samples of sludge, dirt, rust, etc, (AGD-10, -11, -12, -13, -14, -15, -18, and -19), the results in the table are quantitative.

- For inhomogeneous samples such as pieces of coolers and chips of concrete, (AGD-6, -7, -8, -9, -16 , and -17 ), the results are indicative of the identity and relative magnitudes of radionuclides observed, but are not quantitatively comparable to the homogeneous samples. Contact the ASTD Project if definitive quantification of specific samples should be needed. 


\section{REVISED}

Activity Concentration on samples from Above Ground Ducts

\begin{tabular}{|c|c|c|c|c|c|c|c|c|}
\hline BGRR Sample No & AGD-6 & AGD-6A & AGD-7 & AGD-8 & AGD-9 & AGD-10 & AGD-11 & $\begin{array}{c}\text { AGD-12 } \\
\text { REVISED }\end{array}$ \\
\hline Description & $\begin{array}{l}\text { Cooler } \\
\text { Pieces } \\
\text { Front }\end{array}$ & $\begin{array}{c}\text { Cooler } \\
\text { Pieces } \\
\text { Back }\end{array}$ & $\begin{array}{c}\text { Concrete } \\
\text { pcs, } 2 \\
\text { S wall, } \\
\text { S Duct }\end{array}$ & $\begin{array}{c}\text { Concrete pcs } \\
\text { corner } \\
\mathrm{S} \text { wall, } \\
\mathrm{S} \text { Duct }\end{array}$ & $\begin{array}{l}\text { North Duct } \\
\text { pcs of } \\
\text { Cooler Mat. }\end{array}$ & $\begin{array}{l}\text { Rust } \\
\text { from } \\
\text { Cooler } \\
\text { I-beams }\end{array}$ & $\begin{array}{c}\text { North Duct } \\
\text { sand/water } \\
\text { south wall }\end{array}$ & $\begin{array}{l}\text { South Duct } \\
\text { sludge } \\
\text { from } \\
\text { expansion joint }\end{array}$ \\
\hline Sample Mass & 2090.3 & 2090.3 & 863.9 & 275.1 & 115.0 & 1030.7 & 1253.8 & 678.1 \\
\hline $\begin{array}{l}\text { Fractional Fullness } \\
\text { of Liter bottle }\end{array}$ & $\mathrm{n} / \mathrm{a}$ & $\mathrm{n} / \mathrm{a}$ & $1 / 2$ & $1 / 4$ & $4 / 4$ & $3 / 4$ & $3 / 4$ & $1 / 2$ \\
\hline ASTD Sample No & SAM00841 & SAM00842 & SAM00840 & SAM00826 & SAM00827 & SAM00828 & SAM00829 & SAM00830r \\
\hline Radionuclide & \multicolumn{8}{|c|}{ Activity Concentration (homogenized $\mathrm{pCi} / \mathrm{g}$ ) } \\
\hline Am-241 & $\begin{array}{r}\text { ND } \\
{[0.8]} \\
\end{array}$ & $\begin{array}{r}\text { ND } \\
{[0.7]} \\
\end{array}$ & $\begin{array}{r}\text { ND } \\
{[1.0]}\end{array}$ & $53 \pm 12$ & $46 \pm 16$ & $6 \pm 2$ & $280 \pm 50$ & $354 \pm 337$ \\
\hline Cs-137 & $54 \pm 4$ & $47 \pm 4$ & $\begin{array}{c}109 \pm 9 \\
{[0.8]}\end{array}$ & $11,300 \pm 860$ & $4,500 \pm 340$ & $1,900 \pm 140$ & $\begin{array}{c}22,000 \pm \\
1,600\end{array}$ & $61,000 \pm 4,000$ \\
\hline Co-60 & $0.5 \pm 0.1$ & $0.6 \pm 0.1$ & $\begin{array}{r}\text { ND } \\
{[0.3]}\end{array}$ & $14 \pm 1$ & $100 \pm 7$ & $17 \pm 1$ & $440 \pm 20$ & $\begin{array}{c}75 \pm 7.7 \\
{[5.8]}\end{array}$ \\
\hline Eu-152 & $\begin{array}{r}\text { ND } \\
{[0.8]} \\
\end{array}$ & $\begin{array}{r}\text { ND } \\
{[0.9]}\end{array}$ & $\begin{array}{r}\mathrm{ND} \\
{[1.1]}\end{array}$ & $12 \pm 2$ & $81 \pm 11$ & $7.4 \pm 1.3$ & $250 \pm 10$ & $\begin{array}{c}56 \pm 22 \\
{[54]}\end{array}$ \\
\hline Eu-154 & $\begin{array}{r}\text { ND } \\
{[0.6]}\end{array}$ & $\begin{array}{r}\mathrm{ND} \\
{[0.6]}\end{array}$ & $\begin{array}{r}\mathrm{ND} \\
{[0.7]}\end{array}$ & $4 \pm 3$ & $20 \pm 8$ & $1.9 \pm 1.7$ & $93 \pm 8$ & $\begin{array}{c}25 \pm 10 \\
{[32]}\end{array}$ \\
\hline
\end{tabular}

$\mathrm{ND}=$ Not Detected

[ ] = Minimum Detectable Concentration

Uncertainties are counting errors (1.96s); Additional uncertainties

due to volume and density estimates could be approximately $\pm 30 \%$ and should be added to the tabulated results.
Results are reported as if for homogeneously mixed samples with a density of $1.4 \mathrm{~g} / \mathrm{ml}$. Thus the results in the table are quantitative for samples of sludge, dirt, rust, etc. For inhomogeneous samples, such as pieces of coolers and chips of concrete, (AGD-6, -7, -8, -9, -16, and -17) the results are indicative of the identity and relative magnitudes of radionuclides observed. 


\section{REVISED}

Activity Concentration on samples from Above Ground Ducts [continued]

\begin{tabular}{|c|c|c|c|c|c|c|c|c|c|}
\hline BGRR Sample No & AGD-13 & AGD-14 & AGD-15 & AGD-16 & AGD-17 & AGD-17R & AGD-18 & AGD-18R & AGD-19 \\
\hline Description & $\begin{array}{l}\text { North Duct } \\
\text { Sludge } \\
\text { from floor } \\
\text { by cooler }\end{array}$ & $\begin{array}{c}\text { South Duct } \\
\text { Rust } \\
\text { from } \\
\text { South } \\
\text { Venturi }\end{array}$ & $\begin{array}{l}\text { South Duct } \\
\text { sludge } \\
\text { from in } \\
\text { front of } \\
\text { Cooler }\end{array}$ & $\begin{array}{c}\text { South Duct } \\
\text { South Wall } \\
\text { concrete }\end{array}$ & $\begin{array}{l}\text { Chipped } \\
\text { concrete } \\
\text { corner } \\
\text { N. Duct }\end{array}$ & $\begin{array}{l}\text { Re-count of } \\
\text { AGD-17 }\end{array}$ & $\begin{array}{c}\text { S Duct } \\
\text { S Venturi } \\
\text { Dirt }\end{array}$ & $\begin{array}{l}\text { Re-count of } \\
\text { AGD-18 }\end{array}$ & $\begin{array}{l}\text { North Duct } \\
\text { Sludge } \\
\text { from } \\
\text { Expansion } \\
\text { joint }\end{array}$ \\
\hline Sample Mass & 1214.7 & 952.1 & 356.2 & 800.5 & 405.4 & 405.4 & 541.4 & 541.4 & 822.2 \\
\hline $\begin{array}{l}\text { Fractional Fullness } \\
\text { of Liter bottle }\end{array}$ & $3 / 4$ & $3 / 4$ & $1 / 2$ & $1 / 2$ & $1 / 2$ & $1 / 2$ & $3 / 4$ & $3 / 4$ & $1 / 2$ \\
\hline ASTD Sample No & SAM00831 & SAM00832 & SAM00830 & SAM00834 & SAM00835 & SAM00838 & SAM00836 & SAM00839 & SAM00837 \\
\hline Radionuclide & \multicolumn{9}{|c|}{ Activity Concentration (homogenized $\mathrm{pCi} / \mathrm{g}$ ) } \\
\hline Am-241 & $22 \pm 7$ & $55 \pm 12$ & $165 \pm 40$ & $\begin{array}{r}\mathrm{ND} \\
{[1.4]}\end{array}$ & $11 \pm 4$ & $13 \pm 4$ & $83 \pm 22$ & $94 \pm 25$ & $94 \pm 21$ \\
\hline Cs-137 & $9,600 \pm 730$ & $8,500 \pm 650$ & $\begin{array}{c}52,000 \pm \\
4,000 \\
\end{array}$ & $210 \pm 16$ & $1,020 \pm 80$ & $1,200 \pm 90$ & $\begin{array}{c}17,800 \pm \\
1,400\end{array}$ & $\begin{array}{c}20,900 \pm \\
1,600\end{array}$ & $\begin{array}{c}24,900 \pm \\
2000\end{array}$ \\
\hline Co-60 & $74 \pm 3$ & $20 \pm 1$ & $85 \pm 4$ & $\begin{array}{r}\mathrm{ND} \\
{[0.3]} \\
\end{array}$ & $5.7 \pm 0.6$ & $6.5 \pm 0.7$ & $31 \pm 2$ & $35 \pm 2$ & $88 \pm 4$ \\
\hline Eu-152 & $31 \pm 3$ & $16 \pm 2$ & $55 \pm 9$ & $\begin{array}{r}\mathrm{ND} \\
{[1.3]}\end{array}$ & $5.5 \pm 1.6$ & $\begin{array}{c}4.0 \pm 2.5 \\
{[4.9]}\end{array}$ & $\begin{array}{c}23 \pm 4 \\
{[5.1]} \\
\end{array}$ & $29 \pm 4$ & $59 \pm 5$ \\
\hline Eu-154 & $8 \pm 2$ & $8 \pm 2$ & $21 \pm 6$ & $\begin{array}{r}\mathrm{ND} \\
{[0.7]} \\
\end{array}$ & $\begin{array}{c}2.5 \pm 1.1 \\
{[2.5]}\end{array}$ & $\begin{array}{c}2.5 \pm 1.1 \\
{[1.4]} \\
\end{array}$ & $\begin{array}{c}12 \pm 3 \\
{[6.0]} \\
\end{array}$ & $13 \pm 4$ & $21 \pm 4$ \\
\hline
\end{tabular}

\section{$\mathrm{ND}=$ Not Detected}

[ ] = Minimum Detectable Concentration

Uncertainties are counting errors (1.96s); Additional uncertainties due to volume and density estimates could be approximately $\pm 30 \%$ and should be added to the tabulated results.
Results are reported as if for homogeneously mixed samples with a density of $1.4 \mathrm{~g} / \mathrm{ml}$. Thus the results in the table are quantitative for samples of sludge, dirt, rust, etc. For inhomogeneous samples, such as pieces of coolers and chips of concrete, (AGD-6, -7, -8, -9, -16, and 17) the results are indicative of the identity and relative magnitudes of radionuclides observed. 


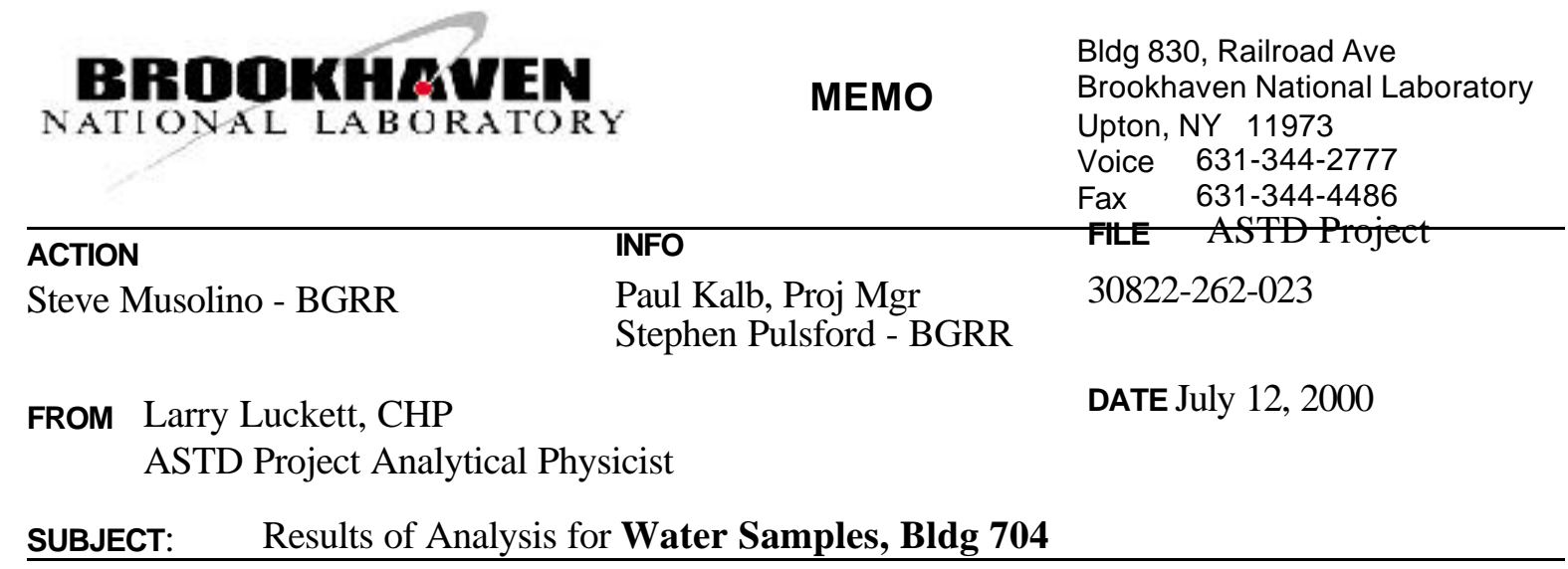

1. Enclosed is a tabulation of the results from the ISOCS analyses of water samples collected by BGRR during the evaluation of water leaking from the cutting area for duct section No 9 , on the roof of Bldg 704. All samples were "ND" for non-detect.

2. Water samples were provided by BGRR personnel in 500-ml HDPE bottles in poly-wrapped bags and were counted on the ISOCS instrument in an ISOCS counting area established on the upper level(143' elevation) of Building 701 near the north face. All samples were received from, and have been transferred back to, BGRR control.

3. Spectrum acquisition was performed by Larry Milian, quantification modeling results were performed by Milian and Eric Barbour, and results were reviewed by Larry Luckett, all members of the ASTD Project Team.

4. The table provides data on Co-60, Cs-137 and Am-241 (BGRR radionuclides of concern). Full gamma spectroscopy analysis reports for each sample are on file with ASTD Project records and are available upon request.

Should you have any questions, please contact me at x-2777. 
Activity Concentration in Water samples from vicinity Duct Section No 9

BGRR Duct Removal Project

Gamma Spectrum Analysis with the ISOCS Instrument

\begin{tabular}{|c|c|c|c|}
\hline $\begin{array}{l}\text { BGRR Sample } \\
\text { Description }\end{array}$ & $\begin{array}{l}\text { Water Inside } \\
\text { containment } \\
\text { Section No } 9\end{array}$ & $\begin{array}{c}\text { Water } \\
\text { @ Roof drain } \\
\text { Bldg } 704\end{array}$ & $\begin{array}{c}\text { Water } \\
\text { @ drain pipe } \\
\text { East side } \\
\text { Bldg } 704\end{array}$ \\
\hline Sample Mass & $534.8 \mathrm{~g}$ & $521.2 \mathrm{~g}$ & $523.9 \mathrm{~g}$ \\
\hline ASTD Sample No & SAM00901 & SAM00902 & SAM00903 \\
\hline Radionuclide & \multicolumn{3}{|c|}{ Activity Concentration ( pCi/g ) } \\
\hline Am-241 & $\begin{array}{c}\mathrm{ND} \\
{[0.25]}\end{array}$ & $\begin{array}{c}\mathrm{ND} \\
{[0.32]}\end{array}$ & $\begin{array}{c}\text { ND } \\
{[0.30]}\end{array}$ \\
\hline Cs-137 & $\begin{array}{l}\text { ND } \\
{[0.44]}\end{array}$ & $\begin{array}{c}\text { ND } \\
{[0.37]}\end{array}$ & $\begin{array}{c}\mathrm{ND} \\
{[0.39]}\end{array}$ \\
\hline Co-60 & $\begin{array}{c}\text { ND } \\
{[0.28]}\end{array}$ & $\begin{array}{l}\text { ND } \\
{[0.38]}\end{array}$ & $\begin{array}{c}\text { ND } \\
{[0.35]}\end{array}$ \\
\hline Eu-152 & $\begin{array}{c}\text { ND } \\
{[0.56]}\end{array}$ & $\begin{array}{c}\mathrm{ND} \\
{[0.52]}\end{array}$ & $\begin{array}{c}\mathrm{ND} \\
{[0.45]}\end{array}$ \\
\hline Eu-154 & $\begin{array}{c}\text { ND } \\
{[0.41]}\end{array}$ & $\begin{array}{c}\text { ND } \\
{[0.34 \text { ] }}\end{array}$ & $\begin{array}{c}\text { ND } \\
{[0.29]}\end{array}$ \\
\hline
\end{tabular}

$\mathrm{ND}=$ Not Detected

[ ] = Minimum Detectable Concentration in $\mathrm{pCi} / \mathrm{g}$

DATA QUALIFIERS:

1. Analysis assumes uniform, homogeneous distribution of contaminants throughout the sample matrix 
Section 13 


\section{ASTD Project-Specific Survey Plan No. 2K-03 Use of ISOCS in Support of BGRR Reactor Pile Characterization}

\subsection{PURPOSE}

The purpose of this Project Specific Survey Plan (PSSP) is to perform ISOCS scans in support of the BGRR need to obtain specific radiological characterization data on the Reactor Pile. The characterization will include but will not be limited to the graphite, fuel channels and penetrations in the graphite, biological shield wall, control rods, large equipment transfer area (Animal tunnel), small equipment transfer area (Instrument tunnel), and the primary air cooling system east and west inlet areas, which are known to have been contaminated during the operation of the BGRR

\subsection{DATA QUALITY OBJECTIVES}

\subsection{State the Problem}

Using the Canberra ISOCS instrument, in contrast to baseline technology, provides the opportunity to obtain data on radionuclide identification and quantification quickly, without having a delay for transportation and preparation of the sample. An area of interest for this application is the characterization of the reactor pile at the BNL Brookhaven Graphite Research Reactor.

Data are needed to determine, with the combination of activity and shielding present,

(a) the radionuclide content of the surface contaminated and activated components of the pile; and

(b) whether the residual radioactivity in the pile is such that it can be detected or bounded by in situ measurements.

Data will be used to support the BGRR determination of extent and magnitude of radioactivity activation and contamination in the pile and its components. Characterization data will be used to establish levels of effort and costs for alternative remediation endstates in disposition of the reactor pile and components.

\subsection{Identify the decision.}

The decision to be made is essentially a simple detection limit decision. What radionuclides does the ISOCS instrument detect in the pile and materials from the pile? Can an upper bound on the activity present be quantified?

\subsection{Identify inputs.}

Information is available on the geometry and constituents of the BGRR pile from construction drawings. BGRR Field Engineer will identify analytical targets and provide samples for analysis.

Results of a prior analysis of a fuel channel plug removed from the North Face of the pile are available for review. 
Table 1.1. Radioactivity Observed on/in a Fuel Channel Plug Removed from the North Pile Face

\begin{tabular}{|c|c|c|}
\hline \multirow{2}{*}{ Radionuclide } & \multicolumn{2}{|c|}{ Total Activity (nanocuries) } \\
\cline { 2 - 3 } & $\begin{array}{c}\text { Innermost End Surface } \\
\text { Facing the Detector }\end{array}$ & $\begin{array}{c}\text { Minimum } \\
\text { Detectable }\end{array}$ \\
\hline Cs-137 & $26.3 \pm 0.8$ & 0.07 \\
\hline Co-60 & $0.65 \pm 0.08$ & 0.06 \\
\hline Eu-152 & $3.82 \pm 0.07$ & 0.12 \\
\hline Am-241 & $0.13 \pm 0.04$ & 0.12 \\
\hline
\end{tabular}

NOTE: Errors are reported as \pm 2 s.

Additional direct surface readings and samples will be obtained by BGRR staff, and the analytical results will be available at a later date to use in interpreting the ISOCS analysis.

\subsection{Define the boundaries.}

The graphite pile was de-fueled in 1968, with the final fuel shipment being made in 1972. The control rods have been inserted into the graphite pile as have the cadmium balls that were intended for emergency shutdown of the pile during operation. Access to the Pile for collecting characterization data will be through the penetration openings that exist on each face of the pile biological shield wall. The characterization data will be gathered at the faces of the biological shield wall access locations and other locations as appropriate. Extracted components, scrapings and wipes will be analyzed ex situ in a sample analysis area designated by BGRR.

Sample/Areas of interest identified in the BGRR Sampling Plan include:

Failed Fuel Channels

Failed Fuel Channels

Fuel Channels

Fuel Channels

Non-Fuel Channels

Non-Fuel Channels

Pneumatic Tubes

Experiment/Instrument Ports

Experiment/Instrument Ports

Animal/Instrument Transfer Pits

Animal/Instrument Transfer Pits

Control Rods

Control Rods
South face 17 of 17

North face 10 of 10

$$
\begin{array}{ll}
\text { South Face } & 4(1 \text { each quadrant) } \\
\text { North Face } & 4(1 \text { each quadrant })
\end{array}
$$

$\begin{array}{ll}\text { South Face } & 4 \text { (1 each quadrant) } \\ \text { North Face } & 4 \text { (1 each quadrant) } \\ \text { North face } & 4 \\ \text { West Face } & 8 \text { of } 36 \\ \text { East Face } & 8 \text { of } 36 \\ \text { West face } & 8 \text { of } 8 \\ \text { East face } & 8 \text { of } 8 \\ \text { Face Corner } & 1 \text { of } 8 \\ \text { Face Corner } & 1 \text { of } 8\end{array}$




\subsection{Develop decision rules.}

If there is an identifiable gamma peak in the ISOCS spectrum that can be attributed to a source location in the ISOCS field of view, the activity will be quantified using a geometric model representing the sample, surface or volume being analyzed. Otherwise, it will be concluded that the combination of source activity and shielding is such that it is below the detection capability of the ISOCS.

\subsection{Specify the tolerable limits on decision errors.}

The decision error of most concern would be to conclude that the instruments cannot detect the activity, when perhaps with a longer spectrum acquisition time or different orientation, it might have been able to. The consequence of counting longer than necessary would primarily be the eventual loss in resolution caused by electronic instrument drift, or the delay of project progress due to overlyconservative counting times. To provide an indication of instrument analysis variability, performance stability, and drift, duplicate and replicate analysis of samples will be performed:

- Field Replicate - 1 in 20 (5\%) samples will be re-counted

- Field Duplicate/Split - 1 in 20 (5\%) samples will be collected as double volume, composited, split, and counted separately

- Field Consistency - each day of sampling, one sample should be re-counted after a period of two hours has elapsed since the initial count

\subsection{Optimization.}

2.7.1 in situ considerations. The use of the ISOCS instrument to directly scan pile and components uncovered in situ during in the characterization is complicated by two aspects:

- the large field of view of the detector without collimators does not allow the distinction between contaminated materials still inside the pile from those in the specific area of interest, and

- when collimators are added to restrict the field of view, the weight of the instrument and cart makes it difficult to maneuver and align with specific fuel channels of interest on the north and south faces.

2.7.2 Sample scanning. The primary analysis mode used in support of the characterization will be the field screening/analysis of samples in a reproducible geometry. The Canberra annular collimators will be arranged to construct a shielded counting cavity around the detector that accepts a 1 liter poly bottle. Soil sample bottle must be filled to the upper crown to meet the description of the geometry model.

2.7.3 Detection sensitivity. The primary information need for the control of characterization is the identity of radionuclides present and whether they are present at levels near or above the DCGL. The gamma spectrum will be accumulated for a time that assures that the minimum 
detectable concentration is less than 50\% of the DCGL for the gamma emitters identified in the BGRR list (Annex B).

- for samples counted in the shielded cavity, the acquisition time will be 5 minutes (300 seconds);

- for analysis of finite objects such as fuel channel plugs, acquisition time will be 5 to 10 minutes (300 to 600 seconds), adjusted for configuration and distance. Often times the distance may need to increased to diminish detector dead-time from highly active samples; and

- for analysis of transfer pits wall/bottom the acquisition time will be 10 minutes.

\subsection{Equipment}

ISOCS Hardware

a. the InSpector portable gamma spectroscopy interface,

b. a broad energy germanium (BEGe) detector with preamp,

c. Multi-Attitude Cryostat with extended detector to allow use of a back-shield,

d. notebook computer with Canberra Genie, PROcount-2000 and ISOCS software,

e. assorted connecting cables, power cords, batteries and battery chargers, and

f. a cart for relocating and positioning the detector and shield assembly,

g. A locally-constructed instrument support stand, and

h. wheel chocks.
Annular shields and field of view collimators

a. Set of 2-inch thick annular shields (3 pieces),

b. 2-inch thick back shield (2 pieces),

c. 1-inch annular shields (3 pieces),

d. 1-inch thick end cap, and

e. Collimator frame extensions

Additional Equipment and Instruments

a. Calibrated microR or microRem meter

b. Digital camera or Polaroid camera w/ film

c. Tape measure, 100 foot or $50 \mathrm{~m}$

d. Field notebook

e. 3.5 inch disk for file transfer

f. DAT vehicle

g. $50 \mathrm{ft}$ extension cords

\subsection{COORDINATION}
4.1 Health and Safety
BGRR Health and Safety POC :
Reggie Suga $\quad \mathrm{x}-8248$
BGRR Lead Radiological Control Tech
D. Mergen $x-2374$

The internal surfaces of the pile are suspected of being contaminated with radionuclides such as Co60, Cs-137, Am-241, Pu-239, Sr-90 and others. There is a radiation work permit (RWP) developed for the performance of the Pile characterization. The requirements of the RWP shall be STRICTLY adhered to in the performance of the work activities prescribed herein. A BGRR procedure (ERDOPM-4.3) has been developed to address the handling of contaminated samples in the field analysis area set up in the BGRR. Personnel should read and be familiar with this procedure prior to performing sample analysis in the BGRR field laboratory area.

\subsection{Facility Access}

Primary: Steve Masciulli $\quad$ x-8247 Alternate: Manni Lilimpakis x-7628 


\subsection{SPECIFIC SCANS AND PARAMETERS}

Specific areas of interest are identified in the BGRR survey plan (Ref 3). Individual targets or scans within the areas may be added at the discretion of the operator when in the area. A project sample identification scheme is described.

\subsubsection{ASTD Project Sample Numbers.}

Targets for gamma spectrum acquisition will be identified with a sample number of the form: aaainnnz

where aaa a three character code identifying the portion of the characterization

(W25) for West Experimental Port No 25

(E53) for East Experimental Port No 53

i a single character code identifying the scan target

S For a sample counted within the field sample analysis cavity

C For a section of fuel channel plug

E For a section of experiment Port plug

T For a view of the transfer pit

nnn is a three digit number incrementing in sequence indicating a sample sequence number for the project

$\mathrm{Z} \quad$ is a single letter indicating a subsequent scan of the same sample, such as at a different target center, or from a different angle or position

For example: W25S012b is the second scan (b) of sample (S) number 12 (012) obtained from the West No 25 Experimental port (W25). The code $\mathbf{S}$ for sample indicates it was counted in the field analysis cavity.

The ASTD Project Sample Number will be entered into the scan description by the instrument operator during scan acquisition, to tie the sample number to the scan record file. The BGRR sample number will also be entered into the scan description field and the field notebook. The ASTD Sample Number will also be cross-referenced with the default scan filename on the File Custody Record Form.

\subsubsection{Scan Acquisition}

a. Scans should be accumulated to detect the radioactivity and to investigate the impact of ISOCS configuration on the analytical results.

b. Initial scan time of 300 seconds; longer if necessary to see activity peaks especially in highly shielded objects such as through the plugged channels

c. ISOCS codes for sample type and geometry
Sample Type
ISOCS Generic
Geometry ISOCS 
Table 5-1. Studies of the BGRR Pile Characterization

\begin{tabular}{|l|c|c|c|c|l|l|}
\hline \multicolumn{1}{|c|}{$\begin{array}{c}\text { Sample } \\
\text { No }\end{array}$} & $\begin{array}{c}\text { Annular } \\
\text { Shield }\end{array}$ & $\begin{array}{c}\text { Field of } \\
\text { View } \\
\text { Count } \\
\text { Time }\end{array}$ & $\begin{array}{c}\text { Initial } \\
\text { Fize or } \\
\text { FOV }\end{array}$ & $\begin{array}{c}\text { Sample } \\
\text { Orientation }\end{array}$ & Note \\
\hline $\begin{array}{l}\text { Sample } \\
\text { Analysis }\end{array}$ & $\begin{array}{c}2 \text { inch around } \\
\text { detector } \\
\text { inch around } \\
\text { sample }\end{array}$ & $\begin{array}{c}180^{0} \text { inside } \\
\text { with cavity } \\
\text { capped }\end{array}$ & $300 \mathrm{sec}$ & 1 liter & $\begin{array}{l}\text { Vertical } \\
\text { sample count } \\
\text { configuration }\end{array}$ & $\begin{array}{l}\text { Sample/scrapings } \\
\text { extracted from the Pile }\end{array}$ \\
\hline $\begin{array}{l}\text { Spectrum } \\
\begin{array}{l}\text { Acquisition } \\
\text { from items } \\
\text { and pieces }\end{array}\end{array}$ & $\begin{array}{c}2 \text { inch around } \\
\text { detector }\end{array}$ & $\begin{array}{c}90^{0} \text { field of } \\
\text { view }\end{array}$ & $600 \mathrm{sec}$ & $\begin{array}{c}1 \text { sq meter } \\
\text { field of } \\
\text { view at } 57 \\
\mathrm{~cm}\end{array}$ & $\begin{array}{l}\text { Vertical down } \\
\text { towards piece } \\
\text { perpendicular to } \\
\text { surface }\end{array}$ & $\begin{array}{l}\text { Channel Plugs } \\
\text { Plugs } \\
\text { graphite pieces }\end{array}$ \\
\hline $\begin{array}{l}\text { Spe ctr u m } \\
\text { Acquisition } \\
\text { through } \\
\text { Bioshield }\end{array}$ & $\begin{array}{c}2 \text { inch around } \\
\text { detector }\end{array}$ & $\begin{array}{c}90^{0} \text { field of } \\
\text { view }\end{array}$ & $600 \mathrm{sec}$ \\
$(?)$ & $\begin{array}{c}12.5 \mathrm{sq} \\
\text { meter FOV } \\
\text { at } 2 \mathrm{~m}\end{array}$ & $\begin{array}{l}\text { Horizontal aligned } \\
\text { with open channel; } \\
\text { distance appropriate } \\
\text { for dead time }\end{array}$ & $\begin{array}{l}\text { "Beam" from open } \\
\text { channel detected } \\
\text { outside contamination } \\
\text { control boundary }\end{array}$ \\
\hline
\end{tabular}

6.0

REFERENCES

6.1 BNL-DAT, In Situ Analysis Quality Assurance Project Plan, Version 1, July 7, 1999.

6.2 BNL-DAT SOP-DAT1, In Situ Gamma Spectroscopy Using the Canberra ISOCS System, version 1, August 19, 1999.

6.3 BNL-DAT SOP-DAT2, Analysis of Gamma Spectrum Files Using Canberra ISOCS System [software ver 3.0], February 23, 2000

6.3 ERD-BGRR-TP-00-07, Characterization Sampling Analysis Plan for Pile, Associated Equipment and Areas (in press) [draft of Apr 25, 2000 used to develop this PSSP].

6.4 ERD-OPM-4.3, Procedure for ASTD Soil Sample Processing to Support BGRR Excavations, Rev 0, December 15, 1999. 
Section 14 


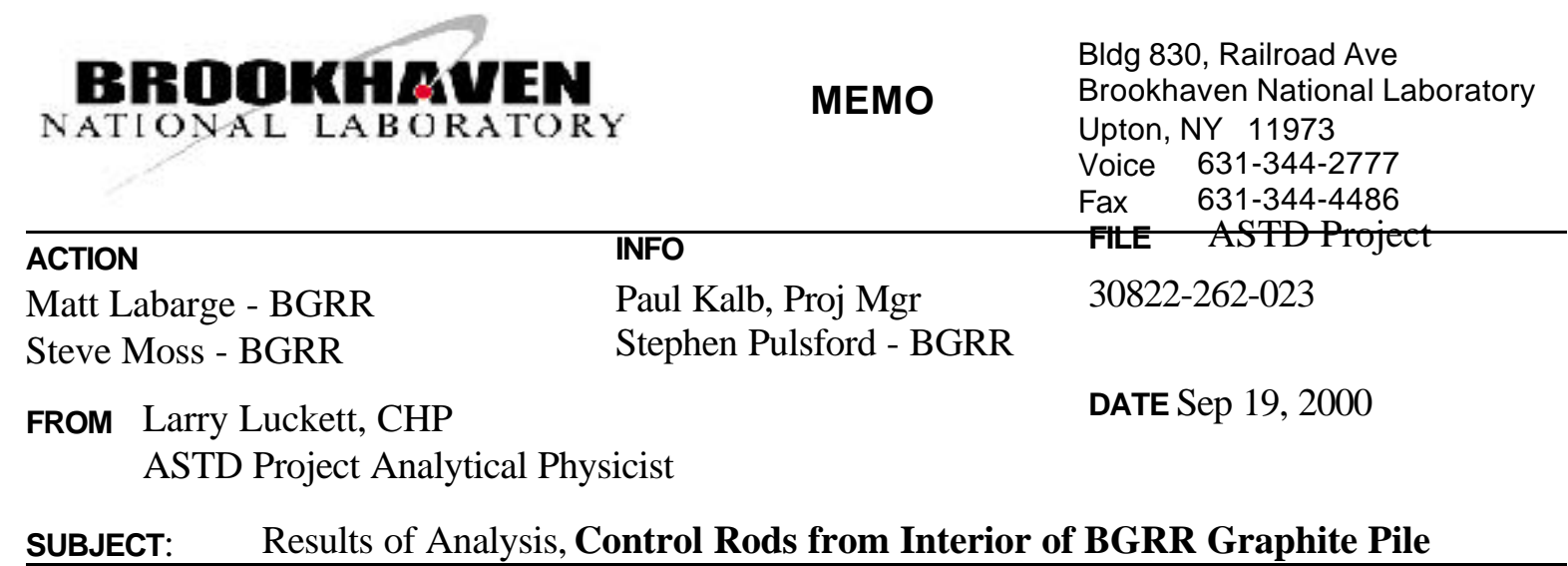

1. Enclosed is a tabulation of the results from the ISOCS analyses of control rods revealed during the pile characterization. Spectra from the control rods were obtained in situ as 24" portions of the rods were exposed as the rods moved in and out of unshielded areas of the control rod drives.

2. Spectrum acquisition was performed by Larry Milian, and quantification modeling results were performed by and results were reviewed by Larry Luckett, both members of the ASTD Project Team.

3. The table provides data on BGRR radionuclides of concern (Co-60, Cs-137 and Am-241). Full gamma spectroscopy analysis reports for each spectrum are on file with ASTD Project records and are available upon request.

4. All rod portions were evaluated assuming a homogenous distribution of activity throughout the rod matrix. Results are reported in units of activity per length of control $\operatorname{rod}(\mu \mathrm{Ci} / \mathrm{ft})$.

Should you have any questions, please contact me at x-2777. 
Activity Concentration in Pile Control Rods

BGRR Graphite Pile Characterization

Gamma Spectrum Analysis with the ISOCS Instrument

\begin{tabular}{|c|c|c|c|c|}
\hline Description & $\begin{array}{l}2^{\prime} \text { section of exposed } \\
\text { control rod } \\
\text { marked 25' and 26' } \\
\text { South East Corner }\end{array}$ & $\begin{array}{c}2^{\prime} \text { section of } \\
\text { exposed } \\
\text { control rod } \\
\text { marked 19' } \\
\text { South East Corner }\end{array}$ & $\begin{array}{l}2^{\prime} \text { section of exposed } \\
\text { control rod } \\
\text { marked } 25^{\prime} \text { and } 26^{\prime} \\
\text { South West Corner }\end{array}$ & $\begin{array}{c}\text { 2' section of } \\
\text { exposed } \\
\text { control rod } \\
\text { marked } 10^{\prime} \text { to } 12^{\prime} \\
\text { South West Corner }\end{array}$ \\
\hline $\begin{array}{l}\text { ASTD } \\
\text { File No }\end{array}$ & IG01352 & IG01354 & IG01356 & IG01358 \\
\hline Radionuclide & \multicolumn{4}{|c|}{ Activity per foot of exposed $\operatorname{rod}(\boldsymbol{\mu C i} / \mathbf{f t})$} \\
\hline Co-60 & $\begin{array}{c}813 \pm 31.5 \\
{[2.23]}\end{array}$ & $\begin{array}{c}245 \pm 9.6 \\
{[0.95]}\end{array}$ & $\begin{array}{c}175 \pm 7.0 \\
{[1.1]}\end{array}$ & $\begin{array}{c}7.4 \pm 0.3 \\
{[0.12]}\end{array}$ \\
\hline Cs-137 & $\begin{array}{c}\mathrm{ND} \\
{[4.3]}\end{array}$ & $\begin{array}{l}\mathrm{ND} \\
{[1.8]}\end{array}$ & $\begin{array}{c}\mathrm{ND} \\
{[2.3]}\end{array}$ & $\begin{array}{c}0.142 \pm 0.123 \\
{[0.20]}\end{array}$ \\
\hline Eu-152 & $\begin{array}{c}\mathrm{ND} \\
{[2.1]}\end{array}$ & $\begin{array}{c}\text { ND } \\
{[0.74]}\end{array}$ & $\begin{array}{l}\mathrm{ND} \\
{[1.2]}\end{array}$ & $\begin{array}{c}\text { ND } \\
{[0.16]}\end{array}$ \\
\hline Eu-154 & $\begin{array}{l}\text { ND } \\
{[4.4]}\end{array}$ & $\begin{array}{l}\mathrm{ND} \\
{[2.0]}\end{array}$ & $\begin{array}{l}\mathrm{ND} \\
{[2.5]}\end{array}$ & $\begin{array}{c}\text { ND } \\
{[0.30]}\end{array}$ \\
\hline Eu-155 & $\begin{array}{l}\text { ND } \\
{[28]}\end{array}$ & $\begin{array}{l}\text { ND } \\
{[12]}\end{array}$ & $\begin{array}{c}\text { ND } \\
{[18]}\end{array}$ & $\begin{array}{c}\mathrm{ND} \\
{[1.5]}\end{array}$ \\
\hline Am-241 & $\begin{array}{c}\text { ND } \\
{[62]}\end{array}$ & $\begin{array}{c}\text { ND } \\
{[27]}\end{array}$ & $\begin{array}{c}\text { ND } \\
{[37 \text { ] }}\end{array}$ & $\begin{array}{c}\mathrm{ND} \\
{[3.3]}\end{array}$ \\
\hline
\end{tabular}

\footnotetext{
$\mathrm{ND}=$ Not Detected

* $\quad=$ Indications of the presence of the radionuclide at non-quantifiable levels near the MDA (one or more, but not all, gamma lines observed)

[ ] = Minimum Detectable Concentration in $\mu \mathrm{Ci} / \mathrm{ft}$
}

DATA QUALIFIERS:

1. Uncertainties reported in the table are counting errors (1.96s); additional uncertainties due to volume, mass, and density estimates could be approximately \pm $50 \%$ and should be added to the tabulated results.

2. Analysis assumes uniform, homogeneous distribution of contaminants throughout the sample matrix; 
BRDDKHAYTEN

NATIONAL LABORATORY

ACTION

Matt Labarge - BGRR

Steve Moss - BGRR

FROM Larry Luckett, CHP

ASTD Project Analytical Physicist
Bldg 830, Railroad Ave

MEMO

Brookhaven National Laboratory

Upton, NY 11973

Voice 631-344-2777

Fax 631-344-4486

FILE ASTD Project

INFO

Paul Kalb, Proj Mgr

30822-262-023

Stephen Pulsford - BGRR

DATE July 25, 2000

SUBJECT: $\quad$ Results of Analysis, in situ West Face Experimental Ports, BGRR Graphite Pile

1. Enclosed is a tabulation of the results from the ISOCS in situ analyses of Experimental Ports during the graphite pile characterization through the penetrations into the West Face of the Biological Shield.

2. Spectrum acquisition was performed by Larry Milian, Tom Roberts, Jay Adams and Eric Barbour, quantification modeling results were performed by Eric Barbour, and results were reviewed by Larry Luckett, all members of the ASTD Project Team.

3. The table provides data on BGRR radionuclides of concern (Co-60, Cs-137 and Am-241). Full gamma spectroscopy analysis reports for each sample are on file with ASTD Project records and are available upon request.

4. All experimental port measurements were performed by aiming the detector, centered, at port openings located on the West side of the pile. The steel port covers were removed prior to each measurement. The following assumptions were made for the port ISOCS models:

- The source of activity is the steel plate liner positioned at 6.5 feet $(1.98 \mathrm{~m})$ into the port and flush to the inside surface of the concrete shielding. The steel of the liner has a density of $7.86 \mathrm{~g} / \mathrm{cm}^{3}$

- The model assumes a homogenous distribution of activity throughout the steel source.

Should you have any questions, please contact me at x-2777. 
Activity Concentration in situ Analysis West Face of Graphite Pile

BGRR Graphite Pile Characterization

Gamma Spectrum Analysis with the ISOCS Instrument

\begin{tabular}{|c|c|c|c|c|c|c|c|c|c|c|}
\hline & \multicolumn{9}{|c|}{ EXPERIMENTAL PORTS } & \multirow{2}{*}{$\begin{array}{c}\text { INSTRUMENT } \\
\text { PORT } \\
\text { I-W5 }\end{array}$} \\
\hline Description & $\mathrm{W}-12$ & W15 & W16 & W30 & W31 & $\mathrm{W}-36$ & W51 & W54 & W56 & \\
\hline $\begin{array}{c}\text { ASTD } \\
\text { Sample No }\end{array}$ & IG01219 & IG01214 & IG01211 & IG01220 & IG01222 & IG01224 & IG01231 & IG01233 & IG01229 & IG01270 \\
\hline Radionuclide & \multicolumn{10}{|c|}{ Activity Concentration ( $\mathrm{pCi} / \mathrm{g}$ ) } \\
\hline Am-241 & $\begin{array}{c}\text { ND } \\
{[188,000 \text { ] }}\end{array}$ & $\begin{array}{c}\text { ND } \\
{[176,000 \text { ] }}\end{array}$ & $\begin{array}{c}\text { ND } \\
{[158,000]}\end{array}$ & $\begin{array}{c}243,000 \pm \\
226,000 \\
{[370,000]}\end{array}$ & $\begin{array}{c}\text { ND } \\
{[207,000]}\end{array}$ & $\begin{array}{c}\text { ND } \\
{[189,000]}\end{array}$ & $\begin{array}{c}\text { ND } \\
{[185,000 \text { ] }}\end{array}$ & $\begin{array}{c}\text { ND } \\
{[222,000]}\end{array}$ & $\begin{array}{c}\text { ND } \\
{[189,000]}\end{array}$ & $\begin{array}{c}\text { ND } \\
{[99,300]}\end{array}$ \\
\hline Cs-137 & $\begin{array}{c}\text { ND } \\
{[9,600]}\end{array}$ & $\begin{array}{c}\text { ND } \\
{[7,600]}\end{array}$ & $\begin{array}{c}\mathrm{ND} \\
{[4,600]}\end{array}$ & $\begin{array}{c}1,200,000 \pm \\
104,000 \\
{[20,500]}\end{array}$ & $\begin{array}{c}90,000 \pm \\
10,200 \\
{[9,900]}\end{array}$ & $\begin{array}{c}\text { ND } \\
{[9,900]}\end{array}$ & $\begin{array}{c}\text { ND } \\
{[6,800]}\end{array}$ & $\begin{array}{c}\text { ND } \\
{[7,200]}\end{array}$ & $\begin{array}{c}\text { ND } \\
{[7,200]}\end{array}$ & $\begin{array}{c}\text { ND } \\
{[3,000]}\end{array}$ \\
\hline Co-60 & $\begin{array}{c}774,000 \pm \\
30,700 \\
{[6,600]}\end{array}$ & $\begin{array}{c}414,000 \pm \\
16,900 \\
{[5,000]}\end{array}$ & $\begin{array}{c}26,200 \pm \\
2,000 \\
{[2,000]}\end{array}$ & $\begin{array}{c}960,000 \pm \\
38,000 \\
{[7,650]}\end{array}$ & $\begin{array}{c}1,450,000 \pm \\
56,500 \\
{[7,2400]}\end{array}$ & $\begin{array}{c}99,300 \pm \\
39,000 \\
{[7,080]}\end{array}$ & $\begin{array}{c}306,000 \pm \\
12,500 \\
{[3,650]}\end{array}$ & $\begin{array}{c}413,000 \pm \\
16,700 \\
{[4,300]}\end{array}$ & $\begin{array}{c}346,000 \pm \\
14,200 \\
{[4,200]}\end{array}$ & $\begin{array}{c}15,000 \pm 1,140 \\
{[986]}\end{array}$ \\
\hline $\mathrm{Eu}-152$ & $\begin{array}{c}210,000 \pm \\
12,100 \\
{[6,300]}\end{array}$ & $\begin{array}{c}155,000 \pm \\
9,000 \\
{[6,700]}\end{array}$ & $\begin{array}{c}196,000 \pm \\
8,300 \\
{[7,450]}\end{array}$ & $\begin{array}{c}153,000 \pm \\
11,500 \\
{[11,100]}\end{array}$ & $\begin{array}{c}121,000 \pm \\
8,300 \\
{[7,410]}\end{array}$ & $\begin{array}{c}89,700 \pm \\
7,240 \\
{[7,200]}\end{array}$ & $\begin{array}{c}261,000 \pm \\
10,400 \\
{[8,400]}\end{array}$ & $\begin{array}{c}316,000 \pm \\
12,600 \\
{[9,300]}\end{array}$ & $\begin{array}{c}221,000 \pm \\
10,200 \\
{[7,020]}\end{array}$ & $\begin{array}{c}95,300 \pm 4,800 \\
{[4,600]}\end{array}$ \\
\hline $\mathrm{Eu}-154$ & $\begin{array}{c}\mathrm{ND}^{*} \\
{[13,600]}\end{array}$ & $\begin{array}{c}58,500 \pm \\
5,300 \\
{[10,000]}\end{array}$ & $\begin{array}{c}\text { ND* } \\
{[7,820]}\end{array}$ & $\begin{array}{c}30,300 \pm \\
17,500 \\
{[39,200]}\end{array}$ & $\begin{array}{c}115,000 \pm \\
7,100 \\
{[12,500]}\end{array}$ & $\begin{array}{c}142,000 \pm \\
9,020 \\
{[14,200]}\end{array}$ & $\begin{array}{c}68,100 \pm \\
4,700 \\
{[8,800]}\end{array}$ & $\begin{array}{c}108,600 \pm \\
6,600 \\
{[12,800]}\end{array}$ & $\begin{array}{c}69,400 \pm \\
5,000 \\
{[8,400]}\end{array}$ & $\begin{array}{c}\mathrm{ND} \\
{[3,600]}\end{array}$ \\
\hline
\end{tabular}

$\mathrm{ND}=$ Not Detected

$*$ = Indications of the presence of the radionuclide at non-quantifiable levels near the MDA

[ ] = Minimum Detectable Concentration in $\mathrm{pCi} / \mathrm{g}$

DATA QUALIFIERS:

3. Uncertainties reported in the table are counting errors (1.96s); additional uncertainties due to volume, mass, and density estimates could be approximately $\pm 30 \%$ and should be added to the tabulated results.

4. Analysis assumes uniform, homogeneous distribution of contaminants throughout the sample matrix; surface depositions probably would have higher pCi/g but less total activity on each piece. 
BRDDKHAYEN

NATIONAL LABORATORY

ACTION

Matt Labarge - BGRR

Steve Moss - BGRR

FROM Larry Luckett, CHP

ASTD Project Analytical Physicist
Bldg 830, Railroad Ave

MEMO

Brookhaven National Laboratory

Upton, NY 11973

Voice 631-344-2777

Fax 631-344-4486

FILE ASTD Project

\section{INFO}

Paul Kalb, Proj Mgr

30822-262-023

Stephen Pulsford - BGRR

SUBJECT: $\quad$ Results of Analysis, Debris Samples from Interior of BGRR Graphite Pile and Tunnels underneath

1. Enclosed is a tabulation of the results from the ISOCS analyses of debris samples obtained during the pile characterization, through a penetration into the West Face of the Biological Shield and from the tunnels underneath the reactor pile. Debris samples were provided by BGRR personnel in 1000-ml HDPE bottles or in poly-wrapped bags and were counted on the ISOCS instrument in an ISOCS counting area established on the ground level (110' elevation) of Building 701. All samples were received from, and have been transferred back to, BGRR control.

2. Spectrum acquisition was performed by Larry Milian, quantification modeling results were performed by Larry Milian, and results were reviewed by Larry Luckett, all members of the ASTD Project Team.

3. The table provides data on BGRR radionuclides of concern (Co-60, Cs-137 and Am-241). Full gamma spectroscopy analysis reports for each sample are on file with ASTD Projectrecords and are available upon request.

4. All dusts were evaluated assuming a homogenous distribution of activity throughout the sample matrix.

Should you have any questions, please contact me at x-2777. 


\section{Activity Concentration Debris Samples \\ BGRR Graphite Pile Characterization}

Gamma Spectrum Analysis with the ISOCS Instrument

\begin{tabular}{|c|c|c|c|}
\hline Description & $\begin{array}{c}\text { Debris from } \\
\text { Experimental Port } \mathrm{W}-32, \\
1 \mathrm{ft} \text { before removable core } \\
32 \mathrm{mR} / \mathrm{hr} \text { on contact }\end{array}$ & $\begin{array}{c}\text { Debris from } \\
\text { Animal Tunnel East }\end{array}$ & $\begin{array}{l}\text { Debris from } \\
\text { Instrument Tunnel East } \\
\text { chunks of debris and } \\
\sim 25 \mathrm{~cm} \text { wire }\end{array}$ \\
\hline $\begin{array}{c}\text { BGRR } \\
\text { Sample No }\end{array}$ & W-32-D & ATE & ITE \\
\hline Mass (g) & 4.6 & 164.8 & 354.2 \\
\hline $\begin{array}{l}\text { ASTD } \\
\text { File No }\end{array}$ & IG01322 & IG01324 & IG01325 \\
\hline Radionuclide & \multicolumn{3}{|c|}{ Activity Concentration ( pCi/g ) } \\
\hline Co-60 & $\begin{array}{c}1.24 \mathrm{E}+08 \pm 6.6 \mathrm{E}+06 \\
{[3.03 \mathrm{E}+05]}\end{array}$ & $\begin{array}{c}2,590 \pm 153 \\
{[24.6]}\end{array}$ & $\begin{array}{c}584 \pm 28 \\
{[12.9]}\end{array}$ \\
\hline Cs-137 & $\begin{array}{c}3.36 \mathrm{E}+06 \pm 4.4 \mathrm{E}+05 \\
{[5.08 \mathrm{E}+05]}\end{array}$ & $\begin{array}{c}128 \pm 39 \\
{[60.0]}\end{array}$ & $\begin{array}{l}46 \pm 13 \\
{[18.4]}\end{array}$ \\
\hline $\mathrm{Eu}-152$ & $\begin{array}{c}\mathrm{ND} \\
{[4.8 \mathrm{E}+05]}\end{array}$ & $\begin{array}{c}581 \pm 44 \\
{[42.5]}\end{array}$ & $\begin{array}{c}1,150 \pm 50 \\
{[40.5]}\end{array}$ \\
\hline Eu-154 & $\begin{array}{c}\mathrm{ND} \\
{[6.1 \mathrm{E}+05]}\end{array}$ & $\begin{array}{c}\text { ND } \\
{[44.2]}\end{array}$ & $\begin{array}{l}\mathrm{ND}^{*} \\
{[37.3]}\end{array}$ \\
\hline $\mathrm{Eu}-155$ & $\begin{array}{c}\mathrm{ND} \\
{[6.4 \mathrm{E}+05]}\end{array}$ & $\begin{array}{c}\text { ND } \\
{[23.2]}\end{array}$ & $\begin{array}{c}\text { ND } \\
{[21.5]}\end{array}$ \\
\hline Am-241 & $\begin{array}{c}\mathrm{ND} \\
{[8.2 \mathrm{E}+05]}\end{array}$ & $\begin{array}{c}\mathrm{ND} \\
{[31.8]}\end{array}$ & $\begin{array}{c}\text { ND } \\
{[30.2 \text { ] }}\end{array}$ \\
\hline
\end{tabular}

\footnotetext{
$\mathrm{ND}=$ Not Detected

$* \quad=\quad$ Indications of the presence of the radionuclide at non-quantifiable levels near the MDA (one or more, but not all, gamma lines observed)

[ ] = Minimum Detectable Concentration in $\mathrm{pCi} / \mathrm{g}$
}

\section{DATA QUALIFIERS:}

1. Uncertainties reported in the table are counting errors (1.96s); additional uncertainties due to volume, mass, and density estimates could be approximately $\pm 50 \%$ and should be added to the tabulated results.

2. Analysis assumes uniform, homogeneous distribution of contaminants throughout the sample matrix; 
BRDDKHAYEN

NATIONAL LABORATORY

ACTION

Matt Labarge - BGRR

Steve Moss - BGRR

FROM Larry Luckett, CHP

ASTD Project Analytical Physicist
Bldg 830, Railroad Ave

MEMO Brookhaven National Laboratory

Upton, NY 11973

Voice 631-344-2777

Fax 631-344-4486

FILE ASTD Project

INFO

Paul Kalb, Proj Mgr

30822-262-023

Stephen Pulsford - BGRR

DATE July 12, 2000

\section{SUBJECT: $\quad$ Results of Analysis for Samples from Plenum Access, BGRR Graphite Pile}

1. Enclosed is a tabulation of the results from the ISOCS analyses of samples collected by BGRR during the graphite pile characterization through the penetrations into the North and South Plenum.

2. Samples were provided by BGRR personnel in poly-wrapped bags or HDPE bottles and were counted on the ISOCS instrument in an ISOCS counting area established on the Main level (110' elevation) of Building 701 near the west face. All samples were received from, and have been transferred back to, BGRR control.

3. Spectrum acquisition was performed by Larry Milian, quantification modeling results were performed by Milian and Eric Barbour, and results were reviewed by Larry Luckett, all members of the ASTD Project Team.

4. The table provides data on Co-60, Cs-137 and Am-241 (BGRR radionuclides of concern). Results are sorted in the table by the pile penetration from which they were extracted. Full gamma spectroscopy analysis reports for each sample are on file with ASTD Project records and are available upon request.

Should you have any questions, please contact me at x-2777. 


\section{Activity Concentration on samples from Plenum Access}

BGRR Graphite Pile Characterization

Gamma Spectrum Analysis with the ISOCS Instrument

\begin{tabular}{|c|c|c|c|c|c|c|c|}
\hline $\begin{array}{c}\text { BGRR Pile Sample } \\
\text { Identification }\end{array}$ & P-1a & $\mathrm{P}-2$ & $\mathrm{P}-3$ & P-4 & P-5 & P-6 & $\mathrm{P}-7$ \\
\hline Description & $\begin{array}{l}\text { Fine graphite } \\
\text { powder in } \\
500 \mathrm{ml} \text { bottle } \\
\text { West CRD } \\
\text { Top Plate }\end{array}$ & $\begin{array}{l}\text { Plug Retainer } \\
\text { Spring, } \\
\text { West side } \\
\text { South Plenum }\end{array}$ & $\begin{array}{c}\text { Plug Retainer } \\
\text { Spring } \\
\text { Scanner Slot \#4 } \\
\text { North Plenum }\end{array}$ & $\begin{array}{l}\text { Graphite Plug } \\
\text { Scanner Slot \#4 } \\
\text { North Plenum }\end{array}$ & $\begin{array}{c}\text { Fuel Anchor } \\
\text { Portion } \\
\text { (Hot end only, in } \\
\text { 1L bottle) }\end{array}$ & $\begin{array}{l}\text { Thermocouple } \\
\text { wire, folded } \\
\text { in 1L bottle } \\
\text { scanner slot \#4 } \\
\text { North Plenum }\end{array}$ & $\begin{array}{c}\text { Particulate debris } \\
\text { from removable } \\
\text { core plate, } \\
\text { sample and rust }\end{array}$ \\
\hline Sample Mass & $-1 \mathrm{~g}$ & $136.5 \mathrm{~g}$ & $71.6 \mathrm{~g}$ & $316.5 \mathrm{~g}$ & $45.1 \mathrm{~g}$ & $31.6 \mathrm{~g}$ & $25.9 \mathrm{~g}$ \\
\hline ASTD Sample No & IG01253 & IG01248 & IG01251 & IG01246 & IG01247 & IG01245 & IG01254 \\
\hline Radionuclide & \multicolumn{7}{|c|}{ Activity Concentration ( $\mathrm{pCi} / \mathrm{g}$ ) } \\
\hline Am-241 & $\begin{array}{c}\mathrm{ND} \\
{[74,000]}\end{array}$ & $\begin{array}{c}\mathrm{ND} \\
{[5,300]}\end{array}$ & $\begin{array}{c}\text { ND } \\
{[79,100]}\end{array}$ & $\begin{array}{c}\text { ND } \\
{[184]}\end{array}$ & $\begin{array}{c}\mathrm{ND} \\
{[4,200]}\end{array}$ & $\begin{array}{c}\text { ND } \\
{[69,400]}\end{array}$ & $\begin{array}{c}2,900 \pm 1,500 \\
{[2,380]}\end{array}$ \\
\hline Cs-137 & $\begin{array}{c}22,000,000[\text { note } 3] \\
{[51,000]}\end{array}$ & $\begin{array}{c}5,200 \pm 800 \\
{[1,050]}\end{array}$ & $\begin{array}{c}7,800 \pm 7,100 \\
{[11,800]}\end{array}$ & $\begin{array}{c}9,000 \pm 820 \\
{[123]}\end{array}$ & $\begin{array}{c}7,600 \pm 1,700 \\
{[2,470]}\end{array}$ & $\begin{array}{c}\mathrm{ND} \\
{[7,670]}\end{array}$ & $\begin{array}{c}202,000 \pm 18,000 \\
{[2,190]}\end{array}$ \\
\hline Co-60 & $\begin{array}{c}578,000 \pm 29,600 \\
{[21,000]}\end{array}$ & $\begin{array}{c}230,000 \pm 9,000 \\
{[763]}\end{array}$ & $\begin{array}{c}3,000,000 \pm \\
120,000 \\
{[11,000]}\end{array}$ & $\begin{array}{c}1,370 \pm 98 \\
{[115]}\end{array}$ & $\begin{array}{c}732,000 \pm 29,000 \\
{[2,110]}\end{array}$ & $\begin{array}{c}2,800,000 \pm \\
100,000 \\
{[5,530]}\end{array}$ & $\begin{array}{c}225,000 \pm 9,000 \\
{[1,350]}\end{array}$ \\
\hline Eu-152 & $\begin{array}{c}\mathrm{ND} \\
{[42,000]}\end{array}$ & $\begin{array}{c}\text { ND } \\
{[574]}\end{array}$ & $\begin{array}{c}\mathrm{ND} \\
{[9,000]}\end{array}$ & $\begin{array}{c}270 \pm 88 \\
{[170]}\end{array}$ & $\begin{array}{c}\mathrm{ND} \\
{[2,240]}\end{array}$ & $\begin{array}{c}\mathrm{ND} \\
{[5,330]}\end{array}$ & $\begin{array}{c}\mathrm{ND}^{*} \\
{[2,000]}\end{array}$ \\
\hline Eu-154 & $\begin{array}{c}\mathrm{ND} \\
{[34,000]}\end{array}$ & $\begin{array}{c}\mathrm{ND} \\
{[1,260]}\end{array}$ & $\begin{array}{c}\mathrm{ND} \\
{[19,200]}\end{array}$ & $\begin{array}{c}\text { ND } \\
{[132]}\end{array}$ & $\begin{array}{c}\mathrm{ND} \\
{[3,830]}\end{array}$ & $\begin{array}{c}\mathrm{ND} \\
{[8,750]}\end{array}$ & $\begin{array}{c}\mathrm{ND} \\
{[2,120]}\end{array}$ \\
\hline
\end{tabular}

$\mathrm{ND}=$ Not Detected

$* \quad=$ Indications of the presence of the radionuclide at non-quantifiable levels near the MDA

[ ] = Minimum Detectable Concentration in $\mathrm{pCi} / \mathrm{g}$

\section{DATA QUALIFIERS:}

1. Uncertainties reported in the table are counting errors (1.96s); additional uncertainties due to volume, mass, and density estimates could be approximately $\pm 30 \%$ and should be added to the tabulated results.

2. Analysis assumes uniform, homogeneous distribution of contaminants throughout the sample matrix; surface depositions probably would have higher pCi/g but less total activity on each piece.

3. The mass of several samples, especially P-1a, was so small that significant uncertainty is associated with the values reported. 


\section{REVISED}

Activity Concentration Graphite Dust Samples

BGRR Graphite Pile Characterization

Gamma Spectrum Analysis with the ISOCS Instrument

\begin{tabular}{|c|c|c|c|c|c|c|c|c|}
\hline Description & \multicolumn{8}{|c|}{ Graphite Dust Sample } \\
\hline $\begin{array}{c}\text { BGRR } \\
\text { Sample No }\end{array}$ & $\mathrm{W}-32-\mathrm{B}-2$ & $\mathrm{~W}-32-\mathrm{C}-3$ & W-32-D-4 & $\mathrm{W}-35-\mathrm{C}-2$ & W-35-3-B(a) & W-35-1-D & W-32-A & W-35-A \\
\hline Mass (g) & 94.2 & 93.0 & 104.3 & 57.3 & 62.5 & 57.4 & 60.0 & 93.9 \\
\hline $\begin{array}{l}\text { ASTD } \\
\text { File No }\end{array}$ & IG01307 & IG01308 & IG01309 & IG01310 & IG01312 & IG01313 & IG01314 & IG01315 \\
\hline Radionuclide & \multicolumn{8}{|c|}{ Activity Concentration ( pCi/g ) } \\
\hline Co-60 & $\begin{array}{c}40,800 \pm 1,550 \\
{[155]} \\
\end{array}$ & $\begin{array}{c}9,400 \pm 380 \\
{[83]}\end{array}$ & $\begin{array}{c}23,800 \pm 910 \\
{[122]}\end{array}$ & $\begin{array}{c}3,860 \pm 180 \\
{[62]}\end{array}$ & $\begin{array}{c}3,310 \pm 155 \\
{[85]}\end{array}$ & $\begin{array}{c}1,670 \pm 94 \\
{[69]} \\
\end{array}$ & $\begin{array}{c}14,000 \pm 560 \\
{[120]}\end{array}$ & $\begin{array}{c}4,990 \pm 210 \\
{[76]}\end{array}$ \\
\hline Ba-133 & $480 \pm 90$ & $560 \pm 90$ & $680 \pm 105$ & $254 \pm 62$ & $634 \pm 87$ & $361 \pm 68$ & $2,510 \pm 230$ & $1,100 \pm 120$ \\
\hline Cs-137 & $\begin{array}{c}2,700 \pm 290 \\
{[250]}\end{array}$ & $\begin{array}{c}760 \pm 120 \\
{[150]}\end{array}$ & $\begin{array}{c}1,200 \pm 160 \\
{[190]}\end{array}$ & $\begin{array}{c}400 \pm 77 \\
{[101]}\end{array}$ & $\begin{array}{c}1,620 \pm 176 \\
{[128]}\end{array}$ & $\begin{array}{c}970 \pm 135 \\
{[152]}\end{array}$ & $\begin{array}{c}4,520 \pm 440 \\
{[236]}\end{array}$ & $\begin{array}{c}2,650 \pm 260 \\
{[126]}\end{array}$ \\
\hline $\mathrm{Eu}-152$ & $\begin{array}{c}\text { ND } \\
{[250]}\end{array}$ & $\begin{array}{c}\text { ND } \\
{[205 \text { ] }}\end{array}$ & $\begin{array}{c}670 \pm 110 \\
{[165]}\end{array}$ & $\begin{array}{l}\text { ND* } \\
{[278 \text { ] }}\end{array}$ & $\begin{array}{l}\text { ND } \\
{[215]}\end{array}$ & $\begin{array}{c}705 \pm 125 \\
{[244]}\end{array}$ & $\begin{array}{l}\text { ND } \\
{[221]}\end{array}$ & $\begin{array}{l}\text { ND } \\
{[165]}\end{array}$ \\
\hline $\mathrm{Eu}-154$ & $\begin{array}{c}14,000 \pm 560 \\
{[230]}\end{array}$ & $\begin{array}{c}21,300 \pm 660 \\
{[144]}\end{array}$ & $\begin{array}{c}20,900 \pm 590 \\
{[190]}\end{array}$ & $\begin{array}{c}13,600 \pm 470 \\
{[167]}\end{array}$ & $\begin{array}{c}18,500 \pm 605 \\
{[189]}\end{array}$ & $\begin{array}{c}25,400 \pm 665 \\
{[200]}\end{array}$ & $\begin{array}{c}10,800 \pm 426 \\
{[170]}\end{array}$ & $\begin{array}{c}13,000 \pm 440 \\
{[136]}\end{array}$ \\
\hline $\mathrm{Eu}-155$ & $\begin{array}{c}1,400 \pm 200 \\
{[118]}\end{array}$ & $\begin{array}{c}2,100 \pm 175 \\
{[119]}\end{array}$ & $\begin{array}{c}1,900 \pm 200 \\
{[106]}\end{array}$ & $\begin{array}{c}1,600 \pm 230 \\
{[193]}\end{array}$ & $\begin{array}{c}2,300 \pm 230 \\
{[177]}\end{array}$ & $\begin{array}{c}2,550 \pm 315 \\
{[193]}\end{array}$ & $\begin{array}{c}1,325 \pm 165 \\
{[184]}\end{array}$ & $\begin{array}{c}1,375 \pm 240 \\
{[118]}\end{array}$ \\
\hline Am-241 & $\begin{array}{c}234 \pm 122 \\
{[190]} \\
\end{array}$ & $\begin{array}{c}154 \pm 94 \\
{[150]} \\
\end{array}$ & $\begin{array}{c}198 \pm 96 \\
{[150]} \\
\end{array}$ & $\begin{array}{c}\text { ND } \\
{[95]}\end{array}$ & $\begin{array}{c}184 \pm 101 \\
{[157]}\end{array}$ & $\begin{array}{c}\text { ND } \\
{[108]}\end{array}$ & $\begin{array}{c}\text { ND } \\
{[123]}\end{array}$ & $\begin{array}{c}\text { ND } \\
{[104]}\end{array}$ \\
\hline Ag-108m & $\begin{array}{c}\text { ND } \\
{[105 \text { ] }}\end{array}$ & $\begin{array}{c}\text { ND } \\
{[105 \text { ] }}\end{array}$ & $\begin{array}{c}\text { ND } \\
{[105]}\end{array}$ & $\begin{array}{c}195 \pm 112 \\
{[100]}\end{array}$ & $\begin{array}{c}\text { ND } \\
{[105]}\end{array}$ & $\begin{array}{c}\text { ND } \\
{[105]}\end{array}$ & $\begin{array}{c}\text { ND } \\
{[105]}\end{array}$ & $\begin{array}{c}119 \pm 41 \\
{[89]}\end{array}$ \\
\hline
\end{tabular}

$\mathrm{ND}=$ Not Detected

* $\quad=$ Indications of the presence of the radionuclide at non-quantifiable levels near the MDA (one or more, but not all, gamma lines observed)

[ ] = Minimum Detectable Concentration in $\mathrm{pCi} / \mathrm{g}$

DATA QUALIFIERS:

1. Uncertainties reported in the table are counting errors (1.96s); additional uncertainties due to volume, mass, and density estimates could be approximately \pm 50 $\%$ and should be added to the tabulated results.

2. Analysis assumes uniform, homogeneous distribution of contaminants throughout the sample matrix; 
BRDDKHAYEN

NATIONAL LABORATORY

ACTION

Matt Labarge - BGRR

Steve Moss - BGRR

FROM Larry Luckett, CHP

ASTD Project Analytical Physicist
Bldg 830, Railroad Ave

Brookhaven National Laboratory

Upton, NY 11973

Voice 631-344-2777

Fax 631-344-4486

FILE ASTD Project

\section{INFO}

Paul Kalb, Proj Mgr

30822-262-023

Stephen Pulsford - BGRR

DATE July 24, 2000

\section{SUBJECT: $\quad$ Results of Analysis for Samples from South Face, BGRR Graphite Pile}

1. Enclosed is a tabulation of the results from the ISOCS analyses of samples collected by BGRR during the graphite pile characterization through the penetrations into the South Plenum and the South Face of the Biological Shield.

2. Samples were provided by BGRR personnel in poly-wrapped bags and were counted on the ISOCS instrument in an ISOCS counting area established on the Main level (110' elevation) of Building 701 near the south face. All samples were received from, and have been transferred back to, BGRR control.

3. Spectrum acquisition was performed by Jay Adams and Eric Barbour, quantification modeling results were performed by Eric Barbour, and results were reviewed by Larry Luckett, all members of the ASTD Project Team.

4. The table provides data on Co-60, Cs-137 and Am-241 (BGRR radionuclides of concern). Full gamma spectroscopy analysis reports for each sample are on file with ASTD Project records and are available upon request.

Should you have any questions, please contact me at x-2777. 
Activity Concentration on samples from South Face of Graphite Pile BGRR Graphite Pile Characterization

Gamma Spectrum Analysis with the ISOCS Instrument

\begin{tabular}{|c|c|c|c|c|c|c|c|c|}
\hline & & & & \multicolumn{5}{|c|}{ GRAPHITE } \\
\hline Description & $\begin{array}{l}\text { Fuel Anchor from } \\
\text { South Plenum } \\
\text { Floor } \\
\text { [hot end removed] } \\
\text { [see note 3] }\end{array}$ & $\begin{array}{l}2^{\text {nd }} \text { Fuel Anchor } \\
\text { from South } \\
\text { Plenum Floor } \\
\text { [whole] }\end{array}$ & $\begin{array}{c}\text { Mock Fuel } \\
\text { Element shell, } \\
\text { Hollow } \\
\text { aluminum vaned } \\
\text { rod }\end{array}$ & $\begin{array}{l}\text { Hollow Graphite } \\
\text { plug from South } \\
\text { Plenum }\end{array}$ & $\begin{array}{c}\text { Graphite Plug } \\
\text { from South face } \\
\text { C-7-14 }\end{array}$ & $\begin{array}{c}\text { Graphite Plug } \\
\text { from South face } \\
\text { C-6-14 }\end{array}$ & $\begin{array}{c}\text { Graphite Plug } \\
\text { from South face } \\
\text { D-13-13 }\end{array}$ & $\begin{array}{c}\text { Graphite Plug } \\
\text { from South face } \\
\text { D-11-13 }\end{array}$ \\
\hline Sample Mass & $200 \mathrm{~g}$ & $330 \mathrm{~g}$ & $680 \mathrm{~g}$ & $310 \mathrm{~g}$ & $1,435 \mathrm{~g}$ & $1,443 \mathrm{~g}$ & $1,534 \mathrm{~g}$ & $1,441 \mathrm{~g}$ \\
\hline $\begin{array}{c}\text { ASTD } \\
\text { Sample No }\end{array}$ & IG01278 & IG01279 & IG01275 & IG01274 & IG01273 & IG01272 & IG01271 & IG01270 \\
\hline Radionuclide & \multicolumn{8}{|c|}{ Activity Concentration ( $\mathrm{pCi} / \mathrm{g}$ ) } \\
\hline Am-241 & $\begin{array}{l}\text { ND } \\
{[844]}\end{array}$ & $\begin{array}{c}\text { ND } \\
{[354]}\end{array}$ & $\begin{array}{l}\text { ND } \\
{[300]}\end{array}$ & $\begin{array}{l}\text { ND } \\
{[340 \text { ] }}\end{array}$ & $\begin{array}{l}\text { ND } \\
{[325]}\end{array}$ & $\begin{array}{l}\text { ND } \\
{[437 \text { ] }}\end{array}$ & $\begin{array}{l}\text { ND } \\
{[302 \text { ] }}\end{array}$ & $\begin{array}{l}\text { ND } \\
{[424]}\end{array}$ \\
\hline Cs-137 & $\begin{array}{c}2,660 \pm 630 \\
{[930]} \\
\end{array}$ & $\begin{array}{c}3,200 \pm 460 \\
{[541]} \\
\end{array}$ & $\begin{array}{c}4,400 \pm 500 \\
{[445]} \\
\end{array}$ & $\begin{array}{c}9,300 \pm 820 \\
{[266]} \\
\end{array}$ & $\begin{array}{c}1,030 \pm 110 \\
{[116]}\end{array}$ & $\begin{array}{c}11,300 \pm 1,020 \\
{[255]}\end{array}$ & $\begin{array}{c}4,960 \pm 460 \\
{[167]} \\
\end{array}$ & $\begin{array}{c}2,500 \pm 260 \\
{[174]} \\
\end{array}$ \\
\hline Co-60 & $\begin{array}{c}265,000 \pm 10,000 \\
{[760]}\end{array}$ & $\begin{array}{c}60,000 \pm 2,400 \\
{[270]} \\
\end{array}$ & $\begin{array}{c}59,200 \pm 2,300 \\
{[197]}\end{array}$ & $\begin{array}{c}310 \pm 70 \\
{[87]} \\
\end{array}$ & $\begin{array}{c}440 \pm 46 \\
{[54]} \\
\end{array}$ & $\begin{array}{c}460 \pm 55 \\
{[67]} \\
\end{array}$ & $\begin{array}{c}270 \pm 41 \\
{[62]} \\
\end{array}$ & $\begin{array}{c}420 \pm 50 \\
{[61]} \\
\end{array}$ \\
\hline $\mathrm{Eu}-152$ & $\begin{array}{c}2,000 \pm 470 \\
{[520]} \\
\end{array}$ & $\begin{array}{c}1,560 \pm 250 \\
{[314]} \\
\end{array}$ & $\begin{array}{c}5,200 \pm 400 \\
{[294]} \\
\end{array}$ & $\begin{array}{c}26,000 \pm 950 \\
{[465]}\end{array}$ & $\begin{array}{c}33,000 \pm 850 \\
{[220]}\end{array}$ & $\begin{array}{c}55,400 \pm 1,400 \\
{[353]} \\
\end{array}$ & $\begin{array}{c}28,000 \pm 730 \\
{[264]}\end{array}$ & $\begin{array}{c}54,100 \pm 1,300 \\
{[383]} \\
\end{array}$ \\
\hline Eu-154 & $\begin{array}{c}\mathrm{ND}^{*} \\
{[900]}\end{array}$ & $\begin{array}{c}\mathrm{ND} \\
{[422]}\end{array}$ & $\begin{array}{l}\text { ND* } \\
{[456]}\end{array}$ & $\begin{array}{l}\text { ND* } \\
{[560]}\end{array}$ & $\begin{array}{l}\text { ND* } \\
{[330]}\end{array}$ & $\begin{array}{c}2,350 \pm 160 \\
{[266]}\end{array}$ & $\begin{array}{l}\mathrm{ND}^{*} \\
{[287]}\end{array}$ & $\begin{array}{c}2,100 \pm 140 \\
{[268]}\end{array}$ \\
\hline
\end{tabular}

ND $=$ Not Detected

$*$ = Indications of the presence of the radionuclide at non-quantifiable levels near the MDA

[ ] = Minimum Detectable Concentration in $\mathrm{pCi} / \mathrm{g}$

DATA QUALIFIERS:

1. Uncertainties reported in the table are counting errors (1.96s); additional uncertainties due to volume, mass, and density estimates could be approximately $\pm 30 \%$ and should be added to the tabulated results.

2. Analysis assumes uniform, homogeneous distribution of contaminants throughout the sample matrix; surface depositions probably would have higher pCi/g but less total activity on each piece.

3. The hot end of this fuel anchor had been separated and was analyzed independently as Sample P-5, reported to BGRR on July 12, 2000. 
BRDDKHAYTEN

NATIONAL LABORATORY

ACTION

Matt Labarge - BGRR

FROM Larry Luckett, CHP

ASTD Project Analytical Physicist
Bldg 830, Railroad Ave

MEMO $\quad \begin{aligned} & \text { Brookhaven National Laboratory } \\ & \text { Upton, NY } 11973\end{aligned}$

Voice 631-344-2777

Fax 631-344-4486

FILE ASTD Project

30822-262-023

Paul Kalb, Proj Mgr

Stephen Pulsford - BGRR

\section{SUBJECT: $\quad$ Results of Analysis for West Face Samples, BGRR Graphite Pile}

1. Enclosed is a tabulation of the results from the ISOCS analyses of samples collected by BGRR during the graphite pile characterization through the penetrations on the west pile face.

2. Samples were provided by BGRR personnel in poly-wrapped bags and were counted on the ISOCS instrument in an ISOCS counting area established on the Main level (110' elevation) of Building 701 near the west face. All samples were received from, and have been transferred back to, BGRR control.

3. Spectrum acquisition was performed by Larry Milian, quantification modeling results were performed by Milian and Eric Barbour, and results were reviewed by Larry Luckett, all members of the ASTD Project Team.

4. The table provides data on Co-60, Cs-137 and Am-241 (BGRR radionuclides of concern). Results are sorted in the table by the pile penetration from which they were extracted. Full gamma spectroscopy analysis reports for each sample are on file with ASTD Project records and are available upon request.

Should you have any questions, please contact me at x-2777. 


\section{Activity Concentration on samples from West face Penetrations}

BGRR Graphite Pile Characterization

Gamma Spectrum Analysis with the ISOCS Instrument

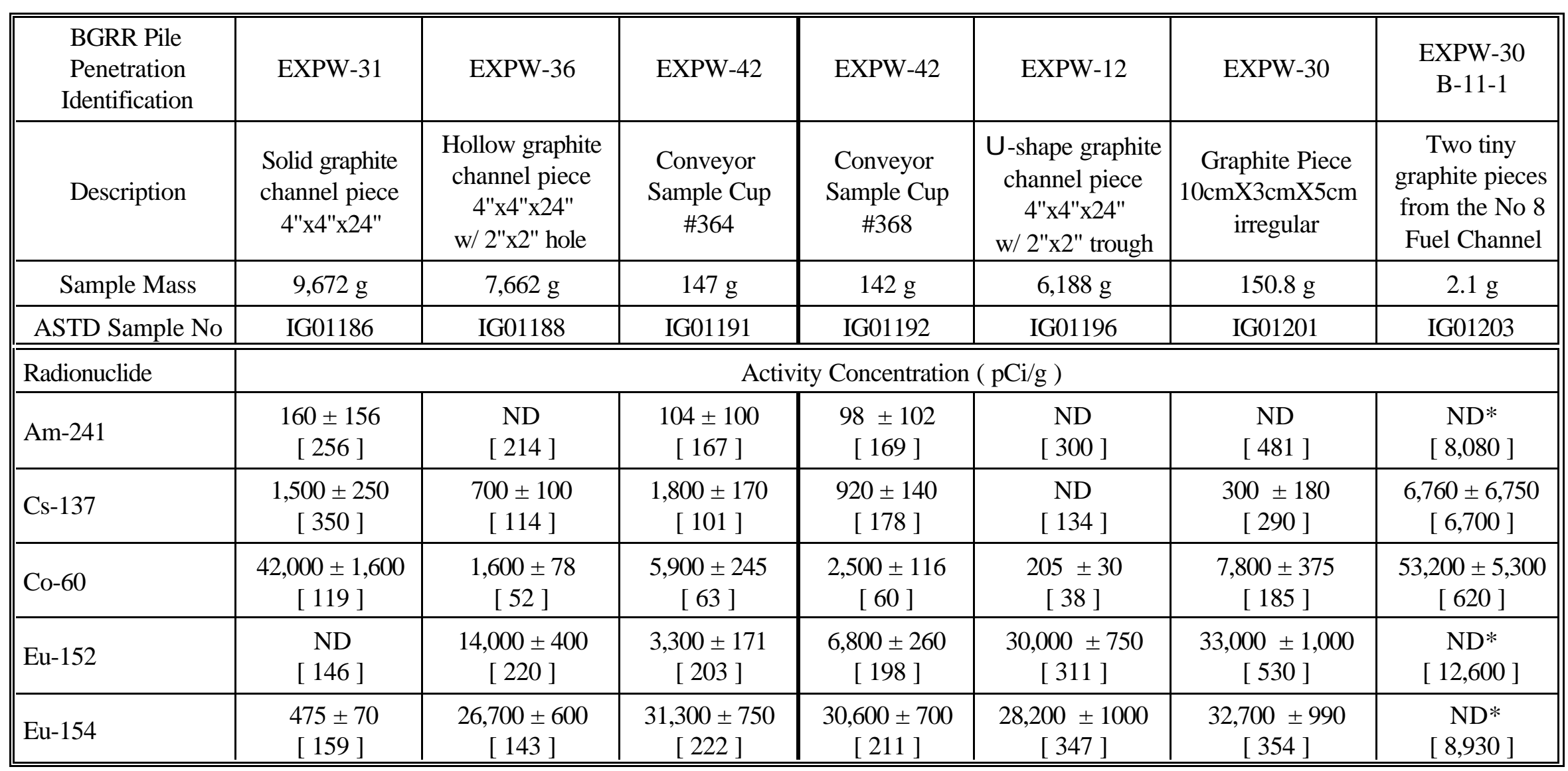

$\mathrm{ND}=$ Not Detected

* $\quad=$ Indications of the presence of the radionuclide at non-quantifiable levels near the MDA

[ ] = Minimum Detectable Concentration in $\mathrm{pCi} / \mathrm{g}$

\section{DATA QUALIFIERS:}

1. Uncertainties reported in the table are counting errors (1.96s); additional uncertainties due to volume and density estimates could be approximately $\pm 30 \%$ and should be added to the tabulated results.

2. Analysis assumes uniform, homogeneous distribution of contaminants throughout the graphite matrix; surface depositions probably would have higher $\mathrm{pCi} / \mathrm{g}$ but less total activity on each piece. 
Section 15 
BRDDKHRYEN

NATIONAL LABORATORY

\section{ACTION}

Matt Labarge - BGRR

Steve Moss - BGRR

FROM Larry Luckett, CHP

ASTD Project Analytical Physicist
Bldg 830, Railroad Ave

MEMO

Brookhaven National Laboratory

Upton, NY 11973

Voice 631-344-2777

Fax 631-344-4486

FILE ASTD Project

\section{INFO}

Paul Kalb, Proj Mgr

30822-262-023

Stephen Pulsford - BGRR

\section{SUBJECT: $\quad$ Results of Analysis, Canal Debris from Interior of BGRR Canal House}

1. Enclosed is a tabulation of the results from the ISOCS analyses of debris samples obtained during the canal/canal house characterization. Debris samples were provided by BGRR personnel and were counted on the ISOCS instrument in an ISOCS counting area established on the ground level (110' elevation) of Building 701. All samples were received from, and have been transferred back to, BGRR control.

2. Spectrum acquisition and quantification modeling results were performed by Larry Milian and results were reviewed by Larry Luckett, both members of the ASTD Project Team.

3. The table provides data on BGRR radionuclides of concern (Co-60, Cs-137 and Am-241). Full gamma spectroscopy analysis reports for each spectrum are on file with ASTD Project records and are available upon request.

4. All samples were evaluated assuming a homogenous distribution of activity throughout the sample matrix. Results are reported in units of activity per mass of sample (pCi/g).

Should you have any questions, please contact me at x-2777. 


\section{Activity Concentration in Canal Debris Samples BGRR Canal and Water Treatment House Characterization}

Gamma Spectrum Analysis with the ISOCS Instrument

\begin{tabular}{|c|c|c|c|c|c|}
\hline $\begin{array}{c}\text { BGRR } \\
\text { Sample No }\end{array}$ & Canal-001 & $\begin{array}{c}\text { Canal-002 } \\
\text { [see note 3] }\end{array}$ & Canal-003 & Canal-004 & $\begin{array}{c}\text { Canal-005 } \\
\text { [see note 3] }\end{array}$ \\
\hline Description & $\begin{array}{c}\text { Debris from Canal } \\
\text { Sump No } 3\end{array}$ & $\begin{array}{c}\text { Debris from Canal } \\
\text { Sump No } 1\end{array}$ & $\begin{array}{l}\text { Debris from Canal } \\
\text { South Bottom Gate }\end{array}$ & $\begin{array}{l}\text { Debris from Canal } \\
\text { North Bottom Joint }\end{array}$ & $\begin{array}{c}\text { Debris from Canal } \\
\text { Sump No } 2\end{array}$ \\
\hline $\begin{array}{c}\text { Sample Mass } \\
\text { (grams) }\end{array}$ & 52.8 & 11.1 & 103.2 & 156.0 & 21.1 \\
\hline $\begin{array}{l}\text { ASTD } \\
\text { File No }\end{array}$ & IG01345 & IG01346 & IG01347 & IG01349 & IG01350 \\
\hline Radionuclide & \multicolumn{5}{|c|}{ Activity concentration ( $\mathrm{pCi} / \mathrm{g}$ ) } \\
\hline Co-60 & $\begin{array}{c}207 \pm 27.6 \\
{[32.2]}\end{array}$ & $\begin{array}{c}3,500 \pm 246 \\
{[179]}\end{array}$ & $\begin{array}{c}62,400 \pm 2,520 \\
{[505]}\end{array}$ & $\begin{array}{c}61.9 \pm 10.5 \\
{[13.4]}\end{array}$ & $\begin{array}{c}1,450 \pm 114 \\
{[93.2]}\end{array}$ \\
\hline Cs-137 & $\begin{array}{c}108,500 \pm 9,500 \\
{[162]}\end{array}$ & $\begin{array}{c}79,500 \pm 7,060 \\
{[405]}\end{array}$ & $\begin{array}{c}410,000 \pm 36,100 \\
{[2,100]}\end{array}$ & $\begin{array}{c}17,600 \pm 1,550 \\
{[54.0]}\end{array}$ & $\begin{array}{l}99,900 \pm 8,800 \\
{[271]}\end{array}$ \\
\hline Eu-152 & $\begin{array}{c}\text { ND } \\
{[160]}\end{array}$ & $\begin{array}{l}\text { ND* } \\
{[457 \text { ] }}\end{array}$ & $\begin{array}{l}\text { ND* } \\
{[874 \text { ] }}\end{array}$ & $\begin{array}{c}\text { ND } \\
{[71.4]}\end{array}$ & $\begin{array}{l}\text { ND } \\
{[356]}\end{array}$ \\
\hline Eu-154 & $\begin{array}{l}\text { ND } \\
{[107]}\end{array}$ & $\begin{array}{l}\text { ND } \\
{[324]}\end{array}$ & $\begin{array}{c}\mathrm{ND}^{*} \\
{[1,020]}\end{array}$ & $\begin{array}{l}\mathrm{ND} \\
{[42.5]}\end{array}$ & $\begin{array}{l}\text { ND } \\
{[247 \text { ] }}\end{array}$ \\
\hline Eu-155 & $\begin{array}{l}\text { ND } \\
{[156]}\end{array}$ & $\begin{array}{l}\text { ND } \\
{[293 \text { ] }}\end{array}$ & $\begin{array}{c}\text { ND } \\
{[20,000]}\end{array}$ & $\begin{array}{l}\text { ND } \\
{[54]}\end{array}$ & $\begin{array}{l}\text { ND } \\
{[246]}\end{array}$ \\
\hline Am-241 & $\begin{array}{l}\text { ND } \\
{[198 \text { ] }}\end{array}$ & $\begin{array}{c}891 \pm 226 \\
{[360]}\end{array}$ & $\begin{array}{c}\text { ND } \\
{[252,000]}\end{array}$ & $\begin{array}{c}\text { ND } \\
{[81.4]}\end{array}$ & $\begin{array}{c}650 \pm 230 \\
{[382]}\end{array}$ \\
\hline
\end{tabular}

ND $\quad$ Not Detected

* $\quad=$ Indications of the presence of the radionuclide at non-quantifiable levels near the MDA (one or more, but not all, gamma lines observed)

[ ] = Minimum Detectable Concentration in $\mathrm{pCi} / \mathrm{g}$

\section{DATA QUALIFIERS:}

1. Uncertainties reported in the table are counting errors (1.96s); additional uncertainties due to volume, mass, and density estimates could be approximately $\pm 50 \%$ and should be added to the tabulated results.

2. Analysis assumes uniform, homogeneous distribution of contaminants throughout the sample matrix.

3. While there is good confidence in the identification of radionuclides and their relative magnitudes, there is considerable uncertainty in the absolute value of activity expressed in units of "pCi/g" due to small sample mass (Samples Canal-002 and Canal-005). 


\begin{tabular}{|c|c|c|c|c|c|c|c|c|c|c|c|}
\hline \multicolumn{12}{|c|}{ Soil Samples Collected in 1 Liter Bottles at the Canal and Water Treatment House Characterization } \\
\hline \multirow{2}{*}{\multicolumn{2}{|c|}{ BGRR Sample ID }} & \multirow{3}{*}{$\begin{array}{c}\text { ANALYSIS } \\
\text { DATE }\end{array}$} & \multirow{3}{*}{$\begin{array}{c}\text { ASTD } \\
\text { Sample ID }\end{array}$} & \multicolumn{8}{|c|}{ Estimated Activity Concentration (pCi/gram) } \\
\hline & & & & \multicolumn{2}{|l|}{ K-40 } & \multicolumn{2}{|c|}{ Co-60 } & \multicolumn{2}{|l|}{ Cs-137 } & \multicolumn{2}{|c|}{ Am-241 } \\
\hline Bore Number & Depth & & & Results & MDC & Results & MDC & Results & MDC & Results & MDC \\
\hline CCB-011 & 0"-6" & $9 / 22 / 2000$ & SAM01041 & $13.6 \pm 3.0$ & 0.4 & $0.3 \pm 0.1$ & 0.2 & $\mathrm{ND}$ & 0.4 & $\mathrm{ND}$ & 0.6 \\
\hline CCB-011 & $06 "-12 "$ & $9 / 22 / 2000$ & SAM01042 & $12.7 \pm 2.8$ & 0.4 & ND & 0.4 & $\mathrm{ND}$ & 0.4 & $\mathrm{ND}$ & 0.4 \\
\hline CCB-011 & $12 "-18 "$ & $9 / 22 / 2000$ & SAM01043 & $9.5 \pm 2.6$ & 2.3 & $0.3 \pm 0.1$ & 0.1 & $\mathrm{ND}$ & 0.3 & ND & 0.4 \\
\hline CCB-011 & $18 "-24 "$ & $9 / 22 / 2000$ & SAM01044 & $12.3 \pm 2.7$ & 0.4 & $\mathrm{ND}$ & 0.3 & $\mathrm{ND}$ & 0.3 & ND & 0.4 \\
\hline CCB-012 & $0 "-6 "$ & 9/22/2000 & SAM01045 & $10.1 \pm 3.7$ & 4.9 & $\mathrm{ND}$ & 0.4 & $\mathrm{ND}$ & 0.4 & ND & 0.6 \\
\hline CCB-012 & $06 "-12 "$ & $9 / 22 / 2000$ & SAM01046 & $9.1 \pm 2.5$ & 2.0 & $\mathrm{ND}$ & 0.3 & ND & 0.3 & ND & 0.4 \\
\hline CCB-012 & $12 "-18 "$ & $9 / 22 / 2000$ & SAM01047 & $8.9 \pm 2.7$ & 2.6 & $\mathrm{ND}$ & 0.3 & $\mathrm{ND}$ & 0.3 & $\mathrm{ND}$ & 0.4 \\
\hline CCB-012 & $18 "-24 "$ & $9 / 22 / 2000$ & SAM01048 & $11 \pm 2.8$ & 0.2 & $\mathrm{ND}$ & 0.3 & ND & 0.3 & $\mathrm{ND}$ & 0.3 \\
\hline CCB-019 & 0"-6" & 9/20/2000 & SAM00980 & $11.6 \pm 2.7$ & 1.6 & $\mathrm{ND}$ & 0.2 & $\pm \quad 0.8$ & 0.3 & ND & 0.5 \\
\hline CCB-019 & $06 "-12 "$ & 9/20/2000 & SAM00981 & $8.9 \pm 2.2$ & 1.4 & $\mathrm{ND}$ & 0.2 & $\mathrm{ND}$ & 0.4 & $\mathrm{ND}$ & 0.4 \\
\hline CCB-019 & $12 "-18 "$ & $9 / 20 / 2000$ & SAM00982 & $11.9 \pm 2.9$ & 1.7 & $\mathrm{ND}$ & 0.3 & $\pm \quad 0.1$ & 0.2 & $\mathrm{ND}$ & 0.5 \\
\hline CCB-019 & $18 "-24 "$ & $9 / 20 / 2000$ & SAM00983 & $8.5 \pm 2.3$ & 1.6 & $\mathrm{ND}$ & 0.2 & ND & 0.3 & ND & 0.3 \\
\hline CCB-019 & $24 "-30 "$ & $9 / 20 / 2000$ & SAM00984 & ND & 5.8 & $\mathrm{ND}$ & 0.2 & \pm 0.6 & 0.3 & ND & 0.4 \\
\hline CCB-019 & $30 "-36 "$ & 9/20/2000 & SAM00985 & $10.4 \pm 2.4$ & 0.4 & $\mathrm{ND}$ & 0.2 & $\pm \quad 0.2$ & 0.2 & $\mathrm{ND}$ & 0.4 \\
\hline CCB-020 & 0"-6" & $9 / 21 / 2000$ & SAM01002 & $11.2 \pm 2.8$ & 2.4 & $\mathrm{ND}$ & 0.2 & $5.1 \pm 0.6$ & 0.2 & $\mathrm{ND}$ & 0.5 \\
\hline CCB-020 & $06 "-12 "$ & $9 / 21 / 2000$ & SAM01003 & $7.9 \pm 2.2$ & 1.7 & $\mathrm{ND}$ & 0.2 & ND & 0.4 & ND & 0.3 \\
\hline CCB-020 & $12 "-18 "$ & $9 / 21 / 2000$ & SAM01004 & $8.7 \pm 2.3$ & 1.5 & ND & 0.3 & \pm 0.1 & 0.2 & ND & 0.4 \\
\hline CCB-020 & $18 "-24 "$ & $9 / 21 / 2000$ & SAM01005 & $7.7 \pm 2.4$ & 2.7 & $\mathrm{ND}$ & 0.2 & $0.6 \pm 0.2$ & 0.2 & $\mathrm{ND}$ & 0.4 \\
\hline CCB-020 & $24 "-30 "$ & $9 / 21 / 2000$ & SAM01006 & $9.8 \pm 2.5$ & 2.2 & $\mathrm{ND}$ & 0.3 & ND & 0.3 & ND & 0.4 \\
\hline CCB-020 & $30 "-36 "$ & $9 / 21 / 2000$ & SAM01007 & $9.1 \pm 2.6$ & 2.6 & $\mathrm{ND}$ & 0.3 & $\mathrm{ND}$ & 0.3 & ND & 0.4 \\
\hline CCB-021 & 0"-6" & $9 / 21 / 2000$ & SAM01008 & ND & 5.7 & ND & 0.2 & $0.3 \pm 0.1$ & 0.2 & ND & 0.4 \\
\hline CCB-021 & $06 "-12 "$ & $9 / 21 / 2000$ & SAM01009 & $10.4 \pm 2.4$ & 3.8 & $\mathrm{ND}$ & 0.3 & ND & 0.3 & $\mathrm{ND}$ & 0.4 \\
\hline CCB-021 & $12 "-18 "$ & 9/21/2000 & SAM01010 & $8.9 \pm 2.3$ & 1.8 & $\mathrm{ND}$ & 0.2 & ND & 0.3 & ND & 0.4 \\
\hline CCB-021 & $18 "-24 "$ & $9 / 21 / 2000$ & SAM01011 & $10.5 \pm 2.6$ & 1.8 & ND & 0.4 & ND & 0.3 & ND & 0.4 \\
\hline CCB-021 & $24 "-30 "$ & $9 / 21 / 2000$ & SAM01012 & $8.6 \pm 2.6$ & 2.5 & $\mathrm{ND}$ & 0.4 & $\mathrm{ND}$ & 0.3 & ND & 0.4 \\
\hline CCB-021 & $30 "-36 "$ & $9 / 21 / 2000$ & SAM01013 & $10.6 \pm 2.8$ & 2.4 & $\mathrm{ND}$ & 0.4 & ND & 0.3 & ND & 0.4 \\
\hline
\end{tabular}




\begin{tabular}{|c|c|c|c|c|c|c|c|c|c|c|c|c|}
\hline \multicolumn{13}{|c|}{ Soil Samples Collected in 1 Liter Bottles at the Canal and Water Treatment House Characterization } \\
\hline \multirow{2}{*}{\multicolumn{2}{|c|}{ BGRR Sample ID }} & \multirow{3}{*}{$\begin{array}{l}\text { ANALYSIS } \\
\text { DATE }\end{array}$} & \multirow{3}{*}{$\begin{array}{c}\text { ASTD } \\
\text { Sample ID }\end{array}$} & \multicolumn{9}{|c|}{ Estimated Activity Concentration (pCi/gram) } \\
\hline & & & & \multicolumn{2}{|l|}{ K-40 } & \multicolumn{2}{|c|}{ Co-60 } & \multicolumn{3}{|c|}{ Cs-137 } & \multicolumn{2}{|c|}{ Am-241 } \\
\hline Bore Number & Depth & & & Results & MDC & Results & MDC & Resi & sults & MDC & Results & MDC \\
\hline CCB-023 & 0"-6" & $9 / 22 / 2000$ & SAM01023 & $11.1 \pm 2.9$ & 2.7 & ND & 0.4 & 0.6 & \pm 0.2 & 0.3 & ND & 0.6 \\
\hline CCB-023 & $06 "-12 "$ & $9 / 22 / 2000$ & SAM01024 & $7.8 \pm 2.4$ & 2.5 & ND & 0.3 & & ND & 0.3 & $\mathrm{ND}$ & 0.4 \\
\hline CCB-023 & $12 "-18 "$ & $9 / 22 / 2000$ & SAM01025 & $10.6 \pm 2.8$ & 2.7 & ND & 0.3 & 0.2 & $\pm \quad 0.1$ & 0.2 & ND & 0.4 \\
\hline CCB-023 & $18 "-24 "$ & $9 / 22 / 2000$ & SAM01026 & $9.5 \pm 2.5$ & 2.0 & ND & 0.3 & & ND & 0.3 & ND & 0.3 \\
\hline CCB-029 & 0"-6" & $9 / 19 / 2000$ & SAM00957 & $12.3 \pm 3.1$ & 2.8 & $\mathrm{ND}$ & 0.3 & 3.4 & $\pm \quad 0.5$ & 0.3 & ND & 0.5 \\
\hline CCB-029 & $06 "-12 "$ & $9 / 19 / 2000$ & SAM00958 & ND & 5.6 & ND & 0.2 & 0.2 & \pm 0.2 & 0.3 & ND & 0.4 \\
\hline CCB-029 & $12 "-18 "$ & $9 / 19 / 2000$ & SAM00959 & $11.3 \pm 2.7$ & 1.8 & $\mathrm{ND}$ & 0.3 & & ND & 0.2 & ND & 0.4 \\
\hline CCB-029 & $18 "-24 "$ & $9 / 19 / 2000$ & SAM00960 & $9.1 \pm 2.3$ & 1.5 & $\mathrm{ND}$ & 0.2 & & ND & 0.2 & ND & 0.3 \\
\hline CCB-029 & 24"-30" & $9 / 19 / 2000$ & SAM00961 & $10.7 \pm 2.5$ & 0.4 & $\mathrm{ND}$ & 0.2 & & $\mathrm{ND}$ & 0.4 & ND & 0.4 \\
\hline CCB-029 & $30 "-36 "$ & $9 / 19 / 2000$ & SAM00962 & $9 \pm 2.3$ & 1.6 & $\mathrm{ND}$ & 0.2 & & ND & 0.3 & ND & 0.4 \\
\hline CCB-029B & 0"-6" & 9/19/2000 & SAM00969 & $14 \pm 3.0$ & 0.4 & ND & 0.4 & $15.5=$ & \pm 1.5 & 0.4 & ND & 0.6 \\
\hline CCB-029B & 06"-12" & $9 / 19 / 2000$ & SAM00970 & $7.7 \pm 2.2$ & 1.5 & ND & 0.3 & 2.4 & $\pm \quad 0.4$ & 0.2 & ND & 0.4 \\
\hline CCB-029B & 12"-18" & $9 / 19 / 2000$ & SAM00971 & ND & 5.5 & ND & 0.3 & 1.4 & \pm 0.3 & 0.3 & ND & 0.4 \\
\hline CCB-029B & 18"-24" & $9 / 19 / 2000$ & SAM00972 & $7.2 \pm 2.2$ & 2.0 & ND & 0.3 & $1.9=$ & \pm 0.3 & 0.3 & ND & 0.4 \\
\hline CCB-029B & 24"-30" & $9 / 19 / 2000$ & SAM00973 & $8.7 \pm 2.5$ & 2.5 & $\mathrm{ND}$ & 0.3 & $4.9=$ & $\pm \quad 0.6$ & 0.3 & ND & 0.5 \\
\hline CCB-029B & 30"-36" & $9 / 19 / 2000$ & SAM00974 & $10 \pm 2.6$ & 2.2 & ND & 0.3 & 8.4 & $\pm \quad 0.9$ & 0.3 & ND & 0.5 \\
\hline CCB-029B & $36 "-44 "$ & $9 / 21 / 2000$ & SAM00992 & $9.1 \pm 2.6$ & 2.6 & ND & 0.2 & $7.7=$ & \pm 0.8 & 0.2 & ND & 0.5 \\
\hline CCB-029B & 44"-52" & $9 / 21 / 2000$ & SAM00993 & $8.3 \pm 2.5$ & 2.5 & $\mathrm{ND}$ & 0.3 & 6.4 & \begin{tabular}{|l|} 
\pm 0.7 \\
\end{tabular} & 0.3 & ND & 0.5 \\
\hline CCB-029B & $52 "-60 "$ & $9 / 21 / 2000$ & SAM00994 & $7.8 \pm 2.0$ & 3.3 & ND & 0.2 & $101=$ & $\pm \quad 8.0$ & 0.5 & ND & 1 \\
\hline CCB-029B & $60 "-68 "$ & $9 / 21 / 2000$ & SAM00995 & $8.9 \pm 2.2$ & 3.7 & ND & 0.2 & $185=$ & \pm 14.3 & 0.9 & ND & 1.4 \\
\hline CCB-029B & 68"-76" & $9 / 21 / 2000$ & SAM00996 & $11.2 \pm 2.7$ & 1.8 & ND & 0.3 & $425=$ & \pm 32.6 & 1.4 & $N D$ & 2.2 \\
\hline CCB-029B & 68"-76"R & $9 / 21 / 2000$ & SAM00998 & $9.7 \pm 2.7$ & 2.7 & $\mathrm{ND}$ & 0.3 & $417=$ & \pm 32.0 & 1.5 & ND & 2.1 \\
\hline CCB-029B & 76"-84" & $9 / 21 / 2000$ & SAM00997 & $11 \pm 2.9$ & 2.9 & ND & 0.3 & $24.4=$ & $\pm \quad 2.1$ & 0.4 & ND & 0.7 \\
\hline CCB-029B & 108" (09') & $9 / 22 / 2000$ & SAM01035 & $8.8 \pm 2.6$ & 2.6 & ND & 0.4 & 7.3 & \pm 0.8 & 0.2 & ND & 0.4 \\
\hline CCB-029B & $120^{\prime \prime}\left(10^{\prime}\right)$ & $9 / 22 / 2000$ & SAM01036 & $8.4 \pm 2.5$ & 2.4 & $0.2 \pm 0.1$ & 0.1 & $102=$ & $\pm \quad 8.1$ & 0.7 & ND & 1.1 \\
\hline CCB-029B & 132" (11') & $9 / 22 / 2000$ & SAM01037 & $N D$ & 5.6 & ND & 0.3 & $51.9=$ & $\pm \quad 4.2$ & 0.7 & $N D$ & 0.9 \\
\hline CCB-029B & 144" (12') & $9 / 22 / 2000$ & SAM01038 & $8.2 \pm 2.2$ & 1.5 & $0.2 \pm 0.1$ & 0.2 & $40.0=$ & $\pm \quad 3.3$ & 0.5 & ND & 0.7 \\
\hline CCB-029B & 156" (13') & $9 / 22 / 2000$ & SAM01039 & $7.5 \pm 2.3$ & 2.3 & ND & 0.3 & $23.7=$ & \pm 2.0 & 0.4 & ND & 0.6 \\
\hline CCB-029B & 168" (14') & $9 / 22 / 2000$ & SAM01040 & $10.5 \pm 2.5$ & 1.7 & $\mathrm{ND}$ & 0.4 & $25.8=$ & \pm 2.2 & 0.4 & ND & 0.7 \\
\hline CCB-035 & 24"-30" & $9 / 19 / 2000$ & SAM00963 & $10 \pm 2.6$ & 1.7 & $\mathrm{ND}$ & 0.3 & & ND & 0.4 & ND & 0.5 \\
\hline CCB-035 & 30"-36" & $9 / 19 / 2000$ & SAM00964 & $10.5 \pm 2.7$ & 1.9 & $\mathrm{ND}$ & 0.2 & & $\overline{N D}$ & 0.3 & ND & 0.4 \\
\hline
\end{tabular}




\begin{tabular}{|c|c|c|c|c|c|c|c|c|c|c|c|c|}
\hline \multicolumn{13}{|c|}{ Soil Samples Collected in 1 Liter Bottles at the Canal and Water Treatment House Characterization } \\
\hline \multirow{2}{*}{\multicolumn{2}{|c|}{ BGRR Sample ID }} & \multirow{3}{*}{$\begin{array}{c}\text { ANALYSIS } \\
\text { DATE }\end{array}$} & \multirow{3}{*}{$\begin{array}{c}\text { ASTD } \\
\text { Sample ID }\end{array}$} & \multicolumn{9}{|c|}{ Estimated Activity Concentration (pCi/gram) } \\
\hline & & & & \multicolumn{2}{|l|}{ K-40 } & \multicolumn{2}{|c|}{ Co-60 } & \multicolumn{3}{|c|}{ Cs-137 } & \multicolumn{2}{|c|}{ Am-241 } \\
\hline Bore Number & Depth & & & Results & MDC & Results & MDC & Resu & ults & MDC & Results & MDC \\
\hline CCB-039 & 0"-6" & 9/20/2000 & SAM00986 & $\mathrm{ND}$ & 5.9 & ND & 0.3 & $16.4 \pm$ & $\pm \quad 1.5$ & 0.3 & $\mathrm{ND}$ & 0.5 \\
\hline CCB-039 & $06 "-12 "$ & 9/20/2000 & SAM00986 & $14.4 \pm 3.0$ & 0.4 & ND & 0.3 & 0.3 & $\pm \quad 0.1$ & 0.1 & $\mathrm{ND}$ & 0.5 \\
\hline CCB-039 & $12 "-18 "$ & $9 / 20 / 2000$ & SAM00986 & $11.5 \pm 1.8$ & 1.8 & ND & 0.3 & & $\mathrm{ND}$ & 0.4 & $\mathrm{ND}$ & 0.4 \\
\hline CCB-039 & $18 "-24 "$ & 9/20/2000 & SAM00986 & $12.6 \pm 2.8$ & 0.4 & ND & 0.3 & 1.7 & $\pm \quad 0.4$ & 0.4 & ND & 0.4 \\
\hline CCB-039 & $24 "-30 "$ & 9/20/2000 & SAM00986 & $11.2 \pm 2.9$ & 2.4 & ND & 0.3 & & ND & 0.3 & ND & 0.4 \\
\hline CCB-039 & 30"-36" & 9/20/2000 & SAM00986 & $10 \pm 2.7$ & 2.6 & ND & 0.2 & 0.8 & $\pm \quad 0.2$ & 0.2 & ND & 0.4 \\
\hline CCB-039 & $4^{\prime}-12^{\prime}$ & 9/22/2000 & SAM01031 & $8.1 \pm 2.2$ & 1.5 & ND & 0.2 & & ND & 0.3 & ND & 0.4 \\
\hline CCB-039 & $20^{\prime}-30^{\prime}$ & $9 / 22 / 2000$ & SAM01032 & $8.6 \pm 2.3$ & 1.5 & ND & 0.4 & & ND & 0.3 & ND & 0.3 \\
\hline CCB-039 & $30^{\prime}-40^{\prime}$ & 9/22/2000 & SAM01033 & $9.7 \pm 2.5$ & 2.0 & ND & 0.4 & & $\mathrm{ND}$ & 0.3 & ND & 0.4 \\
\hline CCB-039 & $40^{\prime}-46^{\prime}$ & 9/22/2000 & SAM01034 & $2.1 \pm 2.5$ & 4.1 & ND & 0.1 & & ND & 0.3 & ND & 0.4 \\
\hline CCB-040 & 0"-6" & 9/22/2000 & SAM01027 & $9.5 \pm 2.5$ & 2.0 & ND & 0.3 & $0.3 \pm$ & $\pm \quad 0.2$ & 0.2 & ND & 0.4 \\
\hline CCB-040 & $06 "-12 "$ & 9/22/2000 & SAM01028 & $8.5 \pm 2.5$ & 2.4 & $\mathrm{ND}$ & 0.3 & & $\mathrm{ND}$ & 0.4 & $N D$ & 0.4 \\
\hline CCB-040 & $12 "-18 "$ & $9 / 22 / 2000$ & SAM01029 & $9.6 \pm 2.4$ & 1.9 & $N D$ & 0.2 & $0.2 \pm$ & $\pm \quad 0.2$ & 0.2 & $N D$ & 0.4 \\
\hline CCB-040 & $18 "-24 "$ & 9/22/2000 & SAM01030 & $9.2 \pm 2.5$ & 2.2 & $\mathrm{ND}$ & 0.3 & 0.2 & $\begin{array}{r} \pm \quad 0.2 \\
\end{array}$ & 0.2 & ND & 0.3 \\
\hline CCB-042 & 0"-6" & 9/19/2000 & SAM00968 & $14.2 \pm 3.0$ & 0.4 & ND & 0.3 & & ND & 0.3 & ND & 0.4 \\
\hline CCB-042 & 06"-12" & $9 / 19 / 2000$ & SAM00966 & $12.1 \pm 2.8$ & 1.7 & ND & 0.3 & & ND & 0.3 & ND & 0.4 \\
\hline CCB-042 & $12 "-18 "$ & 9/19/2000 & SAM00967 & $9.9 \pm 2.6$ & 2.3 & ND & 0.3 & & ND & 0.3 & ND & 0.4 \\
\hline EEC & $0 "-6 "$ & $9 / 25 / 2000$ & SAM01049 & $3 \pm 2.5$ & 4.0 & $N D$ & 0.3 & $1.5 \pm$ & $\pm \quad 0.3$ & 0.3 & $\mathrm{ND}$ & 0.4 \\
\hline EEC & 06"-12" & 9/1/1932 & SAM01050 & ND & 6.0 & ND & 0.3 & $0.5 \pm$ & $\pm \quad 0.2$ & 0.2 & ND & 0.4 \\
\hline EEC & $12 "-18 "$ & 9/1/1932 & SAM01051 & ND & 5.3 & ND & 0.3 & $0.6 \pm$ & $\pm \quad 0.2$ & 0.2 & ND & 0.4 \\
\hline EEC & $18 "-24 "$ & 9/1/1932 & SAM01052 & $5.6 \pm 2.9$ & 4.3 & ND & 0.3 & $1.6 \pm$ & $\pm \quad 0.3$ & 0.2 & ND & 0.4 \\
\hline CJ & 0"-6" & $9 / 25 / 2000$ & SAM01054 & ND & 82.8 & ND & 5.4 & $4,400 \pm$ & $\pm \quad 390$ & 24.5 & ND & 37.9 \\
\hline $\mathrm{CJ}$ & $06 "-12 "$ & 9/25/2000 & SAM01055 & $3.6 \pm 2.8$ & 4.5 & $0.2 \pm 0.1$ & 0.2 & $3,825 \pm$ & $\begin{array}{r} \pm \quad 291 \\
\end{array}$ & 5 & ND & 6.2 \\
\hline CJ & $12 "-18 "$ & 9/25/2000 & SAM01056 & $3.7 \pm 2.6$ & 4.0 & ND & 0.3 & $662 \pm$ & \pm 50.6 & 2 & ND & 2.9 \\
\hline CJ & $12 "-18 " R$ & $9 / 25 / 2000$ & SAM01057 & $2.1 \pm 2.6$ & 4.4 & ND & 0.3 & $662 \pm$ & $\pm \quad 50.6$ & 2 & ND & 2.9 \\
\hline $\mathrm{CJ}$ & $18 "-24 "$ & $9 / 25 / 2000$ & SAM01058 & $2.5 \pm 2.7$ & 4.5 & ND & 0.3 & $158 \pm$ & $\pm \quad 12.3$ & 0.9 & ND & 1.7 \\
\hline CS-3 & $0 "-6 "$ & $9 / 25 / 2000$ & SAM01059 & $5.4 \pm 3.9$ & 6.4 & ND & 1.3 & $16,410 \pm$ & $\pm \quad 1248$ & 14.1 & $\mathrm{ND}$ & 12.7 \\
\hline CS-3 & $06 "-12 "$ & 9/25/2000 & SAM01060 & ND & 5.2 & ND & 0.4 & $5,545 \pm$ & $\pm \quad 422$ & 6 & ND & 7.0 \\
\hline WWS & 0"-6" & 9/25/2000 & SAM01061 & $2.2 \pm 2.3$ & 3.8 & ND & 0.3 & $31.5 \pm$ & $\pm \quad 2.6$ & 0.4 & ND & 0.7 \\
\hline WWS & 06"-12" & $9 / 25 / 2000$ & SAM01062 & $3.1 \pm 2.3$ & 3.7 & ND & 0.2 & 8.9 & $\pm \quad 0.9$ & 0.3 & ND & 0.5 \\
\hline
\end{tabular}


Section 16 
BRDOKHEVEN

NATIONAL LABORATORY
Bldg 830, Railroad Ave

MEMO
Brookhaven National Laboratory

Upton, NY 11973

Voice 631-344-2777

Fax 631-344-4486

FILE ASTD Project

\section{INFO}

Paul Kalb, Proj Mgr

Glenn Van Sickle, ERD

30822-262-023

FROM Larry Luckett, CHP

ASTD Project Analytical Physicist

DATE Sep 20, 2000

\section{SUBJECT: $\quad$ Results of Analysis for Soil Samples, AOC16G, Landscape Soil Remediation}

1. Enclosed is tabulation of the results from the ISOCS analyses of five (5) soil samples collected by ERD during the evaluation of operations from the Landscape Soil Remediation Project. Soils were identified as from Brookhaven Center, AOC16G. Results reflect that CS-137 was the only gammaemitting radionuclide detected, other than primordial radionuclides occurring naturally in soil. Preliminary results were previously provided verbally.

2. Soil samples were provided by ERD personnel and were counted on the ASTD ISOCS instrument in an ISOCS counting area established on the ground level (110' elevation) of Building 701. All samples were received from, and have been transferred back to, ERD control.

3. Spectrum acquisition was performed by Larry Milian, quantification modeling results were performed by Milian, and results were reviewed by Larry Luckett, members of the ASTD Project Team.

4. The table provides data on Cs-137 ( the radionuclide of concern). Full gamma spectroscopy analysis reports for each sample are on file with ASTD Project records and are available upon request.

Should you have any questions, please contact me at x-2777.

NOTE 1: Results are provided "as reported" by ISOCS; they have not yet been corrected by any correlation factor as recommended by EPA.

Activity Concentration of CS-137 in Soil Samples

ERD Landscape Soil Remediation Project

Gamma Spectrum Analysis with the ISOCS Instrument

\begin{tabular}{||c|c|c|c|c|c||}
\hline \multirow{2}{*}{$\begin{array}{c}\text { ASTD } \\
\text { Sample No }\end{array}$} & \multirow{2}{*}{$\begin{array}{c}\text { ERD } \\
\text { Sample No }\end{array}$} & \multirow{2}{*}{$\begin{array}{c}\text { ERD Sample } \\
\text { Description }\end{array}$} & \multirow{2}{*}{$\begin{array}{c}\text { Sample } \\
\text { Mass (g) }\end{array}$} & \multicolumn{2}{|c||}{ Cs-137 concentration ( pCi/g ) } \\
\cline { 5 - 7 } & Activity & MDA \\
\hline SAM00973 & $7411-\mathrm{A}$ & AOC16G, Center A & 1,076 & $15.8 \pm 1.5$ & 0.4 \\
\hline SAM00974 & $7411-\mathrm{B}$ & AOC16G, Center B & 1,107 & $59.8 \pm 4.8$ & 0.6 \\
\hline SAM00975 & $7411-\mathrm{C}$ & AOC16G, Center C & 1,099 & $22.4 \pm 2.0$ & 0.4 \\
\hline SAM00976 & $7411-\mathrm{D}$ & AOC16G, Center D & 1,116 & $59.9 \pm 4.8$ & 0.5 \\
\hline SAM00977 & $7411-\mathrm{E}$ & AOC16G, Center E & 1,222 & $39.3 \pm 3.2$ & 0.4 \\
\hline
\end{tabular}

$\mathrm{ND}=$ Not Detected

MDA $=$ Minimum Detectable Concentration in $\mathrm{pCi} / \mathrm{g}$

Uncertainties are reported at the 95\% confidence level and represent only counting error and ISOCS-related efficiency errors DATA QUALIFIERS:

1. Analysis assumes uniform, homogeneous distribution of contaminants throughout the sample matrix 


\begin{tabular}{|c|c|c|c|}
\hline $\mathrm{NAT}$ & iONAL & MEMO & $\begin{array}{l}\text { Bldg 830, Railroad Ave } \\
\text { Brookhaven National Laboratory } \\
\text { Upton, NY } 11973 \\
\text { Voice } 631-344-2777 \\
\text { Fax } 631-344-4486\end{array}$ \\
\hline$\overline{\text { ACTION }}$ & & INFO & FILE ASTD Project \\
\hline Jim Bro & ower- ERD & $\begin{array}{l}\text { Paul Kalb, Proj Mgr } \\
\text { Glenn Van Sickle, ERD }\end{array}$ & $30822-262-023$ \\
\hline FROM & $\begin{array}{l}\text { Larry Lucke } \\
\text { ASTD Proje }\end{array}$ & icist & DATE Sep 11, 2000 \\
\hline SUBJECT & $\begin{array}{l}\text { Rest } \\
\text { Soil }\end{array}$ & 94, AOC16G and ITD & dscape Soil Remediation \\
\hline
\end{tabular}

1. Enclosed is tabulation of the results from the ISOCS analyses of ten (10) soil samples collected by ERD during the evaluation of operations from the Landscape Soil Remediation Project. Soils were identified as from various locations, including Bldg 494, AOC16G, and ITD. Results reflect that CS-137 was the only gamma-emitting radionuclide detected, other than primordial radionuclides occurring naturally in soil. Preliminary results were previously provided verbally.

2. Soil samples were provided by ERD personnel and were counted on the ASTD ISOCS instrument in an ISOCS counting area established on the ground level (110' elevation) of Building 701. All samples were received from, and have been transferred back to, ERD control.

3. Spectrum acquisition was performed by Larry Milian, quantification modeling results were performed by Milian, and results were reviewed by Larry Luckett, members of the ASTD Project Team.

4. The table provides data on Cs-137 ( the radionuclide of concern). Full gamma spectroscopy analysis reports for each sample are on file with ASTD Project records and are available upon request.

Should you have any questions, please contact me at x-2777.

NOTE 1: Results are provided "as reported" by ISOCS; they have not yet been corrected by any correlation factor as recommended by EPA. 
Activity Concentration of CS-137 in Soil Samples

ERD Landscape Soil Remediation Project

Gamma Spectrum Analysis with the ISOCS Instrument

\begin{tabular}{||c|c|c|c|c|c||}
\hline \multirow{2}{*}{$\begin{array}{c}\text { ASTD Sample } \\
\text { No }\end{array}$} & ERD & ERD Sample Description & \multicolumn{2}{|c|}{$\begin{array}{c}\text { Sample } \\
\text { Mass (g) }\end{array}$} & \multicolumn{2}{|c||}{ Cs-137 concentration ( pCi/g ) } \\
\cline { 5 - 7 } & Sample No & & \multicolumn{2}{|c|}{ Activity } & MDA \\
\hline SAM00938 & $7363-001$ & Hot Soils Bldg 494, depth 4 ft, AOC16E-2 W001 & 1,608 & $8.8 \pm 0.9$ & 0.3 \\
\hline SAM00939 & $7362-001$ & AOC16S-F Final, 0-0.5 ft depth & 1,315 & $7.1 \pm 0.8$ & 0.3 \\
\hline SAM00940 & $7362-002$ & Hot Area in AOC16S-W010, 0-0.16 ft depth & 1,130 & $19.5 \pm 1.8$ & 0.5 \\
\hline SAM00942 & $7381-001$ & AOC16G, depth 0.16' & 1,064 & $23.2 \pm 2.0$ & 0.4 \\
\hline SAM00943 & $7381-002$ & AOC16G, depth 0.16' & 1,429 & ND & 0.3 \\
\hline SAM00944 & $7381-003$ & AOC16G, depth 0.16' & 1,129 & $98.1 \pm 7.7$ & 0.8 \\
\hline SAM00945 & $7381-004$ & AOC16G, depth 0.16' & 1,112 & $52.1 \pm 4.2$ & 0.6 \\
\hline SAM00946 & $7381-005$ & AOC16G, depth 0.16' & 1,044 & $18.6 \pm 0.4$ & 0.4 \\
\hline SAM00947 & $7381-006$ & AOC16G, depth 0.16' & 1,091 & $28.2 \pm 2.4$ & 0.3 \\
\hline SAM00948 & $7381-007$ & AOC16G, depth 0.16' & & & 0.4 \\
\hline
\end{tabular}

$\mathrm{ND}=$ Not Detected

MDA $=$ Minimum Detectable Concentration in $\mathrm{pCi} / \mathrm{g}$

Uncertainties are reported at the $95 \%$ confidence level and represent only counting error and ISOCS-related efficiency errors

DATA QUALIFIERS:

1. Analysis assumes uniform, homogeneous distribution of contaminants throughout the sample matrix 


\begin{tabular}{|c|c|c|c|}
\hline NATI & iONAL & MEMO & $\begin{array}{l}\text { Bldg 830, Railroad Ave } \\
\text { Brookhaven National Laboratory } \\
\text { Upton, NY } 11973 \\
\text { Voice } 631-344-2777 \\
\text { Fax } 631-344-4486\end{array}$ \\
\hline$\overline{\text { ACTION }}$ & & INFO & FILE ASTD Project \\
\hline Jim Bro & ower- ERD & $\begin{array}{l}\text { Paul Kalb, Proj Mgr } \\
\text { Glenn Van Sickle, ERD }\end{array}$ & $30822-262-023$ \\
\hline FROM & \multicolumn{2}{|c|}{$\begin{array}{l}\text { Larry Luckett, CHP } \\
\text { ASTD Project Analytical Physicist }\end{array}$} & DATE Sep 11, 2000 \\
\hline SUBJECT & $\begin{array}{l}\text { Res } \\
\text { Soi }\end{array}$ & E - NYSDEC Samples & dscape Soil Remediation \\
\hline
\end{tabular}

1. Enclosed is a tabulation of the results from the ISOCS analyses of eight (8) soil samples provided by ERD during the evaluation of operations from the Landscape Soil Remediation Project. Soils were identified as samples between ORISE and NYSDEC from various locations. Results reflect that CS-137 was the only gamma-emitting radionuclide detected, other than primordial radionuclides occurring naturally in soil. Preliminary results were previously provided verbally.

2. Soil samples were provided by ERD personnel and were counted on the ASTD ISOCS instrument in an ISOCS counting area established on the ground level (110' elevation) of Building 701. All samples were received from, and have been transferred back to, ERD control.

3. Spectrum acquisition was performed by Larry Milian, quantification modeling results were performed by Milian, and results were reviewed by Larry Luckett, members of the ASTD Project Team.

4. The table provides data on Cs-137 ( the radionuclide of concern). Full gamma spectroscopy analysis reports for each sample are on file with ASTD Project records and are available upon request.

Should you have any questions, please contact me at x-2777.

NOTE 1: Results are provided "as reported" by ISOCS; they have not yet been corrected by any correlation factor as recommended by EPA. 
Activity Concentration of CS-137 in Soil Samples

ERD Landscape Soil Remediation Project

Gamma Spectrum Analysis with the ISOCS Instrument

\begin{tabular}{||c|c|l|c|c|c||}
\hline \hline \multirow{2}{*}{$\begin{array}{c}\text { ASTD Sample } \\
\text { No }\end{array}$} & $\begin{array}{c}\text { ERD } \\
\text { Sample No }\end{array}$ & \multicolumn{2}{|c|}{ ERD Sample Description } & \multirow{2}{*}{$\begin{array}{c}\text { Sample } \\
\text { Mass (g) }\end{array}$} & \multicolumn{3}{|c|}{ Cs-137 concentration ( pCi/g ) } \\
\cline { 5 - 7 } & & & \multicolumn{2}{|c|}{ Activity } & MDA \\
\hline SAM00949 & $7394-001$ & Landscape Soil - ORISE_F1 & 1,510 & $79.2 \pm 6.3$ & 0.3 \\
\hline SAM00950 & $7394-002$ & Landscape Soil - DEC_F1 & 1,432 & $74.4 \pm 5.9$ & 0.7 \\
\hline SAM00951 & $7394-003$ & Landscape Soil - ORISE_F4 & 1,395 & $84.0 \pm 6.7$ & 0.7 \\
\hline SAM00952 & $7394-004$ & Landscape Soil - DEC_F3 & 1,499 & $14.3 \pm 1.3$ & 0.4 \\
\hline SAM00953 & $7394-005$ & Landscape Soil - ORISE_F2 & 1,530 & $12.0 \pm 1.2$ & 0.4 \\
\hline SAM00954 & $7394-006$ & Landscape Soil - ORISE_F3 & 1,588 & $55.8 \pm 4.5$ & 0.6 \\
\hline SAM00955 & $7394-007$ & Landscape Soil - DEC_F2 & 1,512 & $44.2 \pm 3.6$ & 0.6 \\
\hline SAM00956 & $7395-001$ & Landscape Soil - AOC16S6F1 & 1,454 & $20.8 \pm 1.8$ & 0.5 \\
\hline \hline
\end{tabular}

$\mathrm{ND}=$ Not Detected

MDA = Minimum Detectable Concentration in $\mathrm{pCi} / \mathrm{g}$

Uncertainties are reported at the $95 \%$ confidence level and represent only counting error and ISOCS-related efficiency errors

\section{DATA QUALIFIERS:}

1. Analysis assumes uniform, homogeneous distribution of contaminants throughout the sample matrix 


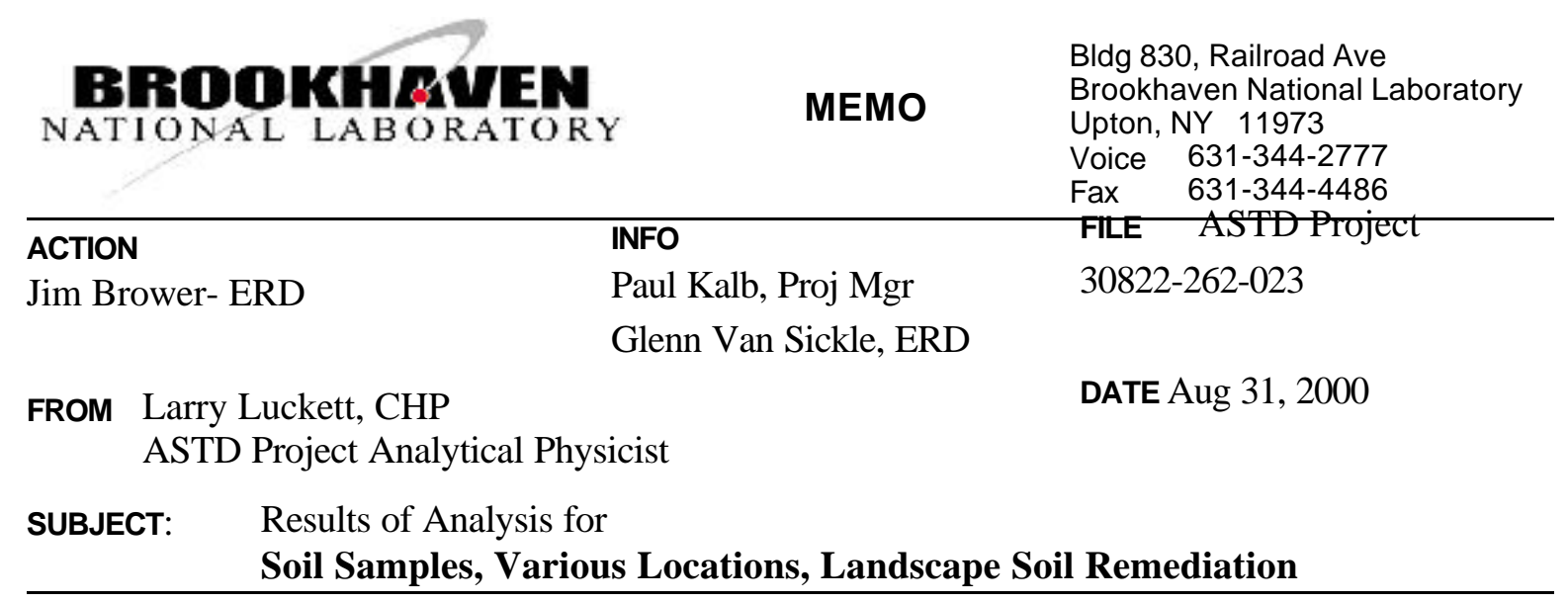

1. Enclosed are tabulation of the results from the ISOCS analyses of ten (10) soil samples collected by ERD during the evaluation of operations from the Landscape Soil Remediation Project. Soils were identified as from various locations, including AOC16E2, AOC16F, Trucks, and ITD. Results reflect that CS-137 was the only gamma-emitting radionuclide detected, other than primordial radionuclides occurring naturally in soil. Preliminary results were previously provided verbally.

2. Soil samples were provided by ERD personnel and were counted on the ASTD ISOCS instrument in an ISOCS counting area established on the ground level (110' elevation) of Building 701. All samples were received from, and have been transferred back to, ERD control.

3. Spectrum acquisition was performed by Larry Milian, quantification modeling results were performed by Milian, and results were reviewed by Larry Luckett, members of the ASTD Project Team.

4. The table provides data on Cs-137 ( the radionuclide of concern). Full gamma spectroscopy analysis reports for each sample are on file with ASTD Project records and are available upon request.

Should you have any questions, please contact me at x-2777.

NOTE 1: Results are provided "as reported" by ISOCS; they have not yet been corrected by any correlation factor as recommended by EPA.

NOTE 2: Soil samples were provided by ERD personnel in 500-ml HDPE containers which is a non-standard geometry for samples. Use of 1-liter wide mouth HDPE bottles would result in more timely, efficient, and accurate analytical results. 
Activity Concentration of CS-137 in Soil Samples

ERD Landscape Soil Remediation Project

Gamma Spectrum Analysis with the ISOCS Instrument

\begin{tabular}{|c|c|c|c|c|c|}
\hline \multirow{2}{*}{$\begin{array}{l}\text { ASTD Sample } \\
\text { No }\end{array}$} & \multirow{2}{*}{$\begin{array}{c}\text { ERD } \\
\text { Sample No }\end{array}$} & \multirow{2}{*}{ ERD Sample Description } & \multirow{2}{*}{$\begin{array}{l}\text { Sample } \\
\text { Mass (g) }\end{array}$} & \multicolumn{2}{|c|}{ Cs-137 concentration ( $\mathrm{pCi} / \mathrm{g})$} \\
\hline & & & & Activity & MDA \\
\hline SAM00927 & AOC16F-W001 & Soil sample $3.5-4.0 \mathrm{ft}$ depth & 1,585 & $12.2 \pm 1.2$ & 0.4 \\
\hline SAM00928 & AOC16F-W002 & Soil sample 3.0 - $3.5 \mathrm{ft}$ depth & 1,597 & $13.2 \pm 1.2$ & 0.3 \\
\hline SAM00929 & $7328-001$ & Hot soil from Pit at $16 \mathrm{~F}$ & 1,401 & $43.8 \pm 3.6$ & 0.5 \\
\hline SAM00930 & $7278-001$ & Landscape soil - Truck 1-A & 855 & $11.7 \pm 1.1$ & 0.4 \\
\hline SAM00931 & $7278-002$ & Landscape soil - Truck 1-B & 919 & $11.7 \pm 1.1$ & 0.4 \\
\hline SAM00932 & $7278-003$ & Landscape soil - Truck 2-A & 1,012 & $7.2 \pm 0.7$ & 0.3 \\
\hline SAM00933 & $7278-004$ & Landscape soil - Truck 2-B & 979 & $9.1 \pm 0.9$ & 0.2 \\
\hline SAM00934 & $7330-001$ & Landscape soil - ITDF & 1,070 & $17.8 \pm 1.6$ & 0.4 \\
\hline SAM00935 & 7330-001R & Recount of 7330-001 & 1,070 & $18.3 \pm 1.7$ & 0.3 \\
\hline SAM00936 & $7331-001$ & Landscape soil $-0-.16$ & 859 & $17.5 \pm 1.7$ & 0.4 \\
\hline SAM00937 & $7332-001$ & AOC16E2-CS15; depth 0-6" & 1,555 & ND & 0.3 \\
\hline
\end{tabular}

$\mathrm{ND}=$ Not Detected

$\mathrm{MDA}=$ Minimum Detectable Concentration in $\mathrm{pCi} / \mathrm{g}$

Uncertainties are reported at the 95\% confidence level and represent only counting error and ISOCS-related efficiency errors

\section{DATA QUALIFIERS:}

1. Analysis assumes uniform, homogeneous distribution of contaminants throughout the sample matrix 